DANIEL SAMPAIO SOUZA

Simulação numérica de ruído de eslate em configurações práticas usando um código comercial 


\section{Simulação numérica de ruído de eslate em configurações práticas usando um código comercial}

Dissertação apresentada à Escola de Engenharia de São Carlos, da Universidade de São Paulo, como parte dos requisitos para obtenção do título de Mestre em Engenharia Mecânica

Área de Concentração: Aeronaves

Orientador: Prof. Dr. Marcello A. Faraco de Medeiros

São Carlos 
Ficha catalográfica preparada pela Seção de Tratamento da Informação do Serviço de Biblioteca - EESC/USP

Souza, Daniel Sampaio

Simulação numérica de ruído de eslate em configurações práticas usando um código comercial. / Daniel Sampaio Souza ; orientador Marcello Augusto Faraco de Medeiros. São Carlos, 2012 .

Dissertação (Mestrado - Programa de Pós-Graduação em Engenharia Mecânica e Área de Concentração em Aeronaves) - Escola de Engenharia de São Carlos da Universidade de São Paulo, 2012 .

1. Aeroacústica. 2. Dispositivos híper-sustentadores. 3. Ruído de eslate. 4. Método Lattice-Boltzmann. 5. Analogia de Ffowcs Williams-Hawkings. I. Título. 
FOLHA DE JULGAMENTO

Candidato: Engenheiro DANIEL SAMPAIO SOUZA.

Título da dissertação: "Simulação numérica de ruído de eslate em configurações práticas usando um código comercial".

Data da defesa: 24/05/2012

\section{Comissão Julgadora:}

Prof. Associado Marcello Augusto Faraco de Medeiros (Orientador) (Escola de Engenharia de São Carlos/EESC)

Prof. Dr. Cesar José Deschamps

(Universidade Federal de Santa Catarina/UFSC)

Dr. Carlos Roberto Ilário da Silva

(Empresa Brasileira de Aeronáutica/EMBRAER)

\section{Resultado:}

Aprovedo

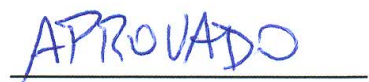

Coordenador do Programa de Pós-Graduação em Engenheira Mecânica:

Prof. Associado Marcelo Areias Trindade

Presidente da Comissão de Pós-Graduação:

Prof. Associado Paulo Cesar Lima Segantine 
À minha família, com amor. 


\section{AGRADECIMENTOS}

Aos meus pais, pelo amor, pelos ensinamentos, pelo apoio de todos os tipos e pela confiança dispensada na minha capacidade, pois todos estes elementos, mais do que qualquer outro, me permitiram estar aqui neste momento.

Aos meus irmãos, Maíra, Davi e Danilo, pelo amor, carinho e compreensão.

Ao meu orientador, Marcello Faraco, pela paciência, pelas orientaçõese explicaçõesque me introduziram em uma nova área do conhecimento e por dividir experiências enriquecedoras.

A Leandro Simões e Lukas Bandle, pelas grandes contribuiçõesna construçãodeste trabalho.

À FAPESP e EMBRAER pelo apoio financeiro e operacional.

Aos alunos de pós-graduaçãoe iniciaçãocientífica do departamento de Engenharia Aeronáutica, pelo companherismo e troca de experiências no dia-a-dia.

Aos moradores e ex-moradores da República Chico Lopes, pelo acolhimento, amizade, companherismo e por proporcionar momenos especiais. 
A definiçãode loucura é fazer sempre a mesma coisa e esperar resultados diferentes.

Albert Einstein 


\section{Resumo}

SOUZA, D. S. Simulação numérica de ruído de eslate em configurações práticas usando um código comercial. 2012. 130f. Dissertação (Mestrado) - Escola de Engenharia de São Carlos, Universidade de São Paulo, São Carlos, 2012.

Com o desenvolvimento para aeronaves de propulsores turbo-fan com elevada razão de derivação, componentes da estrutura do avião passaram a ter relevância na geração de ruído aerodinâmico, principalmente durante a aproximação e o pouso. Dentre esses componentes, o eslate se destaca por ser uma fonte que se estende ao longo de praticamente toda a envergadura da asa. Neste trabalho, simulações numéricas foram feitas no intuito de considerar configurações práticas nas análises do ruído aeroacústico gerado pelo eslate. Um código comercial baseado no Método Lattice-Boltzmann foi usado no cálculo do escoamento transiente em torno do aerofólio MD30P30N. O domínio computacional simulado imitou a configuração geométrica de um túnel de vento. Foi levado em consideração o efeito da presença de duas formas de excrescência que são comuns na cova do eslate de aeronaves comerciais. Uma delas foi um selo que fica posicionado na parede da cova e a outra, um tubo do sistema anti-gelo. Tanto o escoamento transiente na região da cova quanto as características do ruído aeroacústico propagado para o campo distante foram analisados. Uma metodologia que impõe condição de parede com escorregamento livre no eslate e elemento principal, permitindo assim uma redução do custo computacional, foi usada. A abordagem foi ainda testada para a condição de um aerofólio submetido a escoamento cruzado, simulando uma asa infinita com enflechamento. Também uma modificação na metodologia, para que ela possa ser empregada em aerofólios com elevados ângulos de ataque, foi proposta e testada. O código híbrido MSES foi usado para o cálculo da espessura de deslocamento na camada limite do aerofólio. A modificação na geometria baseada em $\delta^{*}$ causou uma melhora da solução aeroacústica de uma simulação empregando paredes com escorregamento livre, tomando como base de comparação a solução com paredes sem escorregamento. Simulações com selo dentro da cova, perto do recolamento, mostraram que, em certas circunstâncias, há um bloqueio dos vórtices da camada de mistura, intensificando picos tonais no espectro do ruído. A variação da posição do selo mostrou um efeito significativo no ruído do eslate, de forma que um selo suficientemente afastado do recolamento modificou o espectro do ruído do eslate. Os resultados com o aerofólio enflechado indicam que, também neste caso, o ruído do eslate não depende diretamente da camada limite na cúspide, mas da circulação do aerofólio. Por sua vez, a presença do tubo na cova aumenta significativamente a intensidade do ruído de banda larga produzido pelo eslate. Em uma asa sem enflechamento, o tubo causa também um aumento substancial na intensidade de picos tonais de baixa frequência.

Palavras-chave: Aeroacústica. Dispositivos Híper-Sustentadores. Ruído de Eslate. Método LatticeBoltzmann. Analogia de Ffowcs Wiliams-Hawkings. 


\section{Abstract}

SOUZA, D. S. Numerical simulation of slat noise in practical configuration by means of a commercial code. 2012. 130f. Dissertação (Mestrado) - Escola de Engenharia de São Carlos, Universidade de São Paulo, São Carlos, 2012.

The development of high by-pass ratio turbo-fan engine turned the airframe noise into an important component in a commercial aiplanes' noise characteristics. Between the airframe noise sources the slat can be highlighted as it extends almost along the whole wing span. Numerical simulation was carried out in order to consider practical configuration in the aeroacoutic noise generated by the slat. The effects of two different excrescences, which are normally present in commercial airplanes' slat cove, were taken into account. One of them was a seal attached to the cove wall and the outher one was a tube that compose the anti-icing system. Both unsteady flow in cove region and far-field noise characteristics were analysed. A methodology that impose free-slip wall boundary condition on slat and main element surfaces was employed, which allowed the reduction of computational requirements. This approach was also tested for airfoil with crossflow, which simulates an infinite swept wing. Also a modification of the methodology was proposed and tested to extend its application in high-lift airfoils under higher angle of attack. A commercial code based on the Lattice-Boltzmann Method was used to compute the unsteady flow over the MD30P30N airfoil. The simulated computational domain imitates the geometry of a wind tunnel. The hybrid Euler/IBL code MSES was employed to calculate the displacement thickness of the airfoil's boundary layers. The geometry modification based on $\delta^{*}$ caused a improvement on the aeroacoustic solution of a free-slip simulation, the no-slip simulation results being taken as reference. Simulations of geometries with relatively small seal close to the reattachment point showed that a blockage of the mixing layer vortices hapens and tonal peaks are intensified in the far-field noise spectrum. The variation of the seal position showed a significant effect on the slat noise, so that a seal farther from the reattachment modified affected both the shape and intensity of the noise spectrum. Results with the swept airfoil indicates that, even in the presence of crossflow, the slat noise does not depend on the cusp boundary layer, namely it is more sensitive to the airfoil circulation. The tube crossing the slat cove augmented significantly the broadband noise generated by the slat. In an unswept wing it also caused a substantial increase in the low-frequency tonal peaks.

Keywords: Aeroacoustics. High-Lift. Slat Noise. Lattice-Boltzmann Method. Ffowcs WilliamsHawkings Analogy. 


\section{Lista de Figuras}

Figura - 1 Principais fontes de som estrutural em uma aeronave comercial. Adaptada de Morgan e Hardin (1975) . . . . . . . . . . . . . . . . . . . . . 25

Figura -2 Campo do escoamento na região da cova do eslate. $\ldots \ldots \ldots \ldots \ldots \ldots \ldots$

Figura - 3 Desenho esquemático de um espectro típico de ruído gerado pelo eslate. . . 29

Figura - 4 Espectros de flutuação de componente de velocidade u em pontos ao longo da camada de mistura. De acordo com os pontos mostrados em (b). Retirado de Lockard e Choudhari (2010). . . . . . . . . . . . . . . . . . 34

Figura - 5 Espectros de flutuação da componente de velocidade u em simulação do aerofólio 30P30N em pontos ao longo da camada de mistura. Retirado de Lockard e Choudhari (2011).

Figura - 6 Espectro de som propagado para um ponto a $10 c_{c r u z}$ da cova do eslate. Retirado de Lockard e Choudhari (2010) e Lockard e Choudhari (2011). 36

Figura - 7 Configuração de voxel usada pelo PowerFLOW. Cada numero inteiro corresponde a uma velocidade $\vec{c}_{i}$.

Figura $-8 \quad$ Exemplo de fronteira entre regiões de nível de refinamento diferente. $\quad \ldots . .46$

Figura - 9 Esquema do conceito empregado para simular condições de parede sem escorregamento (a) e com escorregamento livre (b). ........... 48

Figura - $10 \quad$ Representação gráfica de $V_{i}^{\alpha}(\vec{x}) . \quad \ldots \ldots \ldots \ldots \ldots \ldots \ldots \ldots \ldots \ldots \ldots \ldots$

Figura - 11 Domínio onde as ondas acústicas são geradas e se propagam contendo su-

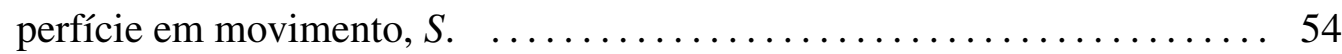

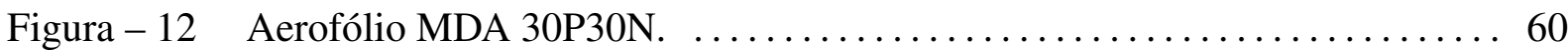

Figura-13 Nomeclatura para descrever configuração dos dispositivos hiper-sustentadores. 60

Figura - 14 Detalhe das zonas de refinamento da malha de referência na região do aerofólio. 
Figura - 15 Detalhe das zonas de refinamento da configuração otimizada de malha na região do aerofólio.

Figura - 16 Espectro de flutuação de pressão no ponto de recolamento no intradorso do eslate para diferentes refinamentos de malha. Retirado de Simões, Souza e Medeiros (2011)

Figura - 17 Densidade de potência espectral de flutuações de pressão no campo acústico distante do aerofólio sem o selo. Retirado de Simões, Souza e Medeiros (2011).

Figura - 18 Modelo do esquema de modificação da superfície do aerofólio.

Figura - 19 Comparação entre o elemento principal original e modificado pela espessura de deslocamento. A curva azul representa a geomatria modificada.

Figura - 20 Região da cavidade do eslate de um Boeing 777. Adaptada de Khorrami e Lockard (2006).

Figura - 21 Três diferentes alturas do selo.

Figura - 22 Três diferentes posições do selo.

Figura - 23 Detalhe da malha na região da cova do eslate com selo. 70

Figura - 24 Esquema da configuração das simulações com escoamento cruzado.

Figura - 25 Tubo do sistema anti-gelo atravessando a cavidade do eslate de uma aeronave EMBRAER-170.

Figura - 26 Detalhe da malha e da geometria usada nas simulações do aerofólio com o tubo do sistema anti-gelo.

Figura - 27 Posições onde os espectros de flutuação de pressão e velocidade do campo próximo foram calculados.

Figura - 28 Referência usada para descrever as posições correspondentes aos cálculos do som propagado.

Figura - 29 Curvas de histórico e desvio padrão do arrasto do aerofólio. 77

Figura - 30 Estudo de convergência de um espectro de flutuações do campo próximo em 
relação ao intervalo desconsiderado.

Figura - 31 Distribuição de pressão na superfície do aerofólio comparando a simulação sem escorregamento e com escorregamento livre, $\operatorname{com} \delta^{*}$ e sem $\delta^{*}$. . . 79

Figura - 32 Campo da componente em $\mathrm{z}$ da vorticidade na região do eslate. 80

Figura - 33 Campo de energia cinética turbulenta com diferentes condições de parede. 80

Figura - 34 Densidade de potência espectral das flutuações da componente de velocidade $u$ em pontos da camada de mistura.

Figura - 35 Densidade de potência espectral das flutuações de pressão em dois pontos na superfície do eslate.

Figura - 36 Densidade de potência espectral da flutuação de pressão em pontos distantes do aerofólio calculdas a partir da analogia de Ffowcs Williams-Hawkings.

Figura - 37 Distribuição de pressão na superfície do aerofólio com um selo no eslate com diferentes alturas.

Figura - 38 Linhas de corrente na região da cova do eslate em geometrias com selo de diferentes alturas.

Figura - 39 Campo médio da energia cinética turbulenta a partir das flutuaçõescom três alturas diferentes do selo bem como da geometria sem o selo.

Figura - 40 Campo instantâneo da componente em $\mathrm{z}$ da vorticidade com três alturas diferentes do selo.

Figura - 41 Espectros das flutuaçõesde u em dois pontos da camada de mistura. Comparação entre selos com três alturas bem como a geometria sem selo.

Figura -42 Iso-superfície de $\lambda_{2}=-10000$ na região da cova do eslate. Geometria com selos de diferentes alturas bem como geometria sem selo.

Figura - 43 Espectros das flutuaçõesde p em dois pontos da superfície do eslate. Comparação entre selos com três alturas bem como a geometria sem selo. . ... 90

Figura - 44 Espectro de flutuação de pressão acústica propagada a partir do eslate em um ponto a uma distância de $10 c_{c r u z}$. Comparação entre três alturas do selo.

Figura - 45 Distribuição de pressão na superfície do aerofólio com um selo no eslate em três posiçõesdiferentes. 
Figura - 46 Linhas de corrente na região da cova do eslate em geometrias com selo em

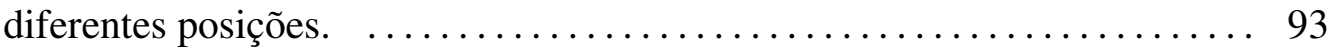

Figura - 47 Campo médio da energia cinética turbulenta a partir das flutuaçõescom selo em três posiçõesdiferentes bem como da geometria sem o selo. ........ 94

Figura - 48 Campo instantâneo da componente de vorticidade na direção z para três posiçõesdiferentes do selo.

Figura - 49 Espectros das flutuaçõesde u em pontos da camada de mistura. Comparação entre três posiçõesdo selo bem como a geometria sem selo.

Figura - 50 Espectros das flutuaçõesde p em dois pontos da superfície do eslate. Comparação entre selos em três posiçõesdiferentes e a geometria sem selo. . . 97

Figura - 51 Espectro de flutuação de pressão acústica propagada a partir do eslate em um ponto a uma distância de $10 c_{c r u z}$. Comparação das três posiçõesdo selo.

Figura - 52 Comparação da distribuição entre duas malhas dos casos com enflechamento de $35^{\circ}$ e $45^{\circ}$.

Figura - 53 Linhas de corrente ao redor do flap. Enflechamento de $35^{\circ}$. 98

Figura - 54 Campo da componente de vorticidade na direção da envergadura na região da cavidade do eslate no caso com enflechamento de $35^{\circ}$.

Figura - 55 Campo da componente de vorticidade na direção da envergadura na região da cavidade do eslate no caso com enflechamento de $45^{\circ}$.

Figura - 56 Perfis de velocidade em pontos escolhidos da camada de mistura. Enflechamento de $35^{\circ}$.

Figura - 57 Perfis de velocidade em pontos escolhidos da camada de mistura. En-

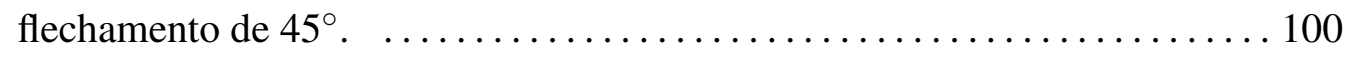

Figura - 58 Campo da energia cinética turbulenta calculada a partir das flutuações de velocidade. Enflechamento de $35^{\circ}$.

Figura - 59 Espectro de flutuações da componente em $\mathrm{x}$ de velocidade em quatro pontos ao longo da camada de mistura. Enflechamento de $35^{\circ}$.

Figura - 60 Espectro de flutuações da componente em $\mathrm{x}$ de velocidade em quatro pontos 
ao longo da camada de mistura. Enflechamento de $45^{\circ}$.

Figura - 61 Espectro de flutuações da pressão em pontos na superfície do eslate. Enflechamento de $35^{\circ}$

Figura - 62 Espectro de flutuações da pressão em pontos na superfície do eslate. Enflechamento de $45^{\circ}$.

Figura - 63 Espectro de flutuações de pressão acústica propagada a partir do eslate para um ponto a uma distância $10 c_{c r u z}$. Enflechamento de $35^{\circ}$.

Figura - 64 Espectro de flutuações de pressão acústica propagada a partir do eslate para um ponto a uma distância $10 c_{c r u z}$. Enflechamento de $45^{\circ}$. 106

Figura - 65 Distribuição de pressão ao longo da superfície do aerofólio com adimen-

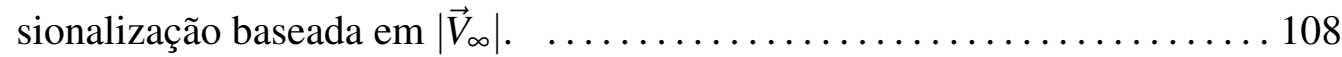

Figura - 66 Distribuição de pressão ao longo da superfície do aerofólio com adimen-

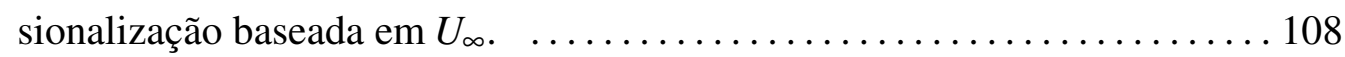

Figura - 67 Linhas de corrente ao redor do flap no caso com enflechamento de $35^{\circ}$. . . 109

Figura - 68 Campo da componente de vorticidade na direção da envergadura. Enflechamento de $35^{\circ}$.

Figura - 69 Campo da componente de vorticidade na direção da envergadura. Enflechamento de $45^{\circ}$.

Figura - 70 Campo de energia cinética turbulenta calculada a partir das flutuações de velocidade no caso com enflechamento de $35^{\circ}$.

Figura - 71 Campo de energia cinética turbulenta calculada a partir das flutuações de velocidade no caso com enflechamento de $45^{\circ}$.

Figura - 72 Componentes $\overline{u^{\prime} u^{\prime}}, \overline{v^{\prime} v^{\prime}}$ e $\overline{w^{\prime} w^{\prime}}$ da tensão de Reynolds, calculadas a partir das simulações Lattice-Boltzmann. Enflechamento de $35^{\circ}$.

Figura - 73 Espectros de flutuações de velocidade $u$ no caso com enflechamento de $35^{\circ}$. 114

Figura - 74 Espectros de flutuações de velocidade $u$ calculados pelo CFL3D em casos sem enflechamento apresentados em publicações diferentes.

Figura - 75 Espectros de flutuação de pressão em dois pontos escolhidos na superfície do aerofólio para três diferentes enflechamentos em função da frequência 
adimensionalizada.

Figura - 76 Espectros de flutuação de pressão nos pontos 3 e 6 em função da frequência absoluta. ............................................... 117

Figura - 77 Espectros de flutuação de pressão propagada a partir do eslate para um ponto a $10 c_{c r u z}$ de distância em função da frequência adimensionalizada.

Figura - 78 Espectros de flutuação de pressão propagada a partir do eslate para um ponto a $10 c_{c r u z}$ de distância em função da frequência absoluta. $\ldots \ldots \ldots \ldots \ldots 118$

Figura - 79 Efeito da camada limite na distribuição de pressão.

Figura - 80 Linhas de corrente em torno no flap mostrando a separação da camada limite. A cruz vermelha e azul indica um local fixo nas duas imagens.

Figura - 81 Efeito da camada limite no campo da componente de vorticidade na direção da envergadura. Enflechamento de $35^{\circ}$.

Figura - 82 Efeito da camada limite no campo da componente de vorticidade na direção da envergadura. Enflechamento de $45^{\circ}$.

Figura - 83 Perfis de velocidade em posições da camada de mistura. Comparação entre soluções do caso com enflechamento de $35^{\circ}$, empregando paredes com e sem escorregamento.

Figura - 84 Perfis de velocidade em posições da camada de mistura. Comparação entre soluções do caso com enflechamento de $45^{\circ}$, empregando paredes com e sem escorregamento.

Figura - 85 Espectros de flutuações de $u$. Comparação entre soluções do caso com enflechamento de $35^{\circ}$, empregando paredes com e sem escorregamento. . . 124

Figura - 86 Espectros de flutuações de $u$. Comparação entre soluções do caso com enflechamento de $45^{\circ}$, empregando paredes com e sem escorregamento. . . 125

Figura - 87 Espectros de flutuações de pressão. Comparação entre soluções do caso com enflechamento de $35^{\circ}$, empregando paredes com e sem escorregamento. . . 125

Figura - 88 Espectros de flutuações de pressão. Comparação entre soluções do caso com enflechamento de $45^{\circ}$, empregando paredes com e sem escorregamento. . . 125

Figura - 89 Espectros de flutuações de pressão propagada a partir do eslate para uma 
distâcia de $10 c_{c r u z}$. Comparação entre soluções empregando paredes com e sem escorregamento.

Figura - 90 Distribuição de pressão na superfície do aerofólio em duas posições da envergadura simulada. Desconsiderando-se efeito do enflechamento.

Figura - 91 Distribuição de pressão na superfície do aerofólio em duas posições da envergadura simulada. Enflechamento de $35^{\circ}$.

Figura - 92 Campo de energia cinética turbulenta calculada a partir das perturbações. Desconsiderando efeito de enflechamento.

Figura - 93 Iso-superfícies de $l a m b d a_{2}$ na cova do eslate.

Figura - 94 Pontos onde da esteira do tubo onde foram medidas as flutuações de pressão. 130

Figura - 95 Espectros de flutuação de pressão em pontos na esteira do cilindro.

Figura - 96 Comparação da PSD de pressão entre casos com e sem escoamento cruzado, ambos com o tubo na cova do eslate.

Figura - 97 Comparação da PSD de pressão no campo distante entre casos com e sem o tubo do sistema anti-gelo. 


\section{Lista de Tabelas}

Tabela - 1 Configuração geométrica do aerofólio 30P30N.

Tabela - 2 Propriedades do escoamento nas simulações considerando espessura de deslocamento.

Tabela - 3 Propriedades do escoamento nas simulações de asa enflechada. 


\section{Lista de Siglas}

BART Túnel de Pesquisa Aerodinâmica Básica (Basic Aerodynamics Research Tunnel)

BGK Bhatnagar-Gross-Krook

CFD Dinâmica dos Fluidos Computacional (Computational Fluid Dynamics)

EPNL Nível Efetivo de Ruído Percebido (Effective Perceived Noise)

FW-H Ffowcs Williams-Hawkings

IBL Integral Boundary Layer

ICAO OrganizaçãoInternacional de AviaçãoCivil (International Civil Aviation Organization)

LES Simulaçãode Grandes Estruturas (Large Eddy Simulation)

MLB Método Lattice-Boltzmann

NASA AdministraçãoNacional de Aeronáutica e Espaço (National Aeronautics and Space Administration)

PIV Velocimetria por Imagem de Partículas (Particle Image Velocimetry)

PSD Densidade de Potência Espectral (Power Spectral Density)

RANS Reynolds Averaged Navier-Stokes

RNG Re-Normalization Group

TKE Energia Cinética Turbulenta (Turbulent Kinetic Energy)

URANS Unsteady Reynolds Averaged Navier-Stokes 


\section{Lista de Símbolos}

V Velocidade

$f(c) \quad$ Função de distribuição

c Velocidade da partícula

$T \quad$ Temperatura

$m \quad$ Massa da partícula

$k \quad$ Constante de Boltzmann

$f_{0} \quad$ Função de distribuição de Maxwell-Boltzmann

$t \quad$ Instante de tempo

$\vec{r} \quad$ Vetor de coordenadas cartesianas

$\vec{F} \quad$ Vetor força

$\Omega \quad$ Operador de colisão

$\vec{a} \quad$ Vetor aceleração

$\rho \quad$ Densidade do fluido

$\vec{u} \quad$ Vetor velocidade do fluido

$\lambda \quad$ Tempo de relaxação

$f^{e q} \quad$ Função de distribuição de equilíbio

$R \quad$ Constante dos gases ideais

$p \quad$ Pressão

$\delta t \quad$ Passo discreto no tempo

$\tau \quad$ Tempo de relaxação adimensional

$k \quad$ Energia cinética turbulenta modelada

$\varepsilon \quad$ Taxa de dissipação da energia cinética turbulenta modelada

$v \quad$ Viscosidade cinemática 
$v_{\text {turb }} \quad$ Viscosidade cinemática turbulenta

$S \quad$ Tensor taxa de deformação do elemento fluido

$\vec{\Omega} \quad$ Vetor vorticidade

$\rho^{\prime} \quad$ Flutuação de densidade

$\rho_{0} \quad$ Densidade do meio em repouso

$a_{0} \quad$ Velocidade do som no meio em repouso

$\delta_{i j} \quad$ Delta de Kronecker

$T_{i j} \quad$ Tensor de Lighthill

$\tau_{i j} \quad$ Tensor de tensões viscosas

$\tau \quad$ Tempo atrasado

V Volume

$\delta(f) \quad$ Delta de dirac de $\mathrm{f}$

$p^{\prime} \quad$ Flutuação de pressão

M Número de Mach

$\delta_{s} \quad$ Deflexão do eslate

$\delta_{f} \quad$ Deflexão do flap

$c_{c r u z}$ Corda do aerofólio em configuração de voo de cruzeiro

$C_{L} \quad$ Coeficiente de sustentação

$C_{D} \quad$ Coeficiente de arrasto

$\delta^{*} \quad$ Espessura de deslocamento

$U_{\infty} \quad$ Componente em $\mathrm{x}$ da velocidade de corrente livre

$\beta \quad$ Ângulo de enflechamento

$\left|\vec{V}_{\infty}\right| \quad$ Módulo do vetor da velocidade de corrente livre

$W_{\infty} \quad$ Componente em $\mathrm{z}$ da velocidade de corrente livre

Re Número de Reynolds

$\delta x_{\min } \quad$ Comprimento da aresta do menor voxel

$C_{p} \quad$ Coeficiente de pressão 
St Número de Strouhal

$h \quad$ Altura do selo da cova do eslate

$\delta_{T E} \quad$ Espessura do bordo de fuga do eslate

$\omega_{z} \quad$ Componente em $\mathrm{z}$ da vorticidade

$s_{T E} \quad$ Distância ao longo da superfície em relação ao bordo de fuga do eslate

$c_{\text {slat }} \quad$ Corda do eslate

$p^{\prime} \quad$ Perturbação de pressão

$L_{z} \quad$ Dimensão do domínio computacional na direção z

$L_{z, F W H}$ Dimensão na direção z da região de integração de Ffowcs Williams-Hawkings 


\section{Sumário}

1 Introdução

2 Revisão Bibliográfica $\quad 27$

3 Metodologia Numérica $\quad 38$

$3.1 \quad$ Método Lattice-Boltzmann . . . . . . . . . . . . . . . . . . . 38

3.1 .1 Equação de Boltzmann . . . . . . . . . . . . . . . . . . 38

3.1.2 Aproximação para Termo de Colisão . . . . . . . . . . . . . . . . . . . 41

3.1.3 Discretização da Equação de Boltzmann . . . . . . . . . . . . . . . . . . 42

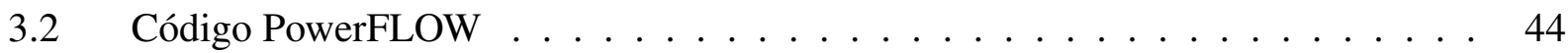

3.2.1 Discretização da Equação de Boltzmann . . . . . . . . . . . . . . . . . . . 44

3.2.2 Modelo de Turbulência . . . . . . . . . . . . . . . . . . . . . 46

3.2.3 Condição de Contorno de Parede . . . . . . . . . . . . . . . . . . . . . 48

3.3 Analogia de Ffowcs Williams e Hawkings . . . . . . . . . . . . . . . . 51

$3.3 .1 \quad$ Analogia de Lighthill $\ldots \ldots \ldots$. . . . . . . . . . . . . . . . . 52

3.3 .2 Equação de Ffowcs Williams-Hawkings . . . . . . . . . . . . . . . . . . . . 54

3.3.3 Formulações do PowerFLOW . . . . . . . . . . . . . . . . . . . 57

4 Configuração das Simulações $\quad 60$

4.1 Simulações Considerando Espessura de Deslocamento . . . . . . . . . . . . 66

$4.2 \quad$ Simulações com Selo no Intradorso do Eslate . . . . . . . . . . . . . . . . . 68

$4.3 \quad$ Simulações com Escoamento Cruzado . . . . . . . . . . . . . . . . . . . 70

4.4 Simulações com Tubo do Sistema Anti-gelo . . . . . . . . . . . . . . . . 72 
5.1 Simulações com Escorregamento Livre Considerando a Espessura de Deslocamento 78

5.2 Efeito Aeroacústico de um Selo Posicionado no Intradorso do Eslate . . . . . . . 83

5.2.1 Efeito do Tamanho do Selo . . . . . . . . . . . . . . . . . . . 84

5.2.2 Efeito da Posição do Selo . . . . . . . . . . . . . . . . . . . . . 92

5.3 Ruído Gerado por Eslate com Escoamento Cruzado . . . . . . . . . . . . . . . . 97

5.3.1 Estudo de Independência de Malha . . . . . . . . . . . . . . . . . . 97

5.3.2 Comparação com Resultados da Literatura . . . . . . . . . . . . . . . . . . 107

5.3.3 Efeito das Camadas Limite no Ruído Provocado pelo Eslate com Escoamento

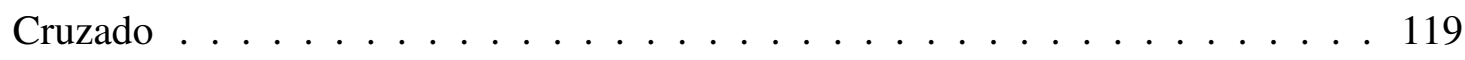

5.4 Efeito do Tubo do Sistema Anti-gelo no Som Gerado pelo Eslate . . . . . . . . 127

6 Conclusões $\quad 134$

Referências 139 


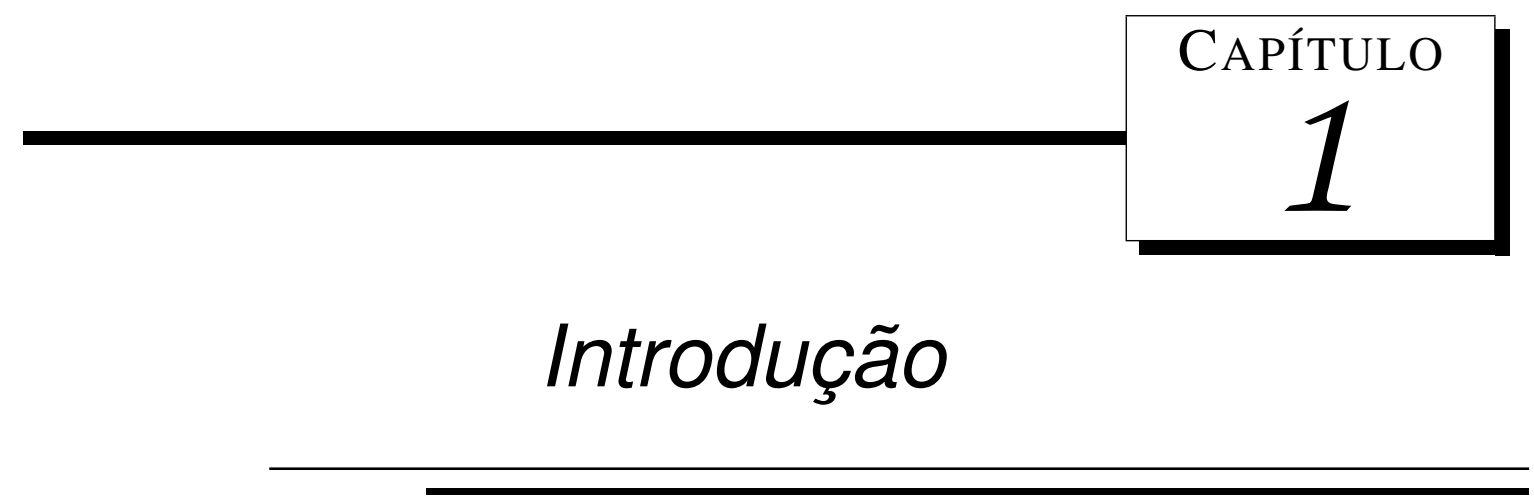

A operação de aeronaves comerciais causa grandes transtornos às comunidades localizadas no entorno de aeroportos. O ruído gerado pelos aviões durante os procedimentos de pouso e decolagem diminui a capacidade de concentração e, a longo prazo, pode causar prejuízos irreversíveis à saude de pessoas que residem ou trabalham próximas a aeroportos. No início da operação de voos comerciais, o número de aeronaves decolando e pousando era pequeno. Entretanto, a popularização das viagens aéreas aumentou drasticamente a frequência de operação de aeronaves em aeroportos e consequentemente o incômodo causado nas comunidades próximas. Para proteger essas comunidades, os órgãos regulamentadores de aviação civil impõem restrições ao nível de ruído emitido pelas aeronaves comerciais.

Para regulamentar a emissão de ruído aeronáutico, muitas nações adotam os limites e procedimentos descritos no volume 1 do anexo 16 da Organização Internacional da Aviação Civil (conhecida pela sigla em inglês, ICAO). O procedimento de certificação referente a ruído externo proposto por esse documento consiste em medir o ruído emitido para o solo pela aeronave. Três pontos são considerados nas medições, a saber, um ponto sob a trajetória da aeronave durante a decolagem, um ponto sob a trajetória da aeronave durante a aproximação e um ponto ao lado da pista. O ruído medido pelos microfones é reportado em escala de nível efetivamente percebibo (cuja unidade é dada por EPNdB). Essa medida é resultado de um cálculo baseado no espectro de ruído, levando em consideração entre outras coisas a maneira como o som é percebido pelo ser humano. O resultado do cálculo é um número que é comparado com o limite imposto pela legislação.

Na primeira versão do anexo 16, para aeronaves projetadas antes de 1977, a distância entre o microfone lateral e a linha central da pista era de $650 \mathrm{~m}$. No capítulo 3 do anexo, vigente para aeronaves projetadas entre 6 de outubro de 1977 e 31 de dezembro de 2005, a distância desse microfone para a linha central da pista diminuiu para $450 \mathrm{~m}$. Adicionalmente o nível máximo 
permitido para o mesmo microfone lateral foi reduzido de $108 E P N d B$ para $103 E P N d B$. O capítulo 4, que regulamenta aeronaves com projeto a partir de 2006, restringe ainda mais o ruído máximo permitido.

Para atender às exigencias cada vez mais rígidas dos órgãos reguladores, pesquisas estão sendo feitas por diversos grupos em diferentes países. A agência aeroespacial americana, NASA (sigla para National Aeronautics and Space Administration), estabeleceu uma meta ambiciosa de reduzir em $10 \mathrm{~dB}$ o ruído percebido de aeronaves em um prazo de dez anos e $20 \mathrm{~dB}$ em vinte e cinco anos (KHORRAMI et al., 2002). A Comunidade Européia publicou um documento com metas para a indústria aeronáutica a serem atingidas até 2020 (ARGÜELLES et al., 2001). Nele se estabelece que o nível de ruído percebido deve ser reduzido até o ano citado em $10 \mathrm{~dB}$ com relação à tecnologia disponível no ano de 2000.

Para reduzir o impacto sonoro dos equipamentos aeronáuticos, é necessário identificar as fontes de som. No princípio da aviação comercial a jato, o ruído produzido pelos propulsores a jato puro se sobressaía ao de qualquer outra fonte presente no avião, de forma que o tratamento das outras fontes não acarretaria em uma redução efetiva do som gerado pela aeronave como um todo. Com o surgimento dos motores turbo-fan com altíssima razão de derivação, o ruído provocado pelo sistema de propulsão caiu drasticamente, tornando significativo o som gerado pela turbulência em outros elementos da aeronave, principalmente em condições de aproximação e aterrissagem.

Em 1975, Morgan e Hardin (1975) apresentaram resultados indicando que o ruído estrutural (não-propulsivo) das aeronaves da época estava entre 5 e 8 EPNdB abaixo do nível total de ruído produzido pela aeronave em condição de aproximação e pouso, mostrando que o som gerado pela estrutura do avião começava a demandar atenção dos projetistas. A partir do reconhecimento da importância do ruído estrutural, diversos esforços foram feitos para entendê-lo e prevê-lo. Inicialmente, a abordagem usada consistia em realizar ensaios com aeronaves já em operação para orientar no desenvolvimento de metodologias empíricas. Alguns ensaios levavam em consideração o ruído geral produzido pela aeronave em configuração de pouso (dispositivos de hiper-sustentação e trens de pouso acionados) com motores desligados ou em condição de potência mínima, enquanto outros experimentos tentavam isolar o efeito de cada possível fonte de som durante a aproximação e o pouso (FINK, 1979; LASAGNA et al., 1980).

As principais fontes de som estrutural em uma aeronave em condição de aproximação e aterrissagem estão mostradas na figura 1 (MORGAN; HARDIN, 1975; FINK, 1979; CRIGHTON, 1991). Analisando os modelos semi-empícos desenvolvidos para previsão de som, Crighton (1991) sugere que a redução do ruído estrutural durante o pouso depende do tratamento das 
fontes relacionadas aos elementos da configuração suja (trens de pouso, eslates e flapes acionados). O nível de ruído emitido por cada um dos componentes mostrados depende das características da aeronave. Em jatos de grande porte para voos intercontinentais, o ruído dos trens de pouso é o mais intenso dos ruídos estruturais, enquanto em aeronaves projetadas para voos regionais, o eslate apresenta emissão de ruído comparável à dos trens de pouso (DOBRZYNSKI, 2010).

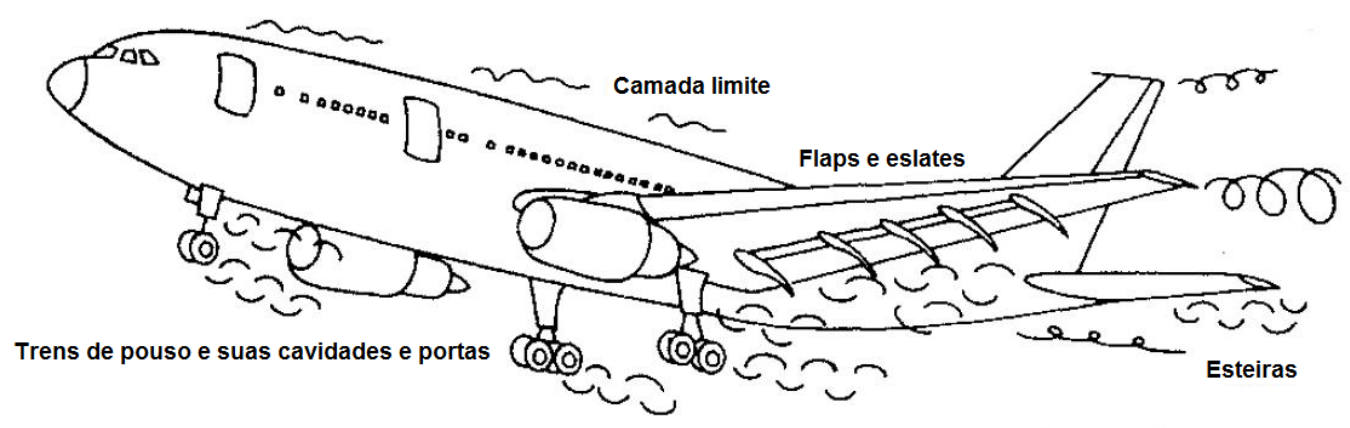

Figura 1 - Principais fontes de som estrutural em uma aeronave comercial. Adaptada de Morgan e Hardin (1975)

Nos últimos 10 anos, grande parte das pesquisas voltadas para o ruído gerado pelo eslate se concentra em identificar os mecanismos de geração de som através da compreensão dos fenômenos hidrodinâmicos transientes que ocorrem na cova e na folga entre o eslate e elemento principal (JENKINS; KHORRAMI; CHOUDHARI, 2004; KHORRAMI; CHOUDHARI; JENKINS, 2004; KOLB et al., 2007; KAEPERNICK; KOOP; EHRENFRIED, 2005). No campo das simulações numéricas, metodologias têm sido propostas para que esses fenômenos hidrodinâmicos e o som gerado sejam previstos com precisão (LOCKARD; CHOUDHARI, 2009, 2010). Como o interesse dessas simulações são os mecanismos básicos de geração de som pelo eslate, em geral, geometrias bidimensionais são analisadas através de simulações tridimensionais com condição de periodicidade na direção da envergadura. Essas análises não incluem alguns aspectos do escoamento em asas reais, como excrescências presentes na cova.

Entre outros grupos de pesquisa na área de ruído gerado por eslate, pode-se destacar os esforços da agência aeroespacial americana, NASA. Dentro do escopo de dois programas de desenvolvimento tecnológico (Advanced Subsonic Technology Program e Quiet Aircraft Technology Program), o grupo liderado por Meelan Choudhari, David Lockard e Medhi Khorrami empregam esforços em âmbito computacional e experimental no intuito de melhor compreender as 
fontes de ruído aeroacústico do eslate. Trabalhos publicados por esse grupo (JENKINS; KHORRAMI; CHOUDHARI, 2004; KHORRAMI; CHOUDHARI; JENKINS, 2004; LOCKARD; CHOUDHARI, 2009, 2010, 2011) são as principais referências no desenvolvimento do trabalho discutido neste texto.

O presente trabalho é parte do projeto Aeronave Silenciosa, uma cooperação entre a Fundação de Amparo à Pesquisa do Estado de São Paulo, a EMBRAER e seis universidades brasileiras. Ele tem um caráter exploratório, na medida que visa estender o emprego de simulações numéricas no cálculo do ruído aeroacústico de eslate para algumas configurações que se aproximem de uma asa real. Uma modificação na metodologia proposta por Simões, Souza e Medeiros (2011), que permite a redução do custo computacional, é testada. Tal modificação permite o uso da metodologia em aerofólios com altos ângulos de ataque. Essa metodologia, sem a modificação para altos ângulos de ataque, foi empregada em simulações que consideram excrescências na cavidade do eslate e testada em casos de aerofólio com escoamento cruzado.

No capítulo 2, um compêndio dos trabalhos disponíveis na literatura a respeito da aerodinâmica de aerofólios com híper-sustentadores e aeroacústica do eslate é apresentado. Nesse capítulo, resultados de esforços numéricos e experimentais de outros grupos de pesquisa são discutidos. Em seguida, uma descrição sucinta das metodologias numéricas utilizadas no trabalho é dada no capítulo 3. O capítulo 4 se dedica a detalhar as configurações das simulações feitas. As características geométricas, as condições do escoamento bem como a discretização do domínio e condições de contorno das simulações são detalhadas nesse capítulo. Em seguida os resultados das simulações são apresentados e discutidos no capítulo 5 . O capítulo 6, por fim, apresenta as discussões finais. 


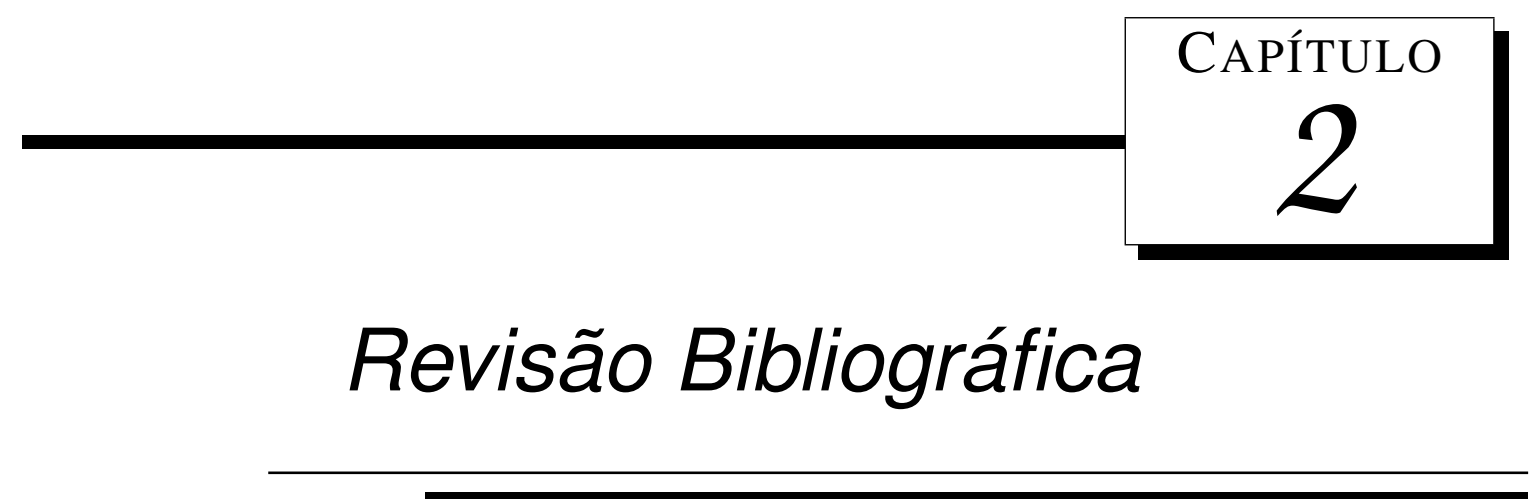

Os dispositivos hiper-sutentadores têm a função de permitir à aeronave distâncias menores do percurso em terra para pouso e decolagem, sem prejudicar a eficiência em condição de cruzeiro. De acordo com Dam (2002), se uma asa maior, sem dispositivos hiper-sustentadores, fosse utilizada para atender aos requisitos de homologação em condição de aproximação, haveria uma redução de $18 \%$ no indicador de eficiência $L / D$ em condição de cruzeiro.

O emprego dos dispositivos hiper-sustentadores aumenta a sustentação e diminui a velocidade de estol, condições favoráveis em situações de pouso e decolagem, mesmo que a custo do aumento do arrasto do aerofólio. Segundo Smith (1975), os princípios básicos que fazem com que um aerofólio com múltiplos elementos tenha capacidade de gerar mais sustentação do que um aerofólio simples são:

- A circulação do elemento a montante modifica a velocidade do elemento a jusante na região do bordo de ataque deste, reduzindo a intensidade do pico de sucção e diminuindo assim a chance de separação da camada limite;

- A circulação de um elemento a jusante induz circulação no elemento a montante, aumentando a sustentação do conjunto;

- A alta velocidade na região do extradorso de um elemento permite que parte da recuperação de pressão do elemento a montante ocorra na esteira, descolada da superfície;

- Como cada elemento desenvolve uma camada limite própria, elas são mais finas do que seriam em um aerofólio simples com a mesma sustentação;

- A esteira de um elemento diminui o pico de sucção do elemento a jusante, retardando a separação neste. 
Entretanto, os dispositivos hiper-sutentadores têm o inconveniente de aumentar o ruído aeroacústico, em especial o eslate, pois este corresponde a uma fonte distribída ao longo de praticamente toda a envergadura da asa. Por isso, grupos de pesquisa na Europa, Estados Unidos e Japão têm desenvolvido trabalhos com a intenção de compreender a dinâmica do escoamento na região do eslate (BERKMAN et al., 2000; TAKEDA; ASHCROFT; ZHANG, 2001; JENKINS; KHORRAMI; CHOUDHARI, 2004; KAEPERNICK; KOOP; EHRENFRIED, 2005). A idéia é, com a compreensão desses fenômenos, conseguir associá-los às características do ruído gerado pelo eslate, além de permitir o aperfeiçoamento das ferramentas de previsão do ruído, bem como, possivelmente, identificar meios de reduzí-lo.

A figura 2 mostra características básicas do escoamento na cova do eslate. Na figura da esquerda, é mostrada uma imagem do campo instantâneo da componente de vorticidade na direção da envergadura, adimensionalizada pela corda do aerofólio e velocidade do escomanento livre. Por sua vez, a imagem da direita mostra o campo de velocidade média adimensionalizada juntamente com as linhas de corrente do escoamento médio.

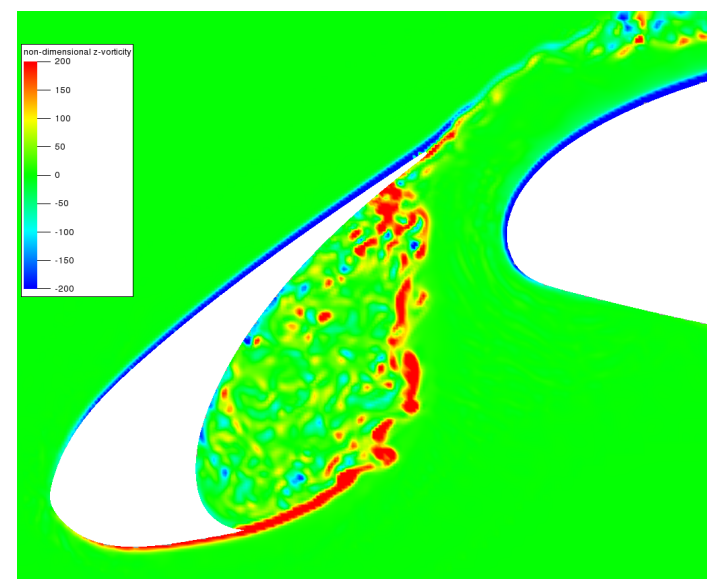

(a)

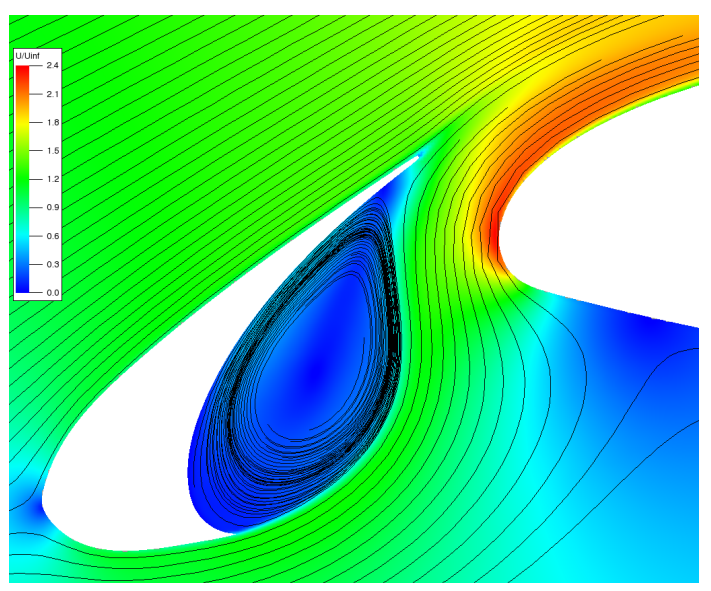

(b)

Figura 2 - Campo do escoamento na região da cova do eslate.

Uma bolha de separação se forma na cova do eslate. Embora as linhas de corrente do escoamento médio indiquem um padrão de escoamento de um grande vórtice no centro da cova, o campo de vorticidade instantânea mostra que o escoamento nesta região é composto por vários vórtices com componente em z positiva (marcas vermelhas) e negativa (marcas azúis) que ficam recirculando. Fora da bolha, forma-se uma região de escoamento potencial que é acelerado à medida que se aproxima da folga entre o eslate e o elemento principal. Separando as duas regiões existe uma faixa de elevado gradiente de velocidade. Esse gradiente alto confere a essa faixa um perfil de velocidade de camada de mistura. Essa camada se forma a partir da separação da camada limite na cúspide do eslate e se choca com a parede inferior do eslate a 
montante do bordo de fuga.

Um esquema representando um espectro típico do ruído gerado pelo eslate é mostrado pela figura 3 (DOBRZYNSKI; POTT-POLENSKE, 2001; LASAGNA et al., 1980; KHORRAMI; SINGER; BERKMAN, 2001; KHORRAMI et al., 2002; KHORRAMI; SINGER; LOCKARD, 2002; KOLB et al., 2007; LOCKARD; CHOUDHARI, 2009). Três elementos podem ser destacados na figura, a saber, um intenso pico tonal de alta frequência, uma componente de banda larga ambrangendo as baixas e médias frequências e alguns picos tonais de baixa frequência se sobressaindo do ruído de banda larga.

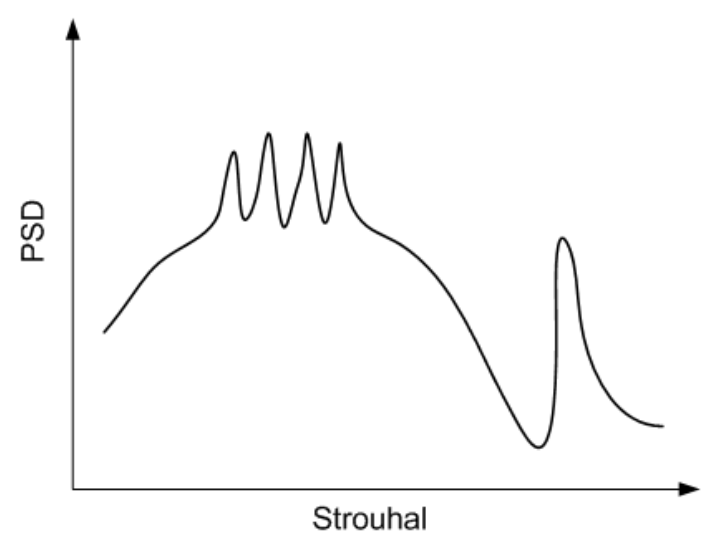

Figura 3 - Desenho esquemático de um espectro típico de ruído gerado pelo eslate.

Choudhari et al. (2002) mediram o som propagado por uma geometria típica de aerofólio com hiper-sustentadores, a partir de experimentos em um túnel de vento, considerando deflexões do eslate $\left(\delta_{S}\right)$ de $30^{\circ}$ e $20^{\circ}$. Eles observaram que o pico tonal de alta frequência praticamente despareceu na configuração $\delta_{s}=20^{\circ}$. Partindo da idéia de que o tom de alta frequência era gerado pelo desprendimento de vórtices no bordo de fuga espesso do eslate, Khorrami, Berkman e Choudhari (2000) simularam numericamente o escoamento na mesma geometria com especial atenção à resolução da malha na região do bordo de fuga. Seus resultados confirmaram a relação entre o pico no espectro e o desprendimento de vórtices.

Para testar a hipótese de que a frequência de desprendimento de vórtice no bordo de fuga do eslate é determinada por um mecanismo de retro-alimentação acústica na folga entre o elemento principal e o eslate, Takeda, Zhang e Nelson (2002) fizeram ensaios em túnel de vento, variando o tamanho da folga. A partir da observação de que a frequência praticamente não se alterou, eles concluiram que o mecanismo não tem influência significativa na configuração testada. Por sua vez, simulações computacionais feitas por Takeda, Zhang e Nelson (2004), usando uma geometria simplificada do eslate também mostram que uma variação no tamanho da folga não provoca a variação na frequência esperada de acordo com hipótese da retro-alimentação acústica. 
Embora o pico relacionado ao desprendimento de vórtices seja captado tanto em ensaios em túnel de vento quanto em simulações numéricas, Dobrzynski e Pott-Polenske (2001) argumentam que este tem pouca probabilidade de ocorrer em aeronaves reais, uma vez que a espessura relativa do bordo de fuga de um eslate real é muito menor do que é observado nos modelos em escala usados nas simulações e experimentos. Para efeito de ilustração Dobrzynski (2010) compara a espesssura de $0,1 \mathrm{~mm}$ que o bordo de fuga de um modelo em escala deveria ter com a faixa entre $0,2 \mathrm{~mm}$ e $0,5 \mathrm{~mm}$ típica dos modelos existentes.

Os mecanismos responsáveis pelos outros dois componentes do espectro de som ainda não são tão bem compreendidos como o do pico de alta frequência. Dobrzynski e Pott-Polenske (2001) associam os picos de baixa frequência à formação de vórtices discretos na camada de mistura que se forma a partir do eslate. Forçando a transição da camada limite do intradorso do eslate a montante da cúspide, o trabalho mostra que os picos praticamente desaparecem e conclui que estes são consequência dos baixos números de Reynolds dos ensaios em túneis de vento.

Kolb et al. (2007) testam a hipótese de que os picos de baixa frequência estão associados a efeitos de ressonância que ocorrem em escoamento sobre cavidades, gerando modos discretos de oscilação da camada de mistura. Em um dos casos ensaiados, as frequências dos picos coincidem com precisão razoável com as frequências previstas. Entretanto, a teoria falha em captar a tendência observada com a variação do ângulo de ataque. Eles sugerem que outra velocidade, que não a velocidade do escoamento livre, seja relevante na determinação das frequências de ocorrência dos picos, mas não indicam qual seria essa velocidade.

O ruído de banda larga de baixa e média frequência é associado por vários autores às oscilações da camada de mistura que se forma na cúspide e se choca com a parede inferior do eslate. Entretanto nenhum mecanismo de geração do ruído foi determinado precisamente. $\mathrm{O}$ perfil de velocidade da camada de mistura indica uma instabilidade do tipo Kelvin-Helmholtz. Paschal, Jenkins e Yao (2000) e Takeda, Zhang e Nelson (2004) identificaram uma ejeção intermitente, através da folga do eslate, de vórtices formados na camada de mistura da cova. Esses vórtices ejetados são identificados por Khorrami, Choudhari e Jenkins (2004) como origem de ondas acústicas de baixa frequência sendo propagadas a partir da cova. Já Dobrzynski e PottPolenske (2001) sugerem que o ruído de baixa frequência do eslate é gerado pela interação dos vórtices oriundos da cova com o bordo de fuga do eslate.

Alguns esforços para se obter uma lei de escala da intensidade do ruído com a velocidade do escoamento são apresentados na literatura. Corrigindo o espectro baseado na hipótese de que a intensidade do som é proporcional à quinta potência da velocidade do escoamento livre, 
Khorrami et al. (2002) mostra que as curvas colapsam nas altas frequências, mas as baixas freqências não apresentam a mesma tendência. Experimentos com um modelo em escala de uma asa tridimensional discutidos por Dobrzynski e Pott-Polenske (2001) apresentam bom colapso dos espectros de som de acordo com $V^{5}$ na faixa de número de Strouhal entre 2 e 10. Porém eles afirmam que as curvas apresentam colapso ainda melhor se corrigidas por $V^{4,5}$.

Devido à complexidade e custo dos ensaios em túnel de vento, agravados quando se trata de ensaios aeroacústicos, simulações numéricas podem ser uma alternativa valiosa no estudo do escoamento em aerofólios com hiper-sustentadores. Esse tipo de escoamento apresenta algumas complexidades ausentes no escoamento de aerofólios simples, como a interação entre a esteira de um elemento com a camada limite de outro e grandes regiões de escoamento separado. Portanto, uma ferramenta computacional deve ser capaz de simular de forma adequada essas características do escoamento.

Para avaliar a sensibilidade de cálculos da aerodinâmica de aerofólios com hiper-sustentadores utilizando Mecânica do Fluidos Computacional, Rumsey et al. (1998) compararam resultados de simulações em regime permanente considerando escoamento completamente turbulento com resultados de simulações em que os pontos de transição das camadas limite eram fixados. A determinação dos pontos de transição foram baseadas em medições de túnel de vento. A comparação mostrou que a consideração dos pontos de transição melhora significativamente a precisão das previsões numéricas dos perfís de velocidade de algumas camadas cisalhantes. Usando um modelo RANS (Reynolds Averaged Navier-Stokes), Berkman et al. (2000) simularam uma geometria bidimensional de um aerofólio multi-elementos típico com um eslate e um flap. Uma boa concordância com observações experimentais foi alcançada com o modelo e os elementos básicos do escoamento médio na cova do eslate foram capturados.

Interessados em testar a hipótese de que perturbações amplificadas na camada de mistura eram responsáveis pelo ruído de baixa frequência do eslate, Khorrami, Singer e Berkman (2001) fizeram simulações numéricas URANS (Unsteady Reynolds Averaged Navier-Stokes) focadas na região da cova do eslate. Após observar que as estruturas vorticais detectadas na cova do eslate em experimentos estavam sendo dissipadas nas simulações eles decidiram excitar o escoamento artificialmente. Essa estratégia se mostrou parcialmente eficaz. Apesar das estruturas na camada de mistura se manterem ao longo da simulação o campo acústico resultante ficou contaminado com as frequências da excitação artificial introduzida no escoamento. Para corrigir esse problema, Khorrami, Singer e Lockard (2002) propuseram que o termo de produção do modelo de turbulência fosse igualado a zero na região da cova. Assim, as estrutras de grande escala se formaram na cova sem a necessidade de uma excitação artificial e não se dissiparam 
tão rapidamente.

Para melhorar a compreensão do escoamento na região da cova do eslate, dois estudos foram desenvolvidos em conjunto, um analisando escoamento a partir do uso de velocimetria por imagem de partículas (designada pela sigla em inglês, PIV) em ensaios de túnel de vento (JENKINS; KHORRAMI; CHOUDHARI, 2004), e outro baseado em simulações URANS bidimensionais com produção de turbulência zerada na cova (KHORRAMI; CHOUDHARI; JENKINS, 2004). Em geral, boa concordância entre os resultados foi observada, entretanto, as estruturas na cova do eslate apresentaram um padrão diferente entre o resultado da simulação e as imagens feitas do ensaio. No escoamento calculado numericamente, devido a impossibilidade do crescimento de perturbações com estruturas na direção da envergadura, os vórtices eram maiores e oscilações mais intensas na camada de mistura e consequentemente no ponto de recolamento foram observadas.

Resultados de simulações CFD com geometrias tridimensionais de aerofólios com hipersustentadores foram apresentados em diversos trabalhos (DECK, 2005; CHOUDHARI; KHORRAMI, 2007; IMAMURA et al., 2008). As simulações empregaram uma abordagem zonal, como a usada por Khorrami, Choudhari e Jenkins (2004), no tratamento das escalas não resolvidas ou um esquema híbrido LES/RANS (Large Eddy Simulation/Reynolds Averaged NavierStokes) de forma que as estruturas da cova não sofressem dissipação excessiva. Diferentes modelos de turbulência foram usados para representar o efeito das escalas não resolvidas. Sem a necessidade de excitação artificial do escoamento, os resultados mostram a formação de vórtices discretos na camada de mistura que são convectados e se chocam com a parede da cova. As oscilações exageradas exibidas pela simulação 2D de Khorrami, Choudhari e Jenkins (2004) não foram observadas nas simulações tridimensionais. O escoamento amplifica perturbações com estrutura na direção da envergadura e tornam os vórtices tridimensionais à medida que se aproximam do ponto de recolamento. Entre o recolamento e o bordo de fuga, vórtices com eixo na direção do escoamento são observados. Esses trabalhos, entre outros, mostraram que efeitos tridimensionais são relevantes na dinâmica do escoamento na cova do eslate.

Uma vez que as simulações tridimensionais foram capazes de reproduzir com precisão razoável o escoamento médio e transiente da cova do eslate, trabalhos baseados em simulações computacionais dedicadas à previsão do ruído foram desenvolvidos. Diversos casos foram simulados utilizando uma geometria tridimensional típica de um aerofólio com hiper-sustentadores, focados nas fontes de ruído de baixa e média frequência do eslate (LOCKARD; CHOUDHARI, 2009, 2010, 2011). Foi assumido que o escoamento médio na cova é homogêneo na direção da envergadura e condição de periodicidade foi imposta nessa direção. Diversas condições foram 
testadas, variando o ângulo de enflechamento, a extensão do domínio na direção da envergadura, número de Mach e número de Reynolds. Os resultados são resumidos abaixo:

- para captar a descorrelação das estruturas vorticais da cova, uma extensão do domínio simulado na direção da envergadura correspondente a $80 \%$ da corda do eslate deve ser adotada;

- ocorrência dos picos tonais de baixa frequência no espectro do som apresentaram boa correspondência com frequências de picos observados nas flutuações do campo próximo;

- um enflechamento de $45^{\circ}$ diminuiu significativamente os picos tonais de baixa frequência no ruído do eslate;

- as flutuações do campo próximo escalam bem em função de $U_{\infty}^{4}$, porém o som propagado apresenta melhor colapso em função de $U_{\infty}^{5}$;

- o número de Reynolds, na faixa testada, não apresenta efeito significativo no ruído de eslate.

Embora tenham sido calculadas pelo mesmo código (CFL3D), simulações discutidas por Lockard e Choudhari (2009), Lockard e Choudhari (2010) e Lockard e Choudhari (2011) apresentam algumas diferenças substanciais entre resultados de casos correspondentes. A figura 4 apresenta os espectros de flutuação da componente de velocidade na direção $x$ em pontos selecionados ao longo da camada de mistura do eslate, conforme publicado por Lockard e Choudhari (2010), por sua vez a figura 5 mostra os espectros de $u$ relatados por Lockard e Choudhari (2011) nos mesmos pontos utilizando o mesmo código CFL3D. Os gráficos da figura 4 correspondem ao caso representado pelas curvas vermelhas $\left(\left|V_{\infty}\right|=0.17\right)$ da figura 5. A mesma configuração de escoamento e extensão do domínio na direção da envergadura foram aplicados nos dois casos. A correção em função de $U_{\infty}$ aplicada nas curvas da figura 5 não provoca qualquer alteração na curva do caso $\left|V_{\infty}\right|=0.17$, uma vez que este é o caso de referência e, portanto, as curvas podem ser comparadas diretamente.

Comparando os gráficos das duas figuras, vê-se que as curvas da figura 5 têm os formatos semalhantes aos das suas correspondentes na figura 4. Porém, todas elas apresentam uma diferença de nível, sendo que as flutuações da publicação de 2011 têm dez vezes a energia das flutuações apresentadas em 2010.

Resultados do espectro do som propagado apresentados por Lockard e Choudhari (2010) e Lockard e Choudhari (2011) são apresentados na figura 6. Os dois gráficos são referentes ao 


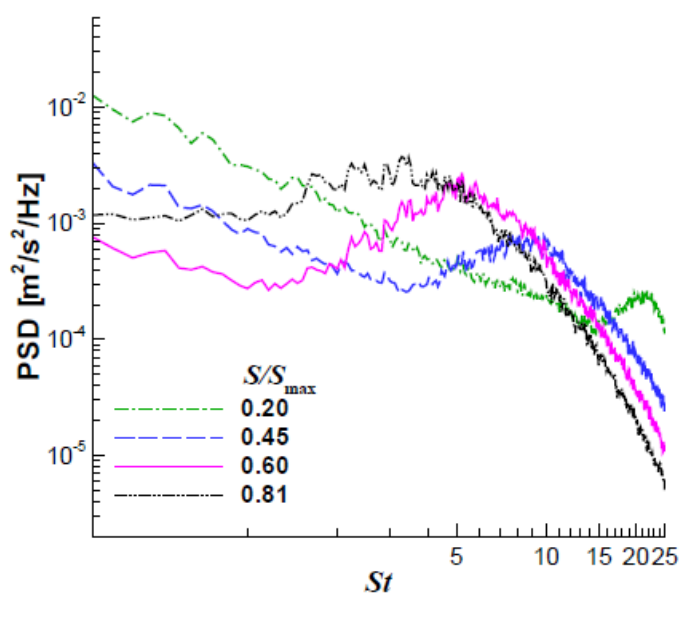

(a)

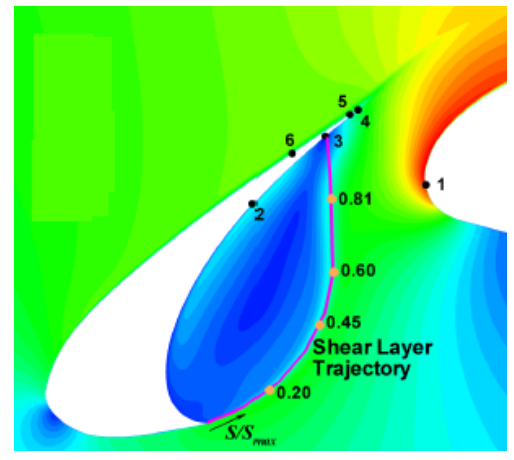

(b)

Figura 4 - Espectros de flutuação de componente de velocidade u em pontos ao longo da camada de mistura. De acordo com os pontos mostrados em (b). Retirado de Lockard e Choudhari (2010).

som propagado para o mesmo ponto a uma distância da cova do eslate igual a dez vezes a corda do aerofólio em condição de cruzeiro, $c_{c r u z}$. Os cálculos foram feitos através da analogia de Ffowcs Williams Hawkings (LOCKARD, 2002). A curva preta da figura 6(a) corresponde uma simulação com as mesmas condições da simulação representada pela curva vermelha da figura 6(b).

Assim como visto para os espectros de velocidade ao longo da camada de mistura, novamente é possível verificar uma diferença entre os resultados. Embora as duas curvas tenham um formato semelhante, inclusive na região do espectro entre $S t=7$ e $S t=10$, onde há um aumento do nível de energia se sobressaindo do restante da curva, o resultado publicado por Lockard e Choudhari (2010) apresenta nível aproximadamente $15 \mathrm{~dB} / \mathrm{Hz}$ acima do que foi apresentado por Lockard e Choudhari (2011). É importante ressaltar que, embora a envergadura simulada tenha sido de $75 \%$ da corda do eslate nos dois casos, a região considerada nos cálculos do som propagado utilizou apenas metade desta envergadura em ambos os cálculos e que a correção em função de $U_{\infty}$ feita às curvas da figura 6(a) não altera seu nível por ser este o caso de referência.

Motivados pela comparação entre resultados de simulações numéricas do som do eslate, que mostraram que, apesar da diferença na espessura da camada limite perto da cúspide, os espectros de som propagado não apresentavam variações significativas, Simões, Souza e Medeiros (2011) decidiram avaliar o efeito da espessura das camadas limite no som produzido pelo eslate. Comparando a densidade de potência espectral de casos com a camada limite laminar e turbulenta na superfície do eslate, apenas variações menores mínimas (menores que a incerteza do 


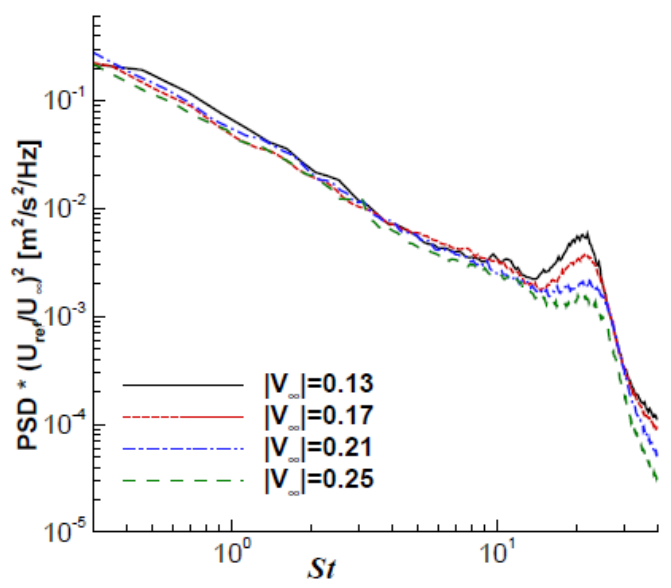

(a) $S / S_{\max }=0,20$

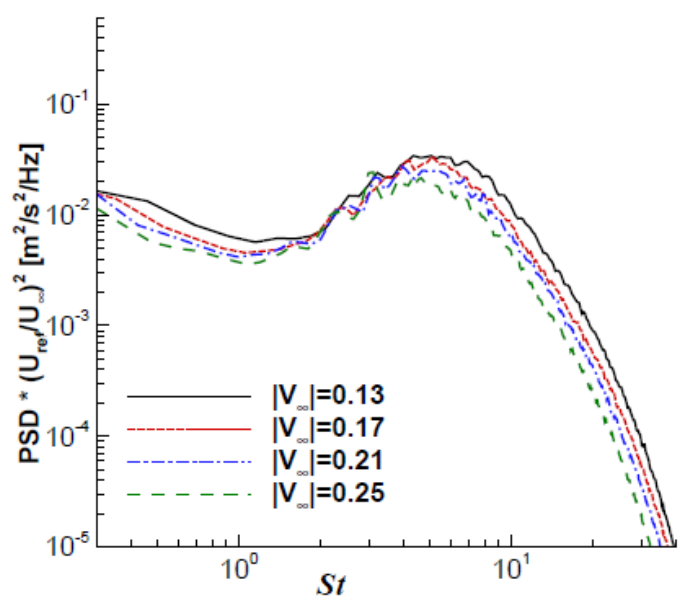

(c) $S / S_{\max }=0,60$

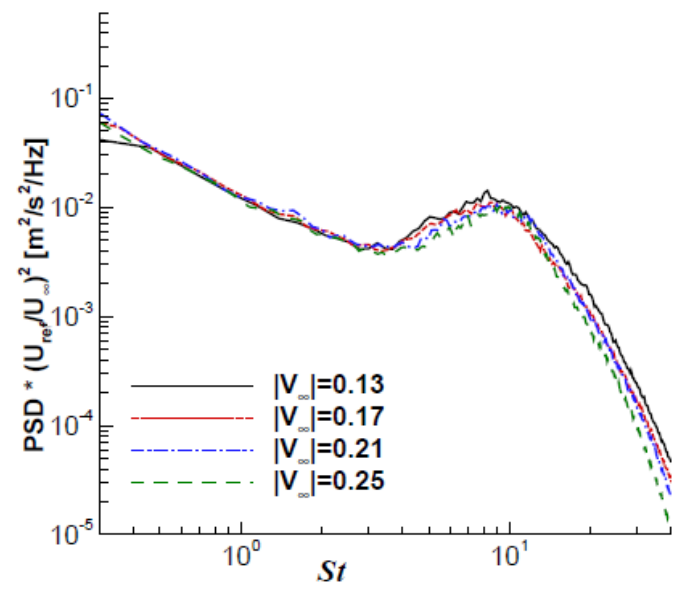

(b) $S / S_{\text {max }}=0,45$

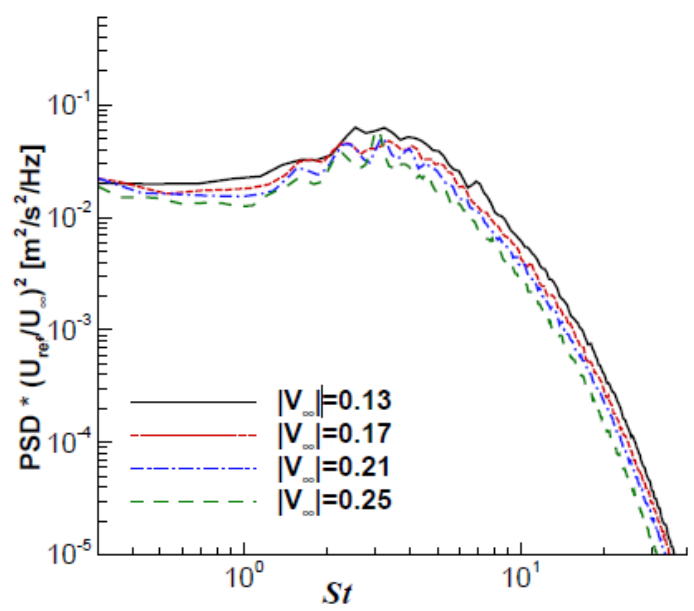

(d) $S / S_{\max }=0,81$

Figura 5 - Espectros de flutuação da componente de velocidade u em simulação do aerofólio $30 \mathrm{P} 30 \mathrm{~N}$ em pontos ao longo da camada de mistura. Retirado de Lockard e Choudhari (2011).

modelo, de aproximadamente $3 \mathrm{~dB} / \mathrm{Hz}$ na densidade de potência espectral) foram observadas, tanto nos espectros de som distante, calculado a partir de métodos integrais, quanto nos espectros de flutuações no campo próximo do eslate. Concluiu-se então que a espessura das camadas limite não tinha impacto no cálculo do som gerado pelo eslate.

Baseado nesses resultados, supôs-se que a dinâmica do escoamento na cavidade do eslate e, consequentemente, o ruído do eslate poderiam ser previstos com precisão adequada, contanto que a circulação dos elementos fosse calculada corretamente. Em condições em que as espessuras das camadas limite são pequenas, uma boa previsão da circulação pode ser conseguida apenas com o cálculo do escoamento potencial e a satisfação da condição de Kutta. Para satisfazer a condição de Kutta, os efeitos viscosos são suficientes, uma vez que eles impedem que uma velocidade infinita ocorra no bordo de fuga, não sendo necessária para isso, portanto, a 


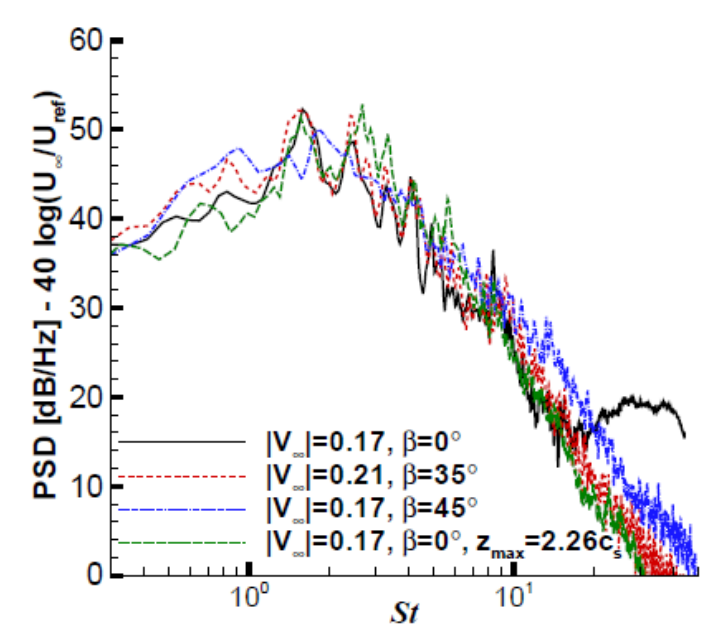

(a) Lockard e Choudhari (2010)

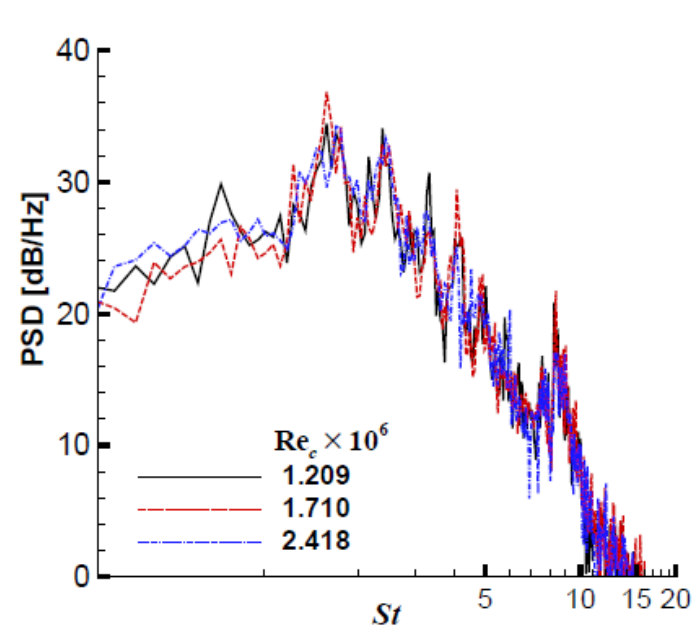

(b) Lockard e Choudhari (2011)

Figura 6 - Espectro de som propagado para um ponto a $10 c_{c r u z}$ da cova do eslate. Retirado de Lockard e Choudhari (2010) e Lockard e Choudhari (2011).

presença de uma camada limite.

Para testar essa hipótese, Simões, Souza e Medeiros (2011) consideraram a superfície do elemento principal e a superfície do eslate externa à cova como paredes com escorregamento livre. Novamente variações menores do que $3 \mathrm{~dB} / \mathrm{Hz}$ na densidade de potência espectral do campo próximo e do campo distante (calculado através da analogia de Ffowcs Williams-Hawkings) foram observadas. A superfície do flap ainda foi considerada como parede sem escorregamento, já que uma separação da camada limite ocorre no extradorso e descosiderar essa camada limite levaria a uma modificação significativa na circulação dos elementos do aerofólio. Por outro lado uma tentiva de calcular o escoamento considerando escorregamento livre na parede da cova foi feita, porém nessa simulação não houve a formação das estruturas vorticais na camada de mistura da cova do eslate.

A possibilidade de se prever corretamente o som do eslate considerando paredes com escorregamento livre representa uma redução significativa no custo computacional das simulações. Uma vez que não há a necessidade de se resolver algumas camadas limite, malhas mais econômicas podem ser usadas. De fato Simões, Souza e Medeiros (2011) apresentam resultados com uma configuração de malha mais eficiente sem diminuição na precisão dos cálculos.

O Método Lattice-Boltzmann vem se mostrando uma alternativa eficiente na solução computacional de problemas de Mecânica de Fluidos em baixos números de Mach (CHEN; DOOLEN, 1998). Em comparação com métodos baseados nas equações de Navier-Stokes, o MLB apresenta algumas vantagens importantes na solução de problemas complexos. Uma vez que a 
malha é sempre cartesiana, não há a necessidade de ajustá-la à geometria simulada, o que reduz o tempo para elaborar o modelo, principalmente em problemas de geometrias complexas. $\mathrm{O}$ tempo de processamento, em geral, também é significativamente menor, pois, como o método utiliza um esquema explícito de integração no tempo, permite uma paralelização massiva da solução.

Marié, Ricot e Sagaut (2009) comparam modelos numéricos baseados nas equações de Navier-Stokes e no MLB no que diz respeito à dissipação e dispersão de ondas. Eles mostram que, para um mesmo erro numérico na dispersão da onda acústica, os modelos Lattice-Boltzmann precisam executar menos operações com números reais. Eles mostram também que a dissipação numérica causada pelo MLB em ondas acústicas é menor que a dissipação numérica de esquemas de alta ordem baseados nas equações de Navier-Stokes. Por sua vez, Brès, Pérot e Freed (2009) comparam com valores teóricos a dispersão e dissipação de ondas acústicas planas calculadas pelo código PowerFLOW. O erro numérico apresentado por eles para a velocidade de fase da onda acústica não passa de $0,02 \%$ do valor teórico quando uma discretização espacial de aproximadamente 9 pontos por comprimento de onda é empregada.

Vê-se, portanto, que a complexidade do escoamento transiente em torno do eslate é um grande desafio para os códigos de Mecância dos Fluidos Computacional, tanto no âmbito das previsões aerodinâmicas quanto no âmbito das previsões aeroacústicas. Entretanto, códigos CFD de alta fidelidade, executados em computadores com elevada capacidade de processamento, têm mostrado bons resultados em comparação com dados experimentais e na comparação entre programas diferentes. Nesse contexto, o Método Lattice-Boltzmann, assim como o código comercial baseado nele, o PowerFLOW, tem se mostrado tão eficiente quanto métodos baseados nas equações de Navier-Stokes. Adicionalmente, a possibilidade de adoção de condição de parede com escorregamento livre em algumas superfícies para a simulação aeroacústica de eslate diminui significativamente os custos de simulações deste tipo. Assim, se torna natural o emprego de simulações no estudo do ruído aeroacústico de eslate em condições complexas que se aproximem da geometria e configuração de aeronaves reais. 


\section{Metodologia Numérica}

\subsection{Método Lattice-Boltzmann}

Tradicionalmente os códigos de dinâmica dos fluidos computacional resolvem numericamente as equações de Navier-Stokes. Estas são equações diferenciais parciais de segunda ordem não lineares. O Métodos dos Volumes Finitos, das Diferenças Finitas e dos Elementos Finitos além de métodos espectrais são comumente usados para resolvê-las. Parâmetros macroscópicos, como velocidade, pressão e temperarura são as variáveis dependentes das equações de Navier-Stokes. As simulações transientes discutidas neste trabalho por sua vez são baseadas no Método Lattice-Boltzmann (MLB). Diferente de códigos baseados nas equações de NavierStokes, o MLB resolve a equação de Boltzmann discretizada. Nos últimos anos esse método vem se popularizando na solução de problemas de mecânica dos fluidos devido à facilidade na programação, à facilidade para resolver problemas com geomentrias complexas e, principalmente à capacidade de paralelização de códigos baseados nesse método, o que é extremamente conveniente, dada a necessidade de programas cada vez mais rápidos para resolver problemas complexos (HE; LUO, 1997).

Este capítulo é dedicado à descrição do Método Lattice-Boltzmann. Primeiro a equação de Boltzmann é apresentada. Em seguida é feita uma discussão a cerca do termo de colisão, cujo o tratamento apropriado é de fundamental importância para o método. E por fim a discretização da equação de Boltzmann é abordada.

\subsubsection{Equação de Boltzmann}

Em 1859 o físico e matemático britânico James Clerk Maxwell propôs que a determinação da função de distribuição era suficiente para descrever o comportamento das variáveis macroscópicas de um meio fluido (MOHAMAD, 2011). A função de distribuição $(f(c))$ repre- 
senta a probabilidade das partículas em um sistema estarem a uma dada velocidade, $c$. A razão entre o número de parículas com velocidade entre $c$ e $c+\delta c$ e o número total de partículas é então dado por $f(c) \delta c$. Assim temos que

$$
\lim _{\delta c \rightarrow 0} f(c) \delta c=f(c) d c
$$

$\mathrm{e}$

$$
\int_{0}^{c_{\max }} f(c) d c=1
$$

sendo $c_{\max }$ a máxima velocidade possível para as partículas.

A partir da teoria cinética, é possível provar que a função de distribuição para um gás em equilíbrio térmico a temperatura $T$ é dada por

$$
f_{0}(\vec{c})=\left(\frac{m}{2 \pi k T}\right)^{\frac{3}{2}} e^{\frac{-m|\vec{c}|^{2}}{2 \pi k T}}
$$

onde $m$ é a massa de cada partícula e $k$ é a constante de Boltzmann. O vetor $\vec{c}$ representa a velocidade das partículas, e é também chamado de fase. A função $f_{0}$ é chamada de função de distribuição de Maxwell-Boltzmann.

Em um instante $t$ a função de distribuição é definida por $f(\vec{r}, \vec{c}, t)$, que representa a probabilidade de se encontrar uma partícula entre o ponto $\vec{r}$ e o ponto $\vec{r}+d \vec{r}$ com velocidade entre $\vec{c}$ e $\vec{c}+d \vec{c}$. Considera-se um grupo de partículas a uma velocidade $\vec{c}$ submetidas a uma força externa $\vec{F}$ ocupando a região ao redor do ponto $\vec{r}$ no instante $t$. Assumindo que não haja colisão entre elas, no instante $t+d t$ essas partículas estarão na posição $\vec{r}+\vec{c} d t$ a uma velocidade $c+\vec{F} d t$. Igualando o numero de partículas em $t$ e $t+d t$, temos que

$$
f(\vec{r}+\vec{c} d t, \vec{c}+\vec{F} d t, t+d t) d \vec{r} d \vec{c}-f(\vec{r}, \vec{c}, t) d \vec{r} d \vec{c}=0
$$

Já se considerarmos as colisões entre as partículas, o valor de $f$ variará entre $t$ e $t+d t$.A razão de variação temporal de f é dada pelo operador de colisão, $\Omega$. Assim a equação 3.4 fica

$$
f(\vec{r}+\vec{c} d t, \vec{c}+\vec{F} d t, t+d t) d \vec{r} d \vec{c}-f(\vec{r}, \vec{c}, t) d \vec{r} d \vec{c}=\Omega(f) d \vec{r} d \vec{c} d t
$$

onde 


$$
\Omega(f)=\frac{d f}{d t}
$$

Para deduzir a equação de Boltzmann, diferenciamos $f=f(\vec{r}, \vec{c}, t)$

$$
d f=\frac{\partial f}{\partial \vec{r}} d \vec{r}+\frac{\partial f}{\partial \vec{c}} d \vec{c}+\frac{\partial f}{\partial t} d t
$$

Dividindo por $d t$

$$
\Omega(f)=\frac{d f}{d t}=\frac{\partial f}{\partial \vec{r}} \cdot \vec{c}+\frac{\partial f}{\partial \vec{c}} \cdot \vec{a}+\frac{\partial f}{\partial t}
$$

sendo $\vec{a}$ a aceleração da partícula, tal que

$$
\vec{a}=\frac{\vec{F}}{m}
$$

Assim

$$
\frac{\partial f}{\partial \vec{r}} \cdot \vec{c}+\frac{\vec{F}}{m} \cdot \frac{\partial f}{\partial \vec{c}}+\frac{\partial f}{\partial t}=\Omega(f)
$$

Se não houver força externa, a equação 3.10 fica

$$
\frac{\partial f}{\partial t}+\nabla f \cdot \vec{c}=\Omega(f)
$$

A equação 3.10 é chamada de equação de Boltzmann e sua forma mais simples (Eq. 3.11) é resolvida numericamente pelo método Lattice-Boltzmann usado neste trabalho. Uma complicação para a solução da equação de Boltzmann, independente da presença de força externa, é o termo de colisão. Ele é composto de duas parcelas, uma referente às partículas retiradas da faixa de velocidade devido às colisões e outra relacionada às partículas que migram para a faixa de velocidade. Por ser formado por integrais, esse termo torna a solução da equação de Boltzmann extremamente complicada, restringindo-a a casos simples. Para possibilitar a solução da equação de Boltzmann em casos mais complexos, uma aproximação para o termo de colisão foi porposto por Bhatnagar, Gross e Krook (1954). Alguns aspectos dessa aproximação são abordados na próxima seção.

A partir da solução da equação de Boltzmann, as variáveis macroscópicas podem ser calculadas pelas integrais 


$$
\begin{gathered}
\rho=\int f d \vec{c}, \\
\rho \vec{u}=\int \vec{c} f d \vec{c}
\end{gathered}
$$

$\mathrm{e}$

$$
\rho \frac{3 k T}{2 m}=\frac{1}{2} \int(\vec{c}-\vec{u})^{2} f d \vec{c} .
$$

\subsubsection{Aproximação para Termo de Colisão}

Bhatnagar, Gross e Krook (1954) propõem uma relação para $\Omega(f)$ da pela equação

$$
\Omega(f)=\frac{1}{\lambda}\left(f^{e q}-f\right)
$$

Ela representa a tendência das colisões de encaminhar o sistema para uma estado de equilíbrio. A velocidade com que o sistema busca o equilíbrio depende da variável $\lambda$, chamada de tempo de relaxação. No modelo proposto, por questão de simplificação, $\lambda$ é considerado independente da velocidade. O tempo de relaxação é relacionado a propriedades macroscópicas do meio, como viscosidade e temperatura, e o valor associado a ele em um modelo baseado no método Lattice-Boltzmann depende também do esquema de discretização da equação de Boltzmann (MOHAMAD, 2011; HE; LUO, 1997).

O termo $f^{e q}$ é de extrema importância para o modelo. Ele representa a função de distribuição no estado de equilíbrio. A definição da função de equilíbrio depende do fenômeno a ser estudado. De forma geral, ela é determinada como uma função da função de distribuição de Maxwell-Boltzmann (Eq. 3.3) com o eixo de simetria transladado para a velocidade macroscópica local, resultando na relação

$$
f^{e q}=\frac{\rho}{(2 \pi R T)^{D / 2}} e^{-\frac{(\vec{c}-\vec{u})^{2}}{2 R T}},
$$

onde $R$ é a constante dos gases ideais e $D$ é o número de dimensões consideradas no cálculo ( $D=1$ para problema simulação unidimensional e assim sucessivamente). O termo exponencial da equação 3.16 pode ser expandido. Desprezando termos de ordem $\vec{u}^{4}$, que é uma hipótese razoável para problemas de baixo número de Mach, teremos 


$$
f^{e q}=\frac{\rho}{(2 \pi R T)^{D / 2}} e^{-\frac{\vec{c}^{2}}{2 R T}}\left[1+\frac{(\vec{c} \cdot \vec{u})}{R T}+\frac{(\vec{c} \cdot \vec{u})^{2}}{2(R T)^{2}}-\frac{\vec{u}^{2}}{2 R T}+\frac{(\vec{c} \cdot \vec{u})^{3}}{6(R T)^{3}}-\frac{\vec{c} \cdot \vec{u}}{2(R T)^{2}} \vec{u}^{2}\right],
$$

sendo os parâmetros macroscópicos dados pelas equações 3.12, 3.13 e 3.14.

Mesmo tendo a função de distribuição dentro de integrais, a equação de Boltzmann no formato apresentado acima pode ser resolvida para problemas mais complexos, pois a função $f$ aparece dentro das integrais em operações simples (produto com $\vec{c}$ ou $(\vec{c}-\vec{u})^{2}$ ). O termo de colisão na forma proposta por Bhatnagar, Gross e Krook (1954) conserva instantaneamente massa, quantidade de movimento e energia. Uma característica fundamental para aplicação do método no problema de aeroacústica de eslate é que ele consiga reproduzir a propagação de uma onda acústica. Aplicando uma análise de pequenas amplitudes ao modelo, é possível mostrar que o método BGK atende a essa exigência (BHATNAGAR; GROSS; KROOK, 1954). A determinação da pressão é dada por uma equação de estado. A partir de uma expansão de Chapman-Enskog, é possível provar que a lei dos gases ideais é recuperada e vale a relação (CHEN; DOOLEN, 1998)

$$
p=\rho T
$$

\subsubsection{Discretização da Equação de Boltzmann}

De acordo com o proposto por He e Luo (1997), para discretizar a equação de Boltzmann no tempo, aplicamos o método das características e reescrevemos a equação da seguinte forma

$$
\frac{d f}{d t}+\frac{1}{\lambda} f=\frac{1}{\lambda} f^{e q}
$$

onde

$$
\frac{d}{d t} \equiv \frac{\partial}{\partial t}+\vec{c} \cdot \nabla
$$

Integrando 3.19 entre 0 e $\delta t$ e desprezando termos de ordem $O\left(\delta t^{2}\right)$ para $f^{e q}$ e $e^{-\delta t / \lambda}$, temos

$$
f(\vec{r}+\vec{c} \delta t, \vec{c}, t+\delta t)-f(\vec{r}, \vec{c}, t)=-\frac{1}{\tau}\left[f(\vec{r}, \vec{c}, t)-f^{e q}(\vec{r}, \vec{c}, t)\right]
$$

que é a equação de avanço discreto de $f$ no tempo com precisão $O(\delta t)$. A variável $\tau$ é o tempo 
de relaxação adimensional e é igual a $\lambda / \delta t$. Em cada passo no tempo, a distribuição de equlíbrio é atualizada através das equações $3.17,3.12$, 3.13 e 3.14 .

Para resolver numericamente a equação de Boltzmann, também a velocidade das partículas $(\vec{c})$ deve ser discretizada. No método Lattice-Boltzmann, os valores discretos de $\vec{c}$ são diretamente relacionados à discretização espacial, de forma que $\vec{c}_{i}=\delta \vec{r} / \delta t$, sendo $\delta \vec{r}$ a distância entre dois pontos do domínio discretizado. Um método de quadratura é utilizado de modo que seja garantida a conservação de massa, quantidade de movimento e energia. Assim, a equação discretizada da distribuição de equilíbrio pode ser escrita da seguinte forma

$$
f_{i}^{e q}=w_{i} \rho\left[1+A\left(\vec{c}_{i} \cdot \vec{u}\right)+B\left(\vec{c}_{i} \cdot \vec{u}\right)^{2}-C(\vec{u} \cdot \vec{u})^{2}\right]
$$

e a equação de Boltzmann na forma discreta fica

$$
f\left(\vec{r}+\vec{c}_{i} \delta t, \vec{c}_{i}, t+\delta t\right)-f\left(\vec{r}, \vec{c}_{i}, t\right)=-\frac{1}{\tau}\left[f\left(\vec{r}, \vec{c}_{i}, t\right)-\frac{1}{W_{i}} f_{i}^{e q}\right]
$$

onde

$$
W_{i}=w_{i}(2 \pi R T)^{D / 2} e^{-\frac{\vec{c}_{i}}{2 R T}}
$$

As variáveis A, B, e C são parâmetros a serem determinados de acordo com o número de dimensões do problema, a discretição espacial e a direção de $\vec{c}_{i}$ enquanto $w_{i}$ é um peso dado pelo método de quadratura. Para calcular os parâmetros macroscópicos, $\rho, \vec{u}$ e $T$, resolve-se numericamente as integrais dadas pelas equações $3.12,3.13$ e 3.14 ,

$$
\begin{gathered}
\rho(\vec{r}, t)=\sum_{i} f_{i}(t), \\
\rho(\vec{r}, t) \vec{u}(\vec{r}, t)=\sum_{i} \vec{c}_{i} f_{i}(t),
\end{gathered}
$$

$\mathrm{e}$

$$
\rho(\vec{r}, t) \frac{3 k T(\vec{r}, t)}{2 m}=\sum_{i}\left(\vec{c}_{i}-\vec{u}\right)^{2} f_{i}(t) .
$$

A discretização de $\vec{c}$ pode ser feita de diversas maneira no que diz respeito às direções consideradas. A nomeclatura padrão para designar determinada forma de discretização da velocidade da partícula é $\mathrm{D} \alpha \mathrm{Q} \beta$, sendo a letra $\alpha$ substituída pela dimensão do problema, e $\beta$ 
pelo número de vetores considerados na discretização. A solução da equação de Boltzmann discretizada é desenvolvida de forma explícita no tempo, ou seja, para calcular o valor de $f$ em determinado ponto em certo instante, basta que se saiba os valores da função em todos os pontos no passo de tempo anterior. Essa técnica de solução permite que códigos de Mecânica dos Fluidos Computacional sejam programados para computação em paralelo de forma eficiente, reduzindo o tempo computacional significativamente.

\subsection{Código PowerFLOW}

As simulações apresentadas neste trabalho foram feitas utilizando o código comercial PowerFLOW 4.2, desenvolvido pela EXA. O PowerFLOW é baseado na formulação Lattice-Boltzmann, apresentada na seção 3.1. Diversos trabalhos disponíveis na literatura comprovam a sua capacidade de resolver problemas tanto de aerodinâmica (SHOCK et al., 2002; LI et al., 2004; FARES, 2006) quanto de aeroacústica (BRÈS; PÉROT; FREED, 2009; LAFITTE; PÉROT, 2009; BRÈS; WESSELS; NOELTING, 2010).

O PowerFLOW emprega uma simplificação no método Lattice-Boltzmann que considera o escoamento isotérmico. Isso significa que a equação 3.27 não é resolvida pelo código e a temperatura $T$, nas equações 3.22 e 3.24, é assumida como uma constante dada como valor de entrada pelo usuário.

\subsubsection{Discretização da Equação de Boltzmann}

De acordo com a nomeclatura apresentada na seção 3.1.3, o código PowerFLOW emprega uma discretização D3Q19 para a fase $\vec{c}$. Para tanto, o domínio é dividido em espaços discretos de formato cúbico, com arestas alinhadas com os eixos das coordenadas cartesianas, chamados de voxels. Em cada voxel, a equação 3.23 é resolvida para 19 vetores de velocidade correspondendo aos diversos $c_{i}$ 's (Fig. 7). Com essa discretização do espaço de fase, a equação da função de distribuição do equilíbrio fica

$$
f_{i}^{e q}=\rho w_{i}\left[1+\frac{\vec{c}_{i} \cdot \vec{u}}{T}+\frac{\left(\vec{c}_{i} \cdot \vec{u}\right)^{2}}{2 T^{2}}-\frac{\vec{u}^{2}}{2 T}+\frac{(\vec{c} \cdot \vec{u})^{3}}{6 T^{3}}-\frac{\vec{c} \cdot \vec{u}}{2 T^{2}} \vec{u}^{2}\right]
$$

Os termos de peso $w_{i}$, por sua vez ficam 


$$
w_{i}=\left\{\begin{array}{rr}
1 / 18, & \text { se } 0 \leq i \leq 5 \\
1 / 36, & \text { se } \quad 6 \leq i \leq 17 \\
1 / 3, & \text { para o vetor } 18 \text { (repouso) }
\end{array}\right.
$$

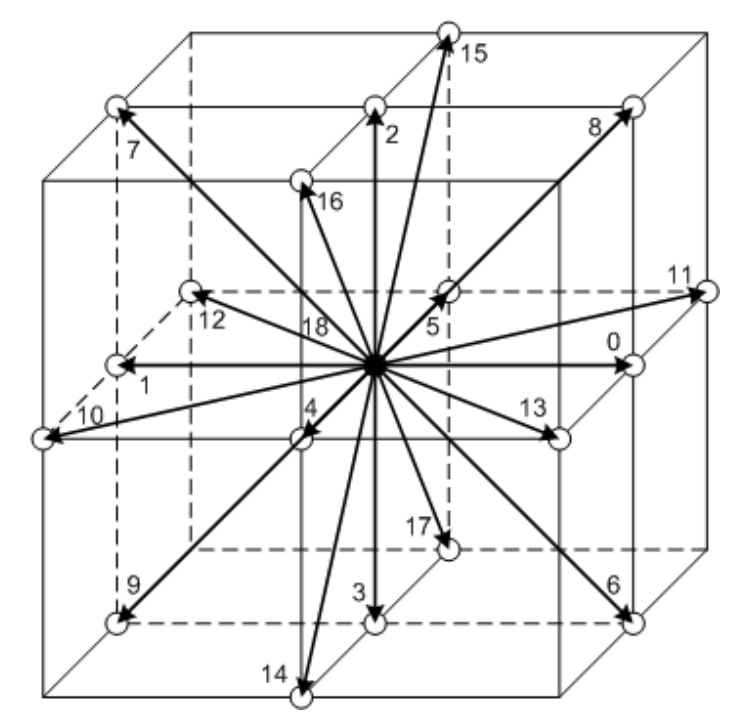

Figura 7 - Configuração de voxel usada pelo PowerFLOW. Cada numero inteiro corresponde a uma velocidade $\vec{c}_{i}$.

Para simulações diretas, ou seja, sem emprego de um modelo de turbulência, o tempo de relaxação $(\lambda)$ é relacionado à viscosidade cinemática através de uma expansão de ChapmanEnskog resultando na equação

$$
\lambda=\frac{v}{T}+\frac{\delta t}{2}
$$

Uma questão relevante para um código CFD para aplicação industrial é que este seja capaz de usar malhas com diferentes níveis de resolução ao longo do domínio para que a simulação seja ao mesmo tempo precisa e eficiente. Como foi citado, o domínio de uma simulação feita no PowerFLOW é discretizado em cubos. É possível aplicar-se diferentes níveis de refinamento ao longo do domínio simulado. A cada região, o programa associa um nível de refinamento designado por um número inteiro (o maior nível associado à região mais refinada), de forma que o tamanho dos voxels não variam em uma escala contínua. Cada nível de refinamento possui voxels com aresta cujo comprimento é uma potência inteira de 2 vezes o comprimento da aresta do menor voxel. Ou seja, os voxels do nível de refinamento 4 têm arestas com o dobro do comprimento das arestas dos voxels do nível 5, e assim sucessivamente. Dessa forma um voxel de um nível de refinamento possui um volume correspondente a 8 vezes o volume de um voxel do nível imediatamente mais refinado (Fig. 8). É importante notar que uma região com deter- 
minado nível de refinamento só pode dividir fronteira com regiões cujo nível de refinamento é adjacente. Assim uma região com nível 3 não pode ter uma fronteira comum com uma região de nível 1 ou 5, apenas 2 e 4 .

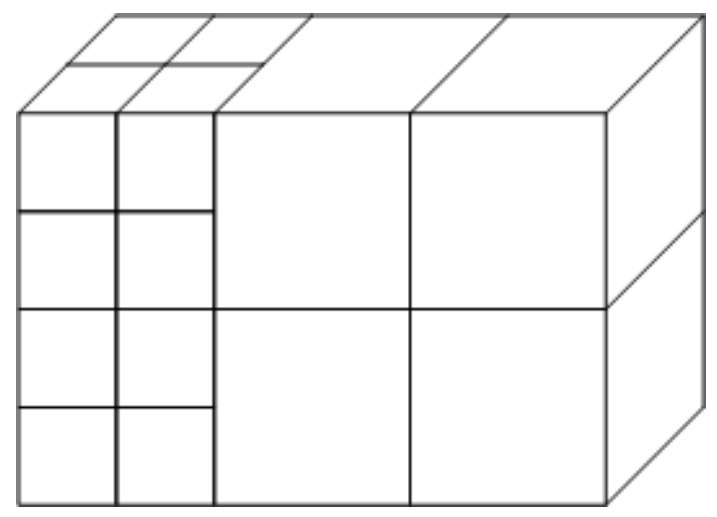

Figura 8 - Exemplo de fronteira entre regiões de nível de refinamento diferente.

O código PowerFLOW utiliza uma formulação volumétrica, descrita por Chen (1998), para resolver a equação de Boltzmann discretizada. O método assume que a transferência de partículas com velocidade $\vec{c}_{i}$ da célula com centroide em $\vec{r}$, aqui designada por $\bar{r}$, para a célula com centroide em $\vec{r}+c_{i} \vec{\delta} t$, designada por $\vec{r}^{\prime}$, é baseada em $\tilde{f}_{i}$, a densidade de distribuição das partículas com velocidade $\vec{c}_{i}$ em $\bar{r}$. A função $\tilde{f}_{i}$ corresponde ao número de partículas com velocidade $\vec{c}_{i}$ por unidade de volume. A distribuição de $\tilde{f}_{i}$ dentro de uma célula não é assumida constante, mas o resultado de uma interpolação de segunda ordem a partir dos valores nas células adjacentes. É possível provar que essa formulação é capaz de manter a conservação de massa e quantidade de movimento para qualquer configuração de malha.

No PowerFLOW, o tamanho do passo de tempo é função da discretização espacial. Ele é calculado de modo a manter constante o parâmetro de estabilidade de Courant-FridrichsLewy (CFL) para uma velocidade de referência constante (SIMõES, 2011). Assim a atualização do valor dos $f_{i}^{\prime} s$ ocorre em intervalos de tempo diferentes para cada nível de refinamento. $\mathrm{O}$ intervalo de atualização para um dado nível de refinamento é um passo de tempo do nível mais refinado multiplicado por uma potência inteira de 2 , tal que o CFL baseado na velocidade do som se mantenha igual a 0,6 em todo o domínio.

\subsubsection{Modelo de Turbulência}

Em casos típicos de engenharia, como a simulação do escoamento sobre o aerofólio de uma aeronave com elevado número de Reynolds, em geral, é inviável a simulação direta das estruturas hidrodinâmicas de menor escala. Os modelos de turbulência são responsáveis por 
incluir no cálculo o efeito no escoamento das estruturas que não são resolvidas. O PowerFLOW usa o modelo de turbulência de duas equações RNG $k-\varepsilon$, descrito por Yakhot e Orszag (1986), com uma modificação para permitir a simulação de estruturas hidrodinâmicas de maior escala.

Em uma simulação baseada no método Lattice-Boltzmman com modelagem de turbulência, o tempo de relaxação, $\lambda$, é modificado para levar em conta tanto a dissipação viscosa quanto a dissipação turbulenta, através de uma viscosidade cinemática turbulenta $v_{t u r b}$. Aplicando uma expansão em potências do número de Knudsen, as equações de Navier-Stokes baseadas nas propriedades médias podem ser recuperadas, sendo a viscosidade total, dada pela soma da viscosidade molecular com a viscosidade turbulenta $\left(v+v_{\text {turb }}\right)$, proporcional a $\lambda$ (CHEN et al., 2003).

Para aplicar o modelo de turbulência no Método Lattice-Boltzmann uma modificação é feita na equação do tempo de relaxação para que os efeitos da viscosidade turbulenta também sejam levados em conta. No modelo implementado no PowerFLOW, o tempo de relaxação efetivo é dado por

$$
\lambda_{e f}=\lambda+C_{\mu} \frac{k^{2}}{\varepsilon} \frac{1}{T \sqrt{1+\tilde{\eta}^{2}}}
$$

onde $C_{\mu}$ é uma constante igual a 0,085 e as variáveis $k$ e $\varepsilon$ são, respectivamente, a energia cinética turbulenta e a taxa de dissipação da mesma, calculadas através das equações

$$
\rho \frac{\partial k}{\partial t}+\rho \mathbf{U}_{i} \frac{\partial k}{\partial x_{i}}=\frac{\partial}{\partial x_{i}}\left[\frac{1}{0,719}\left(\rho v+\rho v_{t u r b}\right) \frac{\partial k}{\partial x_{i}}\right]+\left(2 \rho v_{t u r b} S_{i j}-\frac{2}{3} \rho k \delta_{i j}\right) S_{i j}-\rho \varepsilon
$$

e

$$
\begin{array}{r}
\rho \frac{\partial \varepsilon}{\partial t}+\rho \mathbf{U}_{i} \frac{\partial \varepsilon}{\partial x_{i}}=\frac{\partial}{\partial x_{i}}\left[\frac{1}{0.719}\left(\rho v+\rho v_{t u r b}\right) \frac{\partial \varepsilon}{\partial x_{i}}\right]+ \\
1,42 \frac{\varepsilon}{k}\left(2 \rho v_{t u r b} S_{i j}-\frac{2}{3} \rho k \delta_{i j}\right) S_{i j}-\left[1.68+C_{\mu} \frac{\tilde{\eta}^{3}(1-\tilde{\eta} / 4.38)}{1+0,012 \tilde{\eta}^{3}}\right] \rho \frac{\varepsilon^{2}}{k}
\end{array}
$$

em que $x_{i}$ e $\mathbf{U}_{i}$ correspondem às coordenadas do sistema cartesiano e suas respectivas componentes da velocidade média, respectivamente. O termo $\tilde{\eta}$ é calculado pela equação

$$
\tilde{\eta}=A \frac{k}{\varepsilon}|S|+B \frac{k}{\varepsilon}|\vec{\Omega}|+C \frac{k}{\varepsilon} \frac{|\vec{U} \cdot \vec{\Omega}|}{|\vec{U}|}
$$


sendo A, B e C constantes. Na equação 3.34, $S$ é o tensor de taxa de deformação do elemento fluido e $\vec{\Omega}$ a vorticidade.

O emprego de $\tilde{\eta}$ no formato apresentado pela equação 3.34 resulta em uma diminuição da energia cinética turbulenta em regiões com elevado nível de vorticidade. Dessa forma a dissipação provocada pelas escalas menores da turbulência diminui, permitindo a resolução das estrutras maiores por parte da própria equação do método Lattice-Boltzmann. As equações de transporte da energia cinética turbulenta e da sua taxa de disssipação são resolvidas por uma marcha no tempo baseada no algoritmo de Lax-Wendroff.

\subsubsection{Condição de Contorno de Parede}

Uma grande vantagem do método Lattice-Boltzmann é a facilidade de se implementar uma condição de fronteira na superfície de uma geometria complexa imersa no meio fluido. Duas abordagens ligeiramente diferentes permitem a simulação de paredes com e sem escorregamento (CHEN; TEIXEIRA; MOLVIG, 1999; ZIEGLER, 1993). A figura 9 demonstra o conceito para as duas condições de parede de uma forma geral. Se uma condição de não escorregamento é desejada, as partículas que chegam à superfície com velocidade $c_{i}$ são devolvidas ao domínio fluido com velocidade $c_{i *}=-c_{i}$. No caso de uma condição de escorregamento livre, um reflexão do tipo especular é adotada. Com alguma sofisticação adicional, esse modelo permite a simulação de geometrias cujas superfícies não coincidem com os limites dos elementos da discretização espacial.

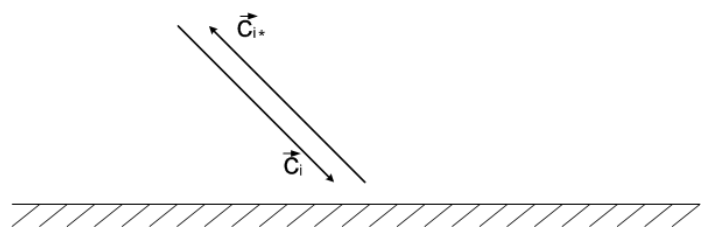

(a)

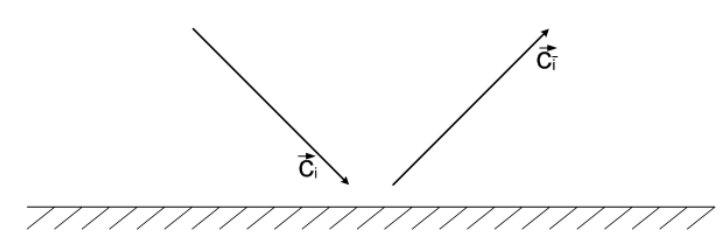

(b)

Figura 9 - Esquema do conceito empregado para simular condições de parede sem escorregamento (a) e com escorregamento livre (b).

Supõe-se uma geometria curva imersa em um meio fluido discretizado em cubos. A superfície curva é aproximada para um polígono cujas faces planas $\left(S^{\alpha}\right)$ têm vetores normais unitários designados por $\hat{n}^{\alpha}$ (Fig. 10). Para se empregar o modelo proposto, a equação de Boltzmann discretizada deve ser resolvida em uma forma volumétrica dada pela equação 


$$
N_{i}\left(\vec{x}+\vec{c}_{i} \delta t, t+\delta t\right)=P\left(\vec{x} \rightarrow \vec{x}+\vec{c}_{i} \delta t\right)\left[N_{i}(\vec{x}, t)+\Omega_{i}(\vec{x}, t)\right]+Q_{i}\left(\vec{x}+\vec{c}_{i} \delta t, t\right)
$$

onde $N_{i}(\vec{x}, t)=f_{i}(\vec{x}, t) \Delta V$, sendo $\Delta V$ o volume do voxel com centróide em $\vec{x}$ e $\Omega_{i}$ é o termo de colisão calculado de acordo com a metodologia apresentada na seção 3.1.2. O volume $\Delta V$ dos elementos cúbicos distantes da superfície são exatamente o volume do cubo, enquanto os elementos que têm uma região de interseção com o sólido têm o volume reduzido no valor do volume dessa interseção.

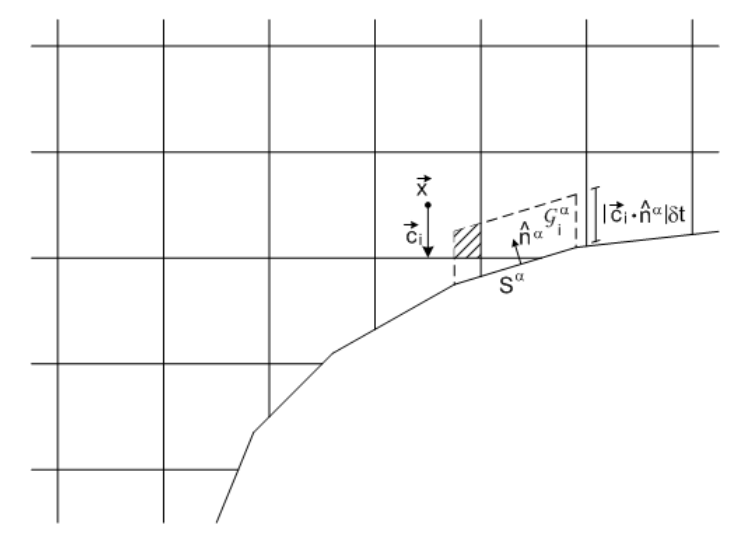

Figura 10 - Representação gráfica de $V_{i}^{\alpha}(\vec{x})$.

A equação 3.35 significa que a função de distribuição volumétrica na direção $i\left(N_{i}\right)$ que é transportada para o elemento com centróide em $\vec{x}+\overrightarrow{c_{i}} \delta t$ é dada pela contribição de uma parcela $P\left(\vec{x} \rightarrow \vec{x}+\vec{c}_{i} \delta t\right) \leq 1$ dos processos de convecção e colisão a partir do elemento com centróide em $\vec{x}$ e de uma quantidade $Q_{i}\left(\vec{x}+\overrightarrow{c_{i}} \delta t, t\right) \geq 0$ que é emitida pela superfície sólida de volta para o fluido. A fração $P\left(\vec{x} \rightarrow \vec{x}+\vec{c}_{i} \delta t\right)$ é calculada por

$$
P\left(\vec{x} \rightarrow \vec{x}+\vec{c}_{i} \delta t\right)=1-P_{i}^{S}(\vec{x})
$$

em que $P_{i}^{S}(\vec{x})$ representa as partículas que, saindo de $\vec{x}$ com velocidade $\vec{c}_{i}$, se chocariam com alguma superfície sólida.

Para o cálculo de $P_{i}^{S}(\vec{x})$ define-se um sólido $\mathscr{G}_{i}^{\alpha}$ resultando da intrusão da face $S^{\alpha}$ para dentro do fluido na direção de $\vec{c}_{i}$ tal que seu volume seja igual a $V_{i}^{\alpha}=\left|\vec{c}_{i} \cdot \hat{n}^{\alpha}\right| A^{\alpha} \delta t$, sendo $A^{\alpha}$ a área da face $S^{\alpha}$ (Fig. 10). A razão entre o número de partículas que sairão do elemento com centróide em $\vec{x}$ e se chocarão com a face $S^{\alpha}$ e o número total de partículas que sairão do elemento com velocidade $\vec{c}_{i}$ é igual à razão entre o volume $V_{i}^{\alpha}(\vec{x})$, comum ao elemento e ao sólido $\mathscr{G}_{i}^{\alpha}$ (demarcado pela área hachurada na figura 10), e o volume total do elemento. $P_{i}^{S}(\vec{x})$ é dado então pela soma das interações com todas as faces, 


$$
P_{i}^{S}(\vec{x})=\sum_{\alpha} P_{i}^{\alpha}(\vec{x})=\sum_{\alpha} \frac{V_{i}^{\alpha}(\vec{x})}{\Delta V(\vec{x})} .
$$

O termo $Q_{i}(\vec{x}, t)$ da equação 3.35 por sua vez é calculado por

$$
Q_{i}(\vec{x}, t)=\sum_{\alpha} \frac{V_{i}^{\alpha}(\vec{x})}{V_{i}^{\alpha}} \Gamma_{i}^{o u t, \alpha}(t)
$$

onde $\Gamma_{i}^{o u t, \alpha}(t)$ é a quantidade de partículas com velocidade $\vec{c}_{i}$ emitidas pela face $S^{\alpha}$ entre o instante $t$ e $t+\delta t$, calculado a partir dos valores das variáveis no instante $t$. A variável $\Gamma_{i}^{\text {out }, \alpha}(t)$ é calculada de formas distintas dependendo se a superfície simulada permite ou não escorregamento do fluido.

Para o caso de parede sem escorregamento, temos que o número de partículas com uma velocidade $\vec{c}_{i}$ emitidas por uma face é igual ao total de partículas com velocidade $\overrightarrow{c_{i *}}=-\vec{c}_{i}$ que convectam para a face, desconsiderando o efeito de colisão entre as partículas $\left(\Gamma_{i *}^{i n, \alpha}(t)\right)$, ou seja

$$
\Gamma_{i}^{\text {out }, \alpha}(t)=\Gamma_{i *}^{i n, \alpha}(t)=\sum_{\vec{x}} P_{i}^{\alpha}(\vec{x}) N_{i}(\vec{x}, t)
$$

Para a simulação de superfícies com escorregamento livre, ou seja, que não exerce nenhuma força no fluido na direção tangencial, uma abordagem mais complexa é utilizada, uma vez que não há como garantir que exista uma velocidade $\vec{c}_{\bar{i}}$ compatível com uma reflexão espectral de $\vec{c}_{i}$, ou seja, tal que sejam atendidas as seguintes condições

- $\vec{c}_{i} \cdot \hat{n}^{\alpha} \leq 0$

- $\vec{c}_{\vec{i}} \cdot \hat{n}^{\alpha}=\vec{c}_{i} \cdot \hat{n}^{\alpha} \mathrm{e}$

- $\vec{c}_{\bar{i}}-\hat{n}^{\alpha} \vec{c}_{\bar{i}} \cdot \hat{n}^{\alpha}=\vec{c}_{i}-\hat{n}^{\alpha} \vec{c}_{i} \cdot \hat{n}^{\alpha}$

O desafio então é encontrar uma forma de calcular o número de partículas sendo emitidas pelas faces com velocidades correspondendo às velocidades $\vec{c}_{i}$, independente se elas formam um par especular com as velocidades com que as partículas se chocam com a superfície. Para isso, primeiro uma função de distribuição, $\tilde{f}_{i}^{\alpha}$, é atribuída à face baseada nas funções de distribuição dos elementos adjacentes. Substituindo $f_{i}$ por $\tilde{f}_{i}^{\alpha}$ nas equações 3.25 e 3.26 e igualando a zero a velocidade normal à face, as variáveis macroscópicas $\rho^{\alpha}(t)$ e $\vec{u}^{\alpha}(t)$ associadas às faces são calculadas. Com a densidade $\left(\rho^{\alpha}(t)\right)$ e velocidade $\left(\vec{u}^{\alpha}(t)\right)$ da face, funções de distribuição de equilíbrio $\left(f_{i}^{e q, \alpha}\right)$ são calculadas. 
Assim, uma função de distribuição de partículas com velocidade $\vec{c}_{i}$ (com sentido da superfície para o fluido), associada à face $S^{\alpha}$ pode ser calculada através da equação

$$
f_{i}^{\alpha}(t)^{\prime}=f_{i}^{e q, \alpha}(t)+\left(1-\frac{\delta t}{\tau}\right)\left[f_{i *}^{\alpha}(t)-f_{i *}^{e q, \alpha}(t)\right]
$$

onde

$$
f_{i *}^{\alpha}(t)=\Gamma_{i}^{i n, \alpha}(t) / V_{i}^{\alpha}
$$

$\forall i *, \overrightarrow{c_{i *}} \cdot \hat{n}^{\alpha} \leq 0$

Podemos, então, calcular $\Gamma_{i}^{\text {out }, \alpha}(t)=V_{i}^{\alpha} f_{i}^{\alpha}(t)^{\prime}$ e substituindo em 3.38 podemos calcular $Q_{i}(\vec{x}, t)$ e consequentemente, $N_{i}\left(\vec{x}+\vec{c}_{i} \delta t, t+\delta t\right)$.

\subsection{Analogia de Ffowcs Williams e Hawkings}

Tanto a geração de ruído aerodinâmico quanto a propagação de ondas acústicas obedecem às leis de conservação. Portanto, uma solução apropriada das equações da continuidade, de quantidade de movimento e da energia é capaz de descrever de forma adequada o campo acústico provocado por escoamentos não estacionários. Porém o cálculo direto das ondas sonoras através de métodos numéricos ainda é uma tarefa inviável para situações práticas de engenharia, mesmo com os avançados recursos computacionais disponíveis atualmente. O som é composto por flutuações de amplitude muito baixa. No limiar da dor do ouvido humano, a amplitude das oscilações de pressão é da ordem de um milésimo da pressão atmosférica (DOWLING; WILLIAMS, 1983). Dessa forma, a discretização espacial de um modelo numérico deve ser refinada em todo o caminho entre a fonte e o observador para que a dissipação numérica não provoque a dissipação das ondas acústicas ao longo do caminho.

Uma prática comum para calcular computacionalmente o som propagado para pontos distantes da fonte é o emprego de analogias acústicas. Essa abordagem consiste em resolver a equação de propagação sonora usando como entrada o resultado de simulações CFD transientes. Assim, apenas a região da fonte necessita de um elevado refinamento da malha. Uma dessas analogias, bem consolidada em estudos de aeroacústica, é proposta por Williams e Hawkings (1969). Essa analogia leva em consideração o som gerado por fontes em movimento. Diversas formulações baseadas na analogia de Ffowcs Williams-Hawkings permitem o cálculo do som propagado por fontes em movimento ou em repouso em relação ao observador (FARASSAT, 2007), no domínio do tempo ou da frequência (LOCKARD, 2002). Esta seção se dedica a de- 
screver a metodologia proposta por Williams e Hawkings (1969) assim como duas formulações distintas de acordo com suas aplicações no código utilizado no trabalho, o PowerFLOW.

\subsubsection{Analogia de Lighthill}

A propagação de ondas acústicas de compressão e rarefação em um meio quiescente é descrita pela equação diferencial homogênea

$$
\frac{\partial^{2} \rho^{\prime}}{\partial t^{2}}-a_{0}^{2} \nabla^{2} \rho^{\prime}=0
$$

A variável $\rho^{\prime}$ é a flutuação de densidade, igual a $\rho-\rho_{0}$, sendo $\rho_{0}$ a densidade do meio em repouso. A dedução da equação 3.42 se baseia nas leis de conservação, assumindo certas hipóteses simplificadoras. Primeiro assume-se que o movimento do fluido é resultado exclusivamente da passagem da onda acústica. Baseando-se no argumento de que as tensões viscosas são muito menores que as tensões introduzidas pela pressão no processo de propagação de ondas acústicas (DOWLING; WILLIAMS, 1983), e que o processo de dissipação da onda acústica pela viscosidade é muito lento (LIGHTHILL, 1952), os termos viscosos são desprezados na dedução da equação 3.42. Outra hipótese assumida é a de que as perturbações causadas pela passagem das ondas acústicas na densidade, na pressão e na velocidade são muito pequenas de forma que os termos formados por produto entre flutuações são desprezados fazendo com que a equação resultante seja linear. Também é considerado que as transformações termodinâmicas ocorrem rapidamente, de forma que não há troca de calor entre elementos fluidos adjacentes. Assim, vale a relação $\frac{\partial p}{\partial \rho}=a_{0}^{2}$

É importante notar que a equação 3.42 descreve apenas a propagação das ondas acústicas, não sendo capaz de modelar a geração de som. O cálculo do campo acústico provocado por condições de fronteira não-estacionárias pode ser feito de forma simples através da aplicação dessas condições na equação 3.42. Porém no presente trabalho, a fonte sonora é composta pelas flutuações do escoamento ao redor do aerofólio, sendo este tratado como um sólido rígido imóvel. Portanto o desafio é calcular o campo sonoro gerado pelas flutuações hidrodinâmicas, tarefa muito mais complexa do que o caso das fronteiras oscilantes. Uma metodologia para relacionar o escoamento transiente ao campo acústico gerado foi proposta por Lighthill (1952). A Analogia de Lighthill, como é chamada essa abordagem, assume que a diferença entre as equações que regem o escoamento e a equação do som linearizada e simplificada (Eq. 3.42) é o termo responsável pela geração das ondas sonoras que se propagam na região afastada das fontes (campo distante). Assim, aplicando o mesmo algebrismo nas equações de conservação 
que foi usado para chegar à equação 3.42, porém sem desprezar os efeitos da viscosidade, os termos não lineares, nem considerar que as transformações são adiabáticas, chega-se à equação

$$
\frac{\partial^{2} \rho^{\prime}}{\partial t^{2}}-a_{0}^{2} \nabla^{2} \rho^{\prime}=\frac{\partial^{2} T_{i j}}{\partial x_{i} \partial x_{j}}
$$

onde

$$
T_{i j}=\rho v_{i} v_{j}+p^{\prime} \delta_{i j}-\tau_{i j}-a_{0}^{2} \rho^{\prime} \delta_{i j}
$$

O termo $T_{i j}$ é chamado de tensor de Lighthill. Ele representa o somatório das tensões, em diferentes formas, aplicadas à fronteira de um elemento fluido. A parcela $\rho v_{i} v_{j}$ é chamada de tensão flutuante de Reynolds e representa a quantidade de movimento na direção $i$ que atravessa a superfície do volume de controle normal à direção $j$. Já $\tau_{i j}$ representa as tensões viscosas. A dissipação da onda acústica através da condução de calor é levada em consideração pelo termo $p^{\prime} \delta_{i j}-a_{0}^{2} \rho^{\prime} \delta_{i j}$ que é nulo para transformações adiabáticas. O termo $\delta_{i j}$ é o delta de Kronecker que assume o valor de 1 se $i=j$ e 0 se $i \neq j$. Avaliando a magnitude dos termos contidos em $T_{i j}$, Lighthill (1952) demonstra que, para escoamentos a baixo número de Mach e alto número de Reynolds, o tensor pode ser aproximado para $T_{i j}=\rho v_{i} v_{j}$.

A solução da equação 3.43 é dada por

$$
\rho^{\prime}(\vec{x}, t)=\frac{1}{4 \pi a_{0}^{2}} \frac{\partial^{2}}{\partial x_{i} \partial x_{j}} \int_{V} \frac{T_{i j}(\vec{y}, \tau)}{|\vec{x}-\vec{y}|} d V
$$

No lado direito da equação 3.45 a integral é desenvolvida nos pontos $\vec{y}$. Essa integral é não nula apenas nas regiões que possuem fontes aerodinâmicas de som. O termo $\tau=t-\frac{|\vec{x}-\vec{y}|}{a_{0}}$ é chamado de tempo atrasado. Ele leva em conta o fato de que a frente de onda que alcança o ponto $\vec{x}$ no instante $t$ foi emitido pela fonte no ponto $\vec{y}$ no instante $t-\frac{|\vec{x}-\vec{y}|}{a_{0}}$. O tensor de Lighthill induz fontes do tipo quadrupolo, o que é inferido pela dupla operação de divergência (DOWLING; WILLIAMS, 1983). Em escoamentos de aplicações práticas, valores significativos de $T_{i j}$ são encontrados em regiões de turbulência intensa, fazendo com que estas regiões sejam importantes fontes sonoras. Porém o caráter de quadrupolo da fonte acústica induzida pela turbulência faz com que a mesma seja pouco eficiente devido a efeitos de cancelamento. A integral do lado direito da equação 3.45 pode ser resolvida para um volume contendo escoamento turbulento, permitindo o cálculo do campo acústico em um ponto fora do domínio computacional usado no cálculo do escoamento. 
Lighthill (1952) também apresenta uma anologia para descrever o campo acústico emitido por uma região de escoamento em movimento em relação ao observador e ao meio onde as ondas sonoras se propagam. Considerando uma região contendo as fontes se movendo a uma velocidade fixa $a_{0} \vec{M}$ e um sistema de coordenadas fixado a ela, a equação de propagação fica

$$
\rho^{\prime}=\frac{1}{4 \pi a_{0}^{2}} \frac{\partial^{2}}{\partial x_{i} \partial x_{j}} \int \frac{T_{i j}(\vec{\eta}, \tau)}{|\vec{x}-\vec{y}|-\vec{M} \cdot(\vec{x}-\vec{y})} d \vec{\eta}
$$

onde $\vec{\eta}$ é a posição em relação ao sistema de coordenadas fixo na região fonte.

Analisando a equação 3.46, é possível ver que, devido ao termo $[|\vec{x}-\vec{y}|-\vec{M} \cdot(\vec{x}-\vec{y})]^{-1}$, o movimento da fonte provoca uma variação na intensidade do som percebido em $\vec{x}$. A amplitude das flutuações medidas pelo observador é maior se a fonte se aproxima e diminui quando a mesma se afasta.

\subsubsection{Equação de Ffowcs Williams-Hawkings}

Assim como a Analogia de Lighthill, a analogia proposta por Williams e Hawkings (1969) permite o cálculo do som propagado por um escoamento transiente, porém esta leva em conta os efeitos de superfícies se movendo no meio fluido em repouso.

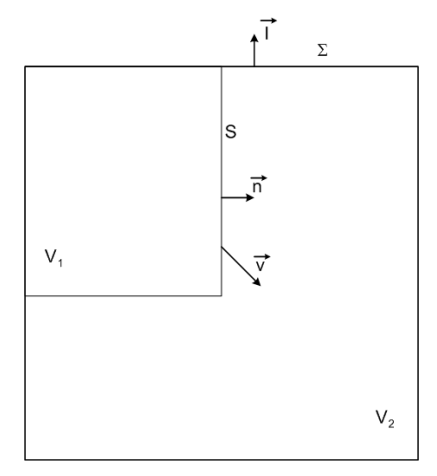

Figura 11 - Domínio onde as ondas acústicas são geradas e se propagam contendo superfície em movimento, $S$.

Para dedução do som gerado aerodinamicamente, considere um volume $V$ limitado pela superfície $\Sigma$, contendo fluido com campo de velocidade dado por $\vec{u}(\vec{x}, t)$ e dividido em dois volumes $\left(V_{1}\right.$ e $\left.V_{2}\right)$, separados pela superfície $S$ (Fig. 11). Os vetores normais à superfície $\Sigma$ e $S$ são $\vec{l}$ e $\vec{n}$, respectivamente. A superfície $S$ é livre para se movimentar dentro dos limites do volume $V$ e sua velocidade é designada por $\vec{v}$. A razão com que a massa do fluido aumenta em $V$ é 


$$
\frac{\partial}{\partial t} \int_{V} \rho d V=\frac{\partial}{\partial t} \int_{V_{1}} \rho_{1} d V+\frac{\partial}{\partial t} \int_{V_{2}} \rho_{2} d V
$$

sendo o vetor $\vec{n}$ direcionado de $V_{1}$ para $V_{2}$, as variações de massa dentro dos volumes 1 e 2 , usando a notação de Einstein, são, respectivamente

$$
\frac{\partial}{\partial t} \int_{V_{1}} \rho_{1} d V=-\int_{\Sigma_{1}}\left(\rho u_{i}\right)_{1} l_{i} d \Sigma-\int_{S}\left[\rho\left(u_{i}-v_{i}\right)\right]_{1} n_{i} d S
$$

e

$$
\frac{\partial}{\partial t} \int_{V_{2}} \rho_{2} d V=-\int_{\Sigma_{2}}\left(\rho u_{i}\right)_{2} l_{i} d \Sigma+\int_{S}\left[\rho\left(u_{i}-v_{i}\right)\right]_{2} n_{i} d S
$$

Somando 3.48 e 3.49 temos

$$
\frac{\partial}{\partial t} \int_{V} \rho d V=-\int_{\Sigma}\left(\rho u_{i}\right) l_{i} d \Sigma+\int_{S}\left\{\left[\rho\left(u_{i}-v_{i}\right)\right]_{2}-\left[\rho\left(u_{i}-v_{i}\right)\right]_{1}\right\} n_{i} d S
$$

Aplicando o teorema da divergência ao primeiro termo do lado direito da equação 3.50,

$$
\int_{V}\left[\frac{\partial \rho}{\partial t}+\frac{\partial}{\partial x_{i}}\left(\rho u_{i}\right)\right] d V=\int_{S}\left\{\left[\rho\left(u_{i}-v_{i}\right)\right]_{2}-\left[\rho\left(u_{i}-v_{i}\right)\right]_{1}\right\} n_{i} d S
$$

É possível mostrar que o lado direito da equação 3.51 pode ser reescrito em uma integral volumétrica em $V$. Assim a mesma pode ser apresentada da seguinte forma

$$
\frac{\partial \rho}{\partial t}+\frac{\partial}{\partial x_{i}}\left(\rho u_{i}\right)=\left\{\left[\rho\left(u_{i}-v_{i}\right)\right]_{2}-\left[\rho\left(u_{i}-v_{i}\right)\right]_{1}\right\} \delta(f) \frac{\partial f}{\partial x_{i}}
$$

sendo f uma função que é definida tal que $f<0$ dentro da superfí́cie $S, f>0$ fora de $S$ e $f=0$ em $S . \delta f$ é a função delta de Dirac.

O mesmo processo pode ser feito para avaliar o transporte de quantidade de movimento através das superfícies $\Sigma$ e $S$. A equação resultante é

$$
\begin{array}{r}
\frac{\partial}{\partial t}\left(\rho u_{i}\right)+\frac{\partial}{\partial x_{j}}\left(\rho u_{i} u_{j}+p \delta_{i j}\right)= \\
\left\{\left[p \delta_{i j}+\rho u_{i}\left(u_{j}-v_{j}\right)\right]_{2}-\left[p \delta_{i j}+\rho u_{i}\left(u_{j}-v_{j}\right)\right]_{1}\right\} \delta(f) \frac{\partial f}{\partial x_{j}} .
\end{array}
$$

Nas equações 3.52 e 3.53, os termos do lado direito são fontes. Para que esses termos 
não sejam nulos, é necessário que haja uma descontinuidade no escoamento na superfície $S$. Caso contrário, a massa e a quantidade de movimento que atravessam $S$ na direção do volume 2 são balanceadas pelo que sai de 1 . Considerando o fluido dentro do volume $V_{1}$ em repouso em relação a um referencial se movendo com velocidade $\vec{v}$ (velocidade de $S$ ), é possível calcular o som gerado por uma superfície em movimento. Considerando-a como impermeável, as equações 3.52 e 3.53 são reescritas

$$
\frac{\partial \rho}{\partial t}+\frac{\partial}{\partial x_{i}}\left(\rho u_{i}\right)=\rho_{0} v_{i} \delta(f) \frac{\partial f}{\partial x_{i}}
$$

$\mathrm{e}$

$$
\frac{\partial}{\partial t}\left(\rho u_{i}\right)+\frac{\partial}{\partial x_{j}}\left(\rho u_{i} u_{j}+p^{\prime} \delta_{i j}\right)=p^{\prime} \delta_{i j} \delta(f) \frac{\partial f}{\partial x_{i}}
$$

sendo $\rho_{0}$ a densidade do meio em repouso. A variável $p^{\prime}$ é a perturbução na pressão a partir do repouso $\left(p_{0}\right)$, de forma que $p^{\prime}=p-p_{0}$. A pressão de repouso some da equação de quantidade de movimento, pois ela assume o mesmo valor em $V_{1}$ e em $V_{2}$, e portanto, se cancela.

Novamente aplicando às equações de massa e quantidade de movimento (3.54 e 3.55) a mesma manipulação algébrica usada para deduzir as equações 3.42 e 3.43, chegamos ao resultado

$$
\left(\frac{\partial^{2}}{\partial t^{2}}-a_{0}^{2} \frac{\partial^{2}}{\partial x_{i}^{2}}\right) \rho^{\prime}=\frac{\partial^{2} T_{i j}}{\partial x_{i} \partial x_{j}}-\frac{\partial}{\partial x_{i}}\left(p^{\prime} \delta_{i j} \delta(f) \frac{\partial f}{\partial x_{j}}\right)+\frac{\partial}{\partial t}\left(\rho_{0} v_{i} \delta(f) \frac{\partial f}{\partial x_{i}}\right)
$$

A equação 3.56 pode ser resolvida de forma análoga à equação 3.43. Para levar em consideração fontes sonoras em movimento em relação ao observador, faz-se uma transformação de coordenadas para um sistema que se desloca juntamente com a fonte. A solução resultante fica

$$
\begin{gathered}
4 \pi a_{0}^{2} \rho^{\prime}(\vec{x}, t)=\frac{\partial^{2}}{\partial x_{i} \partial x_{j}} \int\left[\frac{T_{i j} J}{r\left|1-M_{r}\right|}\right] d \vec{\eta}- \\
\frac{\partial}{\partial x_{i}} \int\left[\frac{p^{\prime} \delta_{i j} n_{j} A}{r\left|1-M_{r}\right|}\right] d S+\frac{\partial}{\partial t} \int\left[\frac{\rho_{0} v_{n}}{r\left|1-M_{r}\right|}\right] d S,
\end{gathered}
$$

onde o Jacobiano da transformação das coordenadas de $\vec{y}$ para $\vec{\eta}$, $J$, e a variável $A$ levam em consideração uma possível expansão ou contração do volume limitado por $S$ e o termo $M_{r}$ é a razão entre a velocidade com que a fonte se aproxima do ponto $\vec{x}$ e a velocidade do som. Além 
disso, $r=|\vec{x}-\vec{y}|$ é a distância entre o observador em $\vec{x}$ e a fonte em $\vec{y}$, posição da fonte no instante em que a frente de onda é gerada.

Nas integrais da equação 3.57 os termos dentro dos colchetes são tomados no instante $\tau=$ $t-r / a_{0}$, quando o som é gerado. Os dois últimos termos devem ser integrados na superfície de descontinuidade, porém o primeiro termo do lado direito deve ser integrado em um volume que contém a superfície $S$. Esse termo representa as fontes do tipo quadrupolo discutidas na seção 3.3.1. Os outros são chamados de termo de carga (do inglês load) e termo de espessura (do inglês thickness) respectivamente, na ordem em que são apresentados na equação 3.57.

\subsubsection{Formulações do PowerFLOW}

Muitas formulações diferentes para a analogia de Ffowcs Williams-Hawkings estão disponíveis na literatura. O programa PowerFLOW, utilizado neste trabalho, emprega a formulação $1 A$ apresentada por Farassat (2007). Essa metodologia considera a equação de Ffowcs WilliamsHawkings para uma superfície permeável em movimento e considera que as fontes quadrupolos estão incluídas dentro dessa superfície, permitindo retirar da equação o termo relacionado ao tensor de Lighthill. Para uma superfície permeável, contendo as fontes quadrupolo, a equação 3.56 é escrita da seguinte forma

$$
\frac{\partial^{2} \rho^{\prime}}{\partial t^{2}}-a_{0}^{2} \frac{\partial^{2} \rho^{\prime}}{\partial x_{i}^{2}}=\frac{\partial}{\partial t}\left[Q_{n} \delta(f)\right]-\frac{\partial}{\partial x_{i}}\left[L_{i} \delta(f)\right]
$$

sendo

$$
Q_{n}=\left[\rho_{0} v_{i}+\rho\left(u_{i}-v_{i}\right)\right] n_{i}
$$

e

$$
L_{i}=\left[P_{i j}+\rho u_{i}\left(u_{j}-v_{j}\right)\right] n_{j}
$$

em que os vetores $\vec{u}$ e $\vec{v}$ se referem à velocidade do fluido e da superfície de integração, respectivamente, enquanto $\vec{n}$ é o vetor unitário normal à superfície em cada ponto.

A formulação $1 A$ é utilizada pelo PowerFLOW de duas maneiras diferentes. Uma delas permite o cálculo de fontes sonoras se movendo em um meio em repouso com o observador também em repouso. A segunda considera uma configuração na qual o observador está em repouso em relação à fonte mas o fluido do meio tem uma velocidade não nula relativa a ambos, 
o que permite a previsão do som propagado em uma configuração típica de túnel de vento. Essa forma é uma adaptação da primeira, bastando para isso considerar que tanto fonte como observador estão à mesma velocidade em relação ao fluido do meio (BRÈS; PÉROT; FREED, 2010). Em ambos os casos, as flutuações de pressão em um ponto distante são dadas pela soma da contribuiçãodo termo de espessura e do termo de carga $\left(p^{\prime}(\vec{x}, t)=p_{T}^{\prime}(\vec{x}, t)+p_{L}^{\prime}(\vec{x}, t)\right)$.

Após aplicar um complicado algebrismo à solução da equação 3.58, Brès, Pérot e Freed (2010) apresentam as equações do termo de espessura $\left(p_{T}^{\prime}(\vec{x}, t)\right)$ e do termo de carregamento $\left(p_{L}^{\prime}(\vec{x}, t)\right)$ para fontes em movimento da seguinte forma

$$
4 \pi p_{T}^{\prime}(\vec{x}, t)=\int_{f=0}\left[\frac{\frac{\partial Q_{i}}{\partial \tau} n_{i}+Q_{i} \frac{\partial n_{i}}{\partial \tau}}{r\left(1-M_{r}\right)^{2}}\right]_{r e t} d S+\int_{f=0}\left\{\frac{Q_{n}\left[r \frac{\partial M_{i}}{\partial \tau} \hat{r}_{i}+a_{0}\left(M_{r}-M^{2}\right)\right]}{r^{2}\left(1-M_{r}\right)^{3}}\right\}_{r e t} d S
$$

$\mathrm{e}$

$$
\begin{array}{r}
4 \pi p_{L}^{\prime}(\vec{x}, t)=\frac{1}{a_{0}} \int_{f=0}\left[\frac{\frac{\partial L_{i}}{\partial \tau} \hat{r}_{i}}{r\left(1-M_{r}\right)^{2}}\right]_{r e t} d S+\int_{f=0}\left[\frac{L_{i} \hat{r}_{i}-L_{i} M_{i}}{r^{2}\left(1-M_{r}\right)^{2}}\right]_{r e t} d S+ \\
\frac{1}{a_{0}} \int_{f=0}\left\{\frac{L_{i} \hat{r}_{i}\left[r \frac{\partial M_{i}}{\partial \tau} \hat{r}_{i}+a_{0}\left(M_{r}-M^{2}\right)\right]}{r^{2}\left(1-M_{r}\right)^{3}}\right\}_{r e t} d S
\end{array}
$$

respectivamente.

Nas equações 3.61 e $3.62, \hat{r}_{i}$ é o vetor unitário na direção de $\vec{r}$ e $\vec{M}$ é o vetor cujo módulo é o número de Mach da superfície de integração. O subescrito ret quer dizer que os termos dentro dos colchetes ou chaves devem ser integrados no instante $\tau$

Na formulação para túnel de vento, considera-se que tanto a fonte quanto o observador se movem à uma velocidade igual à do escoamento na entrada do túnel em magnitude, mas no sentido contrário. Então, considerando um escoamento com velocidade livre igual a $U_{0}$, correspondendo a um número de Mach $M_{0}=U_{0} / a_{0}$, temos que os termos de espessura e carga são, respectivamente

$$
4 \pi p_{T}^{\prime}(\vec{x}, t)=\int_{f=0}\left[\frac{\frac{\partial Q_{i}}{\partial \tau} n_{i}}{R\left(1-M_{R}\right)^{2}}\right]_{r e t} d S+\int_{f=0}\left[\frac{Q_{n} a_{0}\left(M_{R}-M^{2}\right)}{R^{2}\left(1-M_{R}\right)^{3}}\right]_{r e t} d S
$$




$$
\begin{array}{r}
4 \pi p_{L}^{\prime}(\vec{x}, t)=\frac{1}{a_{0}} \int_{f=0}\left[\frac{\frac{\partial L_{i}}{\partial \tau} \hat{R}_{i}}{R\left(1-M_{R}\right)^{2}}\right]_{r e t} d S+ \\
\int_{f=0}\left[\frac{L_{i} \hat{R}_{i}-L_{i} M_{i}}{R^{2}\left(1-M_{R}\right)^{2}}\right]_{r e t} d S+\int_{f=0}\left\{\frac{L_{i} \hat{R}_{i}\left(M_{R}-M^{2}\right)}{R^{2}\left(1-M_{R}\right)^{3}}\right\}_{r e t} d S
\end{array}
$$

Nas equações 3.63 e 3.64, $R$ é a distância acústica efetiva, uma vez que a onda viaja uma distância diferente da distâcia fixa entre a fonte e o observador. O parâmetro $M_{R}$ é a razão entre a componente da velocidade de deslocamento da fonte e do observador na direção de $R$ e a velocidade do som $a_{0}$. Assim como a distância entre a fonte e o observador, $R$ também é uma valor fixo calculado por

$$
R=\frac{-M_{0}\left(x_{1}-y_{1}\right)+R^{*}}{\beta}
$$

onde

$$
R^{*}=\sqrt{\left(x_{1}-y 1\right)^{2}+\beta^{2}\left[\left(x_{2}-y_{2}\right)^{2}+\left(x_{3}-y_{3}\right)^{2}\right]}
$$

$\mathrm{e}$

$$
\beta=\sqrt{1-M_{0}^{2}}
$$

Essa formulação para túnel de vento é muito eficiente em termos de computação uma vez que os termos $R, M_{R}$ e $\beta$ são constantes e podem ser tratados no pré-processamento. 
CAPÍtulo

4

\section{Configuração das Simulações}

Todas as simulações descritas neste trabalho foram feitas com a geometria de aerofólio designada por MDA 30P30N. Este aerofólio com hiper-sustentadores, mostrado na figura 12, é composto por três elementos, um eslate no bordo de ataque, um elemento principal e um flap no bordo de fuga. A deflecção do eslate $\left(\delta_{s}\right)$ e do flap $\left(\boldsymbol{\delta}_{f}\right)$ em relação à linha da corda do aerofólio é de $30^{\circ}$ (ver figura 13). Outros detalhes a respeito da geometria 30P30N estão apresentados na tabela 1. Os valores na tabela 1 são apresentados em frações da corda do aerofólio em condição de cruzeiro, $c_{c r u z}$.

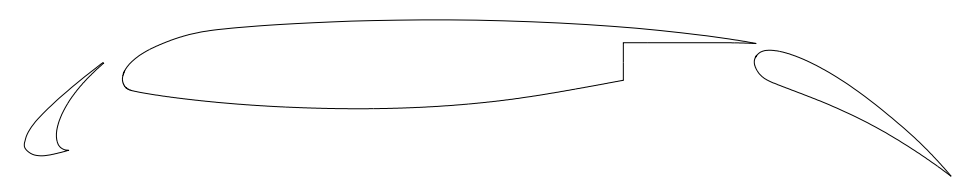

Figura 12 - Aerofólio MDA 30P30N.

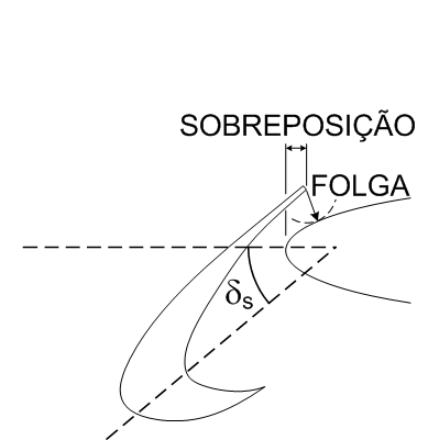

(a) Eslate

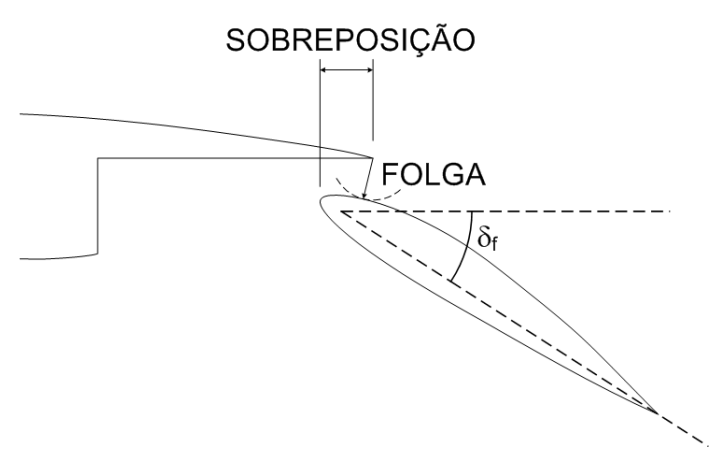

(b) Flap

Figura 13 - Nomeclatura para descrever configuração dos dispositivos hiper-sustentadores. 
Tabela 1 - Configuração geométrica do aerofólio 30P30N.

\begin{tabular}{lccc} 
& folga & sobreposição & corda \\
\cline { 2 - 4 } eslate & $2,95 \%$ & $-2,5 \%$ & $15 \%$ \\
flap & $1,27 \%$ & $0,25 \%$ & $30 \%$
\end{tabular}

Um dos objetivos das simulações apresentadas neste trabalho é comparar o campo próximo de escoamento com resultados numéricos publicados por outros autores. Por esse motivo, a configuração do domínio simulado é baseada nas condições empregadas no experimento de Jenkins, Khorrami e Choudhari (2004), que foi realizado em um túnel de vento de seção fechada designado por BART (sigla para Basic Aerodynamics Research Tunnel). Assim, o domínio tem um formato retangular e seus limites superior e inferior correspondem às paredes do túnel e são dados por paredes com condição de escorregamento livre. Para adequar o domínio das simulações ao túnel de vento BART, utilizado por Jenkins, Khorrami e Choudhari (2004), a distância entre esses limites foi fixada em $0,711 \mathrm{~m}$.

Choudhari e Khorrami (2007) mostraram a importância de se considerar efeitos tridimensionais nos fenômenos hidrodinâmicos que ocorrem na cavidade do eslate e que são diretamente ligados à geração de som pelo mesmo. Portanto, as simulações discutidas neste trabalho empregaram geometrias tridimensionais do aerofólio. Porém, nenhum efeito de afilamento ou da ponta da asa foi levado em consideração, e o comprimento da corda do aerofólio, baseado na configuração de cruzeiro, é constante igual a $c_{c r u z}=0,457 \mathrm{~m}$.

Nos limites laterais do domínio uma condição de periodicidade foi aplicada em todas as simulações. Essa condição de fronteira condiz com uma hipótese de uniformidade do escoamento na direção z. Assim o modelo simulado representa uma asa com envergadura infinita, entretanto o termo "envergadura simulada" será usado neste texto para designar a extensão do domínio simulado na direção normal ao plano do perfil do aerofólio enquanto o termo "direção da envergadura" representa esta direção. Lockard e Choudhari (2009) e Lockard e Choudhari (2010) mostram que uma envergadura simulada aproximadamente igual a $80 \%$ da corda do eslate é suficiente para descorrelacionar as estruturas na camada de mistura. Em simulações com a mesma geometria utilizada nesse trabalho e velocidade de entrada normal ao bordo de ataque, Lockard e Choudhari (2010) apresentam resultados de duas simulações com diferentes extensões do domínio na direção da envergadura. A menor envergadura simulada era igual a 74,7\% da corda do eslate enquanto a maior tinha dimensão igual a $226 \%$ da corda do eslate e nenhuma diferença significativa é apresentada nos resultados de flutuações do campo próximo e variações da ordem de $5 d B$ em regiões específicas do espectro de som propagadado. Na maioria das simulações apresentadas neste trabalho, o domínio teve uma extensão de $0,05078 m$ na direção da 
envergadura, correspondendo a $74 \%$ da corda do eslate.

Em análises aeroacústicas, o transiente inicial provocado pelo surgimento do escoamento e prolongado pelas reflexões de ondas acústicas nas fronteiras do domínio tem uma interferência significativa no resultado. No caso de ensaios em túnel de vento, a velocidade do escoamento aumenta gradativamente até o valor desejado e o experimento pode ser realizado por tempo suficiente para convectar o transiente inicial sem aumento significativo nos custos da análise. Além disso, técnicas de processamento de sinais são capazes de identificar os efeitos de reflexão nas paredes do túnel permitindo que sejam desconsiderados. No caso de simulações numéricas, a velocidade do escoamento surge bruscamente e a simulação por tempo suficiente para que esse efeito seja convectado pode ser inviável. Portanto, nas simulações numéricas, é necessária alguma técnica que minimize o efeito das ondas refletidas nos limites do domínio.

O PowerFLOW permite ao usuário definir uma região periférica do domínio onde a viscosidade é cem vezes a viscosidade da região de interesse. Então, as ondas acústicas que chegam aos limites são amortecidas pelo fluido extremamente viscoso dessa região, aqui chamada de camada anecóica. Assim torna-se necessário a definição da posição da fronteira da camada anecóica de forma que a solução seja independente dessa posição.

Um estudo de independência da solução em relação à localização da fronteira da camada anecóica foi feito por Simões (2011) para a mesma geometria e configuração de túnel de vento do presente trabalho. A fronteira da camada anecóica foi posicionada, sistematicamente, a diferentes distâncias do aerofólio, tanto a montante quanto a jusante do mesmo. O efeito da posição das fronteiras superior e inferior da camada anecóica também foi avaliado.

Os limites do domínio a montante e a jusante foram ajustados de acordo com a camada anecóica. A montante, a variação da fronteira anecóica de $5 c_{c r u z}$ para $10 c_{c r u z}$ à frente do bordo de ataque do aerofólio recolhido apresentou uma variação relativa de $0,71 \%$ no coeficiente de sustentação $\left(C_{L}\right)$ e $6,77 \%$ no coeficiente de arrasto $\left(C_{D}\right)$. Por sua vez, a variação $10 c_{c r u z}$ para $20 c_{c r u z}$ da fronteira anecóica a jusante, considerando o mesmo ponto de referência, apresentou uma variação relativa de $0,35 \%$ em $C_{L}$ e $0,59 \%$ em $C_{D}$.

A posição das fronteiras da camada anecóica acima e abaixo do aerofólio é limitada pelas dimensões do túnel de vento. Comparando os coeficientes de sutentação e arrasto entre uma configuração com uma camada de espessura $0,0555 \mathrm{~m}$ acima e abaixo do aerofólio e uma configuração em que nenhuma camada anecóica está presente nas proximidades dos limites superior e inferior do domínio, Simões (2011) apresentam uma variação relativa de 0,38\% e 6,5\% em $C_{L}$ e $C_{D}$ respectivamente. Baseado nesse estudo, decidiu-se empregar o modelo com as fronteiras da camada anecóica $10 c_{c r u z}$ a montante e a jusante do aerofólio e com espessura de $0,0555 \mathrm{~m}$ 
acima e abaixo do mesmo, por se entender que essa configuração representa o melhor compromisso entre confiabilidade da simulação e demanda de tempo computacional na relaidade da indústria.

Duas configurações básicas de malha foram empregadas nas simulações. Ambas as configurações foram propostas por Simões, Souza e Medeiros (2011) para a simulação do ruído de eslate do aerofólio MDA 30P30N. O detalhe das regiões de refinamento das duas configurações nas proximidades do aerofólio estão apresentados nas figuras 14 e 15 . Essas configurações serão referidas neste trabalho como configuração de referência e configuração otimizada, respectivamente. Com excessão dos casos simulados para estudo de convergência de malha, o menor voxel das malhas utilizadas tem aresta de comprimento igual a 0,2 $\mathrm{mm}$. Esse tamanho de voxel leva o PowerFLOW a impor um passo de tempo de $3,407 E-7 s$ na região mais refinada.

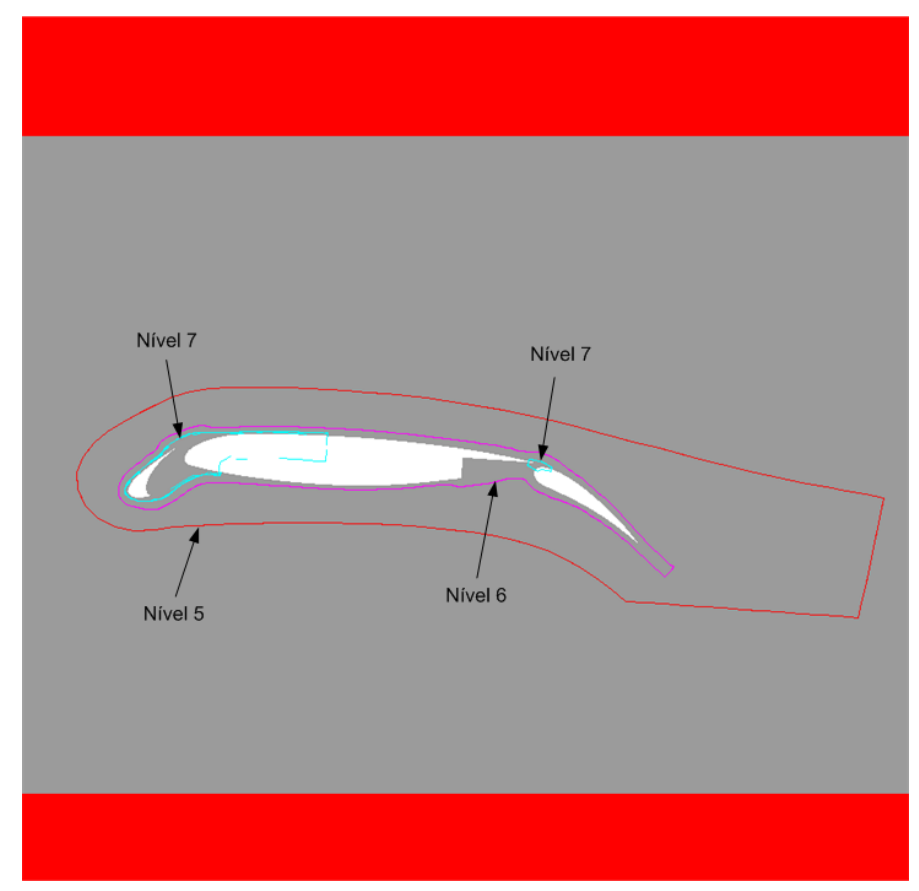

Figura 14 - Detalhe das zonas de refinamento da malha de referência na região do aerofólio.

Um estudo de independência de malha para a configuração de referência é apresentado por Simões, Souza e Medeiros (2011). Três refinamentos foram testados usando as mesmas fronteiras entre as regiões com voxels diferentes. A malha mais refinada tinha o menor voxel com $0,16 \mathrm{~mm}$ de comprimento, a intermediária, 0,20 mm (malha de referência deste trabalho) e a mais grosseira, $0,25 \mathrm{~mm}$. O erro da malha de referência em relação à malha mais refinada foi de $0,4 \%$ para o coeficiente de sustentação e $0,8 \%$ para o coeficiente de arrasto. A figura 16 apresenta o espectro de flutações de pressão no ponto de recolamento da cova do eslate calculado a partir de simulações com as três malhas. Observa-se a semelhança entre as três 


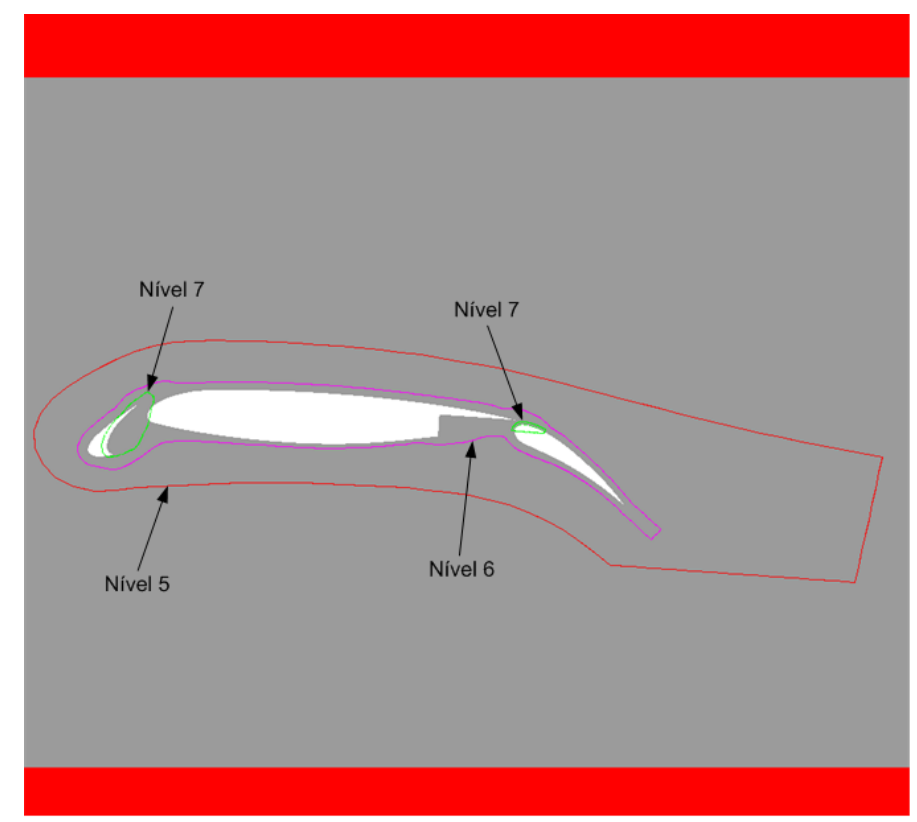

Figura 15 - Detalhe das zonas de refinamento da configuração otimizada de malha na região do aerofólio.

curvas com variações abaixo de $3 d B / H z$ entre elas.

A configuração de malha otimizada foi empregada em casos em que condição de parede com escorregamento livre foi imposta em algumas superfícies do aerofólio. Então, em comparação com a configuração de referência, a otimizada possui menor volume com refinamento elevado, já que não precisa resolver algumas camadas limite, sendo, portanto, mais eficiente. Uma economia de $40 \%$ do tempo computacional (em escala de máquina), devido ao emprego da malha otimizada, foi reportado por Simões, Souza e Medeiros (2011). Na prática, essa economia deve ser ligeiramente menor, uma vez que as simulações com a configuração de malha otimizada foram feitas por um número menor de processadores, o que aumenta a escalabilidade do código. Entretanto o ganho da configuração otimizada ainda muito siginificativo, principalmente em uma realidade de projeto de aeronaves.

A figura 17 mostra o auto-espectro do som propagado a partir do eslate para dois pontos distintos a uma distância igual a $10 c_{c r u z}$ do ponto onde estaria o bordo de fuga do aerofólio se o mesmo estivesse recolhido. Esses gráficos são baseados nos cálculos de Simões, Souza e Medeiros (2011) com a malha de referência (denominada na figura de Baseline mesh) e a malha otimizada (Optimized mesh). Com excessão do pico por volta de $S t=2$, que apresenta descrepância de aproximadamente $3 \mathrm{~dB} / \mathrm{Hz}$, os dois espectros são praticamente iguais. 


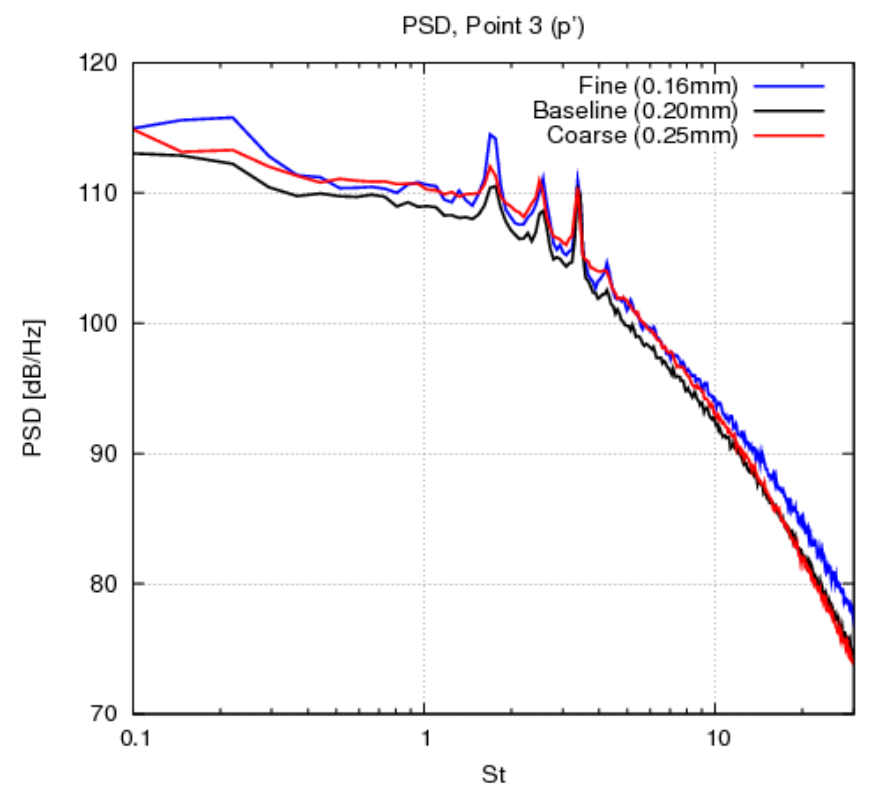

Figura 16 - Espectro de flutuação de pressão no ponto de recolamento no intradorso do eslate para diferentes refinamentos de malha. Retirado de Simões, Souza e Medeiros (2011)

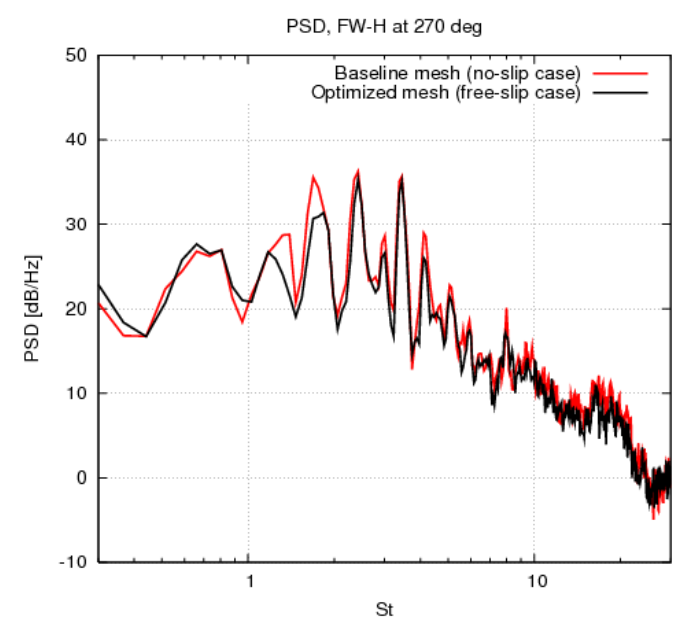

(a)

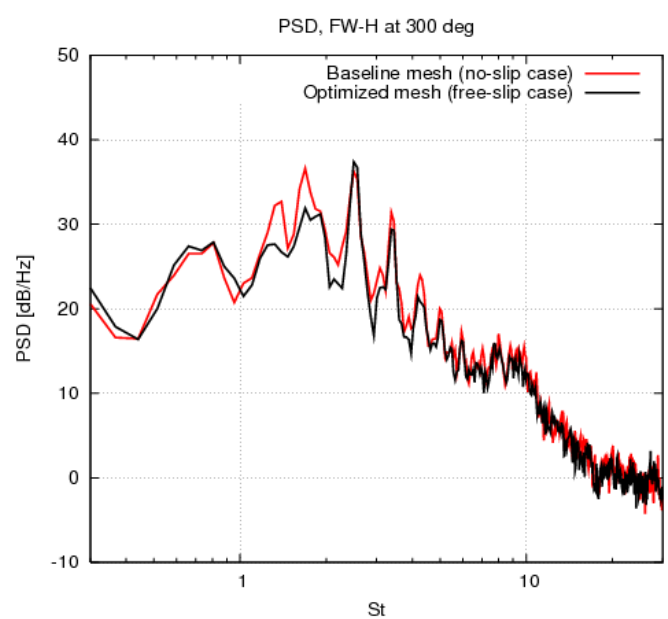

(b)

Figura 17 - Densidade de potência espectral de flutuações de pressão no campo acústico distante do aerofólio sem o selo. Retirado de Simões, Souza e Medeiros (2011). 


\subsection{Simulações Considerando Espessura de Deslocamento}

Estudando a geometria MDA 30P30N com um ângulo de ataque de $4^{\circ}$, Simões, Souza e Medeiros (2011) mostram que algumas camadas limite das superfícies de aerofólios com hipersustentadores não exercem influência na geração de som pelo eslate. A partir dessa observação, conjectura-se que a previsão precisa da circulação do aerofólio é suficiente para resolver as propriedades do escoamento relevantes para o ruído aeroacústico do eslate. Essa conjectura permite que condição de contorno de parede com escorregamento livre seja empregada para representar algumas superfícies do aerofólio, tornando as simulações mais eficientes computacionalmente, uma vez que não é necessário resolver o escoamento de algumas camadas limite. Entretanto o uso dessa metodologia se limita a casos com camadas limite finas, uma vez que estas não causam mudança significativa na circulação dos elementos do aerofólio. Em aerfólios com ângulo de ataque moderados ou altos, as camadas limite são mais espessas e a condição de parede com escorregamento livre pode conduzir a erros significativos.

Uma possível solução para que se possa aplicar condição de parede com escorregamento em aerofólios com alto ângulo de ataque é considerar, de uma forma alternativa, as camadas limite das superfícies onde esta condição de contorno é adotada. Pode-se assumir que o efeito da camada limite no escoamento potencial se resume a apenas modificar as linhas de corrente, afastando-as da parede um distância igual à espessura de deslocamento, $\delta^{*}$, da camada limite. Essa hipótese é válida contanto que $\delta^{*}$ seja pequena em relação ao raio de curvatura das linhas de corrente (LIGHTHILL, 1958).

Para estimar se a consideração da espessura de deslocamento é capaz de aproximar a solução de simulações com paredes com escorregamento livre das soluções com parede sem escorregamento, uma simulação transiente foi feita utilizando uma geometria modificada do aerofólio MDA 30P30N. A modificação consistiu em deslocar as superfícies do aerofólio onde parede com escorregamento livre foi imposta. Para se determinar a espessura de deslocamento ao longo das superfícies do aerofólio, uma simulação foi feita com o código híbrido MSES.

A figura 18 mostra como a espessura de deslocamento foi incorporada à superfície do aerofólio. Uma vez que os pontos utilizados para construir a geometria do aerofólio $(A$ e $B)$ não coincidem com os pontos da malha do MSES ( 1 e 2), uma interpolação entre os pontos da malha mais próximos foi utilizada para determinar o valor de $\delta^{*}$ em cada ponto da geometria. No exemplo da figura, $\delta_{A}^{*}$ foi calculado a partir da equação

$$
\delta_{A}^{*}=\frac{\delta_{1}^{*} s_{2}+\delta_{2}^{*} s_{1}}{s_{1}+s_{2}}
$$




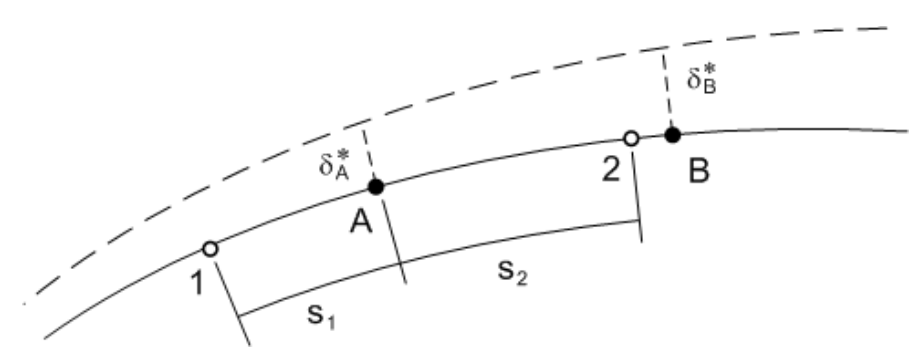

Figura 18 - Modelo do esquema de modificação da superfície do aerofólio.

No contexto das discussões da presente seção duas simulações foram feitas. Na primeira, o código MSES foi utilizado para se obter uma solução estacionária da camada limite do aerofólio, usando a geometria original do MDA 30P30N. Na segunda, o resultado de $\delta^{*}$ da primeira simulação foi utilizado para modificar a superfície do elemento principal e do eslate. A superfície da cova do eslate e a superfície da cova do elemento principal onde se encaixa o flap não sofreram alteração, permitindo que as estruturas das camadas cisalhantes livres das duas regiões se formem normalmente. A comparação entre a geometria original do elemento principal (preta) e a geometria modificada usando $\delta^{*}$ (curva azul) está apresentada na figura 19 como exemplo. Nesta escala é difícil identificar a alteração na geometria do eslate.

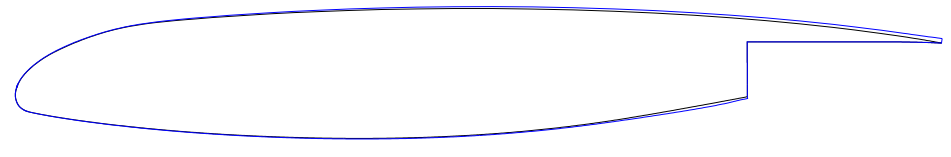

Figura 19 - Comparação entre o elemento principal original e modificado pela espessura de deslocamento. A curva azul representa a geomatria modificada.

As condições do escoamento, tanto na simulação estacionária quanto na transiente, foram configuradas para serem iguais às condições impostas por Simões, Souza e Medeiros (2011) e estão descritas na tabela 2. Na prática não se determina a velocidade de entrada do escoamento no MSES, apenas os número de Reynolds e de Mach, além do ângulo de ataque do aerofólio e a taxa de amplificação crítica, $N_{\text {crit }}$. Assim como nas simulações com o PowerFLOW, a posição e condição de contorno nos limites inferior e superior do domínio da simulação estacionária imitam as paredes do túnel de vento BART. Uma vez que não havia dados a respeito da transição no MDA 30P30N a baixo número de Reynolds, um valor de $N_{\text {crit }}$ igual a 8 , que é comum para simulações em túnel de vento de baixa turbulência, foi escolhido para a simulação com o MSES. Na simulação transiente com a geometria modificada, a envergadura simulada foi a de referência, igual a $0,05078 \mathrm{~m}$. A configuraçãode malha otimizada foi utilizada na presente 
análise.

Tabela 2 - Propriedades do escoamento nas simulações considerando espessura de deslocamento.

\begin{tabular}{|l|c|}
\hline Mach & 0,17 \\
\hline Reynolds & $1,71 E 6$ \\
\hline$U_{\infty}$ & $56 m / s$ \\
\hline$\alpha$ & $4^{\circ}$ \\
\hline
\end{tabular}

\subsection{Simulações com Selo no Intradorso do Eslate}

Diversos trabalhos relacionados à previsão do ruído gerado pelo eslate através de simulações numéricas foram publicados (LOCKARD; CHOUDHARI, 2009, 2010, 2011; DIERKE et al., 2011). Praticamente todos os trabalhos consideram uma geometria idealizada do eslate, não levando em consideração elementos que não tenham função aerodinâmica, como suportes e selos de vedação, que estão presentes nas asas de aeronaves comerciais quando os dispositivos hiper-sustentadores estão acionados. A figura 20, adapatada de Khorrami e Lockard (2006), mostra a região da cova do eslate de um Boeing 777. É possível verificar a presença de diversas excrescências. Entre elas, dois elementos estão em destaque na figura, um selo na cúspide e outro na parede da cova. O primeiro selo tem a função de evitar que ar entre na região entre o elemento principal e o eslate quando os dispositivos hiper-sustentadores estão recolhidos. $\mathrm{O}$ segundo selo, na parede da cova, além da vedação também tem a função de evitar o contato entre as superfícies metálicas do eslate e do elemento principal em condição de cruzeiro.

Khorrami e Lockard (2006) analisaram, através de simulações baseadas nas equações de Navier-Stokes, o efeito da extensão de um selo preso à cúspide do eslate na geração e propagação de ruído. Outro selo localizado na parede da cova também foi considerado nos cálculos, porém, baseado no argumento de que este não provocava modificação significativa nas características aeroacústicas do eslate, apenas uma configuração deste selo foi empregada em todas as simulações. No presente trabalho, simulações foram feitas para avaliar o efeito do selo da parede da cova no som gerado pelo eslate. Diferentes posições e tamanhos do selo foram testados, para avaliar a influência destes dois fatores nas características do som propagado a partir do eslate.

Para simular o selo da cova do eslate, um elemento retangular foi adicionado à geometria do aerofólio MDA 30P30N conforme as figuras 21 e 22. A figura 21 mostra três cofigurações diferentes do selo variando a altura do mesmo. As alturas simuladas correspodem a 3, 6 e 12 vezes a espessura do bordo de fuga do eslate. Todas as três geometrias do dispositivo tiveram 


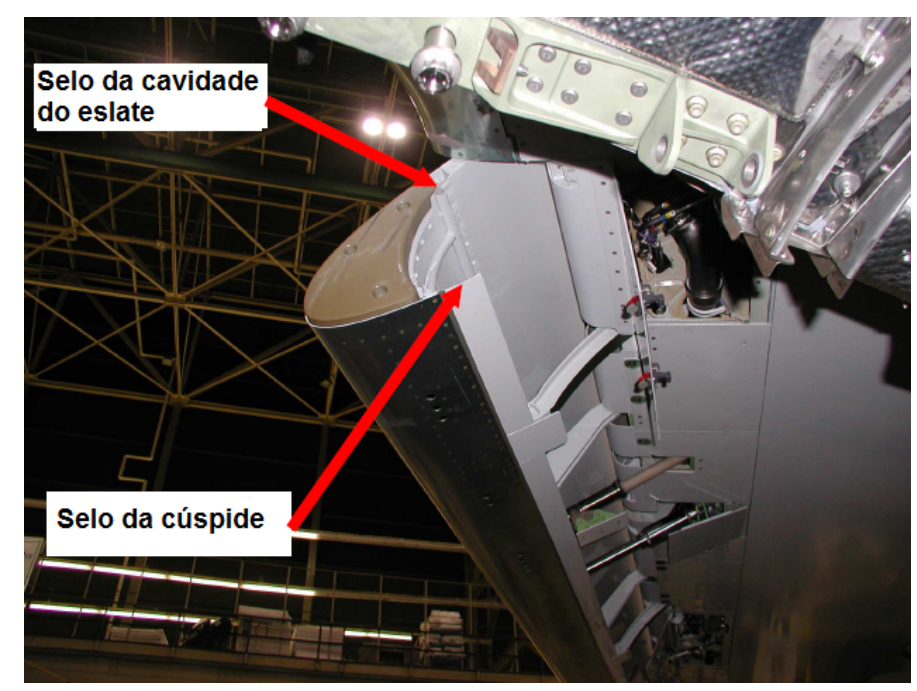

Figura 20 - Região da cavidade do eslate de um Boeing 777. Adaptada de Khorrami e Lockard (2006).

uma largura igual a 3 vezes a espessura do bordo de fuga. A posição do dispositivo nos três casos apresentados na figura 21 corresponde a uma distância do bordo de fuga igual ao dobro da distância entre este e o ponto de recolamento da camada de mistura de acordo com o resultado apresentado por Jenkins, Khorrami e Choudhari (2004) para o caso com $4^{\circ}$ de ângulo de ataque.

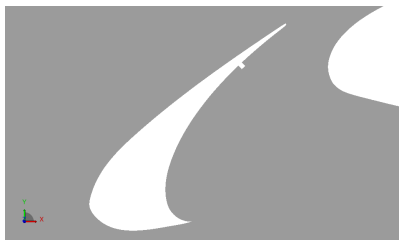

(a)

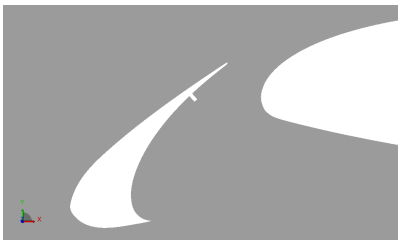

(b)

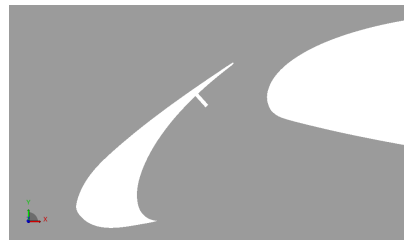

(c)

Figura 21 - Três diferentes alturas do selo.

Uma outra análise foi feita para avaliar o efeito da posição do dispositivo. O dispositivo com altura igual a 6 vezes a espessura do bordo de fuga do eslate foi utilizado nas três posições mostradas na figura 22. O caso da figura 22(a) é o mesmo da figura 21(b). No caso mostrado na figura 22(b), a distância entre o dispositivo e o bordo de fuga do eslate é igual a 3 vezes a distância entre este e o ponto de recolamento da camada de mistura. Por sua vez no caso da figura 22(c) o selo se localiza no ponto de recolamento da camada de mistura. O detalhe da malha na região do eslate está mostrado na figura 23.

Os resultados das simulações com o selo foram comparados entre si e com os resultados apresentados por Simões, Souza e Medeiros (2011). Portanto, a configuração do escoamento em todos os casos foi escolhida de forma que uma comparação direta pudesse ser feita. A 


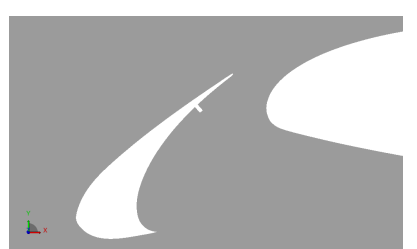

(a)

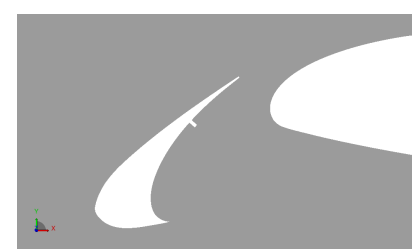

(b)

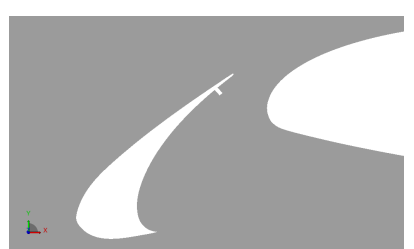

(c)

Figura 22 - Três diferentes posições do selo.

velocidade de entrada simulada foi de $U_{\infty}=56 \mathrm{~m} / \mathrm{s}$, correspondendo a um número de Mach de 0,17 . O ângulo de ataque do aerofólio foi de $4^{\circ}$ e o número de Reynolds simulado foi de 1,71 milhões, baseado no comprimento da corda do aerofólio em condição de cruzeiro e na velocidade de entrada, $U_{\infty}$.

Uma condição de parede com escorregamento livre foi imposto na superfície do elemento principal e do eslate entre a cúspide e bordo de fuga, passando pelo bordo de ataque de acordo com o proposto por Simões, Souza e Medeiros (2011). Por outro lado, as superfícies do flap e da cova do eslate foram consideradas como paredes sem escorregamento.

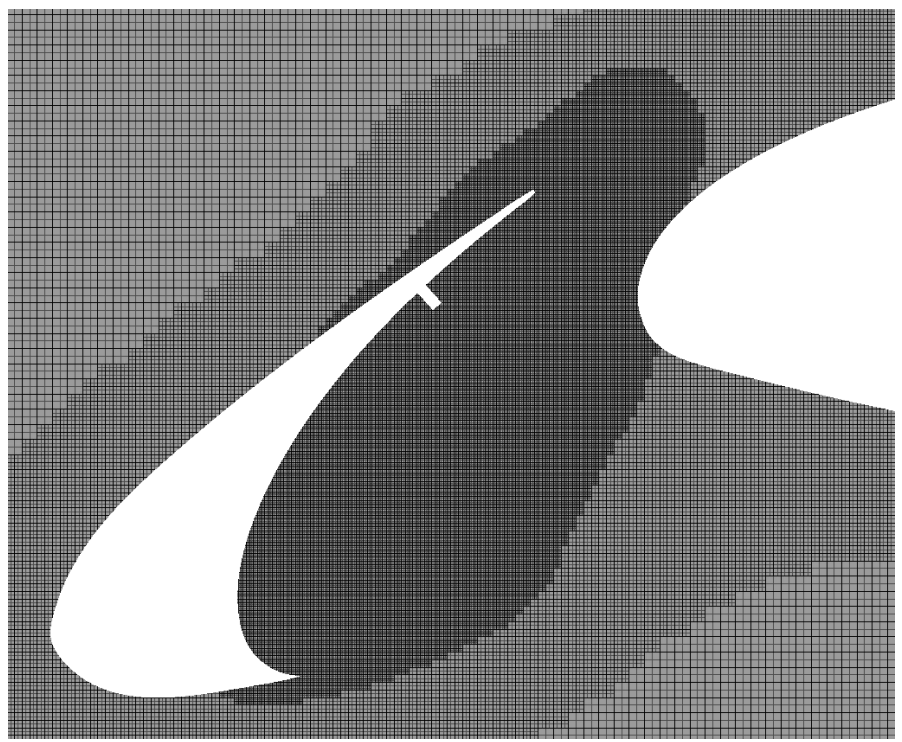

Figura 23 - Detalhe da malha na região da cova do eslate com selo.

\subsection{Simulações com Escoamento Cruzado}

Conforme mostrado na figura 24, para simular o efeito de enflechamento da asa, a velocidade imposta na entrada do domínio possuia uma componente longitudinal e uma componente na direção da envergadura enquanto o bordo de ataque do aerofólio tri-dimensional permaneceu 
paralelo ao plano do limite do domínio a montante. Assim o vetor da velocidade de entrada era oblíquo ao bordo de ataque.

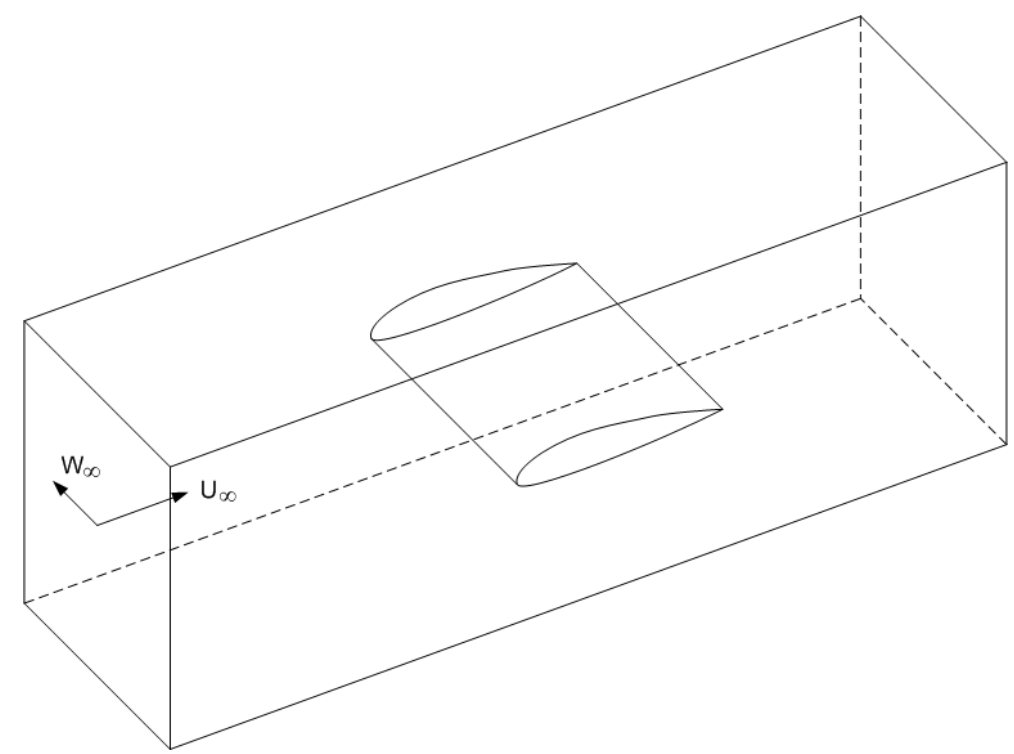

Figura 24 - Esquema da configuração das simulações com escoamento cruzado.

Duas configurações básicas foram analisadas, uma com um ângulo de enflechamento de $\beta=35^{\circ}$ e outra com $\beta=45^{\circ}$. Dessa forma os resultados puderam ser comparados com as simulações apresentadas por Lockard e Choudhari (2010), baseadas nas equações de NavierStokes. Para as duas configurações, o ângulo de ataque do aerofólio foi de $4^{\circ}$. Para permitir uma comparação direta dos resultados das simulações desenvolvidas neste trabalho, os mesmos parâmetros de escoamento considerados por Lockard e Choudhari (2010) nos casos com escoamento cruzado foram adotadas aqui e estão descritos na tabela 3. O número de Reynolds é baseado em $c_{c r u z}$ e na velocidade total na entrada do domínio, $\left|\vec{V}_{\infty}\right|$.

Tabela 3 - Propriedades do escoamento nas simulações de asa enflechada.

\begin{tabular}{|c|cccc|}
\hline$\beta$ & $U_{\infty}(\mathrm{m} / \mathrm{s})$ & $W_{\infty}(\mathrm{m} / \mathrm{s})$ & $\left|\vec{V}_{\infty}\right|(\mathrm{m} / \mathrm{s})$ & $R e_{c}$ \\
\hline \hline $35,26^{\circ}$ & 56 & 39,6 & 68,6 & $1,396 E 6$ \\
\hline $45^{\circ}$ & 39,6 & 39,6 & 56 & $2,4183 E 6$ \\
\hline
\end{tabular}

Além da comparação com resultados da literatura, a hipótese sugerida por Simões, Souza e Medeiros (2011), de que as espessuras das camadas limite têm pouca influência na geração de som pelo eslate, foi testada para os casos com asa enflechada. Para tanto, simulações com duas configurações distintas de condição de parede nas superfícies do aerofólio foram feitas. A primeira configuração considerou condição de parede sem escorregamento em todas as superfícies do aerofólio. Na outra configuração foi adotada condição de escorregamento livre na superfície do elemento principal e na superfície do eslate exterior à cova enquanto as demais 
superfícies, ou seja, do flap e da cova do eslate, foram mantidas como parede sem escorregamento.

Um estudo de independência da solução em relação à malha empregada foi feito para os dois casos com escoamento cruzado. Utilizando a configuração de malha de referência, as soluções dadas por duas malhas com refinamento diferente foram comparadas. Além da malha com voxel de $0,20 \mathrm{~mm}$, uma malha mais refinada foi usada em cada um dos casos. No caso com enflechamento de $35^{\circ}$ a malha mais refinada teve menor voxel com aresta de $0,15 \mathrm{~mm}$, representando uma razão de refinamento de $25 \%$. Por sua vez a razão de refinamento no caso com enflechamento de $45^{\circ}$ foi de $10 \%$, sendo o menor voxel nesse caso um cubo com arestas de $0,18 \mathrm{~mm}$ de comprimento.

Devido à restrição do PowerFLOW de ter apenas voxels cúbicos, a dimensão do domínio na direção da envergadura do aerofólio está sempre relacionada à malha. A extensão do domínio em todas as direções tem que ter o comprimento necessariamente múltiplo da aresta do maior voxel, ou seja, múltiplo de $\delta x_{\min } 2^{N-1}$, sendo $N$ o número de níveis de refinamento e $\delta x_{\min }$ o tamanho da aresta do menor voxel. Portanto decidiu-se manter o número de voxels ao longo da envergadura simulada constante para todas as malhas empregadas. Com a dimesão fixada ao quádruplo do comprimento da aresta do maior voxel, a envergadura simulada foi de $0,05078 \mathrm{~m}$ no caso com menor voxel de $0,20 \mathrm{~mm}, 0,03809 \mathrm{~m}$ para a malha com $\delta x_{\min }=0,15 \mathrm{~mm}$ e 0,04608 no caso com menor voxel de $0,18 \mathrm{~mm}$ de aresta.

\subsection{Simulações com Tubo do Sistema Anti-gelo}

Outra excrescência presente na região da cavidade do eslate de aeronaves comerciais é um tubo por onde escoa fluido do sistema anti-gelo da asa. A figura 25 apresenta a disposição desse tubo em uma aeronave EMBRAER-170. Posicionado desta forma, dentro da cavidade do eslate, o tubo do sistema anti-gelo interage com a camada de mistura recém formada a partir da cúspide, modificando as estruturas hidrodinâmicas presentes na cova. Como as estrutras turbulentas na camada de mistura são a principal responsável pela geração de som no eslate (DOBRZYNSKI, 2010; KOLB et al., 2007; KHORRAMI et al., 2002), o tubo pode provocar alterações nas características aeroacústicas do eslate de um avião comercial. No presente trabalho, simulações foram feitas para avaliar o efeito do tubo do sistema anti-gelo no ruído gerado pelo eslate. Outros elementos como a cavidade e a cobertura não foram considerados nas simulações de forma que o efeito do tubo sozinho pode ser analisado.

A figura 26 mostra o detalhe da geometria simulada na região da cova do eslate bem como 


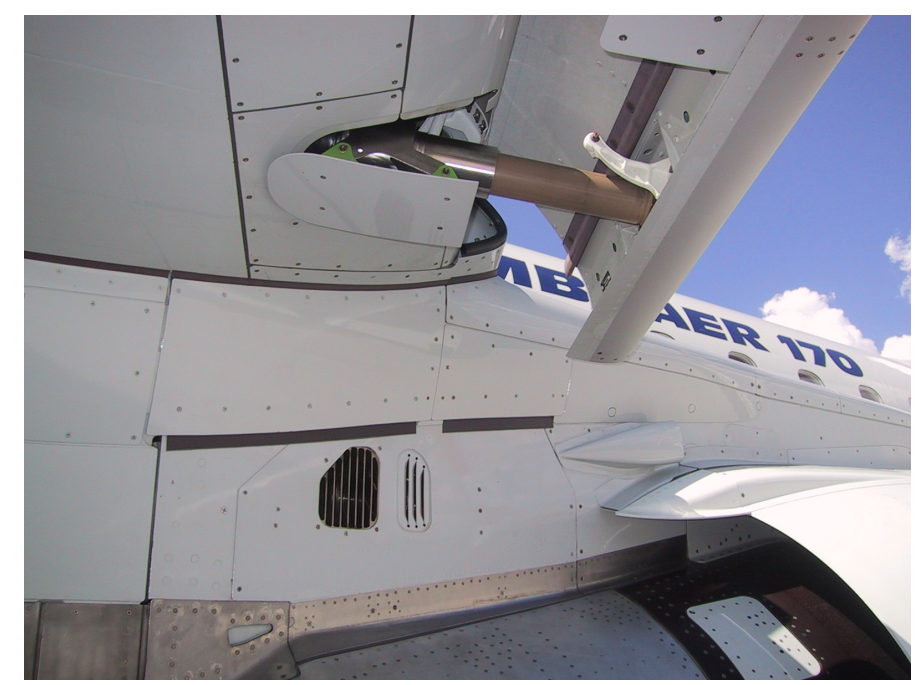

Figura 25 - Tubo do sistema anti-gelo atravessando a cavidade do eslate de uma aeronave EMBRAER-170.

a configuração da malha no plano central do tubo. Uma vez que condição de parede com livre escorregamento foi empregada em parte do eslate e no elemento principal, a malha utilizada baseou-se na configuração otimizada. Entretanto, para as simulações descritas nesta seção, a região de refinamento da cova do eslate foi modificada para que o escoamento seja bem resolvido na região do tubo. Assim como na malha de referência das demais simulações, a aresta do menor voxels foi de $0,2 \mathrm{~mm}$, o que corresponde uma $1 / 45$ do diâmetro do tubo.

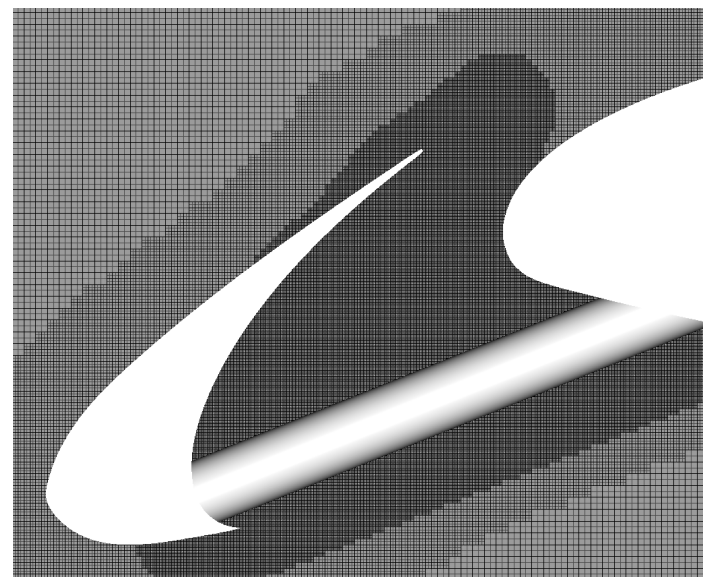

Figura 26 - Detalhe da malha e da geometria usada nas simulações do aerofólio com o tubo do sistema anti-gelo.

Duas configurações de escoamento foram simuladas com o tubo do sistema anti-gelo. A primeira tem condições idênticas às empregadas por Simões, Souza e Medeiros (2011) e nas simulações com o selo na parede da cova, ou seja, não leva em cosideração o enflechamento da asa. A segunda configuração corresponde ao caso com enflechamento de $35^{\circ}$ apresentado na 
seção 4.3. Nas duas configurações o aerofólio foi posicionado com um ângulo de ataque igual a $4^{\circ}$.

Três simulações foram feitas considerando o tubo do sistema anti-gelo, uma sem escoamento cruzado e duas com escoamento cruzado correspondendo a um enflechamento de $35^{\circ}$. Decidiu-se utilizar uma envergadura simulada maior nas simulações com um tubo para evitar que estruturas geradas pela interação da camada de mistura com o tubo voltassem a se chocar com o mesmo devido à condição de periodicidade. Portanto, a envergadura simulada no caso sem escoamento cruzado foi de $0,07617 \mathrm{~m}$, correspondendo a 384 voxels da região mais refinada na direção da envergadura. Essa extensão do domínio na direção z corresponde a um aumento de $50 \%$ em relação a $0,05078 m$ da extensão das demais simulações utilizando a malha de referência com menor voxel de $0,2 \mathrm{~mm}$ de aresta. Por sua vez, duas envergaduras simuladas diferentes foram empregadas no caso com enflechamento para avaliar a influência da condição de periodicidade na solução. No primeiro caso, assim como no caso sem enflechamento, a envergadura simulada foi de $0,07617 \mathrm{~m}$, enquanto o segundo caso apresentou uma extensão de $0,127 \mathrm{~m}$. A razão de aumento da envergadura simulada entre os dois casos com tubo e enflechamento é, então, de $67 \%$. 


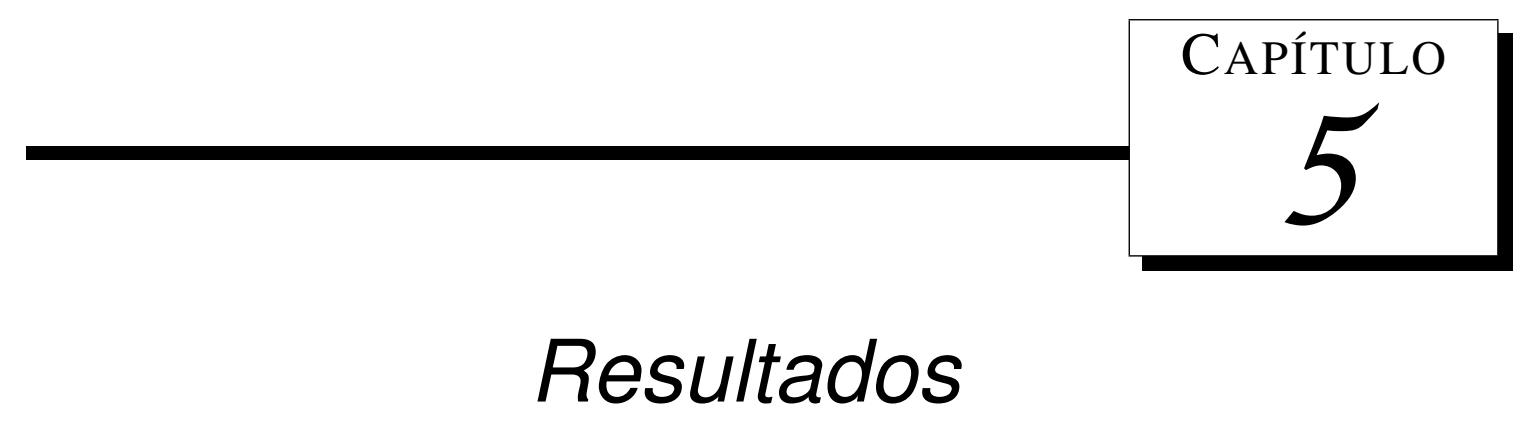

Médias temporais assim com valores instantâneos das propriedades do escoamento da cova do eslate nas diferentes configurações apresentadas no capítulo 4 foram analisadas, assim como espectros de flutuações tanto no campo próximo quanto no campo distante. As análises espectrais apresentadas neste trabalho se referem à Densidade de Potência Espectral (cuja sigla, PSD, vem do inglês, Power Spectral Density). Para calcular a PSD, utilizou-se o método de janelamento de Hanning com uma sobreposição de 50\% entre as janelas e resolução em frequência de $60 \mathrm{~Hz}$. Para evitar a interferência da condição de periodicidade na direção z, a região de integração usada para fazer o cálculo das flutuações acústicas no campo distante através da analogia de Ffowcs Williams-Hawkings (FW-H) foi sempre uma faixa centralizada em $z=0$ com a largura máxima igual à metade da envergadura simulada.

A figura 27 mostra pontos onde os espectros de flutuação do campo próximo foram calculados na maioria das análises discutidas neste trabalho. Os pontos de 1 a 6 são posicionados na superfície do elemento principal e eslate. Neles, espectros de flutuação de pressão foram calculados. Já os pontos afastados da superfície foram posicionados ao longo da camada de mistura e neles foram calculados espectros de flutuação de velocidade. Na figura, $S_{\max }$ representa o comprimento ao longo da camada de mistura a partir da cúspide até o recolamento. É importante ressaltar que, em todas as simulações, as posições dos pontos ao longo da camada de mistura não foram alteradas e consequentemente, estes podem estar ligeiramente afastados do centro da camada em alguns casos. Entretanto, testes que não estão apresentados aqui mostraram que esse deslocamento não causa variação significativa nos espectros calculados. A figura 28, por sua vez, mostra o sistema de referência da posição dos microfones considerados nos cálculos com a analogia de FW-H.

Mesmo com o emprego da camada anecóica, para minimizar a reflexão de ondas acústicas nos limites do domínio computacional, os primeiros instantes das simulações ainda apresentam 


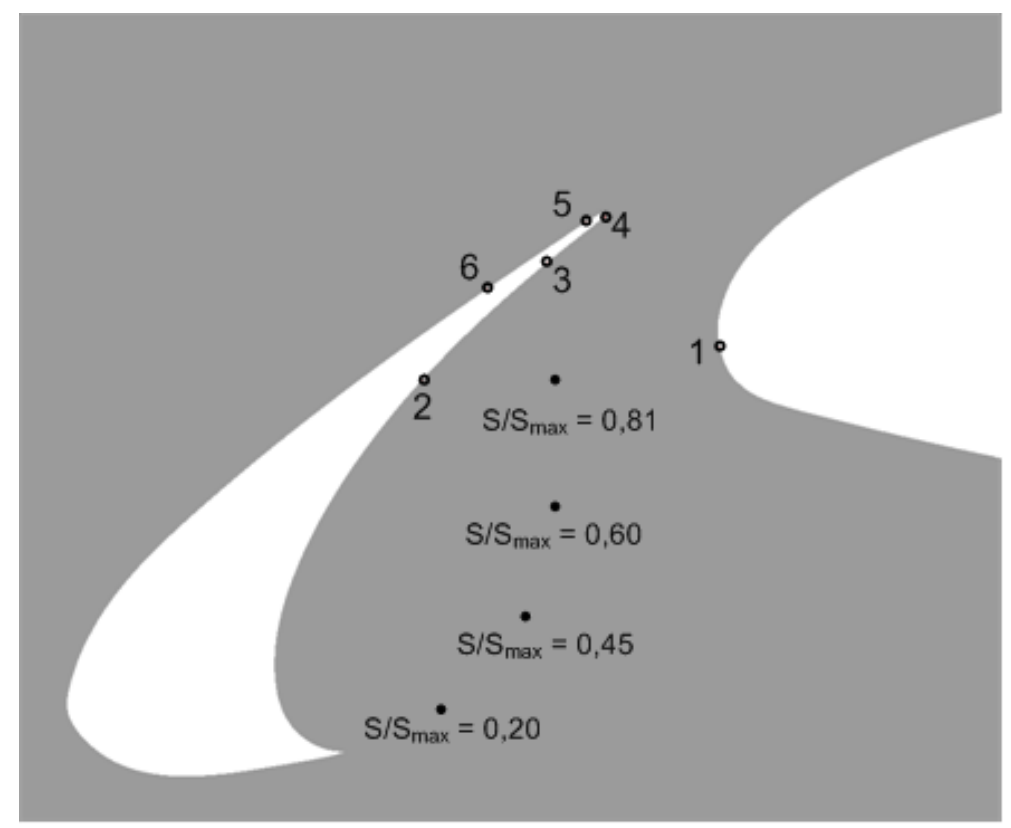

Figura 27 - Posições onde os espectros de flutuação de pressão e velocidade do campo próximo foram calculados.

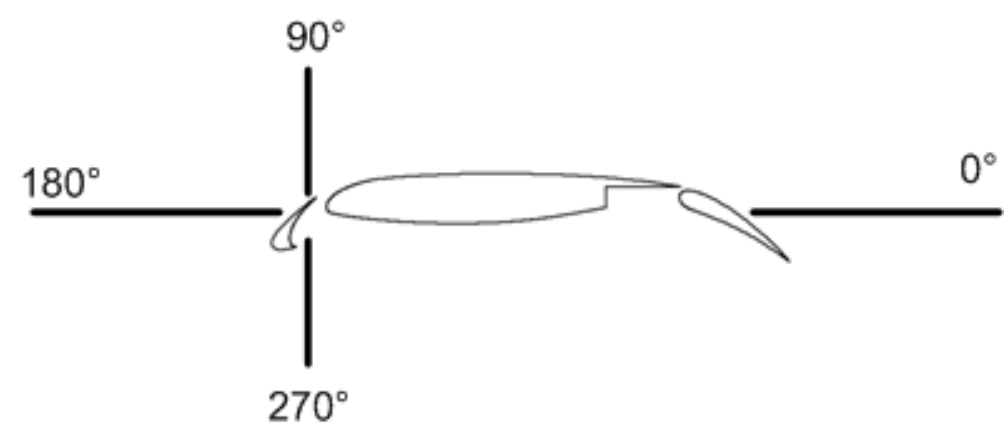

Figura 28 - Referência usada para descrever as posições correspondentes aos cálculos do som propagado. 
fenômenos não físicos que devem ser desconsiderados nas análises. A figura 29(a) mostra o histórico da força de arrasto típico das simulações realizadas, enquanto na figura 29(b) mostra o desvio padrão calculado a partir de uma média móvel de 350 amostras (uma amostra a cada 10 passos de tempo). Observa-se que rapidamente (a partir de $0,05 s$ ) o desvio padrão do arrasto já atinge valores comparáveis com o máximo até o final da simulação. Portanto, seguindo a metodologia empregada por Simões, Souza e Medeiros (2011), exceto se for explicitada outra forma, as análises das simulações desconsideram o intervalo inicial de $0,1 \mathrm{~s}$, tanto no cálculo das médias, quanto no cálculo dos espectros.

Baseado nos estudos de independência de malha apresentados por Simões, Souza e Medeiros (2011) e discutidos no capítulo 4, e no tempo amostral usado para calcular as densidades de potência espectral, a incerteza dos modelos empregados neste trabalho são estimados em $3 d B / H z$. Este valor está de acordo com as necessidades da indústria e maior precisão nos cálculos acarretaria um aumento do custo computacional.

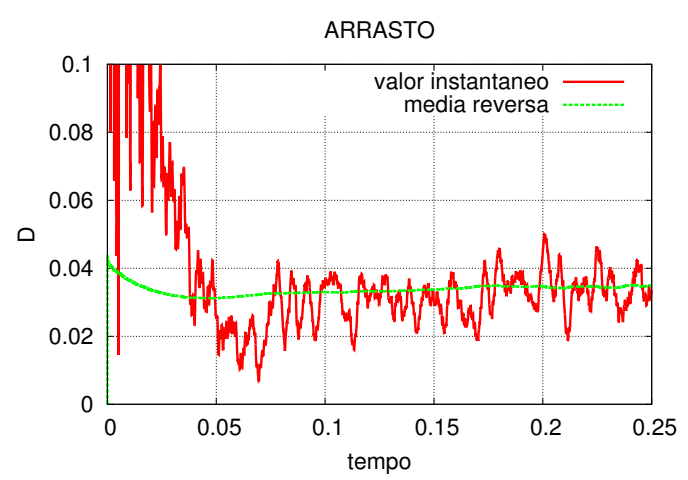

(a)

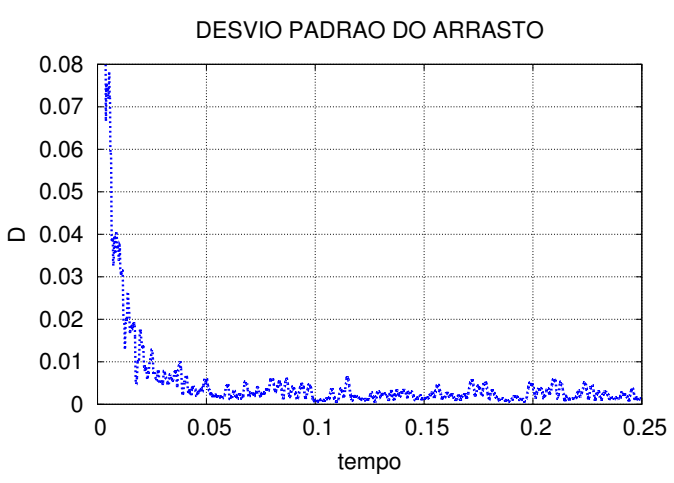

(b)

Figura 29 - Curvas de histórico e desvio padrão do arrasto do aerofólio.

Para avaliar a dependência dos espectros em relação ao intervalo descartado, cálculos com diferentes tamanhos desse intervalo foram comparados. Um caso típico é mostrado na figura 30. Na legenda, o número seguinte à letra "s" representa os centésimos de segundo descartados do início da simulação, e o número depois de "e" representa o instante final considerado em $10^{-2} s$. Observa-se que apenas alterações mínimas ocorrem nos espectros com a variação do intervalo descartado. 


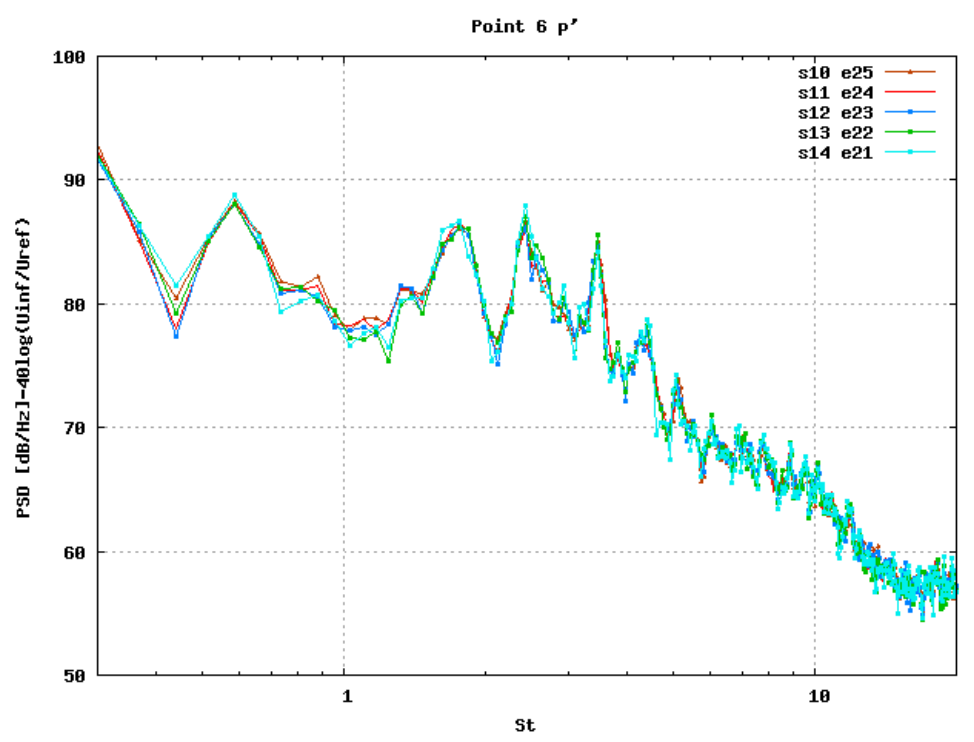

Figura 30 - Estudo de convergência de um espectro de flutuações do campo próximo em relação ao intervalo desconsiderado.

\subsection{Simulações com Escorregamento Livre Considerando a Espessura de Deslocamento}

Nesta seção, os resultados de três simulações são comparados. Uma das simulações considera parede sem escorregamento em todas as superfícies do aerofólio enquanto as outras duas adotam condição de parede com escorregamento livre nas superfícies do eslate e elemento principal. Das simulações com escorregamento livre, uma simula a geometria do aerofólio 30P30N modificada, para avaliar se a consideração da espessura de deslocamento resulta em uma solução aeroacústica mais próxima do caso de paredes sem escorregamento. Os resultados das simulações da geometria sem $\delta^{*}$ são os mesmos apresentados por Simões, Souza e Medeiros (2011). O caso em que todas as superfícies do aerofólio são consideradas como sem escorregamento foi simulado na malha de referência (Fig. 14), enquanto os dois casos com paredes com escorregamento livre no eslate e elemento principal foram calculados na malha otimizada (Fig. 15).

A figura 31 compara a distribuição de pressão no aerofólio a partir de resultados de quatro simulações, três transientes e uma em regime permanente. A simulação em regime permanente, representada pelos pontos vermelhos, foi feita utilizando o código híbrido MSES que resolve as equações de Euler na região de escoamento potencial e emprega uma correção para as camadas limite e esteiras. As simulações transientes foram feitas com o PowerFLOW, considerando escoamento completamente turbulento, mas com variações correspondendo a diferentes formas 
de considerar as camadas limite.

Embora os casos simulados no PowerFLOW que consideram paredes com escorregamento no elemento principal e no eslate não tenham camadas limite nesses dois elementos, a circulação calculada nesses casos ainda é consideravelmente menor que a calculada pelo MSES. Essa diferença pode ser consequência da separação da camada limite no extradorso do flap. O ponto de separação calculado na solução do PowerFLOW está consideravelmente a montante em comparação com a solução do MSES. Como o PowerFLOW considera o escoamento completamente turbulento, a camada limite calculada por este é substancialmente mais grossa, antecipando a separação da mesma em relação à solução do MSES que considera a transição da camada limite e portanto apresenta solução com camadas limites mais finas. Nos dois casos com paredes com escorregamento livre, a ausência da esteira do elemento principal antecipa ainda mais a separação da camada limite do flap.

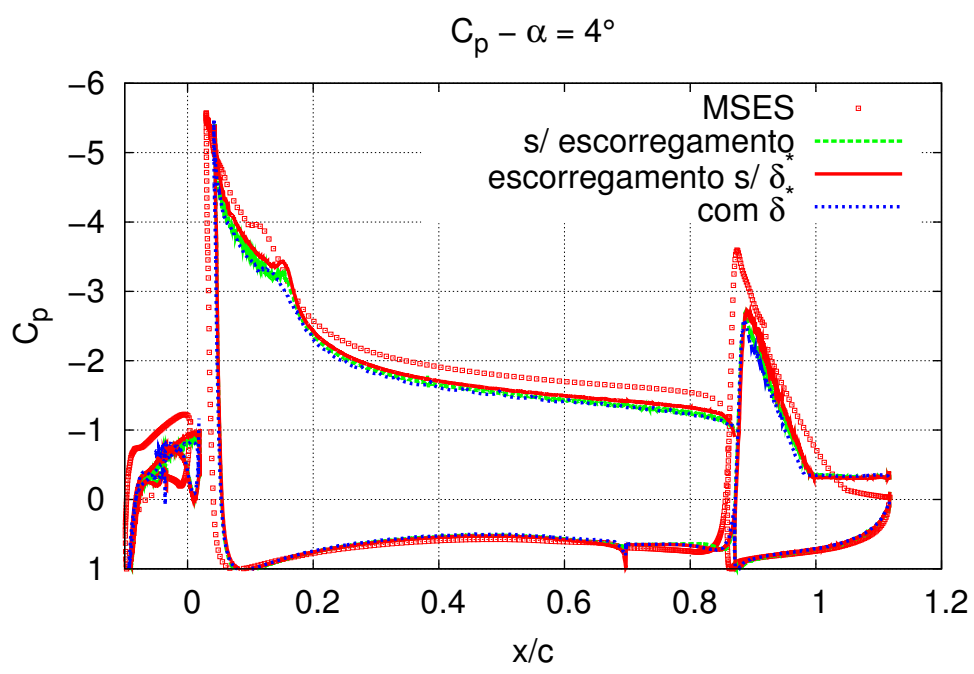

Figura 31 - Distribuição de pressão na superfície do aerofólio comparando a simulação sem escorregamento e com escorregamento livre, $\operatorname{com} \delta^{*}$ e sem $\delta^{*}$.

Entre os casos simulados pelo PowerFLOW, quando parede com escorregamento é adotada sem a modificação da geometria por $\delta^{*}$, ocorre um pequeno aumento na circulação dos elementos, que pode ser visto pelo aumento na sucção do extradorso dos três elementos. Com a modificação da geometria, observa-se um melhor colapso das curvas de $C_{p}$ entre os casos de parede com e sem escorregamento, ou seja, a curva azul está mais próxima da curva verde do que a curva vermelha de linha contínua. Ou seja, mesmo com as difereças na simulação entre PowerFLOW e MSES, o cálculo de $\delta^{*}$ pelo MSES permite uma melhoria significativa na concordância entre o caso com escorregamento e o caso sem escorregamento.

A média temporal da componente da vorticidade na direção da envergadura dos casos sim- 
ulados pelo PowerFLOW é mostrada na figura 32. Os valores, tomados em $z=0$, foram adimensionalizados pela corda do aerofólio e pela velocidade de entrada e são apresentados entre os limites de -200 a 200. Com excessão da ausência das camadas limite no elemento principal e na superfície do eslate externa à cova, nenhuma difereça significativa entre os casos é observada.

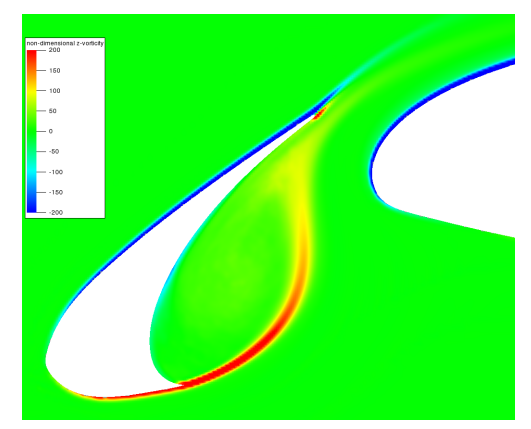

(a) Sem escorregamento

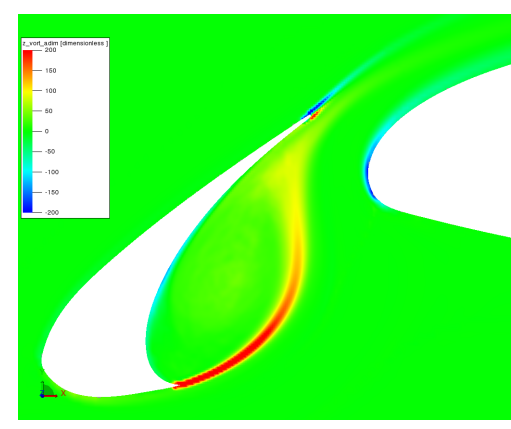

(b) Escorregamento livre, sem $\delta^{*}$

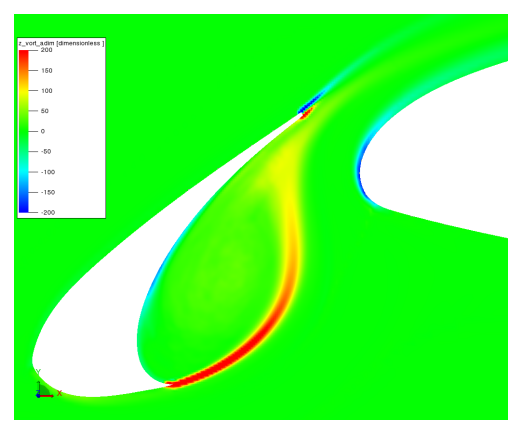

(c) Escorregamento livre, $\operatorname{com} \delta^{*}$

Figura 32 - Campo da componente em z da vorticidade na região do eslate.

A energia cinética turbulenta (TKE) calculada a partir das flutuações resolvidas $\left(0,5\left(\left\langle u^{\prime} u^{\prime}\right\rangle+\right.\right.$ $\left.\left.\left\langle v^{\prime} v^{\prime}\right\rangle+\left\langle w^{\prime} w^{\prime}\right\rangle\right) / U_{\infty}^{2}\right)$ são mostradas na figura 33. A condição de parede com escorregamento livre diminui a energia nas proximidades do ponto de recolamento, como pode ser visto pela comparação entre as figuras 33(a) e 33(b). Com a modificação da geometria por $\delta^{*}$ no caso com escorregamento livre, a TKE nessa região se aproxima mais da solução com paredes sem escorregamento.

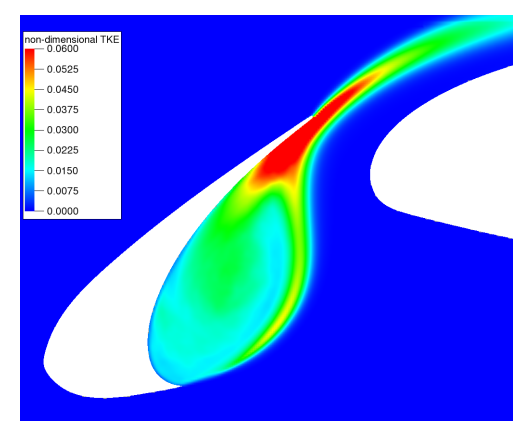

(a) Sem escorregamento

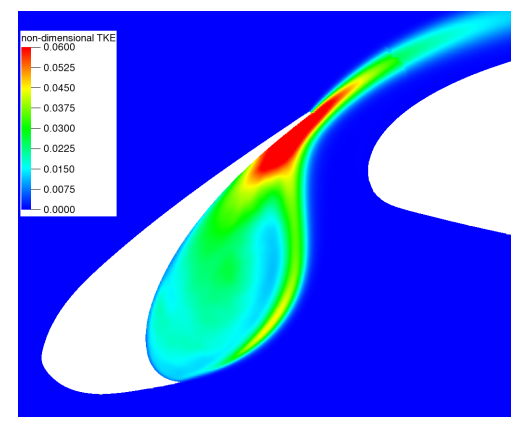

(b) Escorregamento livre, sem $\delta^{*}$

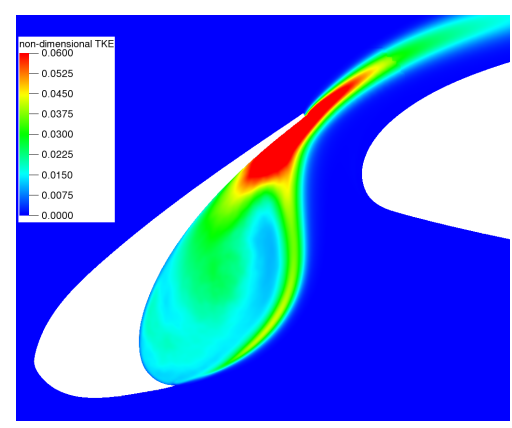

(c) Escorregamento livre, $\operatorname{com} \delta^{*}$

Figura 33 - Campo de energia cinética turbulenta com diferentes condições de parede.

A densidade de potência espectral das flutuações da componente de velocidade na direção $\mathrm{x}$ foi calculada em quatro pontos ao longo da camada de mistura. Os espectros de três desses pontos estão mostrados na figura 34, comparando-se os três casos simulados no PowerFLOW. A potência espectral é apresentada em função da frequência adimensionalizada, $S t=f c_{S} / U_{\infty}$. 
Tipicamente, os espectros apresentam uma região de flutuações intensas (entre $S t \approx 5$ e $S t \approx 11$ em $\left.S / S_{\max }=0,45\right)$, referente ao crescimento de perturbações na camada de mistura. A faixa de frequência em que essa região ocorre diminui à medida em que se avança na camada de mistura em direção ao recolamento.

Analisando os gráficos da figura, vê-se que no ponto $S / S_{\max }=0,45$ a consideração da espessura de deslocamento aproxima a solução com escorregamento livre da solução com paredes sem escorregamento. Entretanto, o contrário ocorre no ponto $S / S_{\max }=0,60$. Nesse ponto, a modificação na geometria afasta ainda mais as curvas do espectro de flutuações de velocidade, apresentando, inclusive, uma modificação visível da frequência típica das perturbações amplificadas. Porém é importante notar que a consideração de $\delta^{*}$ não causa alteração significativa no espectro de $u^{\prime}$ próximo ao ponto de recolamento $\left(S / S_{\max }=0,81\right)$, ponto este tomado por vários autores como extremamente relevante na geração de ruído areacústico (IMAMURA et al., 2008; CHOUDHARI; KHORRAMI, 2007).

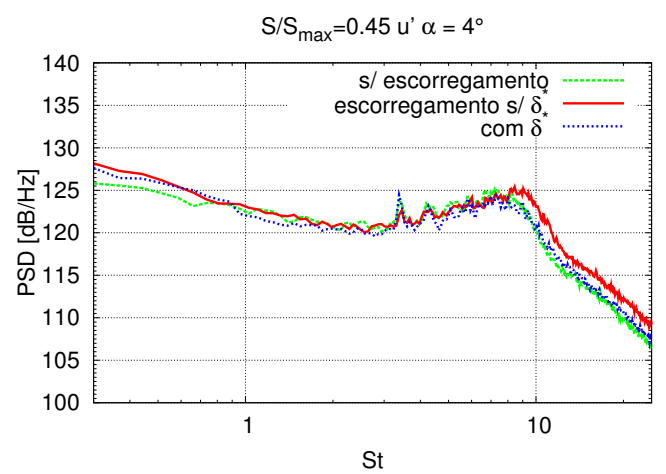

(a) $S / S_{\max }=0,45$

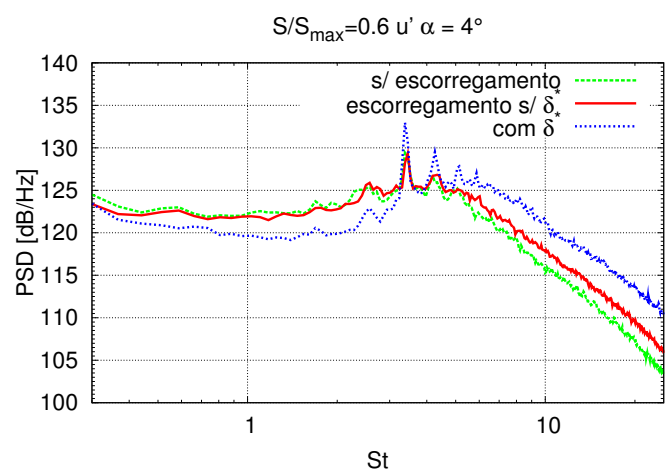

(b) $S / S_{\max }=0,60$

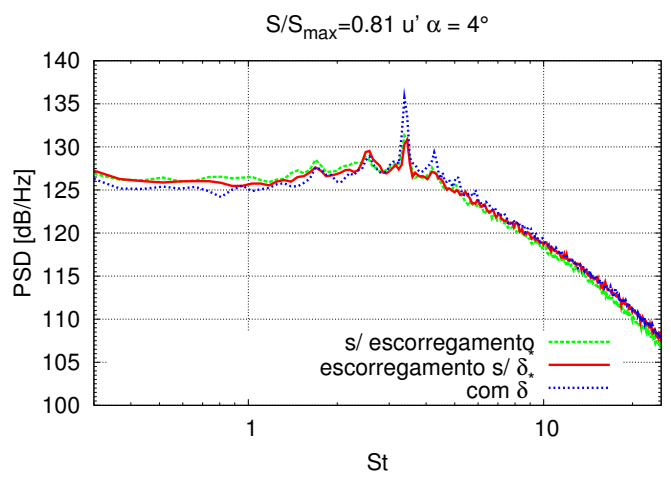

(c) $S / S_{\max }=0,81$

Figura 34 - Densidade de potência espectral das flutuações da componente de velocidade $u$ em pontos da camada de mistura.

A figura 35 compara os espectros de flutuação de pressão em dois pontos no eslate. No espectro do ponto 4 observa-se uma degradação na comparação com o cálculo com paredes sem 
escorregamento quando se considera o efeito da espessura de deslocamento. Essa discrepância pode estar relacionada com a alteração da espessura efetiva do bordo de fuga do eslate. Mesmo que a malha utilizada nessa região não seja capaz de resolver o desprendimento de vórtices no bordo de fuga, a alteração na sua espessura é suficiente para modificar a dinâmica do escoamento nesse ponto.

Na comparação do ponto 6, embora a diferença entre os dois casos sem alteração da geometria seja pequena, é possível observar uma melhora da solução com parede com escorregamento livre quando a geometria é modificada. O nível da maioria dos picos tonais se aproxima do valor calculado pelo modelo de paredes sem escorregamento. Além disso, há uma melhora no cálculo das flutuações com frequência acima de $S t=10$. Porém o pico tonal em $S t \approx 3,3$ é superestimado nesse caso. O aumento nesse pico é observado no espectro de todos os pontos da superfície do aerofólio onde o espectro de flutuações de pressão foi calculado.

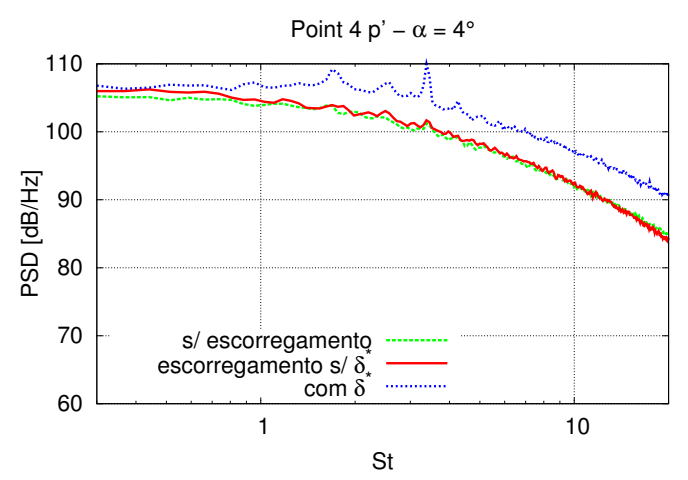

(a) Ponto 4

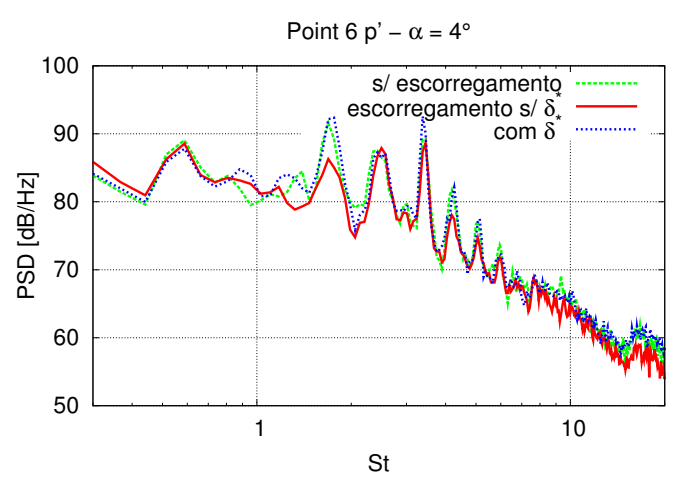

(b) Ponto 6

Figura 35 - Densidade de potência espectral das flutuações de pressão em dois pontos na superfície do eslate.

O efeito da modificação na geometria no som propagado a partir da região do eslate é mostrado na figura 36. O cálculo do ruído propagado para dois pontos sob o aerofólio foi feito por um algoritmo Ffowcs Williams-Hawkings baseado na formulação descrita na seção 3.3.3. Os dois pontos estão localizados em uma circunferência de raio igual a 10 vezes a corda do aerofólio quando eslate e flap estão recolhidos. A posição angular dos pontos se refere à nomeclatura apresentada na figura 28.

Embora o espectro do ponto 4, tenha mostrado uma grande diferença no caso com $\delta^{*}$, esse erro não é propagado para o campo acústico distante. Assim como foi observado no espectro de flutuações da pressão no ponto 6, no ruído propagado a modificação da geometria pela espessura de deslocamento melhora a solução da maioria dos picos tonais entre $S t=1$ e $S t=5$. O pico em $S t=3,3$, entretanto, é superestimado. Na região acima de $S t=10$, a energia calculada no 
ponto a $300^{\circ}$ é maior na simulação com a geometria modificada em comparação com as demais.

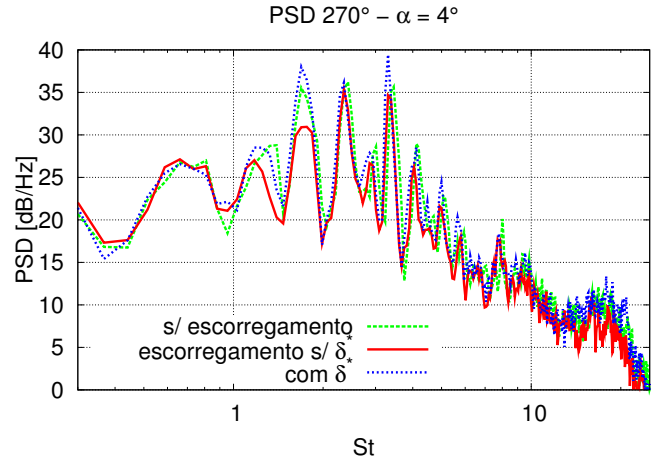

(a) $270^{\circ}$

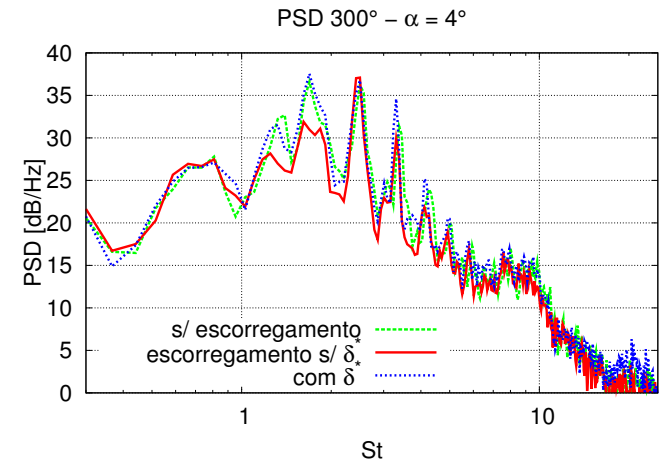

(b) $300^{\circ}$

Figura 36 - Densidade de potência espectral da flutuação de pressão em pontos distantes do aerofólio calculdas a partir da analogia de Ffowcs Williams-Hawkings.

Os resultados apresentados mostram uma ligeira melhora causada pela modificação da geometria por $\delta^{*}$ na precisão do cálculo do ruído aeroacústico de eslate a partir de simulações considerando parede com escorregamento livre. Entretanto, não é possível afirmar em definitivo que a metodologia é capaz de melhorar a solução aeroacústica, uma vez que, no caso estudado, as diferenças no espectro de ruído entre as soluções sem escorregamento e com escorregamento sem $\delta^{*}$ estão dentro da incerteza estatística do modelo. Portanto um teste semelhante deve ser feito com o aerofólio em um ângulo de ataque mais elevado, de modo que a simples consideração de paredes com escoreegamento não seja capaz de resolver com precisão o ruído aeroacústico.

\subsection{Efeito Aeroacústico de um Selo Posicionado no Intradorso do Eslate}

Cinco simulaçõesconsiderando paredes com escorregamento livre no eslate e elemento principal foram feitas para avaliar o efeito de um selo posicionado na cova do eslate na geração e propagação de ruído aeroacústico. Primeiramente o efeito da altura do selo foi analisado através da comparação entre três casos com diferentes alturas e o caso sem o selo apresentado por Simões, Souza e Medeiros (2011). O efeito da posição do selo foi estudado em seguida, comparando três configuraçõesdiferentes com o selo, além da geometria sem o selo. Tanto propriedades do campo próximo quanto o espectro do som propagado a partir do eslate foram analisados. Como os casos com selo estudados nesta seção são muito semehantes ao caso estudado por Simões, Souza e Medeiros (2011), a escolha da malha utilizada se baseou nos estudos 
apresentados por estes e discutidos brevemente no capítulo 4. Portanto, a configuração de malha otimizada mostrada na figura 15 foi utilizada.

\subsubsection{Efeito do Tamanho do Selo}

Com o selo posicionado a uma distância do bordo de fuga igual a duas vezes a distância entre este e o ponto de recolamento, três alturas foram simuladas. A média temporal da distribuição do coeficiente de pressão ao longo da superfície do aerofólio inteiro e, em detalhe, no eslate, é mostrada na figura 37 para as três alturas do selo e para a geomeria sem o selo. Os valores são tomados em uma fatia central da envergadura simulada. Observa-se um variação na distribuição da região da cova do eslate. Entretanto esta variação não é suficiente para alterar a distribuição no restante do aerofólio. Assumindo-se que o ponto médio de recolamento da camada de mistura é o local no intradorso do eslate onde o $C_{p}$ atinge um máximo local, é possível observar na figura 37(b) que, no caso $h=12 \delta_{T E}$ o ponto de recolamento está ligeiramente mais distante do bordo de fuga do eslate em relação aos outros casos.

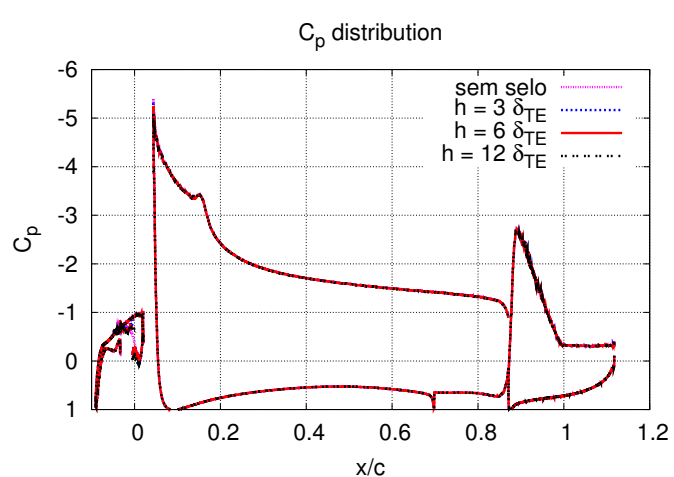

(a) Aerofólio

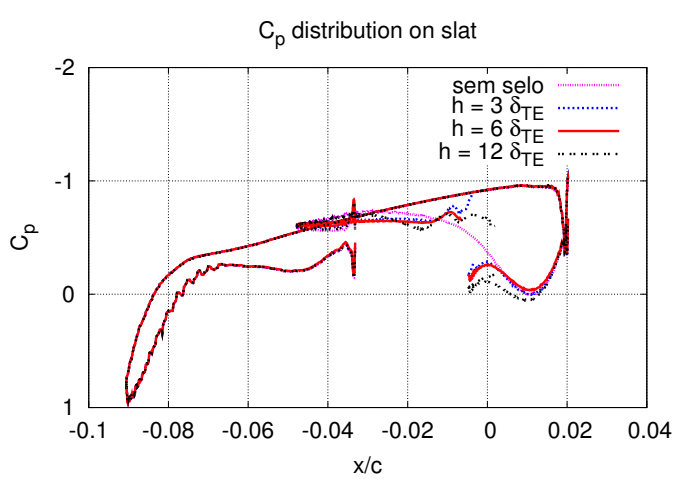

(b) Eslate

Figura 37 - Distribuição de pressão na superfície do aerofólio com um selo no eslate com diferentes alturas.

A figura 38 mostra as linhas de corrente dentro da cova do eslate. As linhas de corrente são baseadas na média temporal do escoamento em $z=0$. Embora selos com alturas razoavelmente distintas tenham sido simulados, o padrão de escomento na cova não se altera significativamente entre os casos com o selo. Após o recolamento da camada de mistura na parede da cova, parte do escoamento é bombeado através da folga entre o eslate e o elemento principal, e uma parte é direcionada para dentro da região de recirculação, se chocando com o selo. Atrás do selo, uma outra região de recirculação pequena se forma, girando em sentido contrário à recirculação principal. Porém observa-se que nos casos com selo de altura $h=3 \delta_{T E}$ e $h=6 \delta_{T E}$ o centro da recirculação na cova é alterado e fica mais próximo do ponto de recolamento em comparação 
com o caso sem o selo. O mesmo não se observa no caso com o selo de altura $h=12 \delta_{T E}$. Podese notar, também através das linhas de corrente, que a distância entre o ponto de recolamento da camada de mistura e o bordo de fuga do eslate é ligeiramente maior no caso com o maior selo.

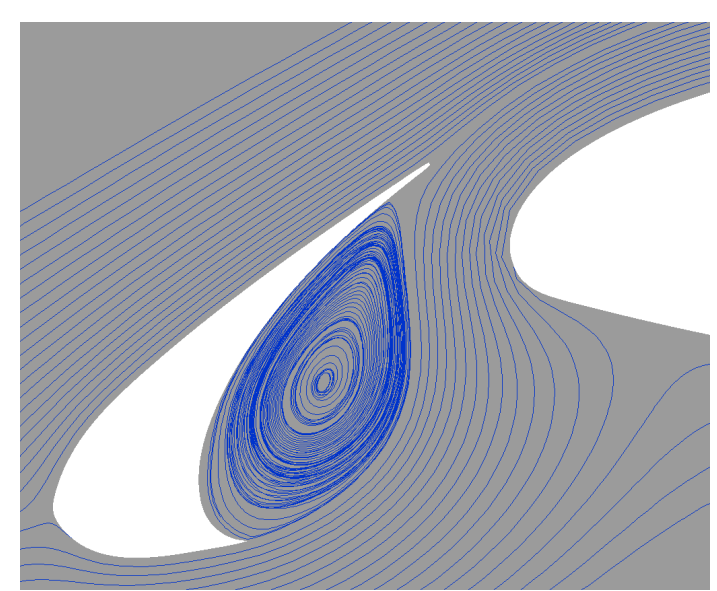

(a) Sem selo

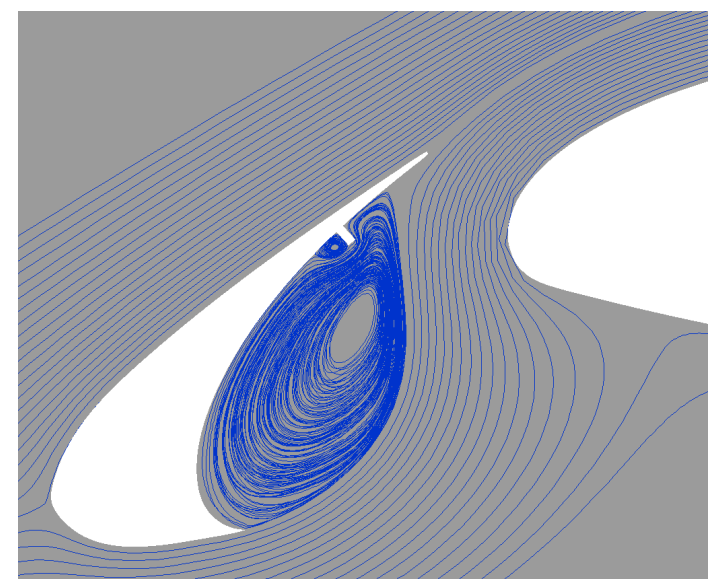

(c) $h=6 \delta_{T E}$

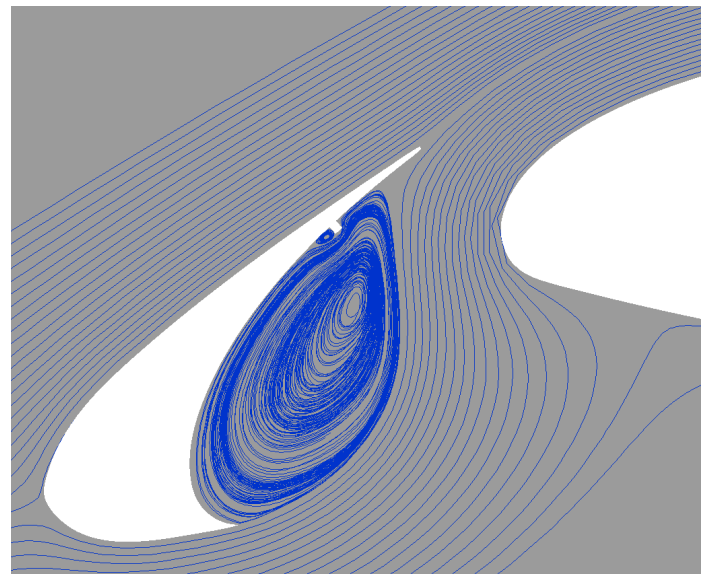

(b) $h=3 \delta_{T E}$

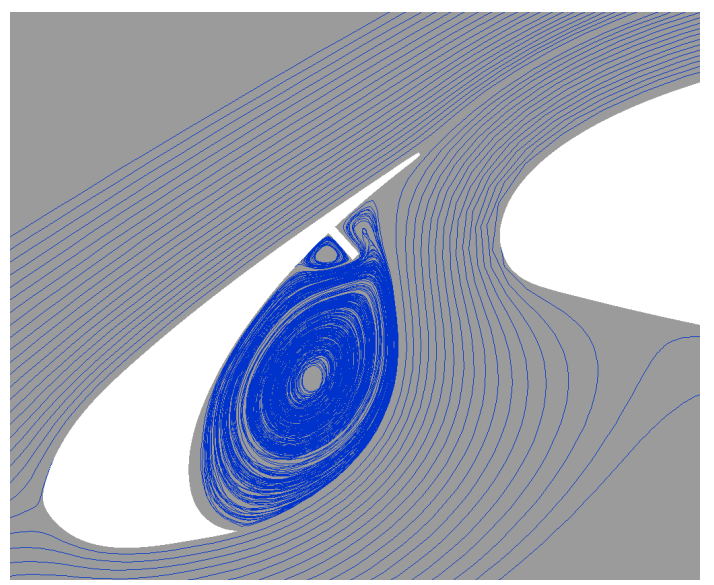

(d) $h=12 \delta_{T E}$

Figura 38 - Linhas de corrente na região da cova do eslate em geometrias com selo de diferentes alturas.

A média temporal da energia cinética turbulenta foi calculada e os contornos na região do eslate estão mostrados na figura 39 para uma faixa central da envergadura. O valor da energia é adimensionalizado por $U_{\infty}^{2}$. A energia cinética turbulenta calculada através do modelo de turbulência k- $\varepsilon$ não é considerado nos cálculos. Portanto somente as flutuaçõesresolvidas estão representadas na figura.

Observa-se que a presença do selo diminui substancialmente a intensidade das flutuaçõesna região de recirculação dentro da cova. Uma vez que o selo está posicionado dentro da região de recirculação, próximo ao recolamento, é possível que este sirva como uma barreira para as estruturas vorticais que são formadas na camada cisalhante livre. O selo com altura igual a 6 
vezes a espessura do bordo de fuga provoca uma redução maior da TKE na cova do que o selo com altura de $3 \delta_{T E}$. Entretanto essa tendência não é confirmada pelo resultado do caso $h=$ $12 \delta_{T E}$. Parece que, como o selo está muito próximo da camada de mistura, a sua extremidade livre interage com a camada antes desta se chocar com a parede da cova e direciona alguns vórtices para dentro da região de recirculação. Essa interação prematura é mais efetiva no caso com o selo maior.

À medida que os vórtices formados na camada de mistura se aproximam do recolamento, estes são distorcidos, aumentando a energia cinética turbulenta nesta região. Esse fato é observado nos quatro casos como mostra a figura 39. Nos casos $h=3 \delta_{T E}$ e $h=6 \delta_{T E}$ vê-se que o selo intensifica esse aumento das flutuaçõesem comparação com o caso sem o selo, enquanto o caso com o selo maior parece apenas modificar o formato da região de maior energia. Esse comportamento parece estar relacionado com a interação das estruturas da camada de mistura com estruturas com componente de vorticidade em $\mathrm{z}\left(\omega_{z}\right)$ negativa que se formam a partir da aresta do selo. Como mostra a figura 40, essa interação ocorre próximo ao ponto de recolamento nos dois casos com os menores selos. No caso com o selo maior, as estruturas com $\omega_{z}$ negativa tendem a circular pela cova se chocando com a camada de mistura na região próxima à cúspide. No caso sem selo, há uma interação entre as estruturas com $\omega_{z}<0$ e a camada de mistura de forma semelhante ao que ocorre no caso $h=12 \delta_{T E}$. Esse comportamento está de acordo com a observação de que há uma variação no centro de recirculação médio nos dois casos com os selos menores (Fig. 38).

A figura 41 mostra a PSD da componente de velocidade em $\mathrm{x}$ em dois pontos da camada de mistura. No ponto $S / S_{\max }=0,20$, próximo à cúspide, o espectro indica um nível mais baixo de flutuaçõesde banda larga nas geometrias com selo, principalmente nos casos com selo de altura igual a $3 \delta_{T E}$ e $6 \delta_{T E}$. Entretanto, esses casos apresentam intensos picos tonais ao longo do espectro. Embora os espectros dos dois casos com os menores selos tenham níveis de energia significativamente menores em quase todo o espectro, o pico em $S t=10$ apresenta praticamente a mesma intensidade nos quantro casos comparados. Esse pico é observado ao longo da camada de mistura e se desloca gradativamente para frequências menores à medida que a camada se torna mais espessa.

Seguindo com a comparação entre os espectros de $u^{\prime}$ dos quatro casos ao longo da camada de mistura, observa-se que a diferença no nível de flutuaçõesde banda larga diminui gradativamente, porém os picos tonais dos casos com selo permanecem. Esse fato pode ser observado na figura 41(b). Na faixa de frequência que contém os picos, as curvas dos casos $3 \delta_{T E}$ e $6 \delta_{T E}$ apresentam flutuaçõesmais intensas, enquanto nas frequências acima de $S t=5$, as quatro curvas 


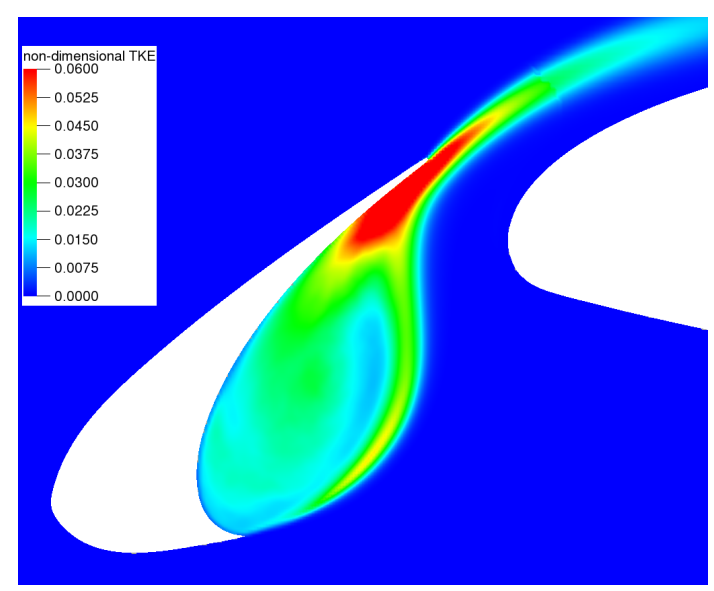

(a) Sem selo

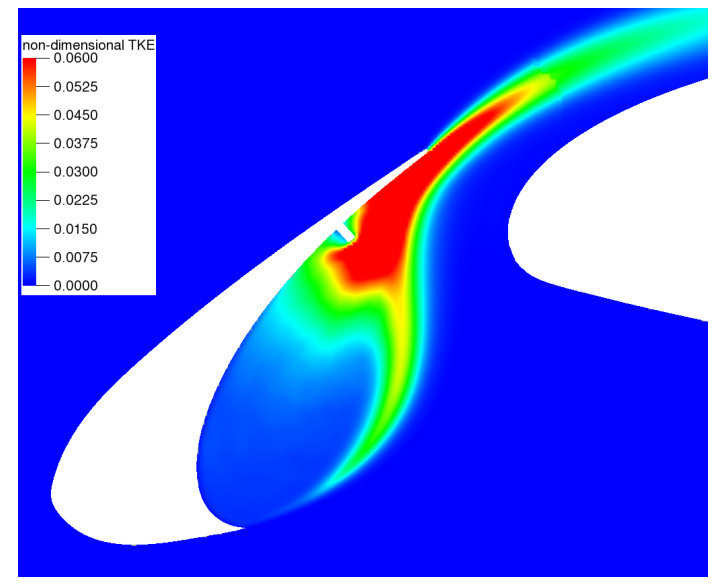

(c) $h=6 \delta_{T E}$

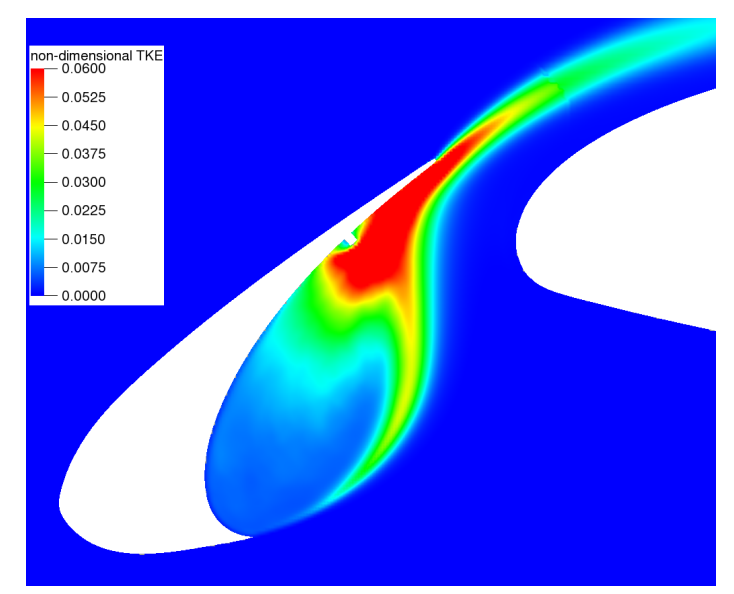

(b) $h=3 \delta_{T E}$

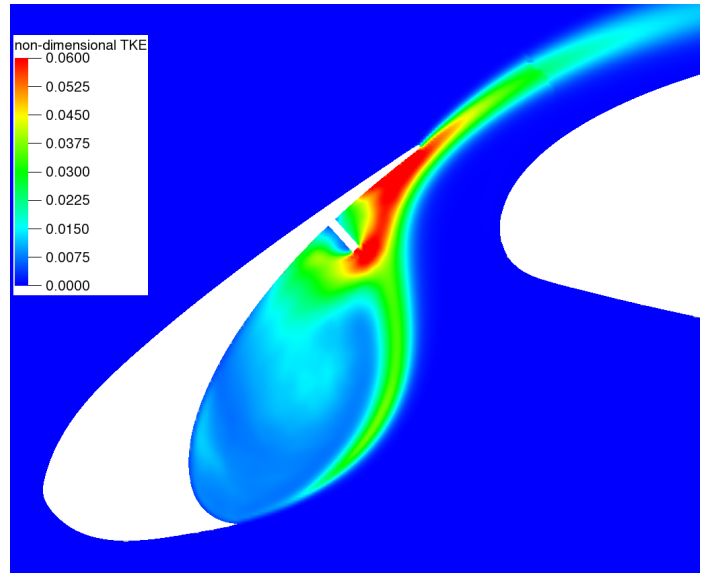

(d) $h=12 \delta_{T E}$

Figura 39 - Campo médio da energia cinética turbulenta a partir das flutuaçõescom três alturas diferentes do selo bem como da geometria sem o selo.

colapsam razoavelmente.

Na figura 42, superfícies marcando posiçõesonde o parâmetro $\lambda_{2}$ tem valor igual -10000 são mostradas em um instante de tempo para os quatro casos. $\lambda_{2}$ representa o autovalor intermediário da matriz dada por $\mathbf{S}^{2}+\Omega^{2}$, sendo $\mathbf{S}$ o tensor da taxa de deformação e $\Omega$ a parte anti-simétrica do tensor de gradiente de velocidade. Regiões onde $\lambda_{2}$ é negativo corresponde ao núcleo de vórtices. Pode-se observar que a região da cova do eslate, próxima à cúspide, contém menos estruturas vorticais nos casos com o selo. Por sua vez, comparando apenas os casos com o selo, a geometria com o maior selo resulta em um maior número de estruturas nessa região, conforme foi observado na figura 39. Observa-se também que, nos casos com selo, as estrutras se mantêm coerentes por um percurso mais longo na camada de mistura, mas em seguida ocorrem emparelhamentos e tridimesinalização dos vórtices e as estrutras são deformadas, de forma que, próximo ao recolamento, os quatro casos apresentam uma configaração comparável. 


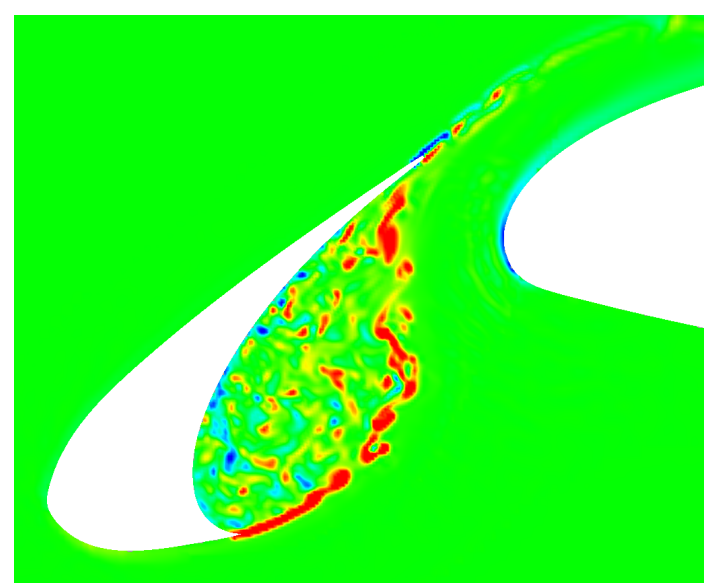

(a) Sem selo

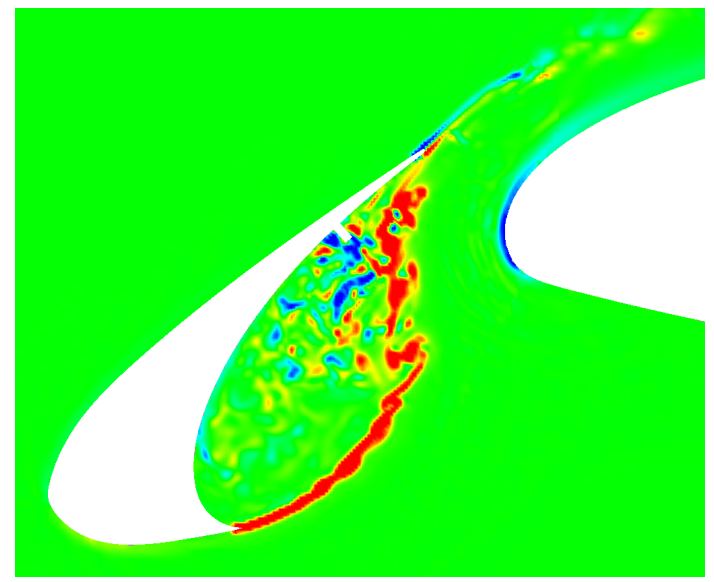

(c) $h=6 \delta_{T E}$

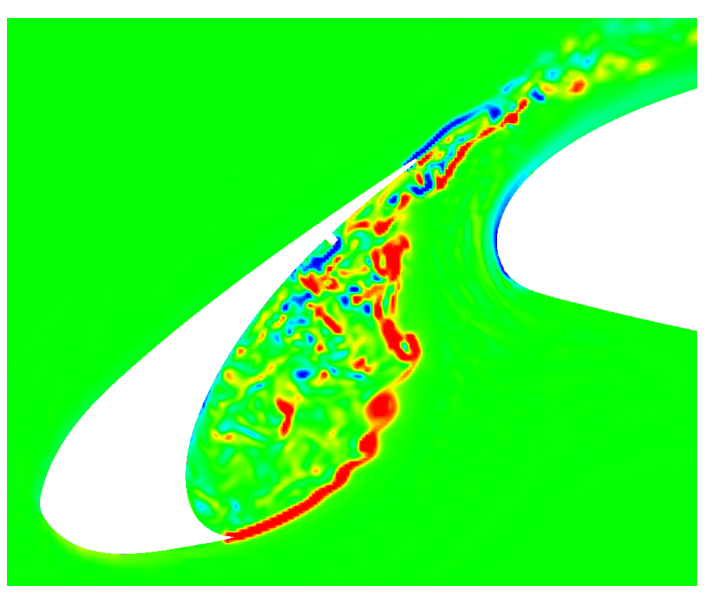

(b) $h=3 \delta_{T E}$

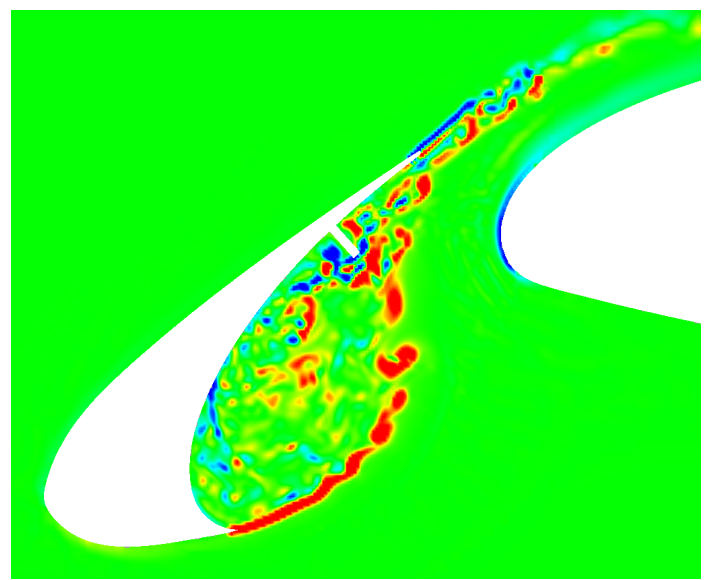

(d) $h=12 \delta_{T E}$

Figura 40 - Campo instantâneo da componente em z da vorticidade com três alturas diferentes do selo.

A densidade de potência espectral das flutuaçõesde pressão em dois pontos na superfície do eslate é mostrada na figura 43. No ponto 3, posicionado no ponto de recolamento da camada de mistura, vê-se que, de forma semelhante ao espectro de $u^{\prime}$ em $S / S_{\max }=0,81$, os casos $h=3 \delta_{T E}$ e $h=6 \delta_{T E}$ apresentam flutuaçõesmais intensas abaixo de $S t=5$. Entretanto, embora o espectro do caso sem o selo se nivele ao destes dois nas frequências mais elevadas, o caso $h=12 \delta_{T E}$ mantém o nível menor ao longo de todo o espectro. Como visto no campo de energia cinética turbulenta, esse caso apresenta um menor intensidade de flutuações.

No ponto 6, não há estrutras vorticas como as percebidas pelos ponto dentro da cova (pontos 2 a 4), e a resolução da malha não é suficiente para resolver as perturbaçõesamplificadas da camada limite. Portanto a oscilação de pressão desse ponto provém basicamente das flutuaçõesacústicas propagadas a partir do eslate e da oscilação na circulação dos elementos do aerofólio. Novamente os dois casos com selo menor apresentam flutuaçõesmais intensas nas 


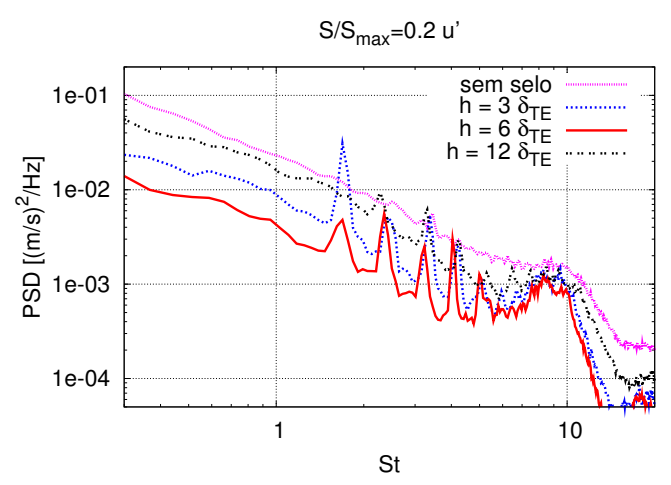

(a) $S / S_{\max }=0,20$

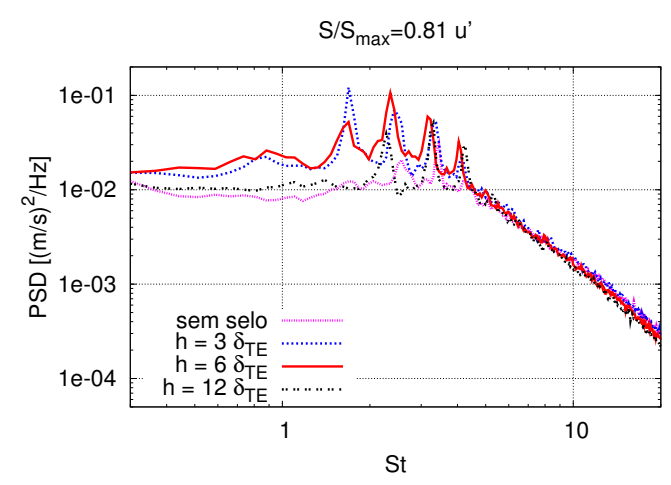

(b) $S / S_{\max }=0,81$

Figura 41 - Espectros das flutuaçõesde u em dois pontos da camada de mistura. Comparação entre selos com três alturas bem como a geometria sem selo.

freqências abaixo de $S t=5$. Entretanto, a diferença entre esses casos e os outros dois é muito pequena nas frequências mais altas.

Na figura 44, o espectro de flutuação de pressão calculado para um ponto distante do aerofólio a partir da analogia de Ffowcs Williams-Hawkings é mostrado. O cálculo foi feito para um observador posicionado a uma distância igual a dez vezes a corda do aerofólio a $290^{\circ}$, de acordo com o sistema mostrado na figura 28. Confirmando o que havia sido observado nas flutuaçõesdo ponto 6 , os casos sem selo e com o maior selo apresentam níveis compatíveis ao longo do espectro. Os casos $h=3 \delta_{T E}$ e $h=6 \delta_{T E}$, por sua vez, apresentam maior nível de ruído abaixo de $S t=5$ e alguns picos tonais substancialmente mais salientes.

Conclui-se que o selo pode funcionar como uma barreira para os vórtices da camada de mistura, reduzindo a turbulência dentro da região de recirculação e consequentemente as flutuaçõesde banda larga na região da camada de mistura próxima à cúspide. Porém esse efeito não reduz o ruído aeroacústico no campo distante. Além disso, os picos tonais do ruído são intensificados, pois as estruturas da camada de mistura se tornam mais coerentes com a presença do selo. Um selo muito grande, por sua vez, mostrou uma menor capacidade de bloquear os vórtices e apresenta características de ruído semelhante às da geometria sem selo. Os resultados indicam que a diferença do efeito do selo na região de recirculação parece estar ligada à posição onde este interage com os vórtices da camada de mistura. 


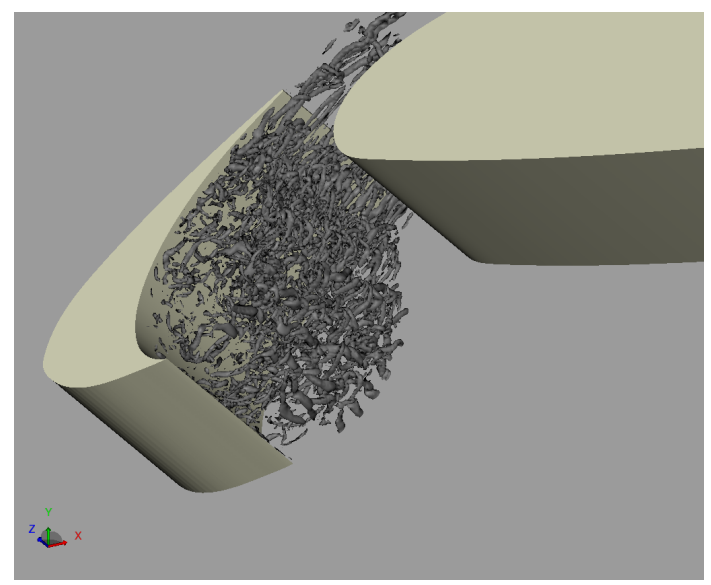

(a) Sem selo

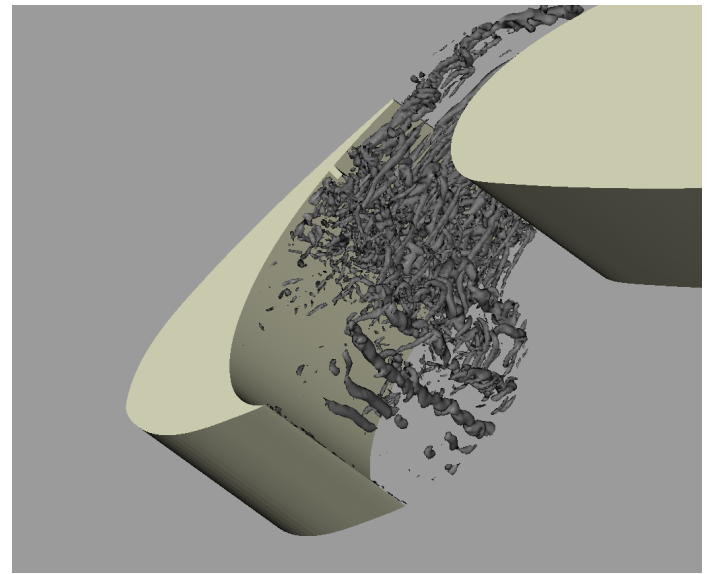

(c) $h=6 \delta_{T E}$

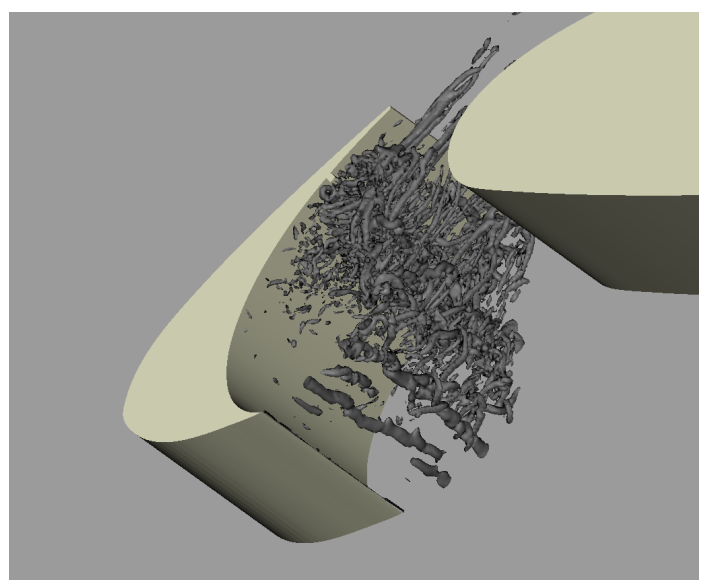

(b) $h=3 \delta_{T E}$

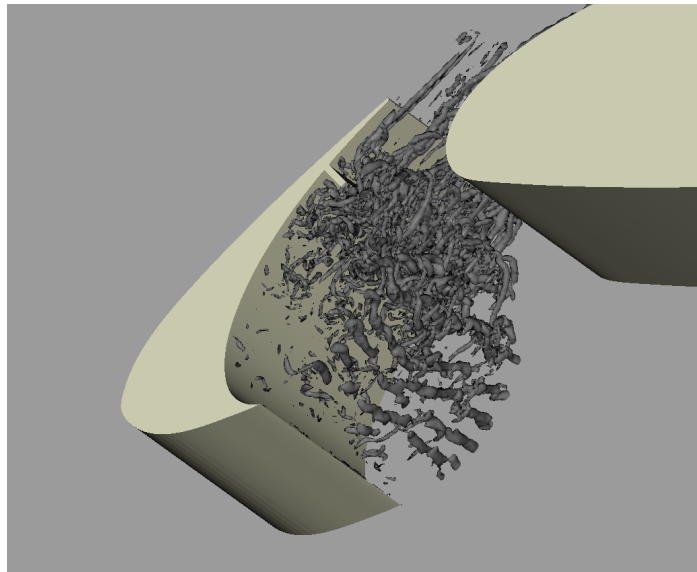

(d) $h=12 \delta_{T E}$

Figura 42 - Iso-superfície de $\lambda_{2}=-10000$ na região da cova do eslate. Geometria com selos de diferentes alturas bem como geometria sem selo.

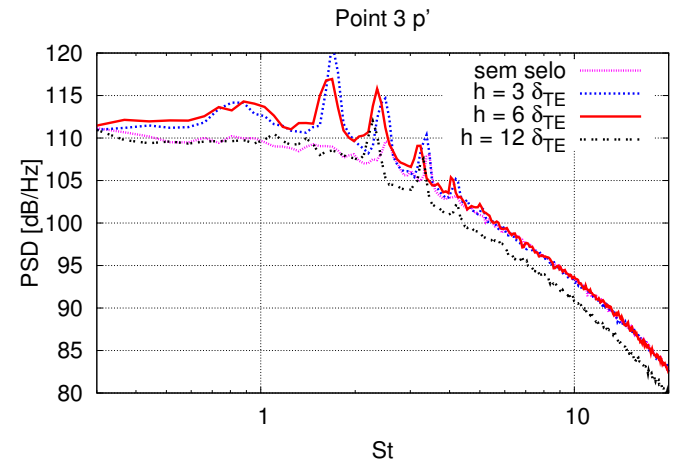

(a) Ponto 3

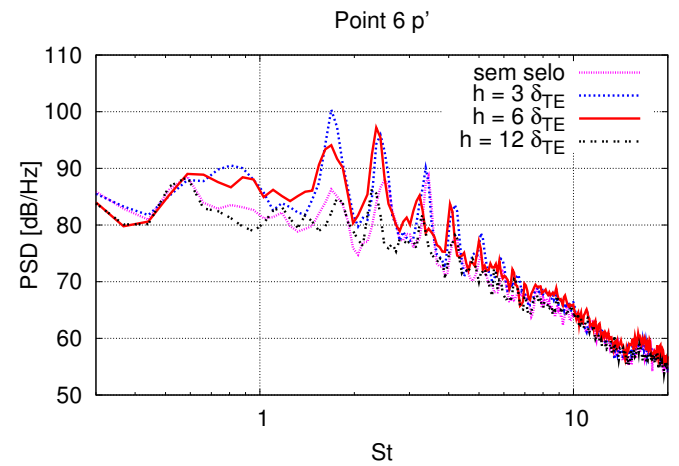

(b) Ponto 6

Figura 43 - Espectros das flutuaçõesde p em dois pontos da superfície do eslate. Comparação entre selos com três alturas bem como a geometria sem selo. 


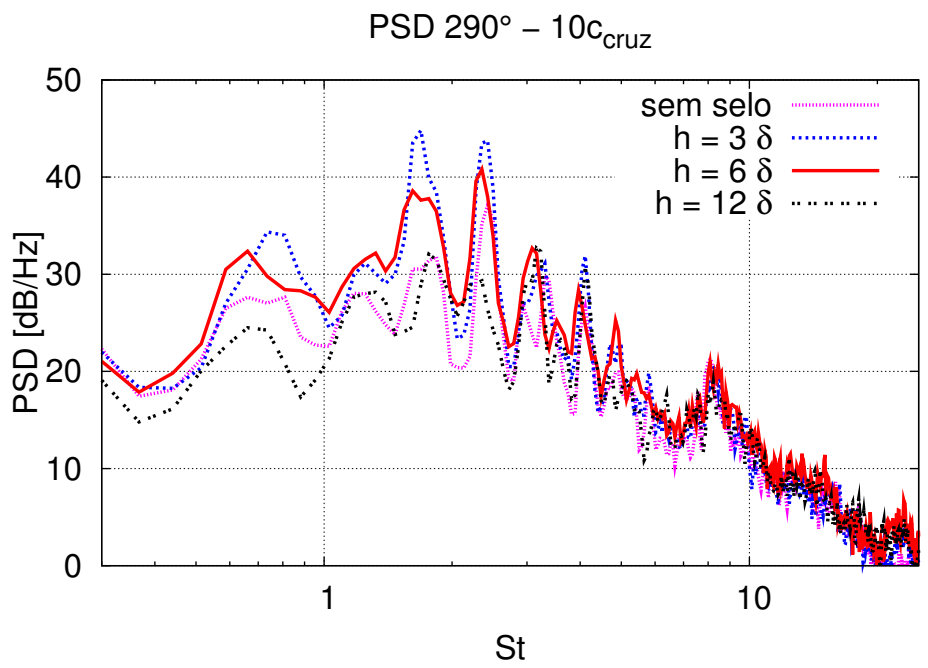

Figura 44 - Espectro de flutuação de pressão acústica propagada a partir do eslate em um ponto a uma distância de $10 c_{c r u z}$. Comparação entre três alturas do selo. 


\subsubsection{Efeito da Posição do Selo}

O selo de altura igual a $6 \delta_{T E}$ foi simulado em três posiçõesdiferentes na cova do eslate para avaliar o efeito da posição no escoamento e no som propago pelo eslate. Analisando o efeito das três posiçõesna distribuição de pressão do aerofólio (Fig. 45), observa-se que não há variação significativa em nenhuma das três configuraçõescom o selo. Apenas a região muito próxima do selo apresenta alguma mudança, como visto pelo gráfico da figura 45(b).

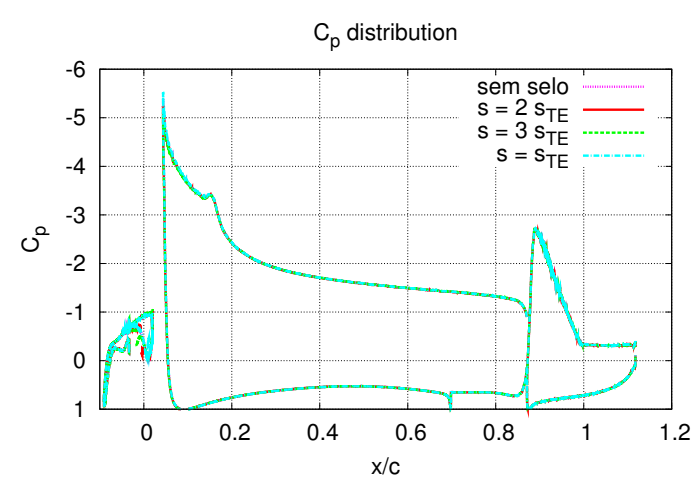

(a) Aerofólio

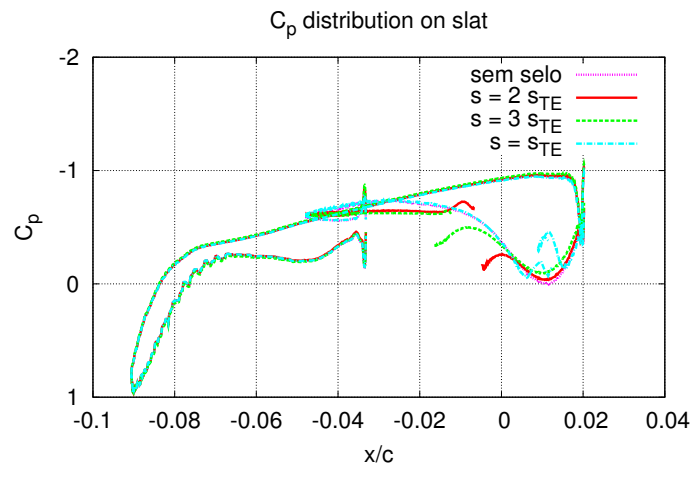

(b) Eslate

Figura 45 - Distribuição de pressão na superfície do aerofólio com um selo no eslate em três posiçõesdiferentes.

Comparando-se as linhas de corrente do escoamento médio (no tempo) na região da cova, pode-se observar que o caso $s=3 s_{T E}$ apresenta uma mudança radical no escoamento da região de recirculação. Nesse caso, duas regiões de recirculação de tamanho comparáveis se formam na cavidade do eslate. Por outro lado, o caso em que o selo é posicionado no ponto de recolamento presenta uma escoamento na cova muito semelhante ao caso sem selo, com excessão de um pequeno vórtice formado pela separação do escoamento que se choca com a extremindade livre do selo.

O campo da energia cinética das flutuaçõesé mostrado para os casos com o selo nas três posiçõese o caso sem o selo na figura 47. Nos casos com o selo entre o recolamento e a cúspide $\left(s=2 s_{T E}\right.$ e $\left.s=3 s_{T E}\right)$, observa-se uma região com menor nível de flutuaçõesdentro da cova, reforçando a idéia de que o selo funciona como uma barreira, restringindo a passagem de estrutras formadas na camada de mistura para dentro da região de recirculação. Já no caso em que o selo está posicionado exatamente no ponto de recolamento, esse efeito não ocorre e o campo de energia cinética turbulenta dentro da cova nesse caso é semelhante ao da geometria sem o selo.

A camada de mistura do caso com o selo mais afastado do bordo de fuga apresenta níveis de flutuação muito mais elevados que os demais casos. Esse aumento na energia cinética turbulenta 


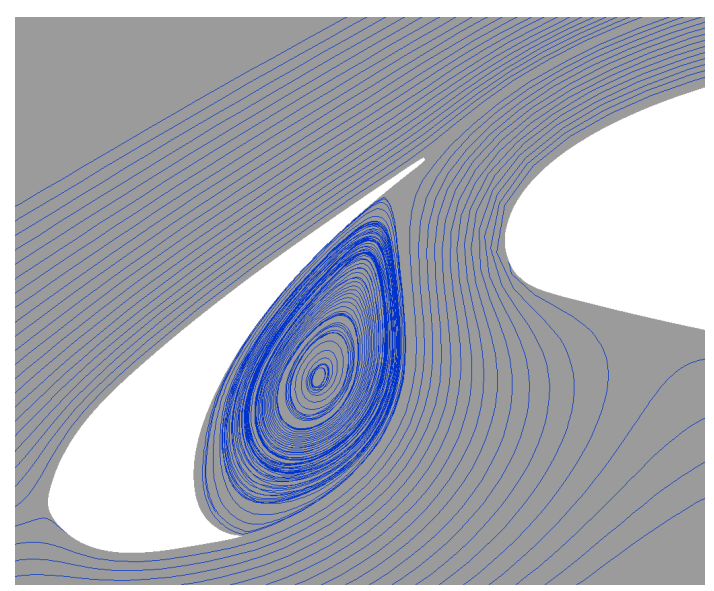

(a) Sem selo

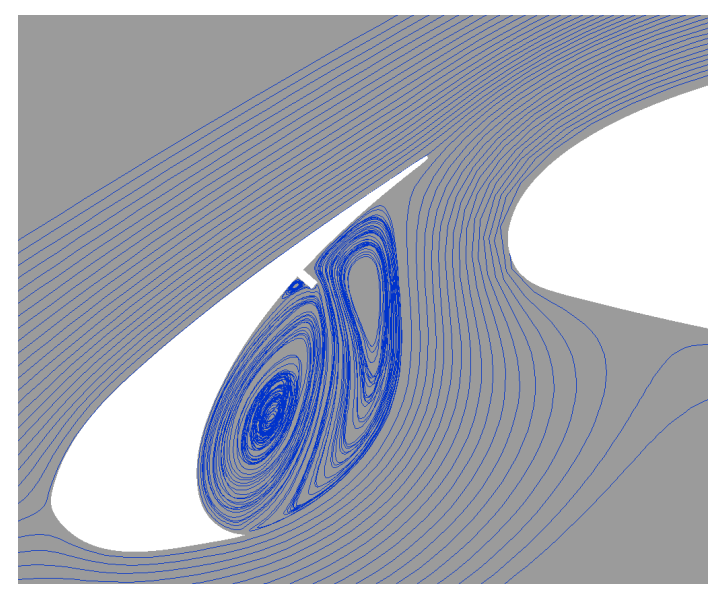

(c) $s=3 s_{T E}$

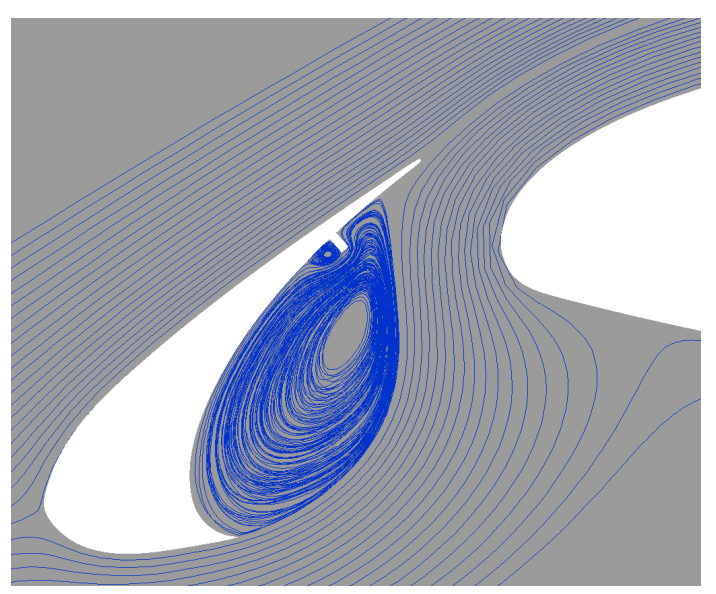

(b) $s=2 s_{T E}$

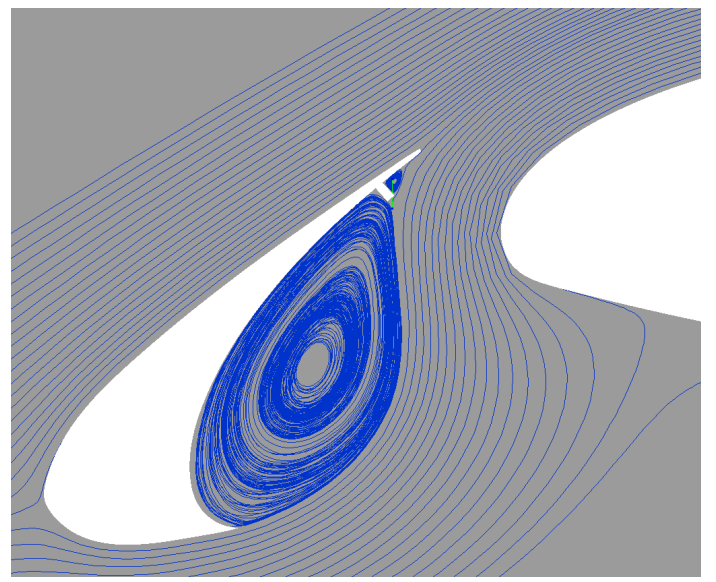

(d) $s=s_{T E}$

Figura 46 - Linhas de corrente na região da cova do eslate em geometrias com selo em diferentes posições.

na camada cisalhante livre formada a partir da separação na cúspide se deve provavelmente à interação mais intensa desta com as estruturas que, após se chocarem com a parede do eslate ficam presas na região de recirculação mais externa (Fig. 48(c)). Assim, a quebra das estruturas coerentes ocorre mais próximo da cúspide e a dinâmica do escoamento resultante na camada de mistura é mais tridimensional nesse caso.

Os espectros de flutuaçõesda componente de velocidade na direção $\mathrm{x}$, mostrados na figura 49 , confirmam a diferença no padrão do escoamento na cova do eslate no caso $s=3 s_{T E}$. Embora o formato dos espectros dos quatro casos se tornem gradativamente mais semelhantes à medida em que se aproxima do ponto de recolamento, no espectro referente ao ponto $S / S_{\max }=0,81$ ainda é possível notar que a componente de banda larga das flutuaçõestem seu máximo deslocado para frequências mais baixas no caso com o selo mais afastado do bordo de fuga. Além disso, a taxa de decaimento da energia com a frequência nesse caso não se iguala aos demais 


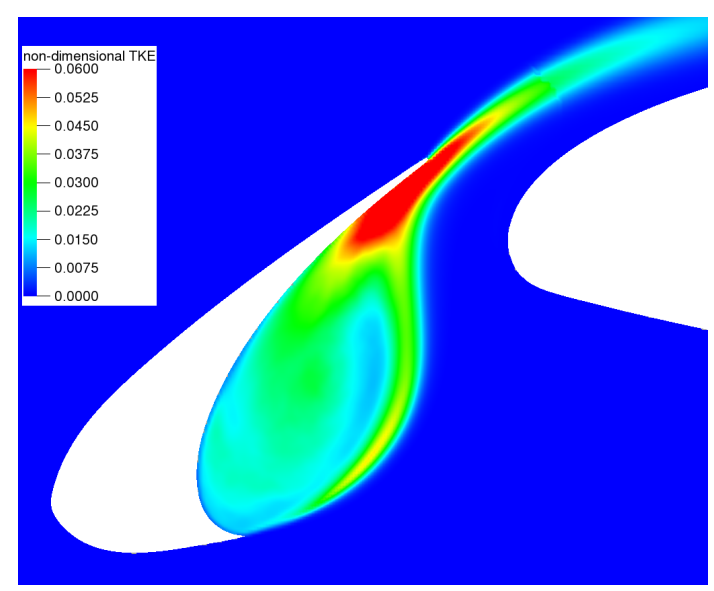

(a) Sem selo

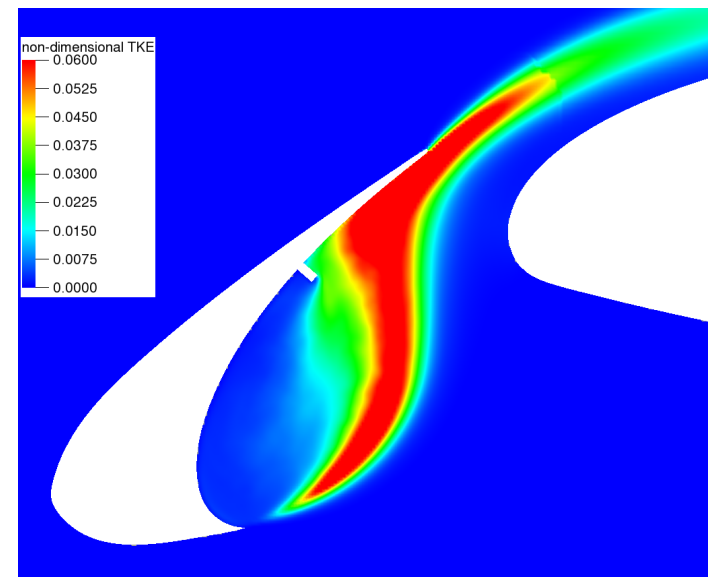

(c) $s=3 s_{T E}$

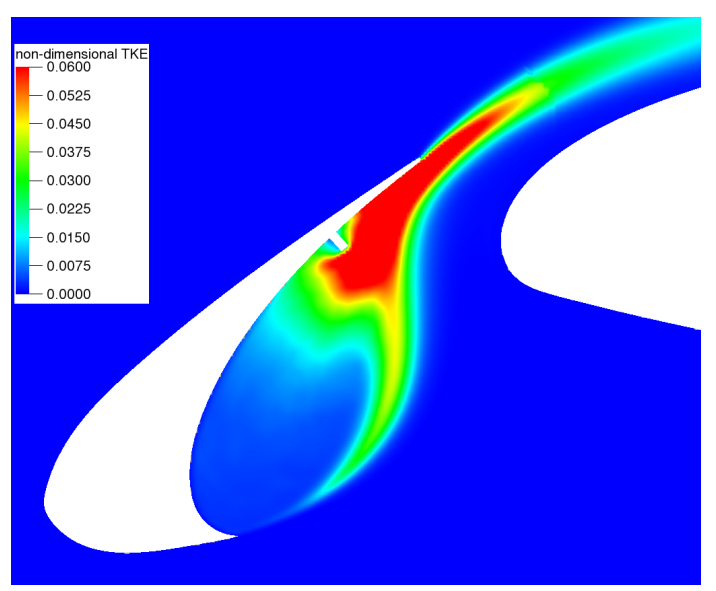

(b) $s=2 s_{T E}$

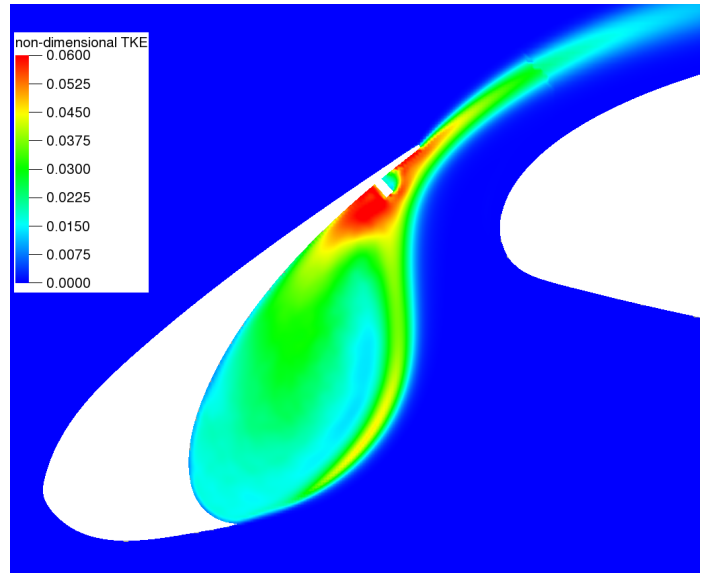

(d) $s=s_{T E}$

Figura 47 - Campo médio da energia cinética turbulenta a partir das flutuaçõescom selo em três posiçõesdiferentes bem como da geometria sem o selo.

nas frequências mais elevadas. Por outro lado, posicionando o selo no ponto de recolamento, praticamente não há alteração nos espectros em relação à geometria sem o selo.

Diferente dos espectros de flutuação de velocidade na camada de mistura, as flutuaçõesde pressão em pontos na superfícies do aerofólio não exibem diferenças tão significativas no espectro do caso $s=3 s_{T E}$, como pode ser visto nos gráficos da figura 50. Exceto pela posição dos picos tonais entre $S t=1$ e $S t=5$ e a presença de flutuaçõesintensas em $S t=0,8$, o nível da densidade de potência espectral desse caso é comparável ao dos outros três no bordo de fuga do eslate (ponto 4) e ao do caso $s=2 s_{T E}$ no extradorso (ponto 6). Com relação às flutuaçõesde pressão na superfície quando o selo é posicionado no ponto de recolamento, pouca alteração é observada em relação ao caso sem selo.

A comparação do espectro do ruído gerado na região do eslate pelas geometrias com o selo em diferentes posições, bem como pela geometria sem o selo, é mostrada na figura 51. O ponto 


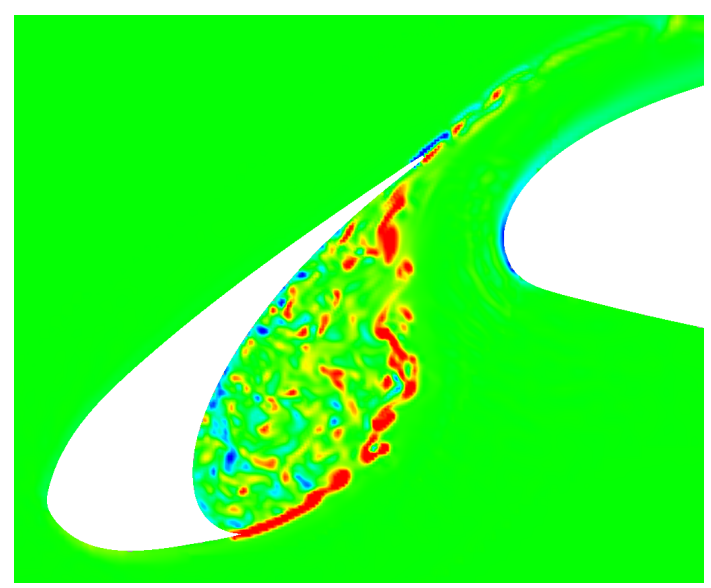

(a) Sem selo

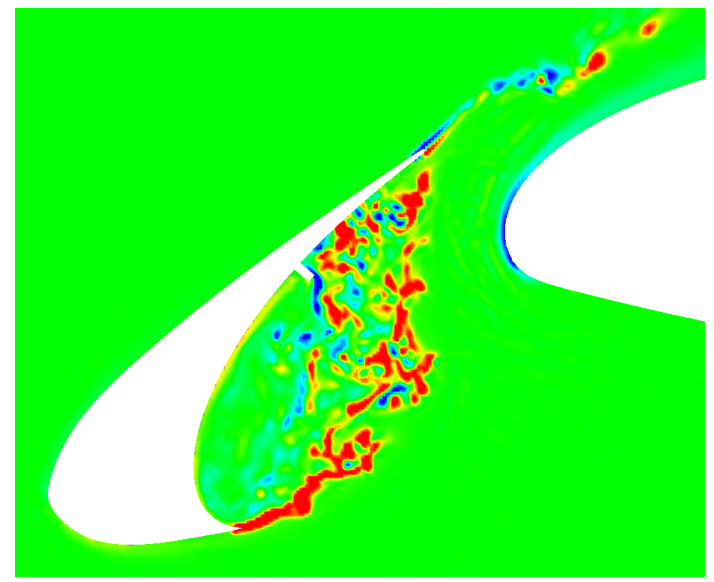

(c) $s=3 s_{T E}$

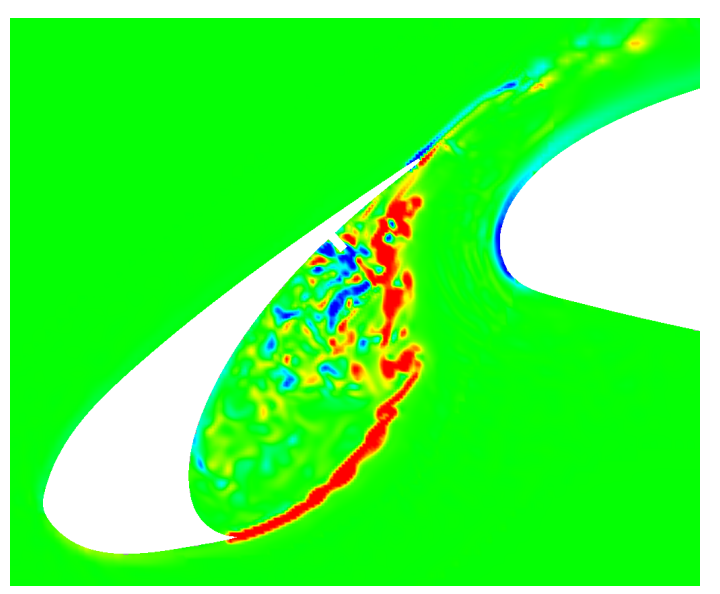

(b) $s=2 s_{T E}$

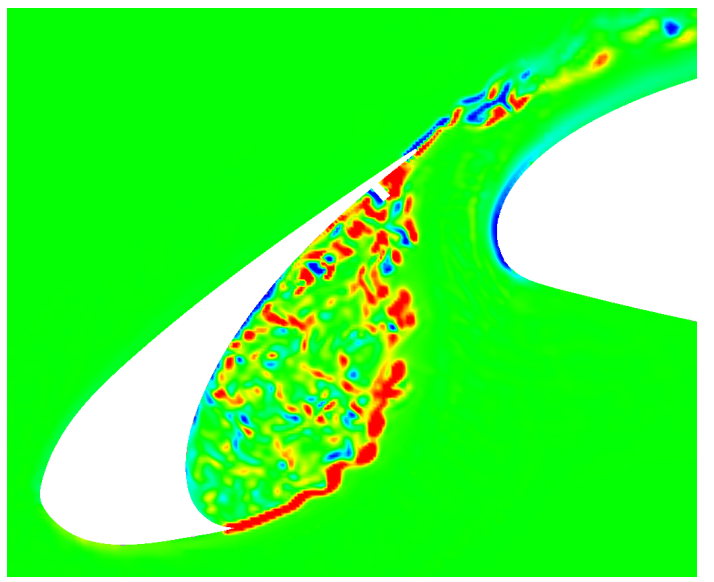

(d) $s=s_{T E}$

Figura 48 - Campo instantâneo da componente de vorticidade na direção z para três posiçõesdiferentes do selo.

onde os cálculos baseados na analogia de Ffowcs Williams-Hawkings foram feitos se refere a um observador no mesmo ponto considerado na figura 44. Observa-se que os dois casos com o selo dentro da cova apresentam um ruído de banda-larga ligeiramente mais intenso do que o caso sem o selo ou com o selo no ponto de recolamento. Já a intensidade dos picos aumenta substancialmente quando o selo é posicionado dentro da cova. Comparando-se os espectros do caso sem o selo e do caso com selo no ponto de recolamento, estes são muito semelhantes. Apenas um pequeno aumento no ruído de banda-larga e uma redução no pico tonal em $S t \approx 3,3$ ocorrem no caso com o selo.

Em comparação com o efeito do tamanho do selo a posição onde o mesmo é colocado na cova do eslate parece então ter uma influência maior no escoamento, e consequentemente no ruído gerado. Muito afastado do ponto de recolamento, dentro da região de recirculação, o selo provoca uma mudança substancial nas linas de corrente dentro da cova, o que modifica de forma 


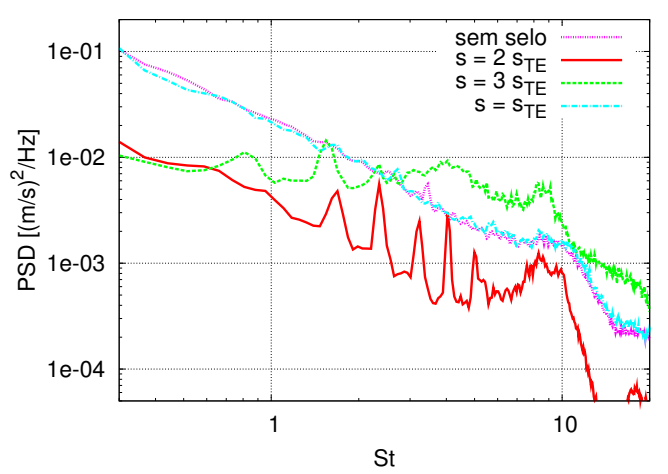

(a) $S / S_{\max }=0,20$

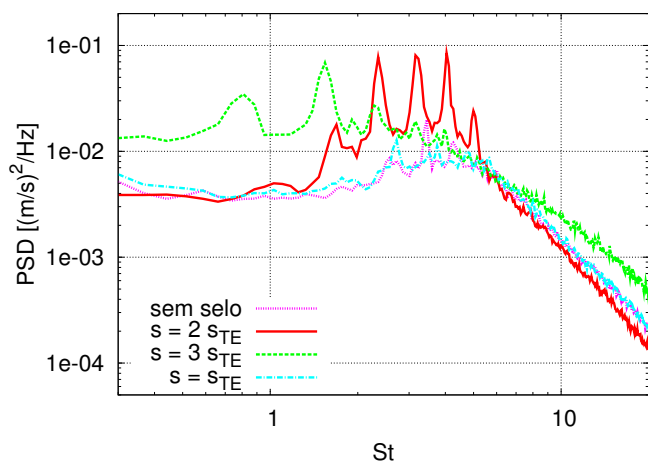

(c) $S / S_{\max }=0,60$

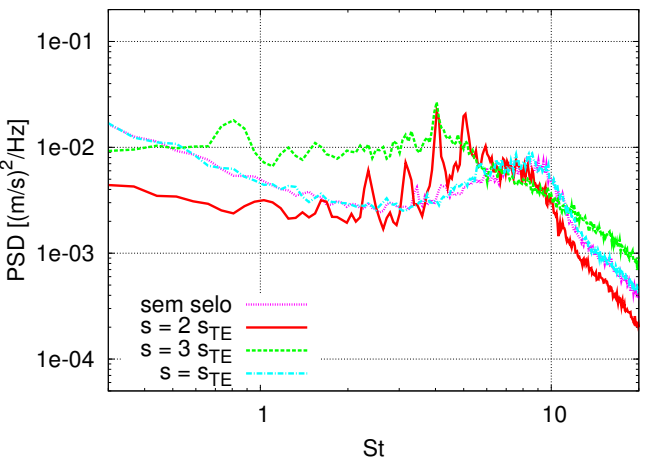

(b) $S / S_{\max }=0,45$

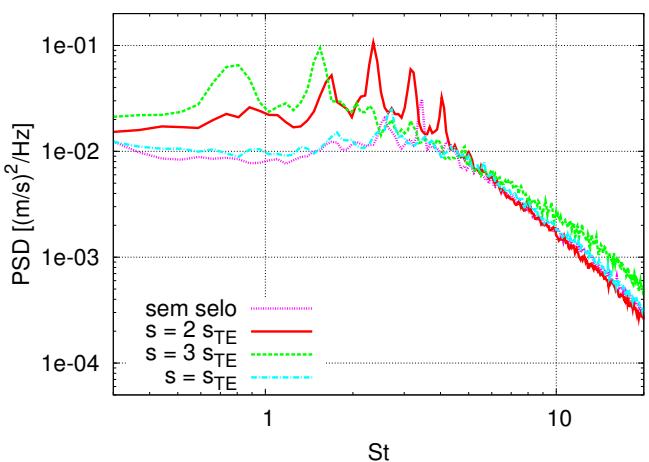

(d) $S / S_{\max }=0,81$

Figura 49 - Espectros das flutuaçõesde u em pontos da camada de mistura. Comparação entre três posiçõesdo selo bem como a geometria sem selo.

significativa a dinâmica dos vórtices. Assim um aumento de até $7 d B / H z$ e uma alteração no formato são observados no espectro de ruído propagado em comparação com a configuração limpa. 


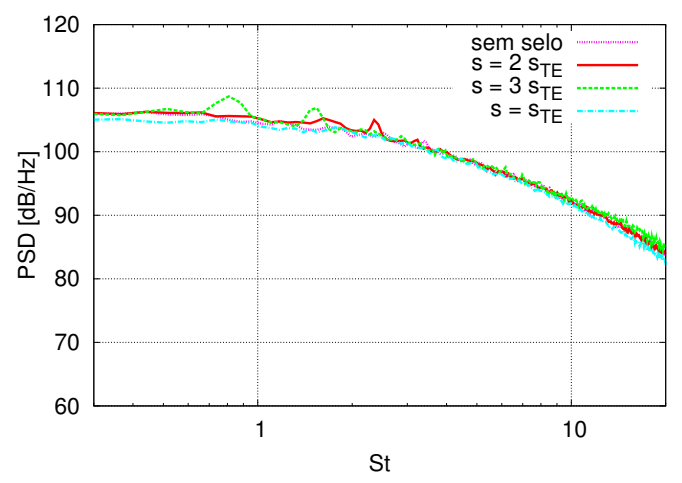

(a) Ponto 4

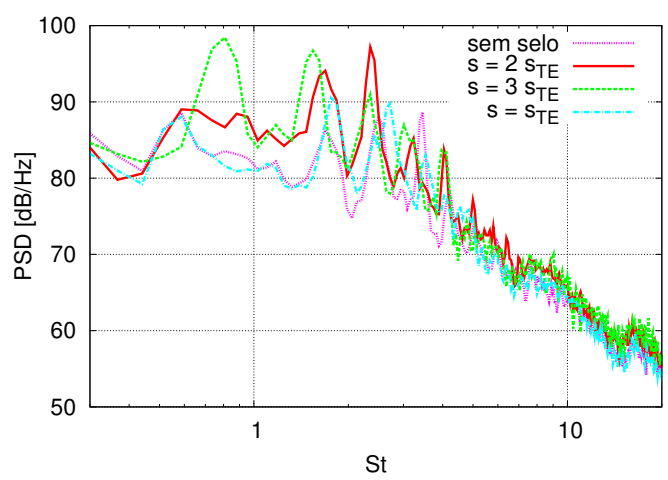

(b) Ponto 6

Figura 50 - Espectros das flutuaçõesde p em dois pontos da superfície do eslate. Comparação entre selos em três posiçõesdiferentes e a geometria sem selo.

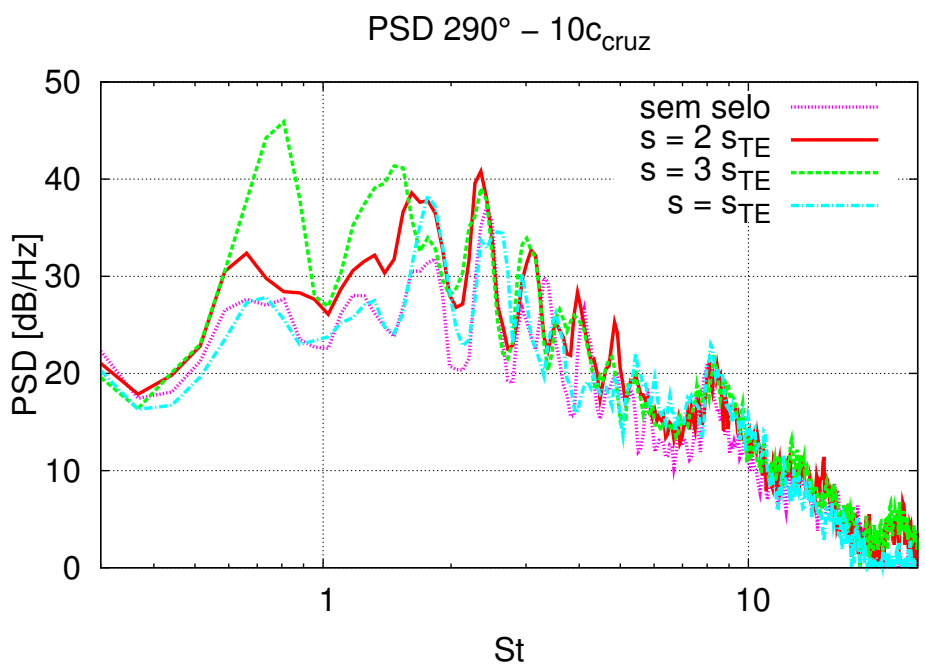

Figura 51 - Espectro de flutuação de pressão acústica propagada a partir do eslate em um ponto a uma distância de $10 c_{c r u z}$. Comparação das três posiçõesdo selo.

\subsection{Ruído Gerado por Eslate com Escoamento Cruzado}

\subsubsection{Estudo de Independência de Malha}

Como a inclusão da componente transversal no escomento em torno do aerofólio pode acarretar em uma modificação do escoamento em relação aos casos analisados nas seções anteriores, um estudo de convergência de malha foi feito para os casos de aerofólio com enflechamento. As simulações com as malhas diferentes foram feitas considerando paredes sem escorregamento em todas as superfícies do aerofólio e portanto a malha testada é a configuração de referência. Duas malhas foram comparadas para cada valor de enflechamento analisado. No caso com 
enflechamento maior $\left(45^{\circ}\right)$, a relação de refinamento é relativamente baixo, portanto a comparação deve ser feita com cautela, pois a semelhança entre os resultados pode ser consequência da pequena variação na resolução da malha.

A figura 52 mostra o efeito do refinamento na distribuição de $C_{p}$. Praticamente nenhuma alteração é observada, exceto pelo ponto de separação do flap que se move ligeiramente na direção do bordo de ataque, como mostra a figura 53 para o caso com enflechamento de $35^{\circ}$. A alteração no caso $\beta=45^{\circ}$ é menor, provavelmente devido à menor variação no tamanho do voxel.

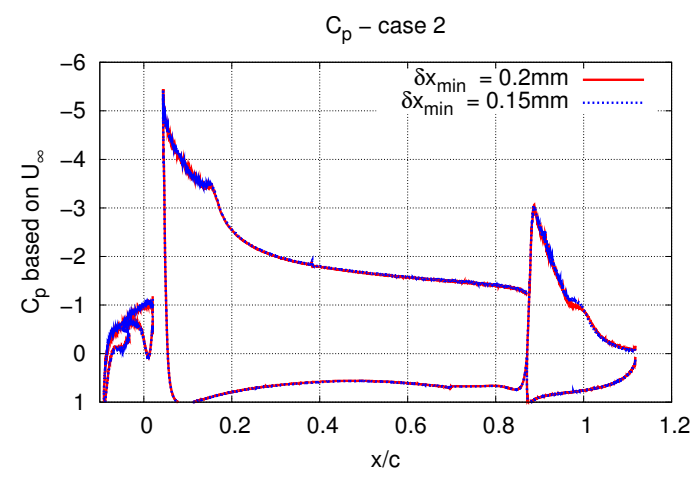

(a) Enflechamento: $35^{\circ}$

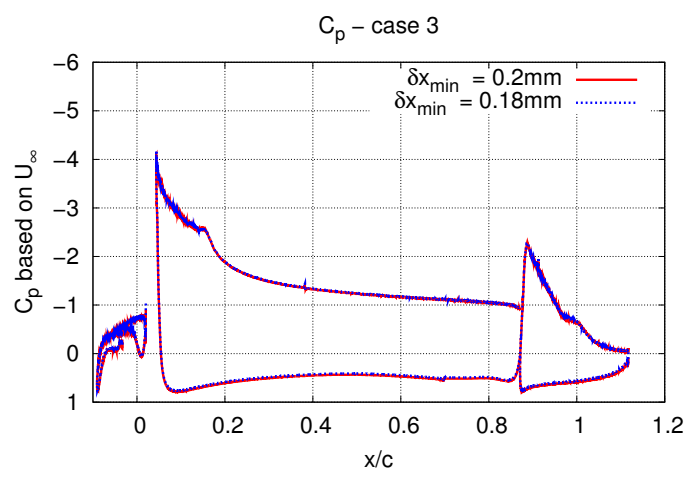

(b) Enflechamento: $45^{\circ}$

Figura 52 - Comparação da distribuição entre duas malhas dos casos com enflechamento de $35^{\circ}$ e $45^{\circ}$.

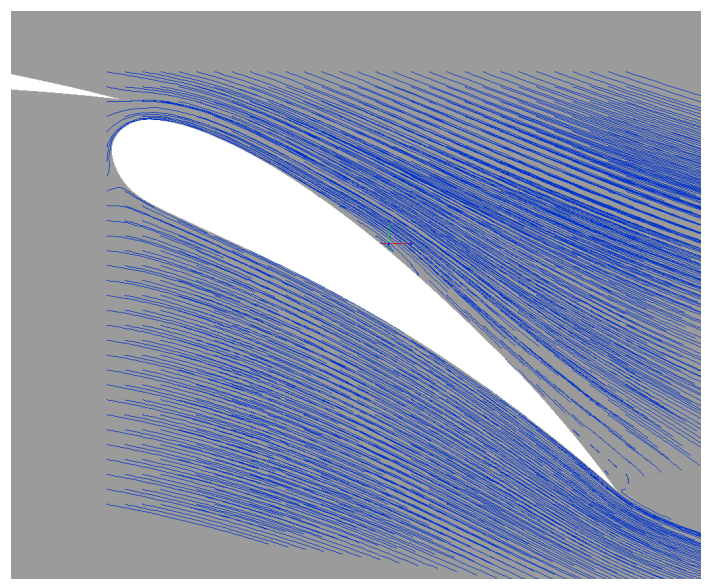

(a) $\delta_{\text {min }}=0,20 \mathrm{~mm}$

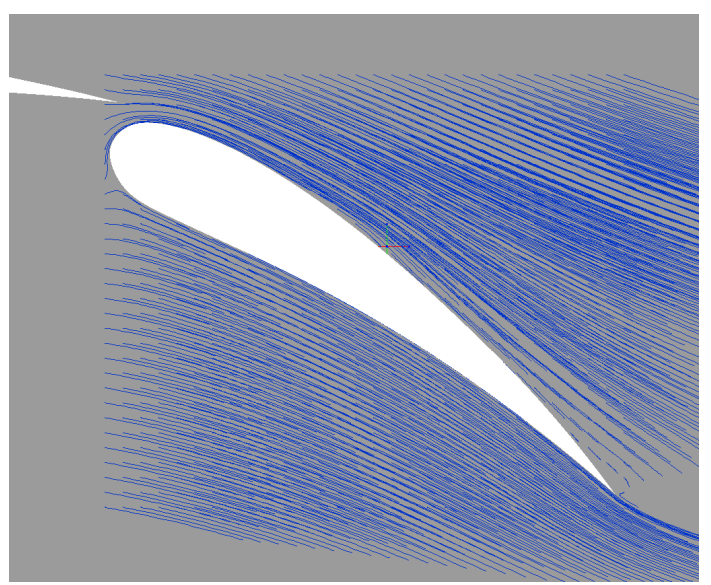

(b) $\delta_{\text {min }}=0,15 \mathrm{~mm}$

Figura 53 - Linhas de corrente ao redor do flap. Enflechamento de $35^{\circ}$.

As figuras 54 e 55 mostram a comparação entre diferentes malhas na componente de vorticidade na direcao z. Nenhuma modificação significativa é observada. Nas figuras 56 e 57 os perfís de velocidade ao longo das duas linhas linhas pretas da figura 54 são comparados. 
Novamente apenas alterações mínimas são observadas. No caso $\beta=35^{\circ}$, ocorre um ligeiro espessamento da camada de mistura perto da cúspide (Fig. 56(a)). Porém, essa diferença não é observada na região próxima do recolamento (Fig. 56(b)). No caso $\beta=45^{\circ}$, os perfis de velocidade são praticamente idênticos ao longo das duas linhas.

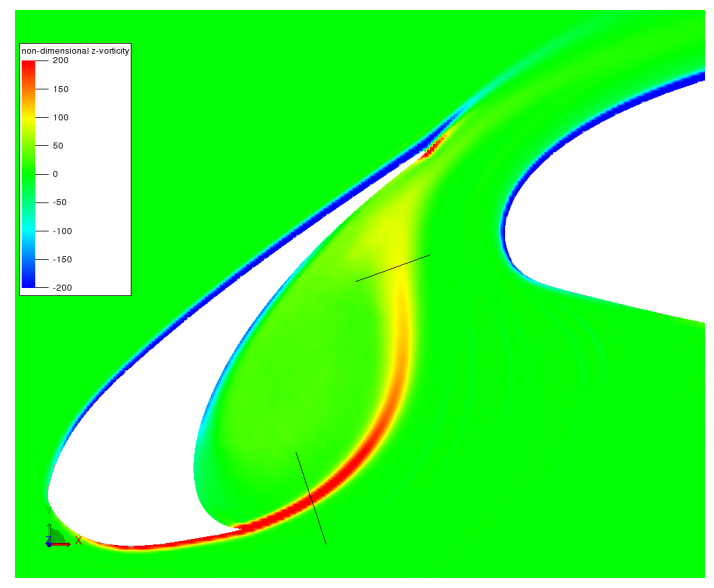

(a) $\delta_{\min }=0,20 \mathrm{~mm}$

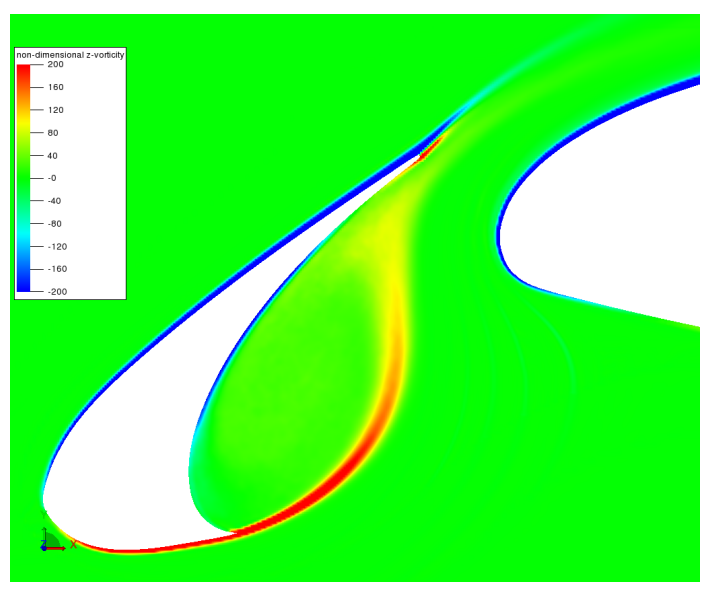

(b) $\delta_{\min }=0,15 \mathrm{~mm}$

Figura 54 - Campo da componente de vorticidade na direção da envergadura na região da cavidade do eslate no caso com enflechamento de $35^{\circ}$.

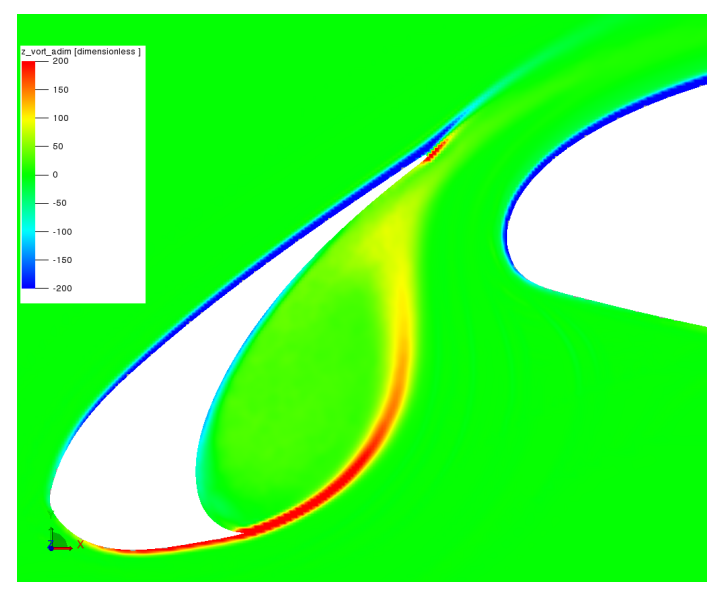

(a) $\delta_{\min }=0,20 \mathrm{~mm}$

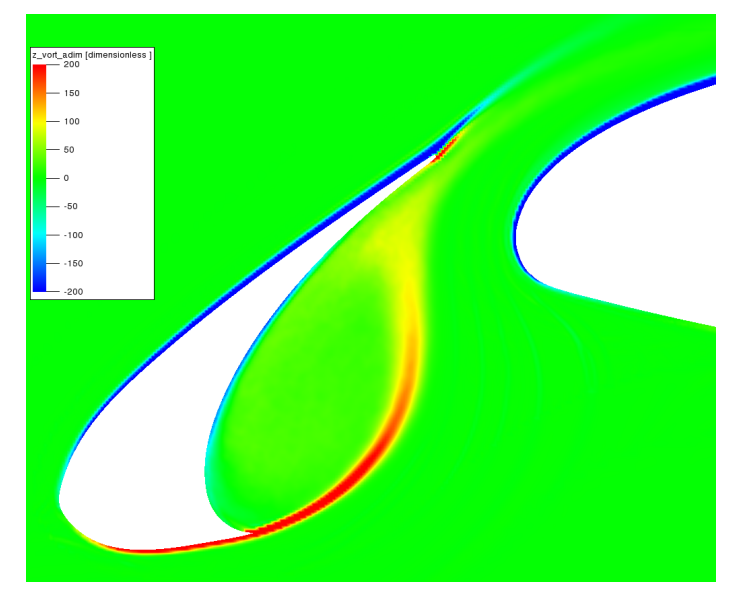

(b) $\delta_{\min }=0,18 \mathrm{~mm}$

Figura 55 - Campo da componente de vorticidade na direção da envergadura na região da cavidade do eslate no caso com enflechamento de $45^{\circ}$.

A figura 58 mostra o campo de energia cinética turbulenta $\left(0,5\left(\left\langle u^{\prime} u^{\prime}\right\rangle+\left\langle v^{\prime} v^{\prime}\right\rangle+\left\langle w^{\prime} w^{\prime}\right\rangle\right) / U_{\infty}^{2}\right)$ na região da cova do eslate para o caso $\beta=35^{\circ}$. A principal alteração causada pelo refinamento da malha é uma diminuição da energia na região próxima ao recolamento. Uma pequena diminuicao na energia turbulenta dentro da região de recirculaçãotambém é observada. Esta provavelmente é consequência da variação no ponto de recolamento. Alterações semelhantes, porém mais sutís, são observadas no caso $\beta=45^{\circ}$. 


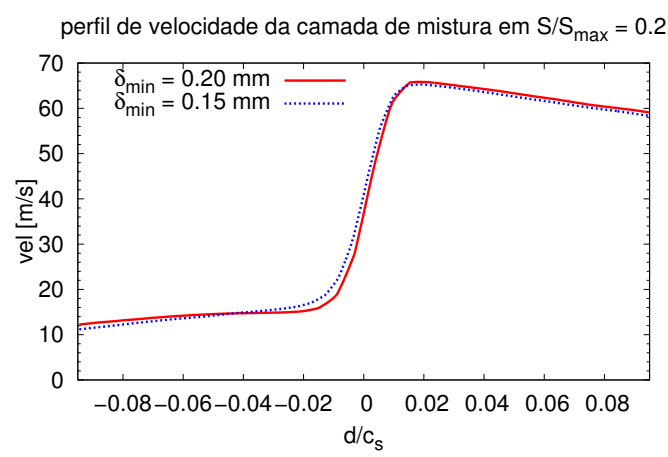

(a) $S / S_{\max }=0,20$

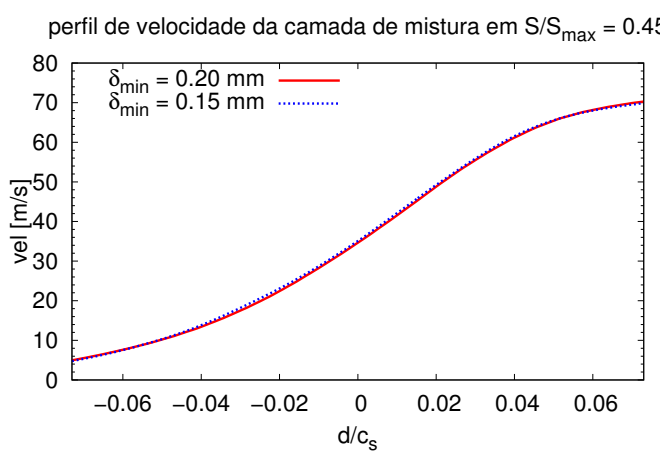

(b) $S / S_{\max }=0,81$

Figura 56 - Perfis de velocidade em pontos escolhidos da camada de mistura. Enflechamento de $35^{\circ}$.

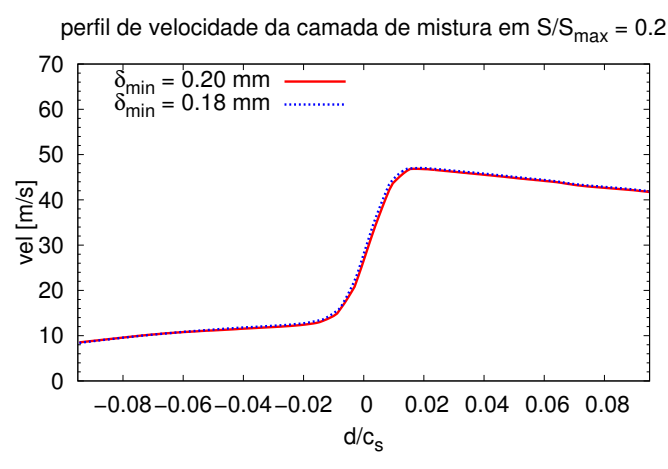

(a) $\delta_{\min }=0,20 \mathrm{~mm}$

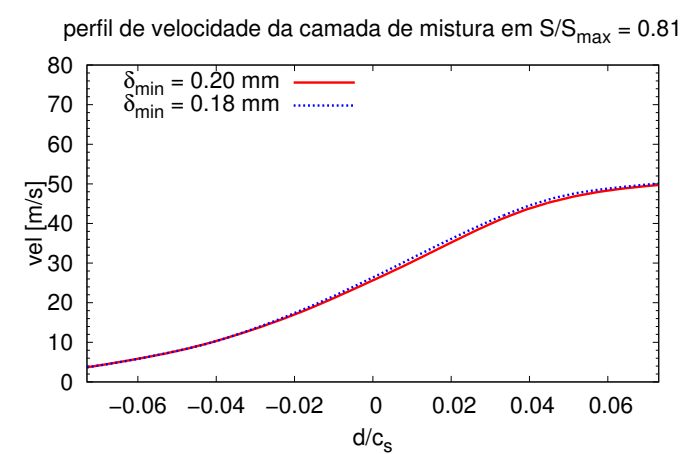

(b) $\delta_{\min }=0,81 \mathrm{~mm}$

Figura 57 - Perfis de velocidade em pontos escolhidos da camada de mistura. Enflechamento de $45^{\circ}$.

O efeito do refinamento nos espectros de flutuação de velocidade em quatro pontos ao longo da camada de mistura é mostrado na figura 59 para o caso $\beta=35^{\circ}$. O refinamento da malha aumenta a frequência do intenso pico abaixo de $S t=1$ nos quatro pontos. No ponto $S / S_{\max }=$ 0,20 , há um pequeno aumento na intensidade das oscilações de alta frequência. Essa variação é normal, já que a malha mais refinada permite que o esquema numérico resolva estruturas de escala menor. O pico largo presente no espectro do ponto $S / S_{\max }=0,45 \mathrm{em} S t \approx 10$ é significativamente reduzido com o refinamento da malha. Porém, essa diferença diminui à medida que se avança na direção do recolamento, como pode ser visto pelo espectro dos pontos $S / S_{\max }=0,6$ e $S / S_{\max }=0,81$.

Também no caso $\beta=45^{\circ}$ (Fig. 59) há uma variação da posição no espectro de picos de baixa frequência devido ao refinamento da malha. No restante do espectro, por outro lado, não se observa alteração significativa em nenhum dos quatro pontos na camada de mistura. 


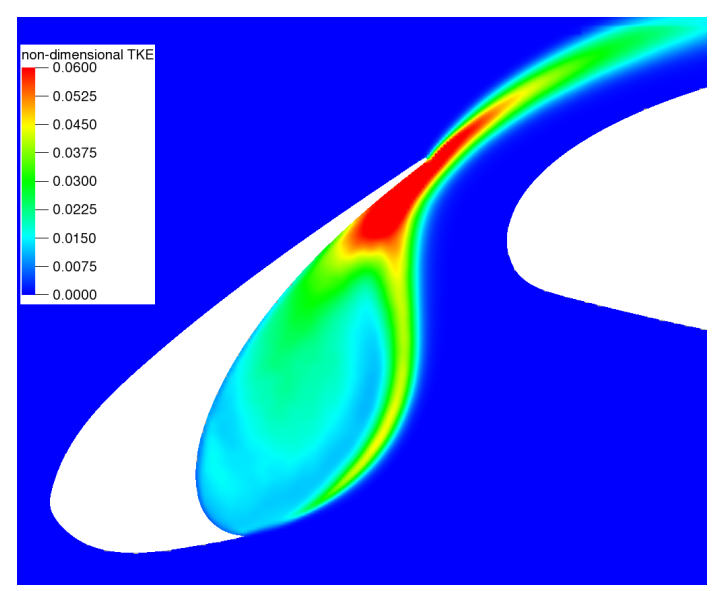

(a) $\delta_{\min }=0,20 \mathrm{~mm}$

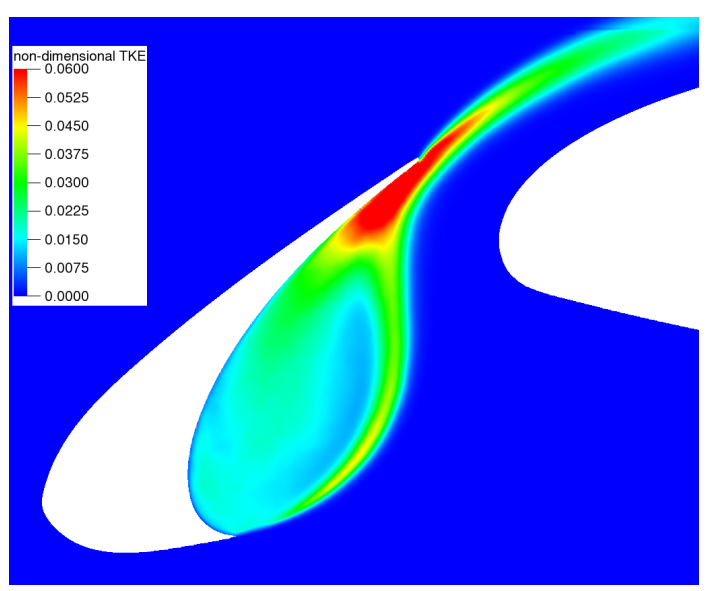

(b) $\delta_{\min }=0,15 \mathrm{~mm}$

Figura 58 - Campo da energia cinética turbulenta calculada a partir das flutuações de velocidade. Enflechamento de $35^{\circ}$.

Assim como no caso com enflechamento menor, nesse caso as variações no espectro diminuem gradativamente à medida em que se aproxima do recolamento, de forma que a variação no ponto $S / S_{\max }=0,81$ se mantém abaixo de $3 \mathrm{~dB} / \mathrm{Hz}$ ao longo do espectro analisado.

As figuras 61 e 62 apresentam a densidade de potência espectral da pressão em três pontos da superfície do eslate, mostrando o efeito do refinamento da malha nos espectros. Assim como nos espectros de flutuação de velocidade na camada de mistura, os espectros do ponto 3 (ponto de recolamento) apresentam variação da frequência dos picos abaixo de $S t=1 \mathrm{em} \beta=35^{\circ}$ e abaixo de $S t=3$ no caso $\beta=45^{\circ}$. No ponto 4 , o refinamento causa uma variação significativa no espectro, principalmente no caso $\beta=45^{\circ}$. Embora a malha não seja suficientemente refinada para resolver a formação de vórtices discretos no bordo de fuga do eslate, o refinamento parece provocar uma variação na dinâmica das oscilações nessa região. Apesar das diferenças observadas nos pontos 3 e 4 entre malhas com diferentes refinamentos, o espectro do ponto 6 , onde as flutuações de pressão são, principalmente devido à passagem de ondas acústicas, praticamente não se altera com refinamento da malha em ambos os casos.

Para avaliar se a solução do som propagado para o campo distante e independente da malha, a analogia de FW-H foi usada para calcular as oscilações de pressão em um ponto a $290^{\circ}$ (de acordo com referência da figura 28) a uma distância de $10 c_{c r u z}$ da cova do eslate. Os espectros em PSD estão mostrados nas figuras 63 e 64. Como o refinamento da malha resulta em uma redução da envergadura simulada, conforme explicado no capítulo 4 , as curvas são corrigidas em função do comprimento na direção z da região de integração da analogia acústica.

A figura 63 indica que ainda não há uma convergência de malha da solução do campo 


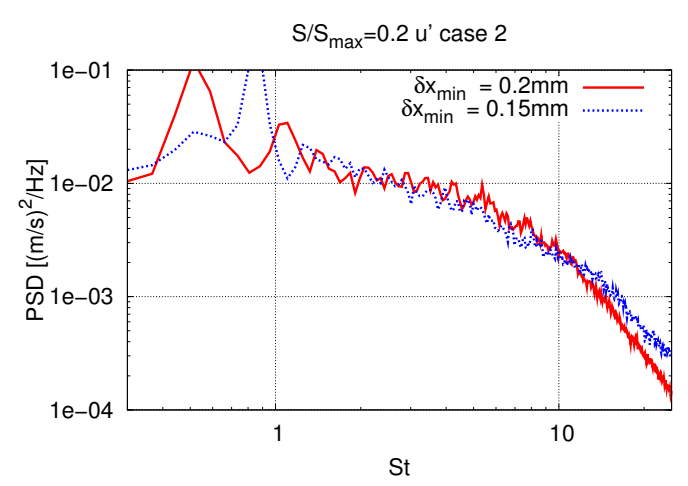

(a) $S / S_{\max }=0,20$

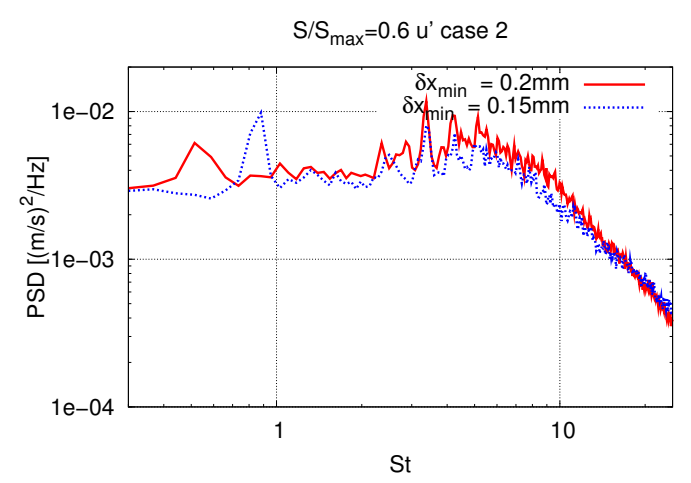

(c) $S / S_{\max }=0,60$

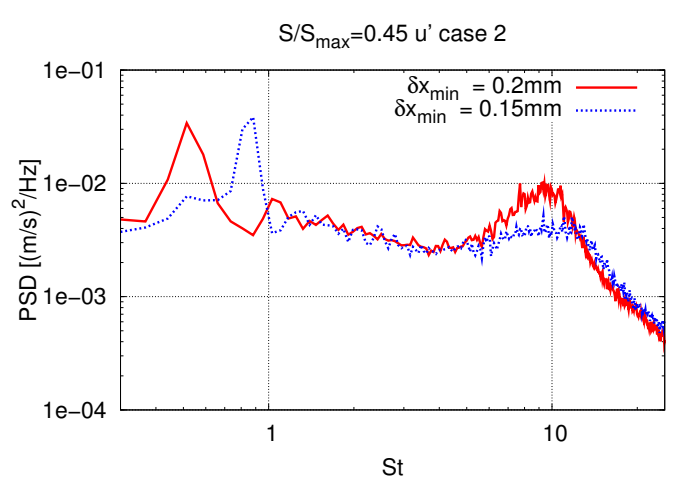

(b) $S / S_{\max }=0,45$

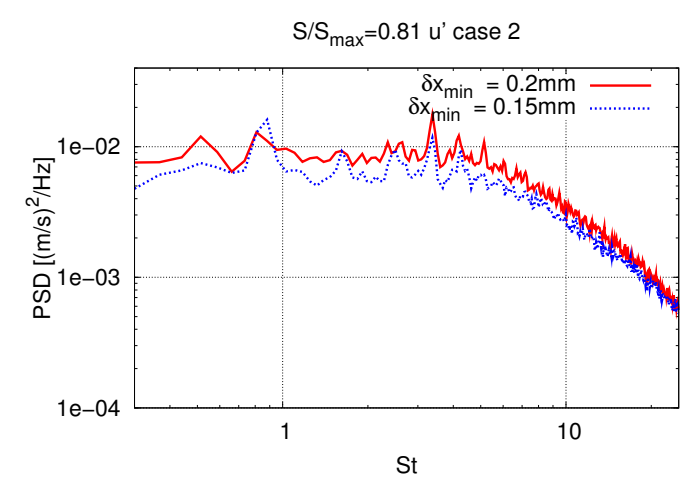

(d) $S / S_{\max }=0,81$

Figura 59 - Espectro de flutuações da componente em x de velocidade em quatro pontos ao longo da camada de mistura. Enflechamento de $35^{\circ}$.

distante para o caso enflechamento de $35^{\circ}$. Observa-se que, com o refinamento, o espectro inteiro sofre um deslocamento para frequências mais elevadas, mas mantém seu formato básico. Tomando os picos tonais como referência, esse deslocamento é de aproximadamente 7,5\% no valor da frequência. Comparando as duas malhas usadas no caso $\beta=45^{\circ}$, vê-se que não há alteração significativa no espectro. Entretanto, não se pode afirmar que a solução atingiu a convergência, uma vez que a razão de refinamento é muito pequena. Porém, pode-se concluir que as alterações causadas pelo refinamento no campo próximo, a saber, a mudança nos picos de baixa frequência e no espectro de flutuações no bordo de fuga, não são propagadas para o campo distante através das ondas acústicas no caso com maior enflechamento.

Conclui-se, portanto, que a solução aeroacústica não é independente da malha no nível de resolução testado no caso $\beta=35^{\circ}$. Porém, não se sabe o motivo do deslocamento do espectro do ruído no campo distante, uma vez que este não é percebido no ponto 6 , onde principalmente oscilações acústicas são observadas. Com relação ao caso $\beta=45^{\circ}$, embora o refinamento não tenha causado alteração significativa no espectro de ruído, não se pode afirmar que a solução é independente da malha, uma vez que a variação na resolução da malha foi pequena entre os 


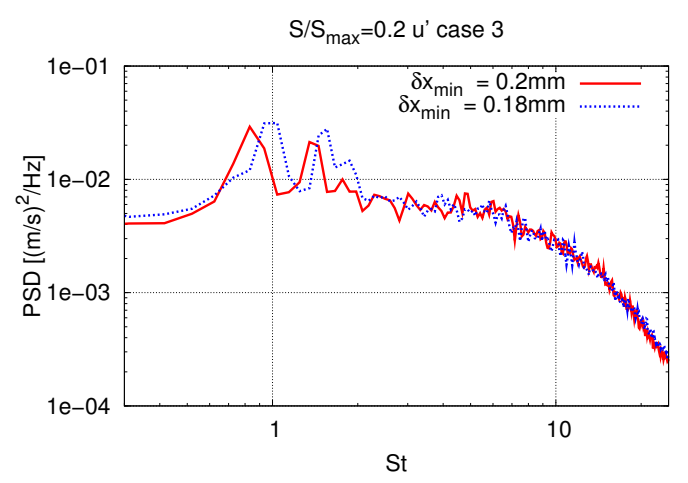

(a) $S / S_{\max }=0,20$

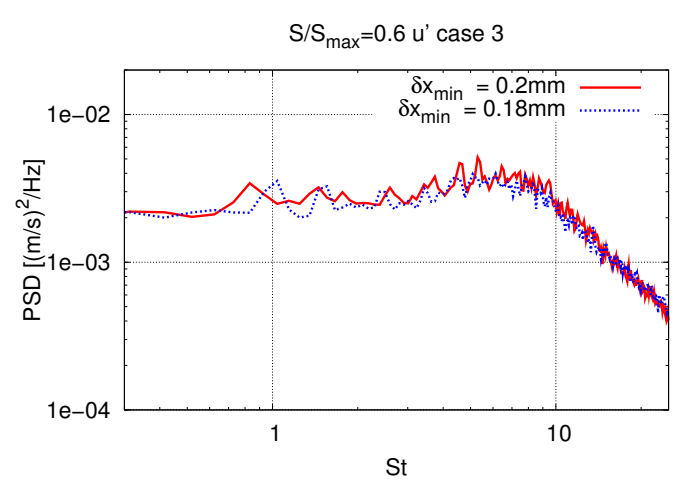

(c) $S / S_{\max }=0,60$

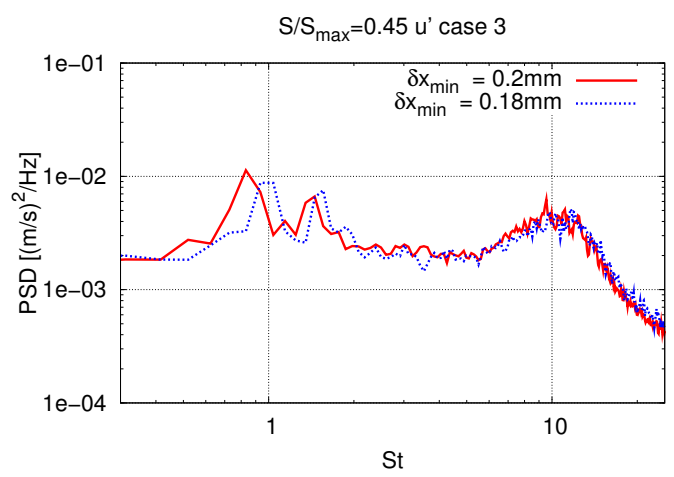

(b) $S / S_{\max }=0,45$

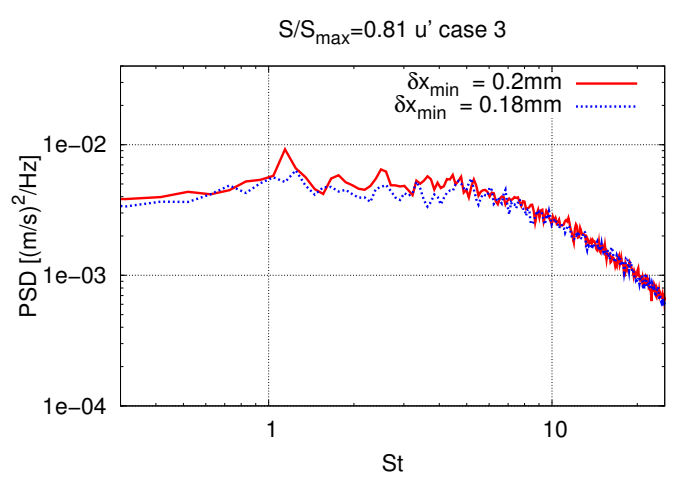

(d) $S / S_{\max }=0,81$

Figura 60 - Espectro de flutuações da componente em x de velocidade em quatro pontos ao longo da camada de mistura. Enflechamento de $45^{\circ}$.

casos comparados. 


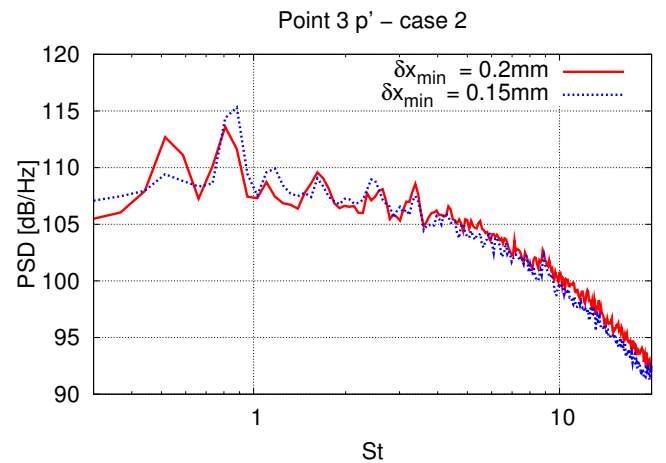

(a) Ponto 3

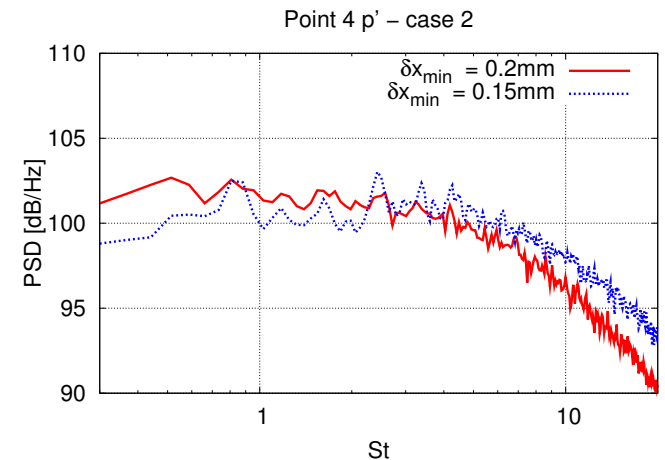

(b) Ponto 4

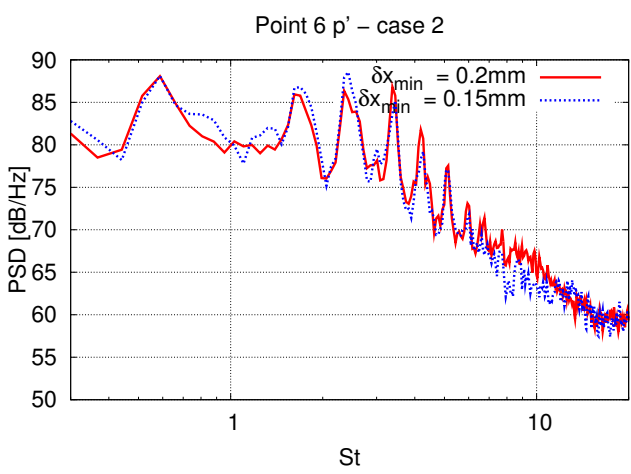

(c) Ponto 6

Figura 61 - Espectro de flutuações da pressão em pontos na superfície do eslate. Enflechamento de $35^{\circ}$. 


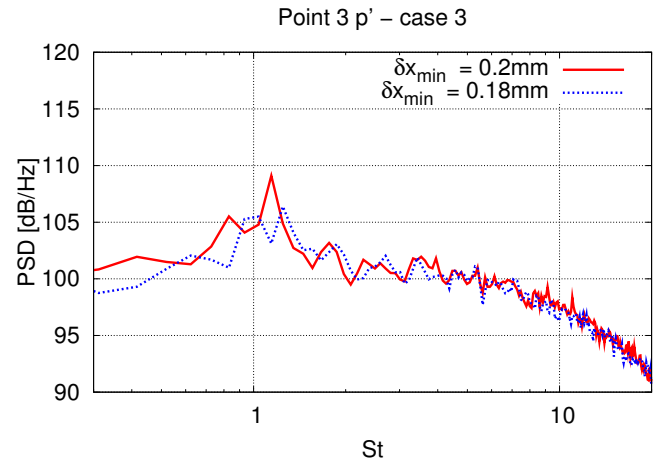

(a) Ponto 3

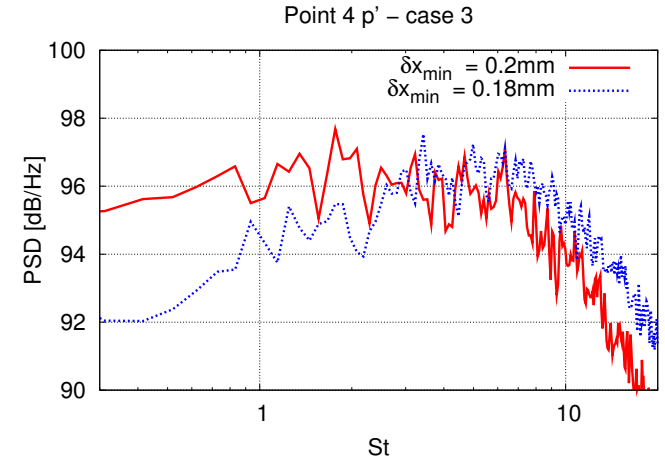

(b) Ponto 4

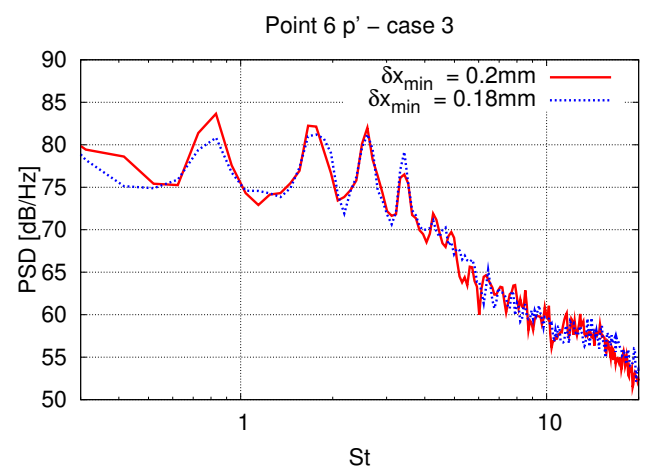

(c) Ponto 6

Figura 62 - Espectro de flutuações da pressão em pontos na superfície do eslate. Enflechamento de $45^{\circ}$.

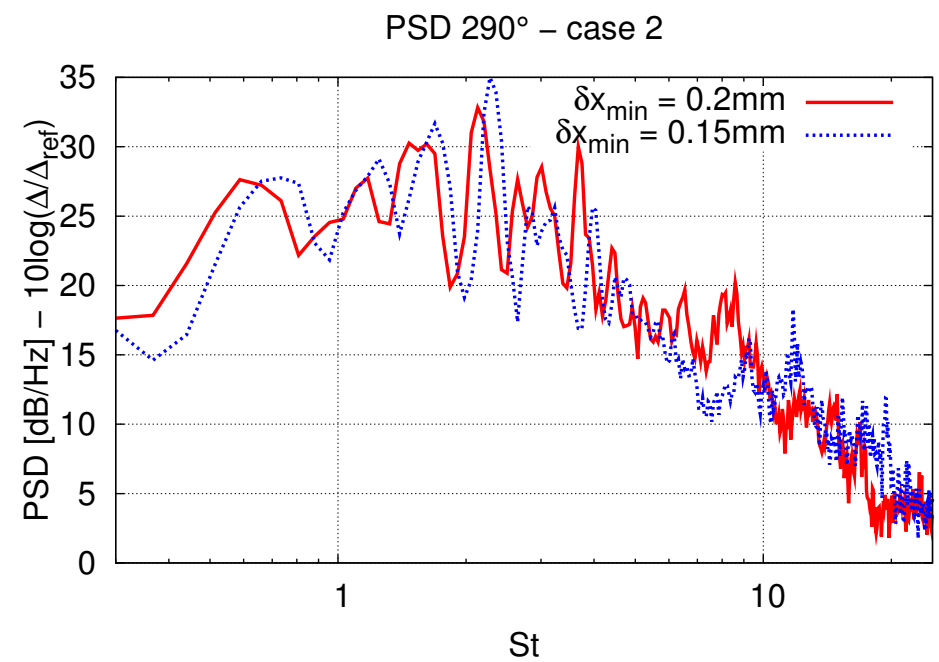

Figura 63 - Espectro de flutuações de pressão acústica propagada a partir do eslate para um ponto a uma distância $10 c_{c r u z}$. Enflechamento de $35^{\circ}$. 


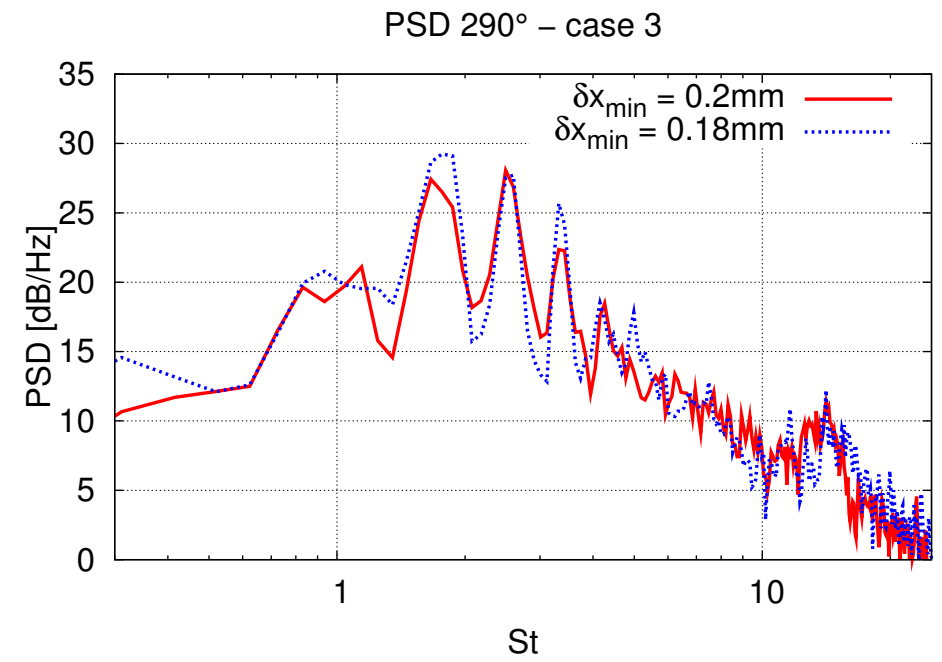

Figura 64 - Espectro de flutuações de pressão acústica propagada a partir do eslate para um ponto a uma distância $10 c_{c r u z}$. Enflechamento de $45^{\circ}$. 


\subsubsection{Comparação com Resultados da Literatura}

Uma vez que resultados experimentais dedicados à aeroacústica do aerofólio MDA 30P30N ainda não estão disponíveis na literatura, as condições de escoamento determinadas para as simulações do aerofólio com enflechamento foram escolhidas com base no trabalho de Lockard e Choudhari (2010), para que os resultados das simulações com o PowerFLOW pudessem ser comparadas com simulações de um código baseado nas equações de Navier-Stokes. É importante destacar que o domínio das simulações de Lockard e Choudhari (2010) não se limita às dimensões do túnel de vento, como o presente trabalho. Ao invés disso, uma condição de fronteira longínqua é adotada nos limites inferior e superior. $\mathrm{O}$ efeito das paredes do túnel é levado em consideração através da modificação do ângulo de ataque do aerofólio de forma que a distribuição de $C_{p}$ no eslate seja a mesma do caso no túnel. Assim o ângulo de ataque simulado por eles é de $5,5^{\circ}$.

De acordo com a conveniência, alguns resultados das simulações discutidas por Simões, Souza e Medeiros (2011) serão mostrados ao longo da seção para que diferenças entre soluções do aerofólio com e sem escoamento cruzado sejam discutidas tanto para os resultados do PowerFLOW quanto do CFL3D. Mesmo não sendo possível assegurar a convergência na malha da solução no campo distante no caso com enflechamento de $35^{\circ}$, os resultados da malha $\delta_{\text {min }}=0,20 \mathrm{~mm}$ serão usados nas comparações. Dessa forma, os resultados do PowerFLOW com mesma envergadura simulada serão comparados.

A distribuição do coeficiente de pressão ao longo da superfiície do aerofólio, calculada a partir das simulações com o PowerFLOW e com o CFL3D, está mostrada nas figuras 65 e 66. $\mathrm{Na}$ figura 65 a pressão na superfície é adimensionalizada com base no módulo da velocidade de entrada, $\left|\vec{V}_{\infty}\right|$. Por sua vez, a adimensinalização usada nos gráficos da figura 66 se baseia na componente em x da velocidade de entrada, $U_{\infty}$. As curvas referentes às simulações LatticeBoltzmann são resultados de uma média temporal da pressão ao longo da superfície em uma fatia central da envergadura. Por sua vez as curvas do CFL3D são resultado de uma média tanto temporal quanto ao longo da envergadura. Os gráficos da solução do PowerFLOW contém as soluções para o enflechamento de $35^{\circ}$ e $45^{\circ}$, enquanto os gráficos referentes ao CFL3D incluem também o caso $\beta=0^{\circ}$.

A partir das figuras 65 e 66 fica claro que, para os dois modelos (Lattice-Boltzmann e Navier-Stokes), o colapso das curvas é conseguido através da adimensionalização por $U_{\infty}$, ou seja a componente de velocidade na direção da envergadura não tem efeito direto sobre a circulação nos elementos do aerofólio. Esta observação está de acordo com o princípio de independência do escoamento potencial em relação ao enflechamento, discutido por Kaltenbach e 


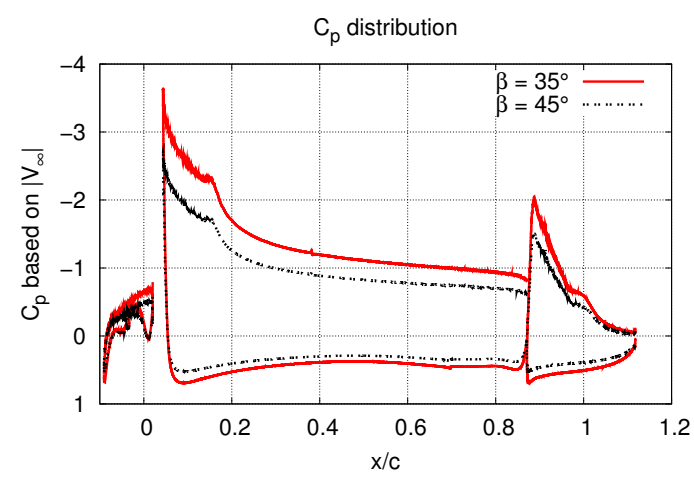

(a) PowerFLOW

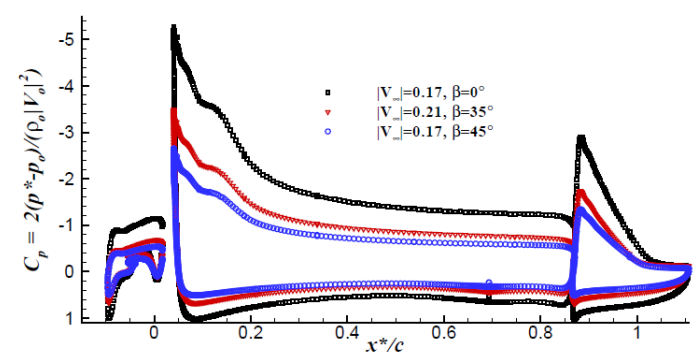

(b) Lockard e Choudhari (2010)

Figura 65 - Distribuição de pressão ao longo da superfície do aerofólio com adimensionalização baseada em $\left|\vec{V}_{\infty}\right|$.

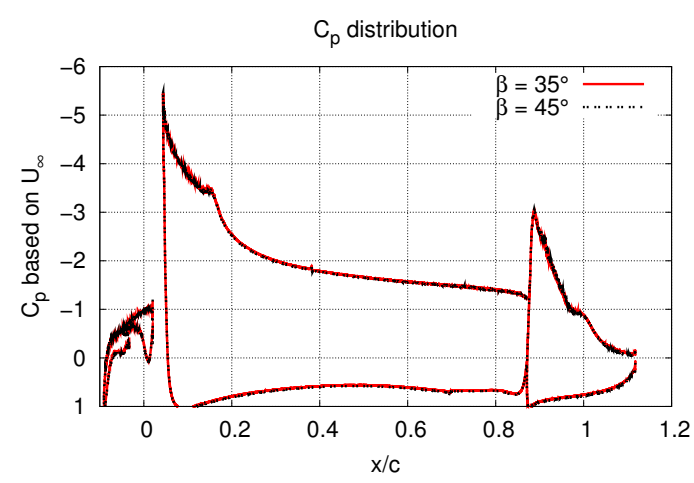

(a) PowerFLOW

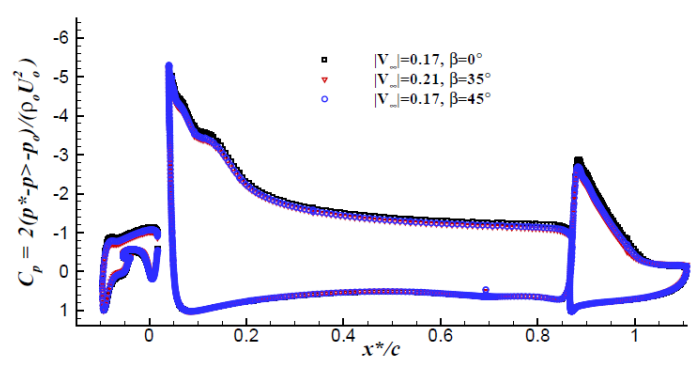

(b) Lockard e Choudhari (2010)

Figura 66 - Distribuição de pressão ao longo da superfície do aerofólio com adimensionalização baseada em $U_{\infty}$.

Janke (2000). Esse princípio é resultado de se considerar um escoamento laminar como homogêneo na direção z. Dessa forma, as equações de transporte de quantidade de movimento nas direções x e y são desacopladas da equação referente à direção z. O princípio permanece uma hipótese razoável para pequenos níveis de turbulência e deixa de ser válido à medida que as componentes $\overline{u^{\prime} w^{\prime}}$ e $\overline{v^{\prime} w^{\prime}}$ das tensões de Reynolds passam a interferir de forma significativa nas demais componentes, que por sua vez têm influência nas médias temporais de $u$ e $v$, designadas por $U$ e $V$. Para o caso do degrau expansor com enflechamento, Kaltenbach e Janke (2000) mostram que a hipótese é válida até um enflechamento de aproximadamente $40^{\circ}$. Porém, para o caso de um aerofólio, esse valor deve ser maior, uma vez que os gradientes envolvendo $U$ e $V$ são mais intensos devido à circulação, e $\overline{u^{\prime} w^{\prime}}$ e $\overline{v^{\prime} w^{\prime}}$ são então menos significativos nas equações de quantidade de movimento em média temporal.

Comparando as soluções Lattice-Boltzmann e Navier-Stokes entre si, vê-se uma corre- 
spondência no nível de $C_{p}$, bem como no formato da curva ao longo de todo o elemento principal. No flap, as soluções concordam no nível do pico de sucção e na distribuição no intradorso, entretanto a separação da camada limite no extradorso é prevista mais a montante nas simulações com PowerFLOW. Além disso, diferente da solução do CFL3D, a distribuição de $C_{p}$ não assume um formato plano após a separação, apresentando o aspecto de uma bolha com posterior recolamento. De fato o recolamento ocorre para os dois valores de enflechamento, conforme mostrado na figura 67 para o caso com enflechamento de $35^{\circ}$. O motivo da discrepância entre as soluções se deve, provavelemente, à proximidade das paredes do túnel de vento na simulação com o Powerflow. Embora o ângulo de ataque tenha sido modificado na simulação com o CFL3D, o valor de $5,5^{\circ}$ foi escolhido de forma a manter o mesmo carregamento no eslate que a configuração do túnel de vento BART e ângulo de ataque de $4^{\circ}$, o que não garante o mesmo comportamento para os demais elementos. Outra possível explicação seria a diferença na espessura das camadas limite, já que o PowerFLOW tipicamente calcula camadas limite mais espessas que as calculadas pelo CFL3D (SIMõES; SOUZA; MEDEIROS, 2011), o que as torna mais suscetíveis à separação.

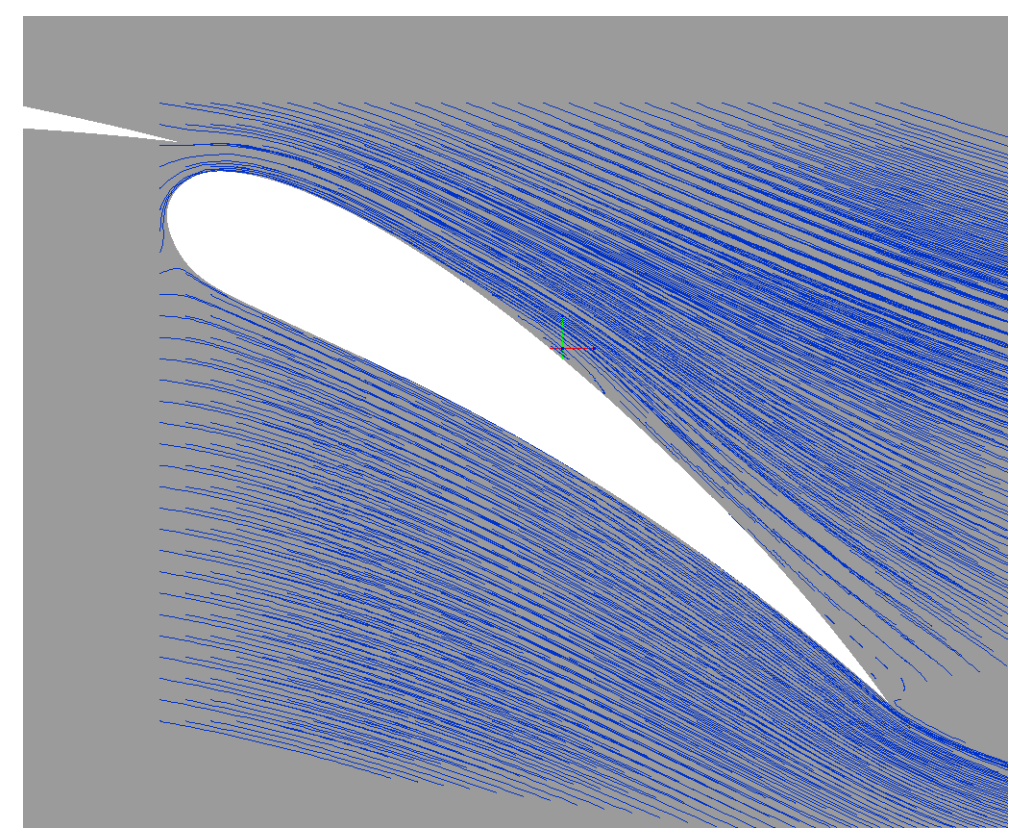

Figura 67 - Linhas de corrente ao redor do flap no caso com enflechamento de $35^{\circ}$.

Outra diferença significativa entre as duas soluções é a distribuição de pressão no extradorso do eslate. Pode-se observar que o $C_{p}$ calculado pelo PowerFLOW é menos negativo nessa região principalmente na região próxima ao bordo de ataque. Uma possível explicação para essa diferença é a espessura da camada limite, uma vez que o aumento desta provoca uma diminuição na circulação. Como os dois códigos usam modelos de turbulência distintos e a malha nas simulações com PowerFLOW é mais grosseira nas paredes, é esperado que as espessuras da 
camada limite calculadas pelas duas metodologias sejam diferentes.

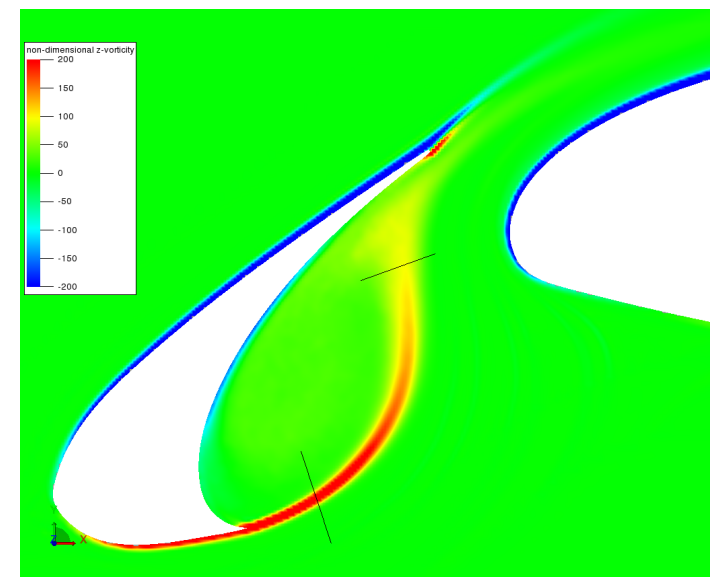

(a) PowerFLOW

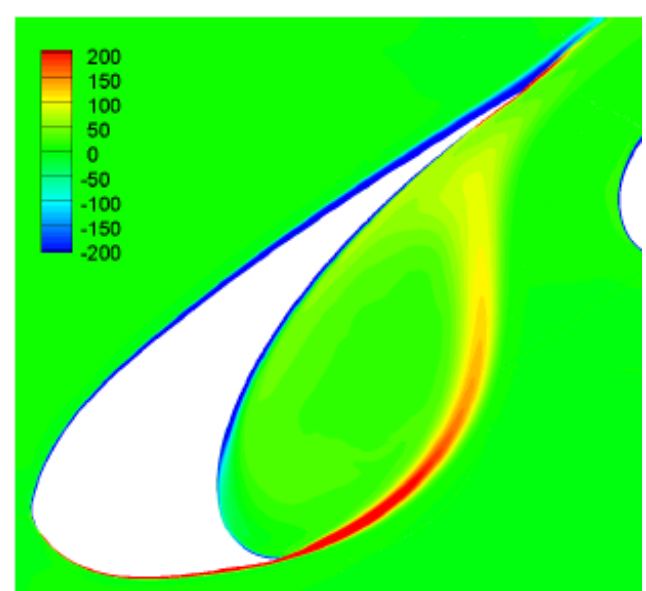

(b) Lockard e Choudhari (2010)

Figura 68 - Campo da componente de vorticidade na direção da envergadura. Enflechamento de $35^{\circ}$.

As figuras 68 e 69 mostram a média temporal da componente de vorticidade na direção da envergadura adimensionalizada pela corda do aerofólio com os elementos retraídos, $c_{c r u z}$, e pela componente em $\mathrm{x}$ da velocidade de corrente livre, $U_{\infty}$, ou seja $\omega_{z} c_{c r u z} / U_{\infty}$. Para os dois casos, as soluções do PowerFLOW e do CFL3D são semelhantes. Entretanto, as camadas limite calculadas pelo PowerFLOW são mais espessas.

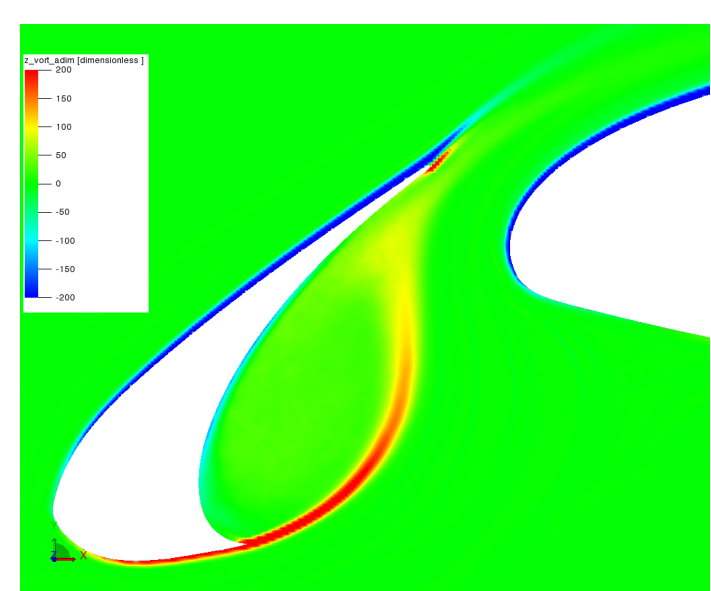

(a) PowerFLOW

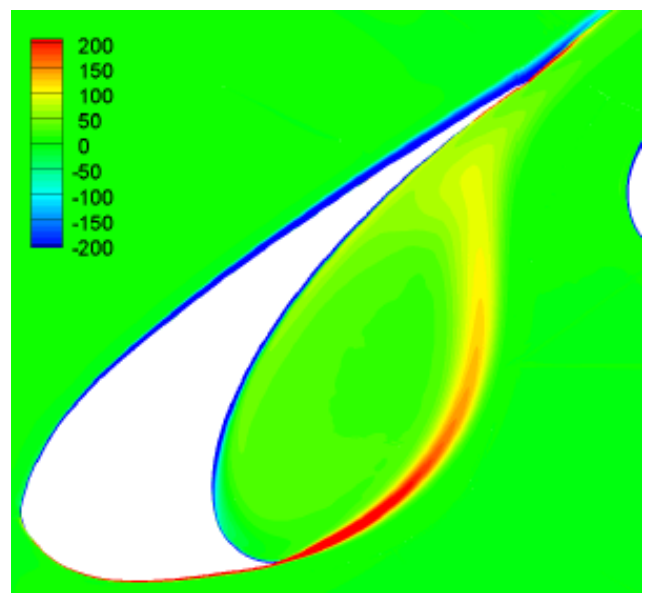

(b) Lockard e Choudhari (2010)

Figura 69 - Campo da componente de vorticidade na direção da envergadura. Enflechamento de $45^{\circ}$.

A energia cinética turbulenta adimensionalizada, calculada a partir das flutuações resolvidas, estão mostradas nas figuras 70 e 71 para os casos com enflechamento de $35^{\circ}$ e $45^{\circ}$ respectivamente. Tantos as soluções Lattice-Boltzmann quanto as baseadas nas equações de Navier- 
Stokes têm um comportamento geral semelhante. A energia cresce gradativamente ao longo da camada cisalhante livre, atingindo um máximo local aproximadamente na metade do caminho até a parede inferior do eslate. Próximo ao recolamento a energia cinética turbulenta sofre um aumento brusco. Também dentro da região de recirculação as previsões são semelhantes.

Entretanto algumas diferenças são observadas. Enquanto a região de flutuações intensas próximo ao recolamento pode ser visivelmente separada em duas, nas simulações de referência, as soluções do PowerFLOW apresentam uma única região maior com flutuações mais intensas. De acordo com a discussão apresentada por Lockard e Choudhari (2010), a região de elevada energia turbulenta adjacente à parede é consequência do aumento nas flutuações na direção da envergadura, $\left\langle w^{\prime} w^{\prime}\right\rangle$, enquanto a região mais abaixo se deve ao aumento das flutuações da componente vertical de velocidade, $\left\langle v^{\prime} v^{\prime}\right\rangle$. A figura 72 apresenta contornos das componentes $\left\langle u^{\prime} u^{\prime}\right\rangle^{\prime}$, $\left\langle v^{\prime} v^{\prime}\right\rangle$ e $\left\langle w^{\prime} w^{\prime}\right\rangle$ das tensões de Reynolds baseada nas simulações do PowerFLOW para o caso com enflechamento de $35^{\circ}$. O mesmo comportamento descrito para as simulações de referência é observado na região de recolamento da camada de mistura. Porém, observa-se que as regiões de elevada $\left\langle v^{\prime} v^{\prime}\right\rangle$ e $\left\langle w^{\prime} w^{\prime}\right\rangle$, perto do recolamento, são substancialmente maiores que as regiões mostradas nas figuras 70(b). Embora não esteja mostrado aqui, o mesmo comportamento é observado no caso com enflechamento de $45^{\circ}$.

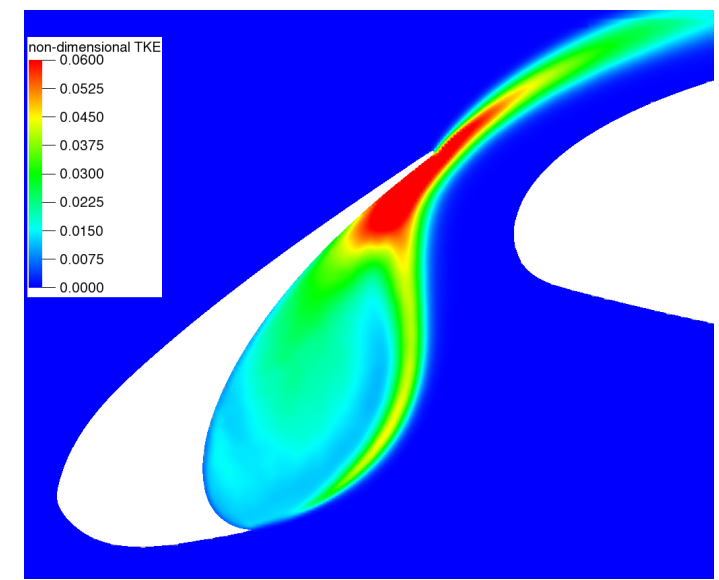

(a) PowerFLOW

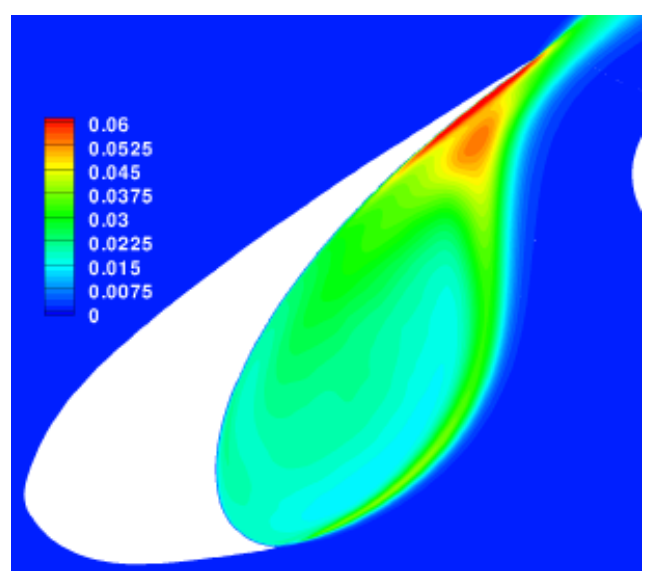

(b) Lockard e Choudhari (2010)

Figura 70 - Campo de energia cinética turbulenta calculada a partir das flutuações de velocidade no caso com enflechamento de $35^{\circ}$.

A figura 73 compara os espectros de flutuação da componente de velocidade $u$ em pontos escolhidos ao longo da camada de mistura do caso com enflechamento de $35^{\circ}$. A frequência foi adimensionalizada pela corda do eslate, $c_{\text {slat }}$ e pela componente $U_{\infty}$ da velocidade de entrada. É clara a diferença entre os níveis de flutuação calculados através do PowerFLOW e do CFL3D. Enquanto os níveis das simulações de referência se concentram entre $5 \times 10^{-4}(\mathrm{~m} / \mathrm{s})^{2} / \mathrm{Hz}$ e 


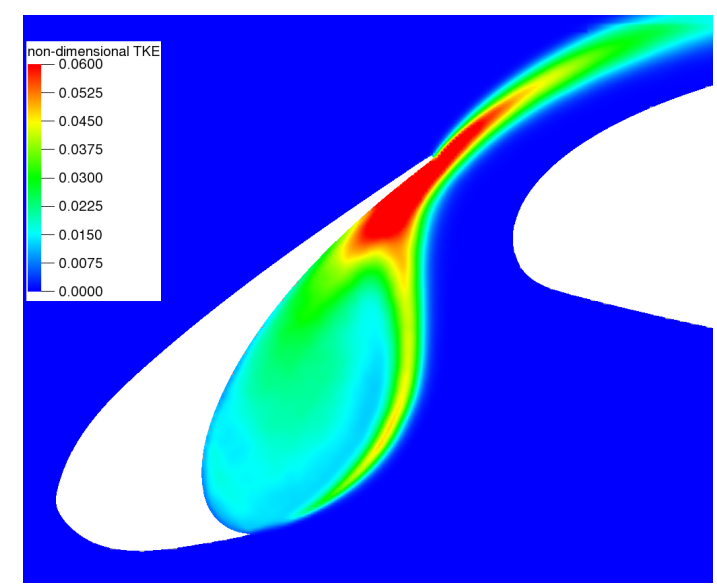

(a) PowerFLOW

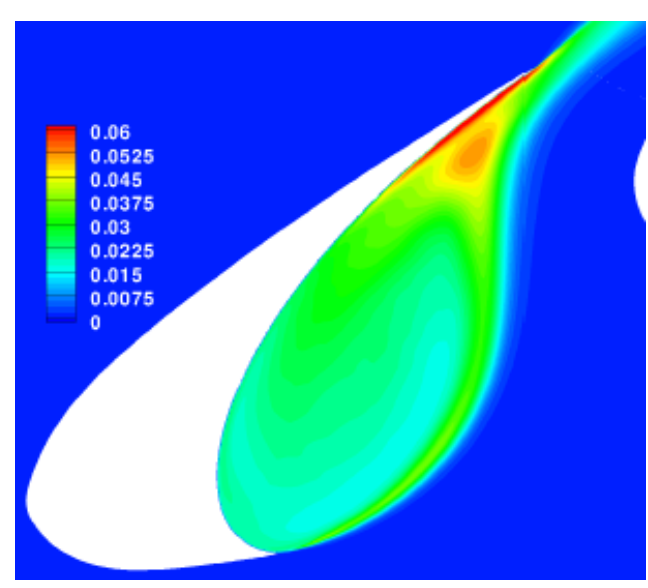

(b) Lockard e Choudhari (2010)

Figura 71 - Campo de energia cinética turbulenta calculada a partir das flutuações de velocidade no caso com enflechamento de $45^{\circ}$.

$3 \times 10^{-3}(\mathrm{~m} / \mathrm{s})^{2} / \mathrm{Hz}$ em boa parte do espectro, as curvas referentes ao presente trabalho ocupam tipicamente a faixa de $3 \times 10^{-3}(\mathrm{~m} / \mathrm{s})^{2} / \mathrm{Hz}$ a $1 \times 10^{-2}(\mathrm{~m} / \mathrm{s})^{2} / \mathrm{Hz}$. Como mostrado na figura 74(a), nas simulações sem enflechamento, Lockard e Choudhari (2010) apresentam espectros de $u^{\prime}$ com intensidades compatíveis às mostradas na figura 73(b), entretanto, conforme discutido no capítulo 2 e mostrado na figura 74(b), resultados apresentados por Lockard e Choudhari (2011) usando o mesmo código para a condição sem enflechamento mostraram PSD de $u^{\prime}$ tipicamente entre $1 \times 10^{-3}(\mathrm{~m} / \mathrm{s})^{2} / \mathrm{Hz}$ a $5 \times 10^{-2}(\mathrm{~m} / \mathrm{s})^{2} / \mathrm{Hz}$ ao longo da camada de mistura, ou seja em desacordo com os resultados de Lockard e Choudhari (2010).

Apesar da diferença entre os níveis de flutuação, o formato geral das curvas se assemelham entre os resultados do PowerFLOW e do CFL3D. A evolução da camada de mistura é prevista de forma semelhante pelos dois códigos. Contudo, o cálculo do PowerFLOW não apresenta o pico captado no espectro do ponto $S / S_{\max }=0,2$ pela simulação de referência em $S t=20$. Outra diferença significativa entre as soluções é a taxa de decaimento da energia de flutuações com a frequência. Observa-se que a solução pelo MLB apresenta uma taxa de decaimento menor em comparação com a simulação pelas equações de Navier-Stokes. A curva designada por $-5 / 3$ corresponde a uma variação proporcional a $f^{-5 / 3}$, de acordo com a teoria de Kolmogorov. Vê-se, portanto, que a solução do PowerFLOW está mais próxima da teoria com relação à dissipação das estruturas turbulentas. As mesmas observações feitas a respeito do caso $\beta=35^{\circ}$ estão presentes na comparação entre as soluções do MLB e Navier-Stokes no caso com $45^{\circ}$ de enflechamento.

Espectros das flutuações de pressão em dois pontos da superfície do eslate estão mostrados na figura 75. Os gráficos da coluna da esquerda foram feitos a partir das simulações com 


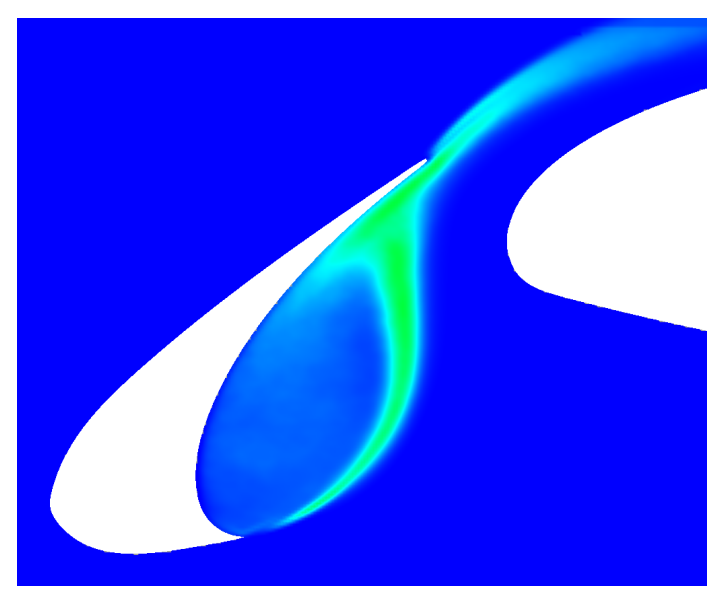

(a) $\overline{u^{\prime} u^{\prime}}$

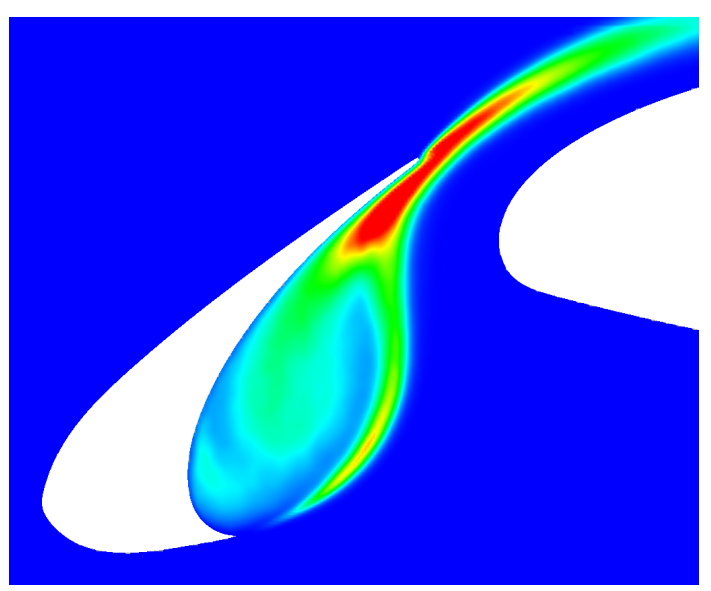

(b) $\overline{v^{\prime} v^{\prime}}$

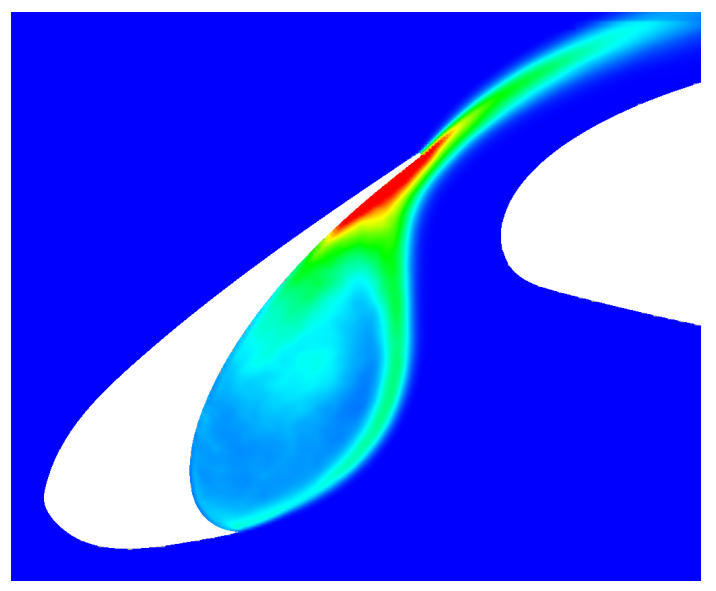

(c) $\overline{w^{\prime} w^{\prime}}$

Figura 72 - Componentes $\overline{u^{\prime} u^{\prime}}, \overline{v^{\prime} v^{\prime}}$ e $\overline{w^{\prime} w^{\prime}}$ da tensão de Reynolds, calculadas a partir das simulações Lattice-Boltzmann. Enflechamento de $35^{\circ}$.

o PowerFLOW e incluem os resultados apresentados por Simões, Souza e Medeiros (2011) para $\beta=0^{\circ}$. Os gráficos da coluna da direita foram retirados de Lockard e Choudhari (2010). Nos dois casos as curvas foram ajustadas de acordo com a hipótese de que $p^{\prime} \sim U_{\infty}^{2}$ e são apresentadas em função da frequência adimensional $S t=f c_{s l a t} / U_{\infty}$. Algumas tendências são capturadas de forma semelhante pelos dois métodos. Enquanto as curvas referentes ao ponto 6, no extradorso do eslate, colapsam razoavelmente bem, o mesmo não ocorre nas curvas do pontos 3 (ponto de recolamento). Além disso, tanto nas simulações com o PowerFLOW quanto nas simulações com o CFL3D, alguns picos observados nos espectros do ponto 6 são mais suaves no caso de enflechamento de $45^{\circ}$.

Por outro lado, algumas características são distintas entre os gráficos da esquerda e os da direita. Na faixa de frequências mais baixas, até $S t \approx 3$, os espectros apresentam diferenças de $3 d B$ a $5 d B$ entre as metodologias. Nos cálculos do PowerFLOW, os picos são significativa- 


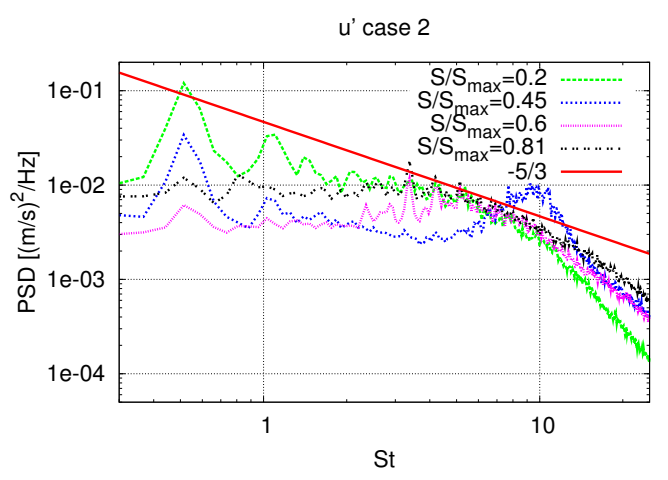

(a) PowerFLOW

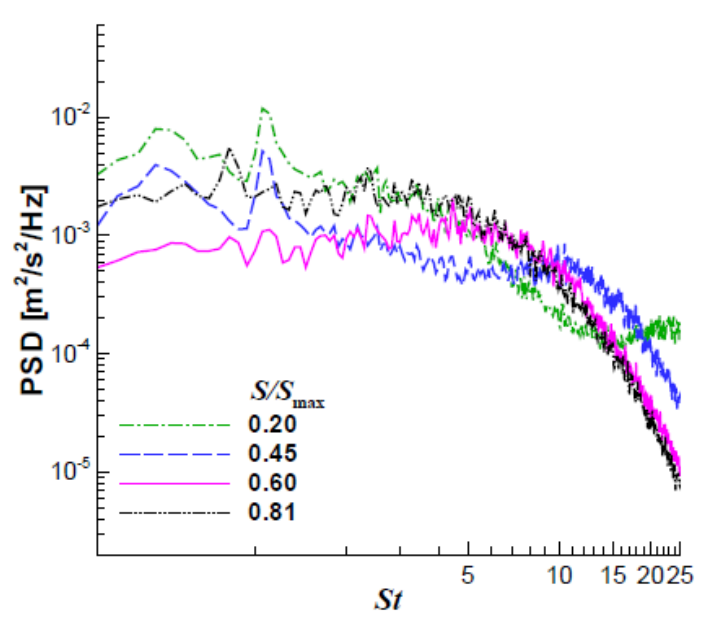

(b) Lockard e Choudhari (2010)

Figura 73 - Espectros de flutuações de velocidade $u$ no caso com enflechamento de $35^{\circ}$.

mente mais salientes do que nas simulações Navier-Stokes. No caso $\beta=45^{\circ}$ eles praticamente somem nos gráficos baseados no CFL3D, enquanto os resultados do PowerFLOW para este caso mostram alguns picos tão prominentes quanto dos outros dois casos. Assim como os espectros de velocidade, os espectros de pressão calculados no presente trabalho também possuem uma taxa de decaimento da energia das flutuações menor do que a prevista pelo CFL3D.

A figura 76 também mostra os espectros de pressão nos pontos 3 e 6 , porém sem a adimensionalização da frequência. Vê-se que, no ponto 3 , os espectros dos casos $\beta=35^{\circ}$ e $\beta=45^{\circ}$ colapsam entre si mas não colapsam com o espectro do caso sem enflechamento. O mesmo comportamento ocorre com os espectros de flutuação de pressão nos pontos 2 e 4 . Por sua vez, a escala em Strouhal provoca um melhor colapso entre as curvas dos casos com enflechamento no ponto 6, tanto nas simulações com MLB quanto nas simulações com as equações de NavierStokes.

A propagação de ruído gerado pelo eslate foi calculado através da analogia de Ffowcs Williams-Hawkings utilizando a formulação apresentada na seção 3.3.3. De acordo com o sistema de coordenadas polares apresentado na figura 28 o ponto está localizado a $290^{\circ}$ e a uma distância de $10 c_{c r u z}$ da cova do eslate. Esse ponto se encontra na posição de máxima energia acústica propagada para a região abaixo do aerofólio de acordo com cálculos preliminares das flutuações em todas as frequências no presente trabalho. A densidade de potência espectral para esse ponto está apresentada nas figuras 77 e 78 em função da frequência adimensionalizada e absoluta respectivamente. Os resultados dos cálculos baseados no PowerFLOW são comparados com os resultados do CFL3D e as curvas foram ajustadas de acordo com a hipótese $p^{\prime} \sim U_{\infty}^{2}$ 


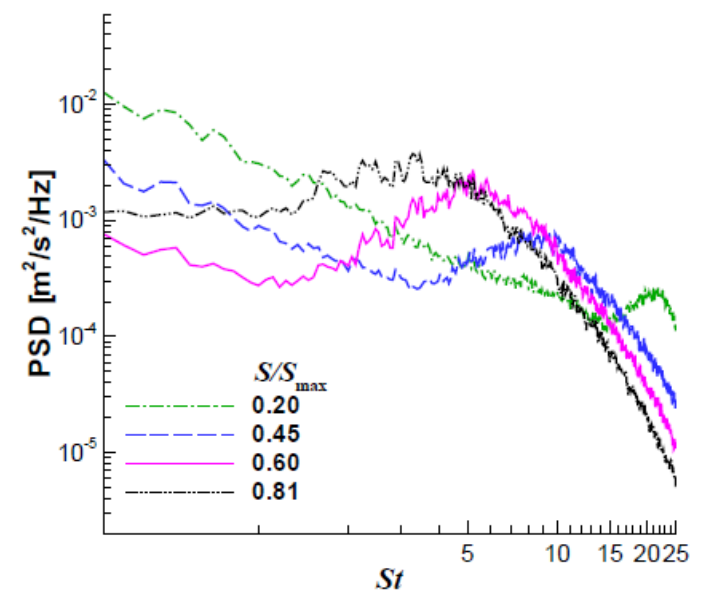

(a) CFL3D (Lockard e Choudhari (2010))

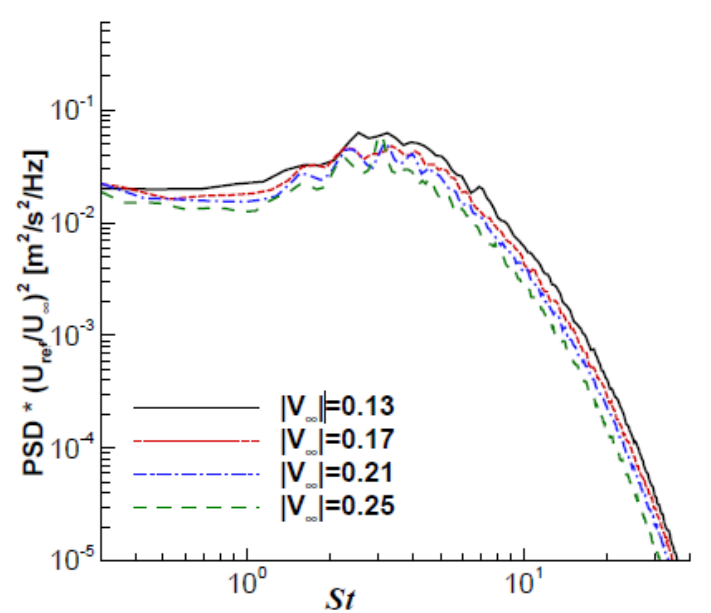

(b) CFL 3D $S / S_{\max }=0,81$ Lockard e Choudhari (2011)

Figura 74 - Espectros de flutuações de velocidade $u$ calculados pelo CFL3D em casos sem enflechamento apresentados em publicações diferentes.

Assim como nos espectros de flutuação de velocidade ao longo da camada de mistura, uma diferença significativa no nível das curvas é observado entre os resultados das simulações deste trabalho e das simulações do trabalho usado como referência. Essa discrepância já foi observada entre resultados do CFL3D publicados em trabalhos distintos para a mesma configuração, como mostrados no capítulo 2. O nível da densidade de potência espectral calculada pelo PowerFLOW é compatível com os resultados publicados por Lockard e Choudhari (2011), inclusive no que se refere à taxa de decaimento com a frequência. Porém, esse trabalho não apresentada resultados de simulações com escoamento cruzado, portanto as curvas das simulações com o PowerFLOW são comparadas com os resultados publicados por Lockard e Choudhari (2010).

Um padrão do ruído é observado nos espectros calculados a partir das simulações utilizando os dois métodos, a saber a sucessão de picos tonais entre $S t \approx 1,5$ e $S t \approx 5$ seguidos de flutuações com características de banda larga nas frequências mais elevadas. Outra característica comum aos dois métodos é a diminuição dos picos tonais de baixa frequência no caso com o enflechamento mais elevado. Entretanto esse picos quase desaparecem na simulação com o CFL3D mas ainda são visíveis na simulações com o PowerFLOW. É possível notar também que, para as soluções utilizando os dois códigos, a adimensionalização da frequência não provoca um bom colapso das curvas na região das frequências mais elevadas, onde o ruído é tipicamente de banda larga.

Em geral uma boa concordância é observada entre os resultados baseados na metodologia com o PowerFLOW e o CFL3D. As propriedades do escoamento apresentaram características 


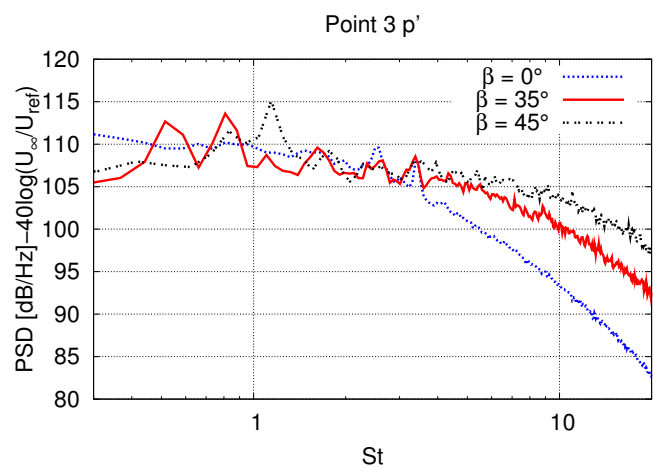

(a) Ponto 3 - PowerFLOW

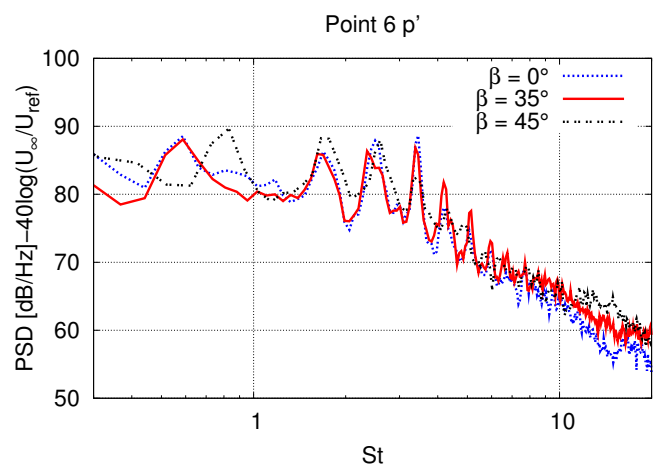

(c) Ponto 6 - PowerFLOW

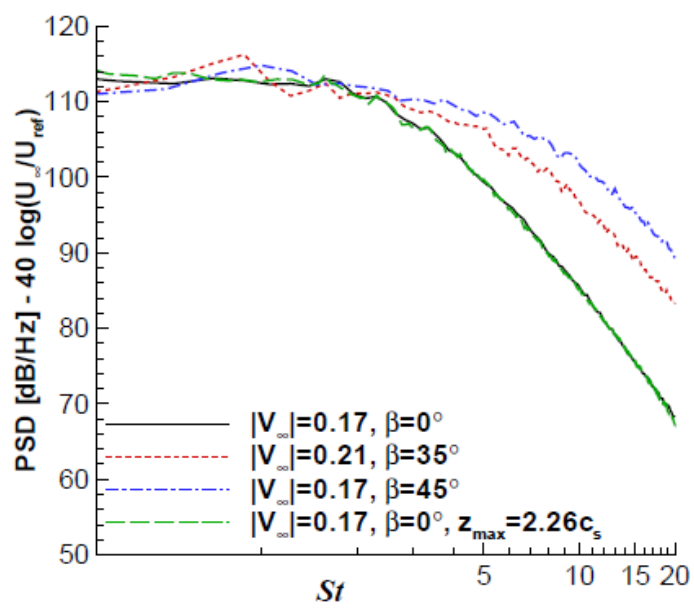

(b) Ponto 3 - Lockard e Choudhari (2010)

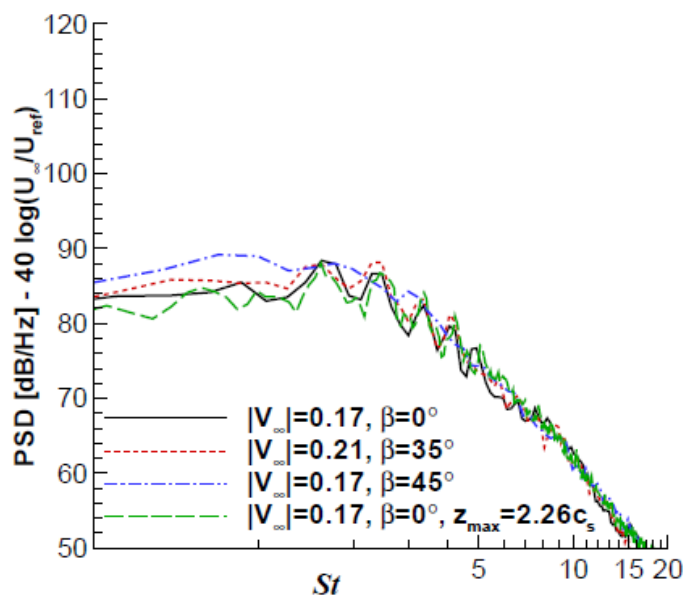

(d) Ponto 6 - Lockard e Choudhari (2010)

Figura 75 - Espectros de flutuação de pressão em dois pontos escolhidos na superfície do aerofólio para três diferentes enflechamentos em função da frequência adimensionalizada.

qualitativas comuns além de valores compatíveis no campo próximo. A exceção é o nível de energia cinética turbulenta no ponto de recolamento. Também o formato dos espectros de flutuação e o efeito do escoamento cruzado nestes são semelhantes nas duas metodologias. Porém não foi possível comparar de forma apropriada o nível de flutuação de velocidade ao longa da camada de mistura devido a alterações nos resultados do CFL3D entre publicações diferentes. $\mathrm{O}$ mesmo ocorreu com o espectro de flutuações no campo distante calculado a partir da analogia de FW-H. 


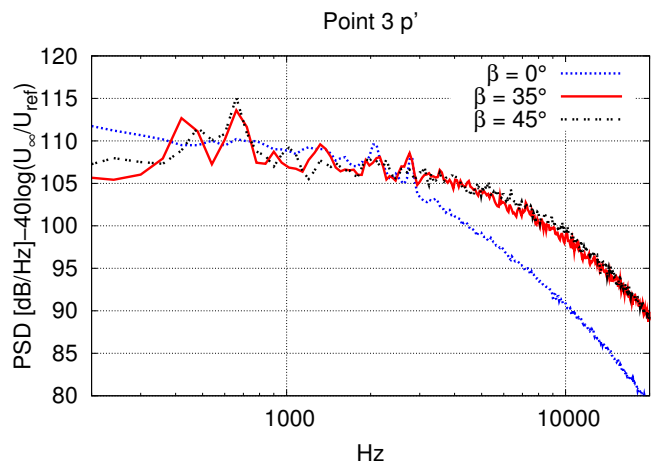

(a) Ponto 3 - PowerFLOW

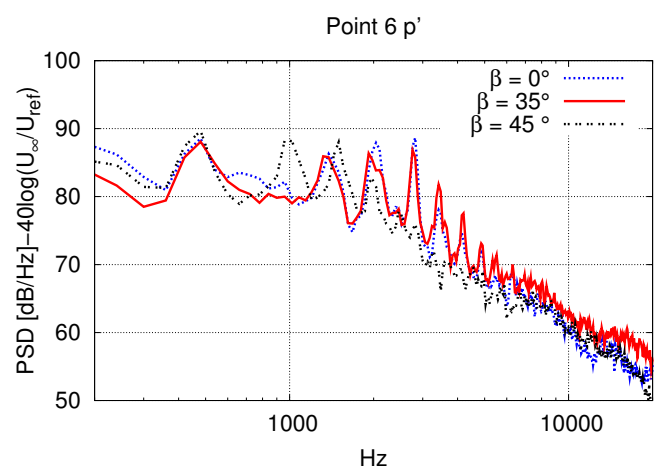

(c) Ponto 6 - PowerFLOW

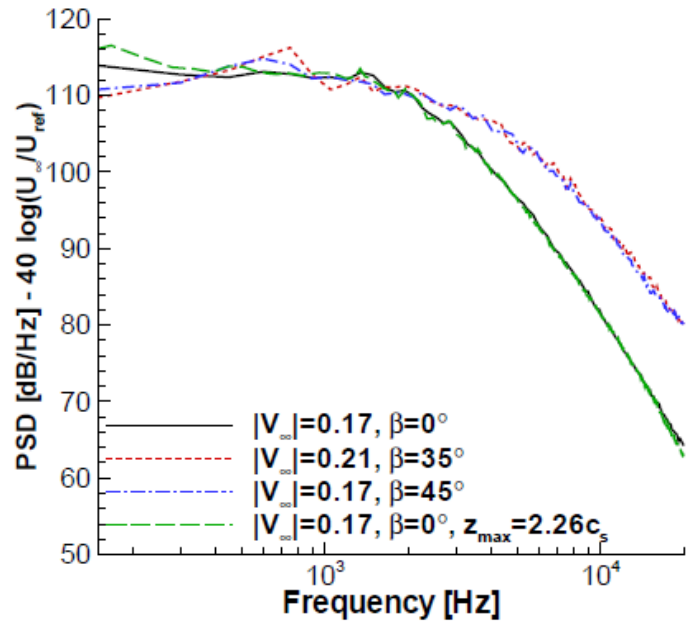

(b) Ponto 3 - Lockard e Choudhari (2010)

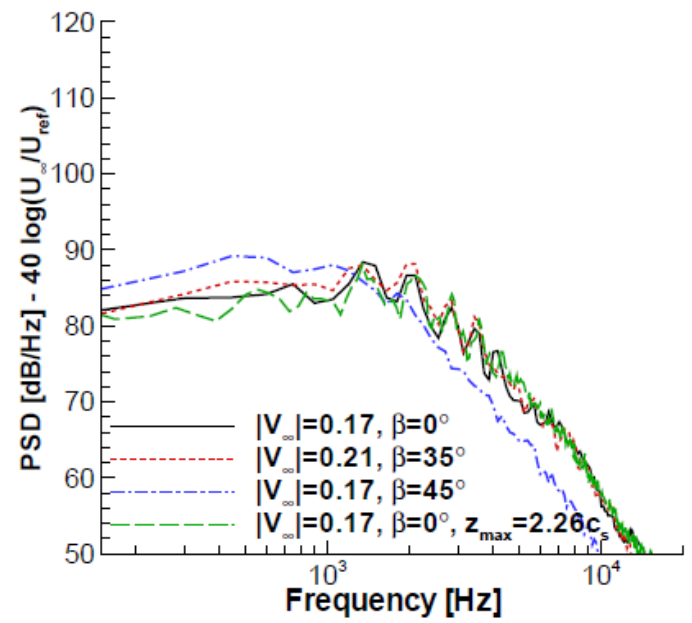

(d) Ponto 6 - Lockard e Choudhari (2010)

Figura 76 - Espectros de flutuação de pressão nos pontos 3 e 6 em função da frequência absoluta. 


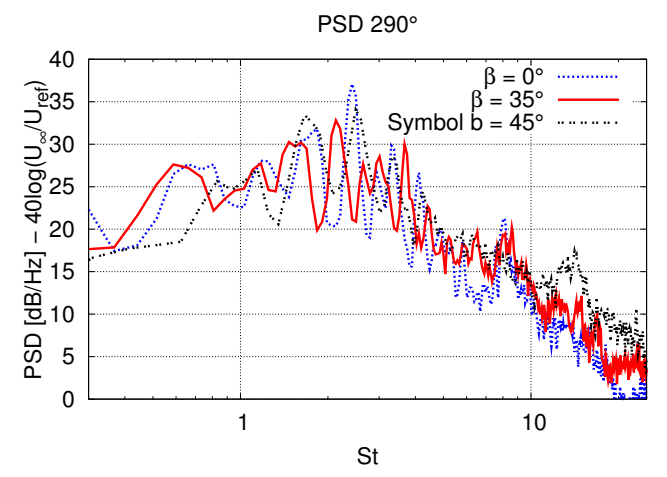

(a) PowerFLOW

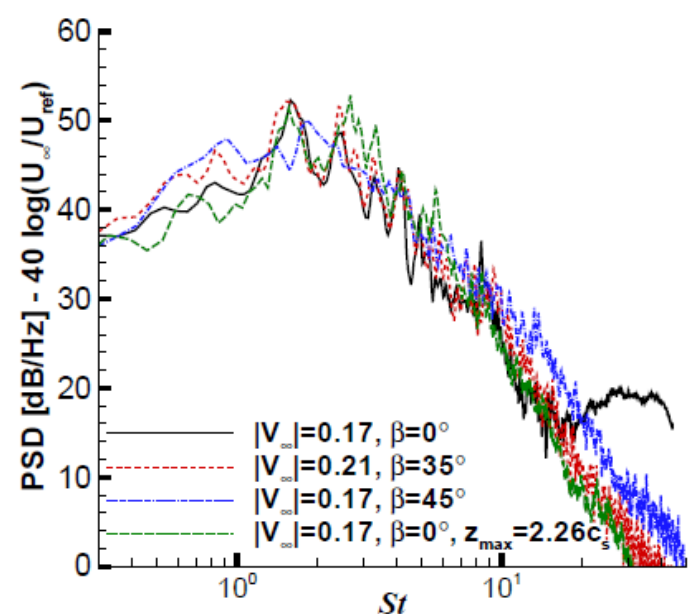

(b) Lockard e Choudhari (2010)

Figura 77 - Espectros de flutuação de pressão propagada a partir do eslate para um ponto a $10 c_{c r u z}$ de distância em função da frequência adimensionalizada.

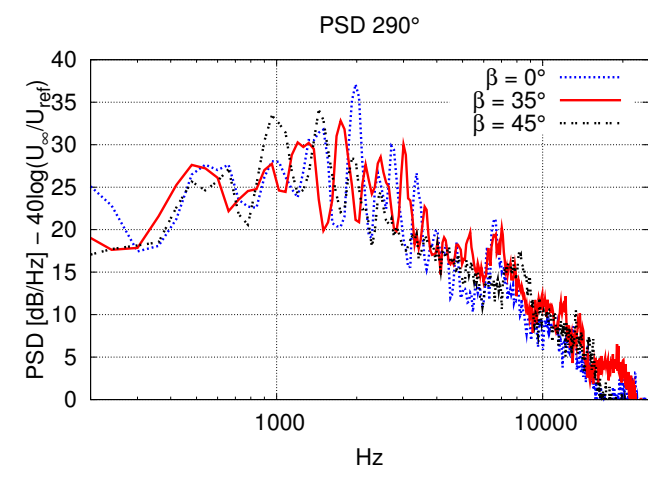

(a) PowerFLOW

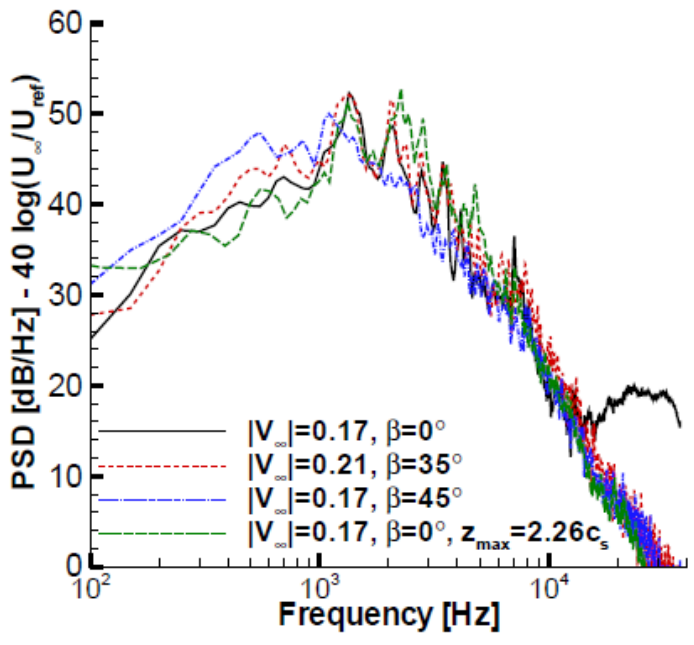

(b) Lockard e Choudhari (2010)

Figura 78 - Espectros de flutuação de pressão propagada a partir do eslate para um ponto a $10 c_{c r u z}$ de distância em função da frequência absoluta. 


\subsubsection{Efeito das Camadas Limite no Ruído Provocado pelo Eslate com Escoamento Cruzado}

Simões, Souza e Medeiros (2011) demonstraram que, pelo menos em certas circunstâncias, as propriedades aeroacústicas do eslate não dependem das camadas limite deste e do elemento principal. Eles mostraram que a consideração de parede com escoamento livre não altera significativamente o cálculo do ruído produzido pelo eslate. No presente trabalho foram feitas simulações para avaliar se essa hipótese também pode ser adotada na simulação de aerofólios com escoamento cruzado. Os resultados do PowerFLOW para os casos $\beta=35^{\circ}$ e $\beta=45^{\circ}$, comparados na seção 5.3.2 com resultados de simulações Navier-Stokes, são comparados nesta seção com resultados de simulações correspondentes considerando condição de parede com escorregamento livre na superfície do elemento principal e parte da superfície do eslate. A superfície da cova do eslate e a superfície de todo flap foram considerados como parede sem escorregamento em todas as simulações. A configuração de malha otimizada (Fig. 15) também foi testada nos dois casos com escoamento cruzado.

Na figura 79 é mostrado o efeito das camadas limite na distribuição de pressão na superfície do aerofólio. Ao contrário do que se espera, a ausência das camadas limite do eslate e elemento principal causou uma diminuição na sucção no extradorso dos três elementos. Essa ocorrência inesperada é, provavelmente, consequência de uma cadeia de causas e consequências. A ausência da esteira do elemento principal antecipou a separação da camada limite do flap, diminuindo sua circulação, o que provocou a diminuição na circulação do elemento principal e, em menor escala, do eslate.

A figura 80 mostra as linhas de corrente na região do flap para as três configurações do caso com enflechamento de $45^{\circ}$, deixando clara a variação no ponto de separação da camada limite. Para facilitar a comparação, a cruz marca a mesma posição nas três imagens. Uma variação ligeiramente menor ocorre no caso com enflechamento de $35^{\circ}$, como pode-se inferir do gráfico $\operatorname{de} C_{p}$.

As médias temporais de $\omega_{z} c_{c r u z} / U_{\infty}$ na região da cova do eslate são mostradas nas figuras 81 e 82 , onde $\omega_{z}$ é a componente de vorticidade na direção da envergadura. Os contornos são para uma fatia do escoamento no centro da envergadura simulada. Nas figuras 81(b), 81(c), 82(b) e 82(c), percebe-se claramente a ausência das camadas limite no elemento principal e na superfície do eslate externa à cova.

Embora as figuras 81 e 82 não tenha exibido uma diferença significativa na camada de mistura da cova do eslate entre as soluções com diferentes condições de parede, os perfis de ve- 


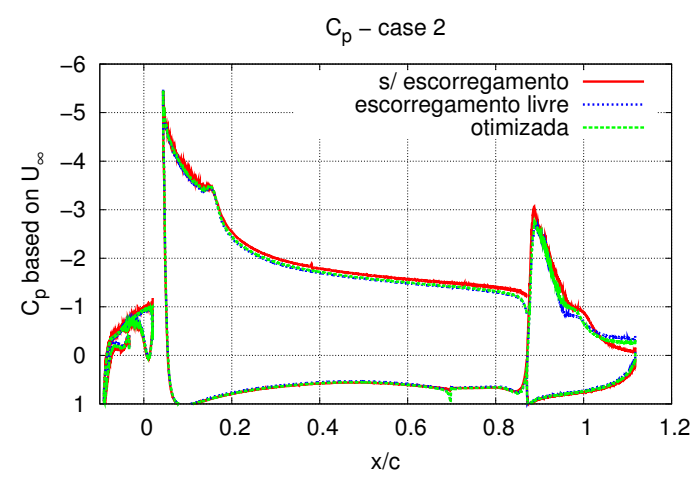

(a) Enflechamento: $35^{\circ}$

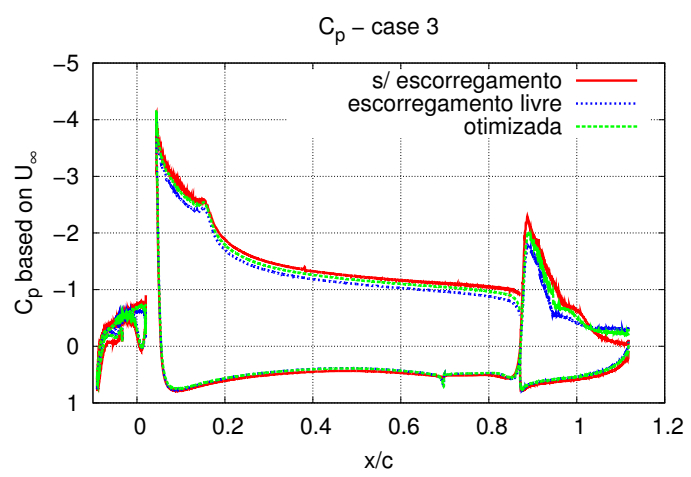

(b) Enflechamento: $45^{\circ}$

Figura 79 - Efeito da camada limite na distribuição de pressão.

locidade ao longo das linhas mostradas na figura 81(a) mostram que houve algumas alterações, sendo que todas são mais visíveis no caso com maior ângulo de enflechamento. Como é visto mais claramente através da figura 84(a), a velocidade do núcleo potencial entre o eslate e o elemento principal é maior nas simulações que consideram paredes com escorregamento livre. Como pode ser visto nos gráficos de $C_{p}$, nos casos com escorregamento livre, a pressão no intradorso do eslate é menor, o que em uma aproximação grosseira pela equação de Bernoulli, resulta em uma velocidade mais alta.

O emprego da configuração de malha otimizada tem efeitos distintos nos dois casos com enflechamentos diferentes. No caso $\beta=35^{\circ}$ observa-se que as soluções com condições de escorregamento livre são semelhantes. Já no caso com enflechamento de $45^{\circ}$, a solução com a malha otimizada assume uma posição intermediária entre as soluções com a malha de referência no que diz respeito ao perfil de velocidade na camada de mistura. Esse comportamento é semelhante ao observado na distribuição de pressão no aerofólio.

As figuras 85 e 86 mostram os espectros de flutuações da componente de velocidade na direção x em dois pontos da camada de mistura, comparando-se as soluções com e sem as camadas limite no elemento principal e no eslate. Na região da camada de mistura mais próxima da cúspide observa-se uma mais energia nas frequências mais elevadas quando se adota a condição de parede com escorregamento livre (Fig. 85(a) e 86(a)). No entanto, à medida que se avança na camada de mistura em direção ao recolamento, os espectros se tornam praticamente idênticos. No caso com enflechamento de $35^{\circ}$, apenas os picos se diferenciam ligeiramente no espectro do ponto $S / S_{\max }=0,81$. Por sua vez uma pequena diferença no nível do espectro é observada no caso com enflechamento de $45^{\circ}$. Porém essa diferença é muito pequena e está dentro do nível de incerteza do próprio modelo, ou seja, abaixo de $3 \mathrm{~dB} / \mathrm{Hz}$. 


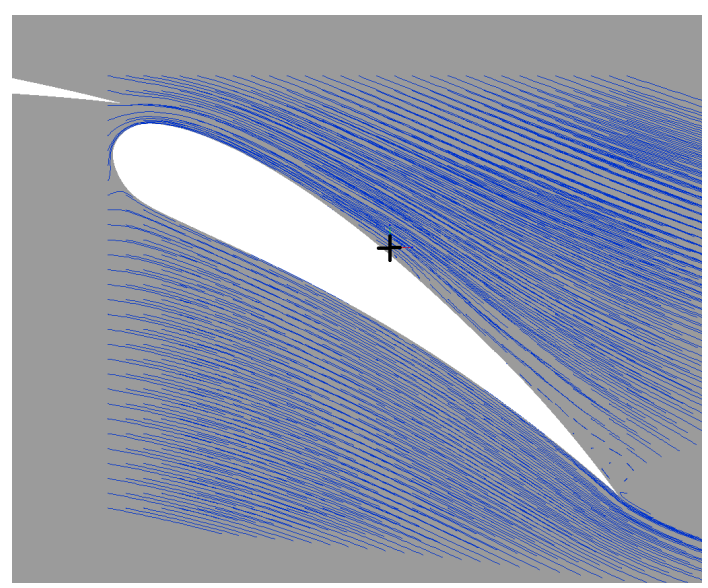

(a) Sem escorregamento

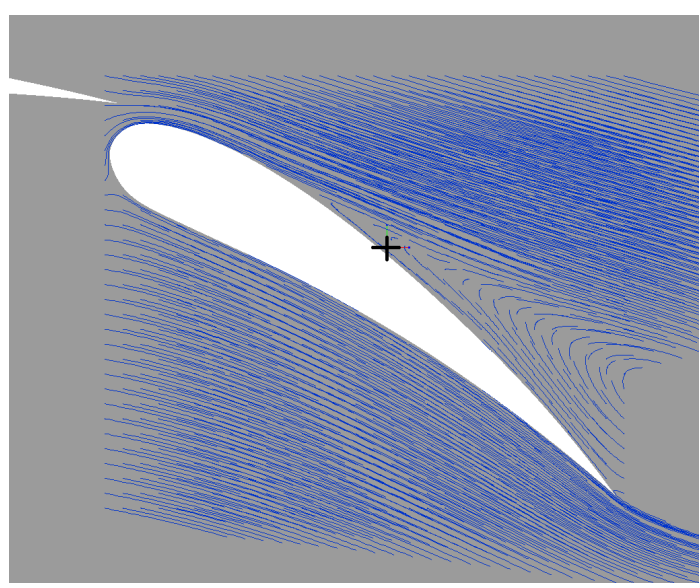

(b) Escorregamento livre

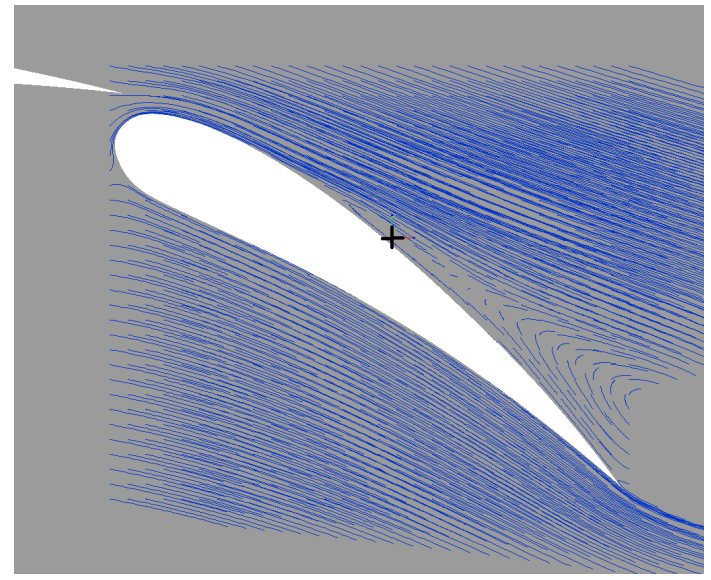

(c) Escorregamento livre (malha otimizada)

Figura 80 - Linhas de corrente em torno no flap mostrando a separação da camada limite. A cruz vermelha e azul indica um local fixo nas duas imagens.

Curvas da densidade de potência espectral da pressão em dois pontos na superfície do aerofólio estão apresentadas nas figuras 87 e 88 . Novamente, variações abaixo de $3 \mathrm{~dB} / \mathrm{Hz}$ são encontradas, quando se emprega parede com escorregamento livre, com excessão da altura do pico em $S t \approx 0,8$ no espectro do ponto 3 do caso $\beta=45^{\circ}$, que apresenta uma diferença de $5 d B / H z$. Embora não esteja clara a razão para essa discrepância, esta pode estar liga a uma variação nas oscilações na superfícies do flap que é propagada para o restante do aerofólio.

Os espectros do som propagado para um ponto a uma distância de $10 c_{c r u z}$ da cova do eslate a $290^{\circ}$ estão mostrados na figura 89. A concordância entre a solução com parede com escorregamento livre e sem escorregamento é significativamente maior para o caso $\beta=35^{\circ}$. Esse fato está provavelmente associado à maior degradação da circulação do flap no caso $\beta=45^{\circ}$ quando se emprega parede com escorregamento livre no elemento principal e no eslate. Entretanto, mesmo no caso de maior enflechamento, a variação na potência causada pela ausência das camadas lim- 


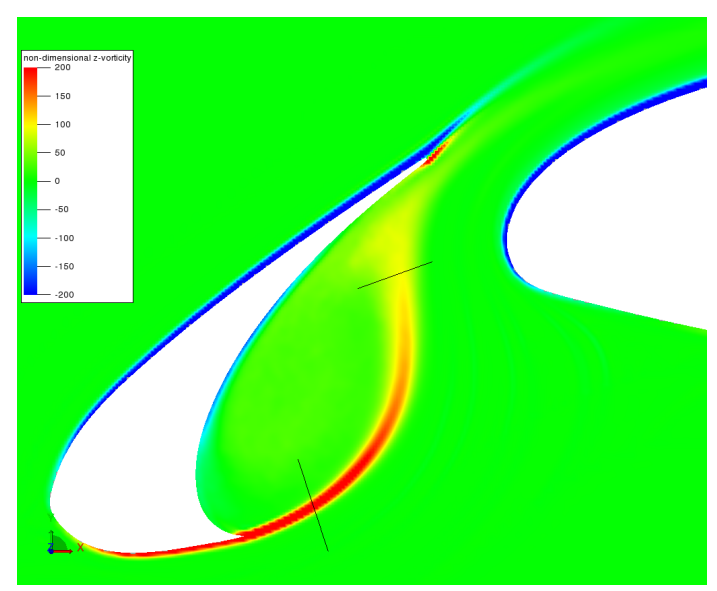

(a) Sem escorregamento

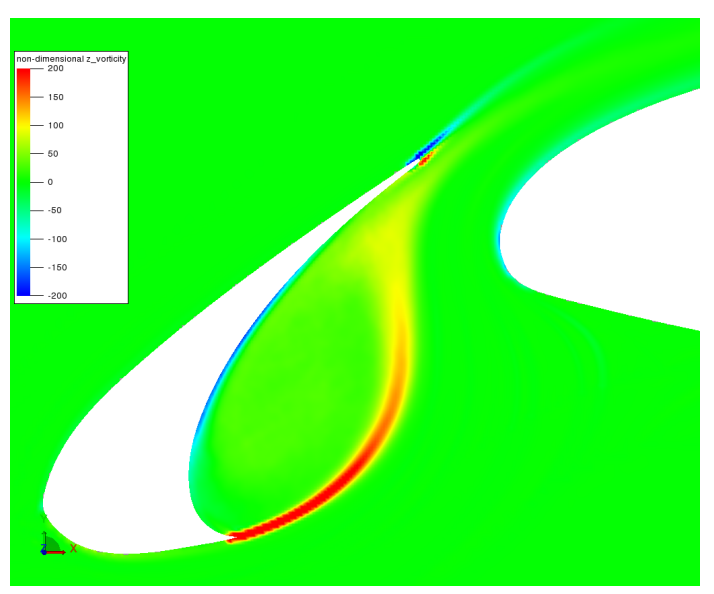

(b) Escorregamento livre

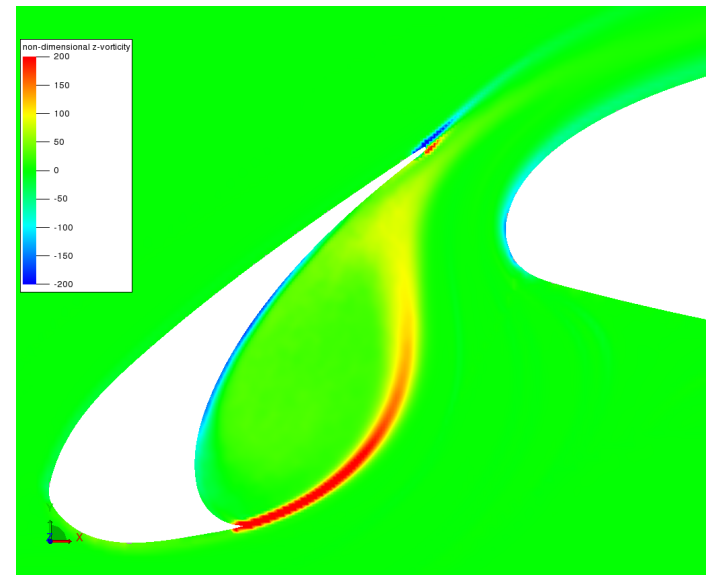

(c) Escorregamento livre (malha otimizada)

Figura 81 - Efeito da camada limite no campo da componente de vorticidade na direção da envergadura. Enflechamento de $35^{\circ}$.

ite se limita a $5 \mathrm{~dB} / \mathrm{Hz}$. Se considerarmos apenas as flutuações de banda-larga (única presente em um aerofólio com hiper-sustentadores em escala real (DOBRZYNSKI, 2010)), essa diferença fica em $3 d B / H z$. Um aumento significativo é observado por volta de $S t=0,3$ nos dois casos. O aumento do intervalo amostral descartado no início da simulação diminui a intensidade desse pico, indicando que este está associado ao transiente inicial da simulação.

Já o resultado do cálculo com a analogia de Ffowcs Williams-Hawkings a partir da solução com a malha otimizada é significativamente diferente da solução com a malha de referência no caso com enflechamento de $35^{\circ} \mathrm{em}$ toda a faixa de frequência analisada. A causa para essa discrepância não é compreendida uma vez que a concordância dos parâmetros do campo próximo entre as malhas nesse caso é maior do que no caso $\beta=45^{\circ}$.

Portanto, assim como foi mostrado por Simões, Souza e Medeiros (2011) para o aerofólio sem enflechamento, também na presença de escoamento cruzado, nas condições analisadas, 


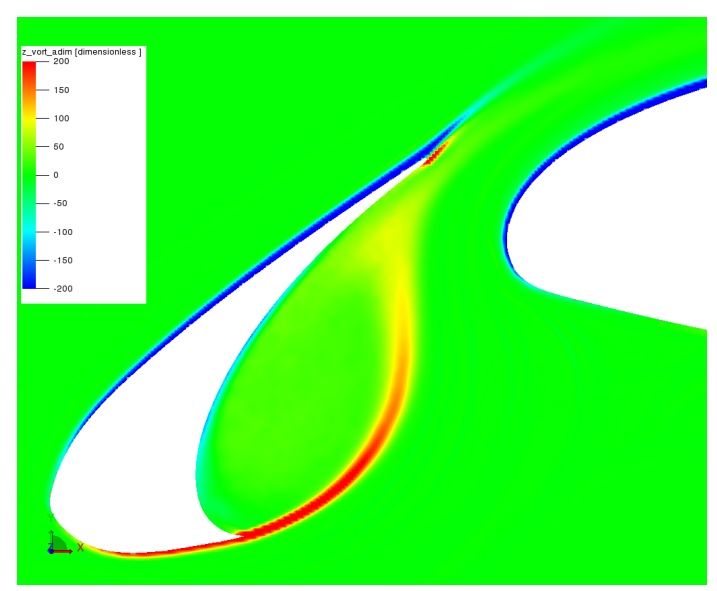

(a) Sem escorregamento

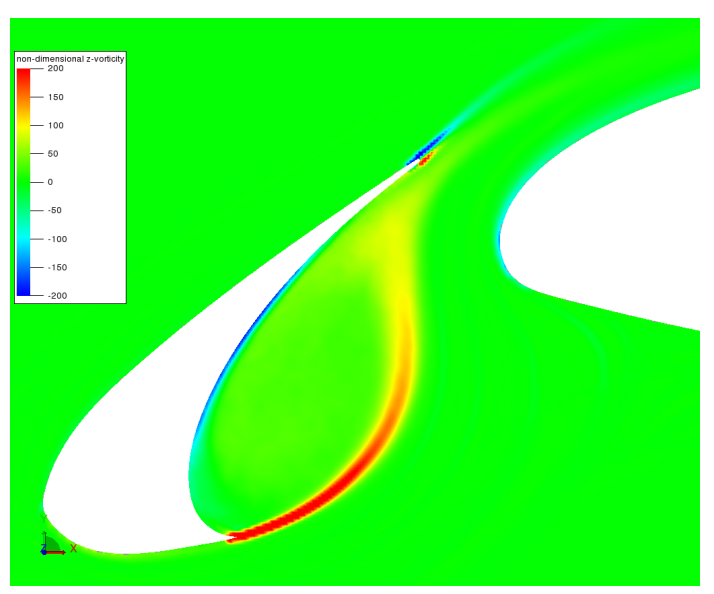

(b) Escorregamento livre

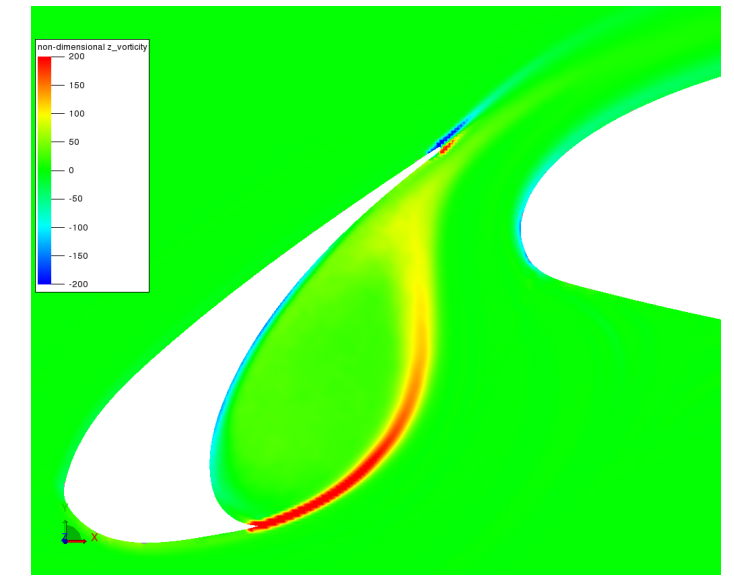

(c) Escorregamento livre (malha otimizada)

Figura 82 - Efeito da camada limite no campo da componente de vorticidade na direção da envergadura. Enflechamento de $45^{\circ}$.

o ruído aeroacústico de eslate independe da camada limite na cúspide. A análise do casos com enflechamento de $45^{\circ}$ indica ainda que mesmo uma alteração significativa na circulação do flap e elemento principal causa apenas um pequena variação no ruído gerado pelo eslate. Esses resultados reforçam a idéia de que o ruído do eslate está mais relacionado à circulação dos elementos. Essa propriedade permite que previsões do ruído de eslate sejam feitas com precisão aceitável para a indústria, mesmo que não se calcule as camadas limite com precisão.

Entretanto, a configuração de malha otmizada proposta por Simões, Souza e Medeiros (2011) para resolver o ruído aeroacústico do eslate no caso sem enflechamento não se mostrou capaz de calcular o ruído no caso com enflechamento de $35^{\circ}$, embora uma boa concordância tenha havido nos resultados de campo próximo entre esta configuração e a configuração de malha tomada como referência. Assim, uma configuração de malha alternativa deve ser analisada de forma que o cálculo seja feito com um menor custo computacional. 


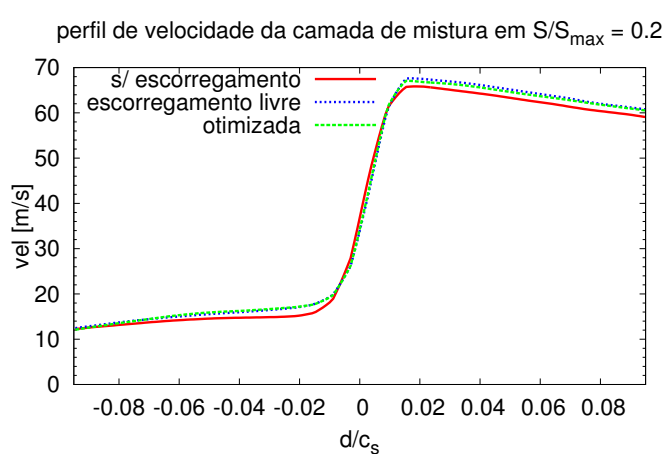

(a) $S / S_{\max }=0,20$

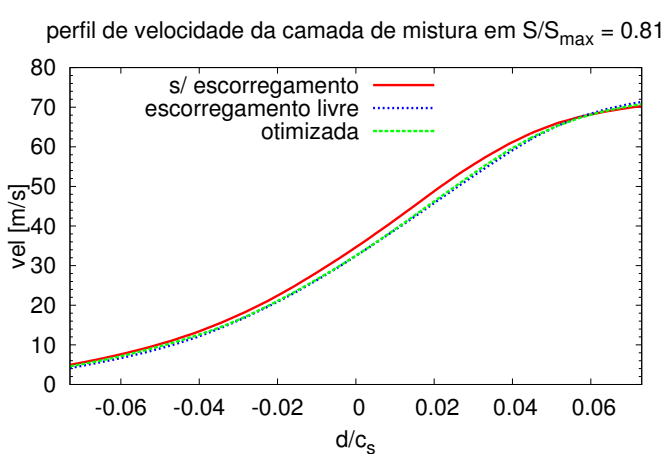

(b) $S / S_{\max }=0,81$

Figura 83 - Perfis de velocidade em posições da camada de mistura. Comparação entre soluções do caso com enflechamento de $35^{\circ}$, empregando paredes com e sem escorregamento.

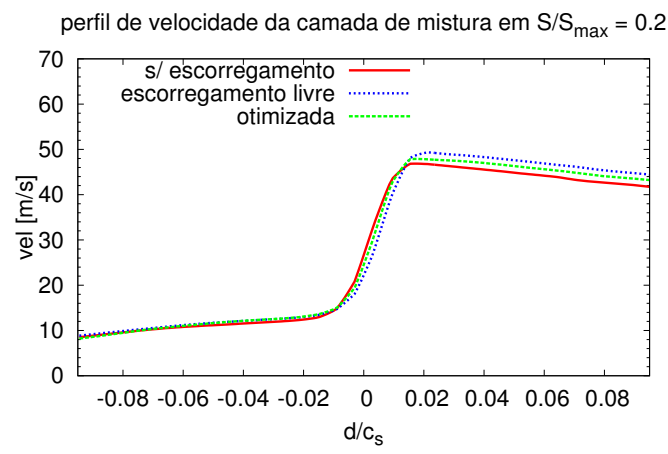

(a) $S / S_{\max }=0,20$

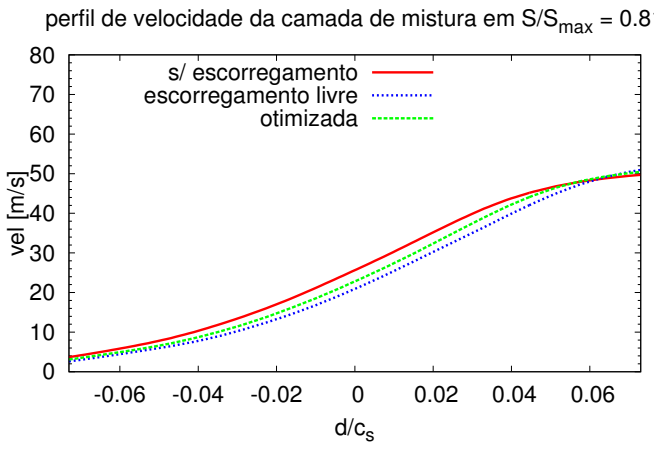

(b) $S / S_{\max }=0,81$

Figura 84 - Perfis de velocidade em posições da camada de mistura. Comparação entre soluções do caso com enflechamento de $45^{\circ}$, empregando paredes com e sem escorregamento.

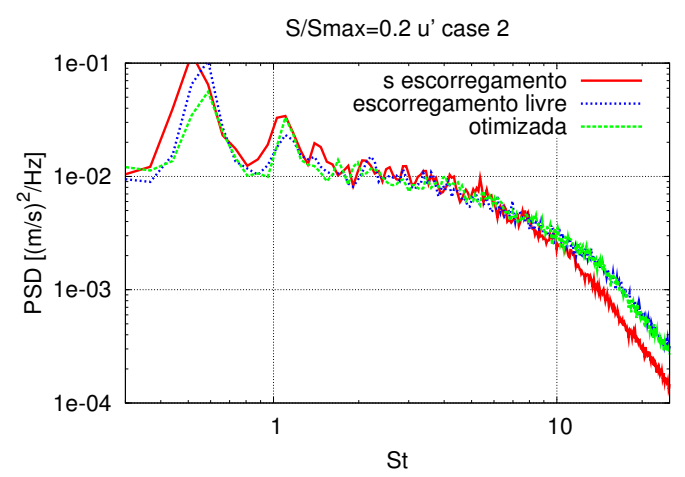

(a) $S / S_{\max }=0,20$

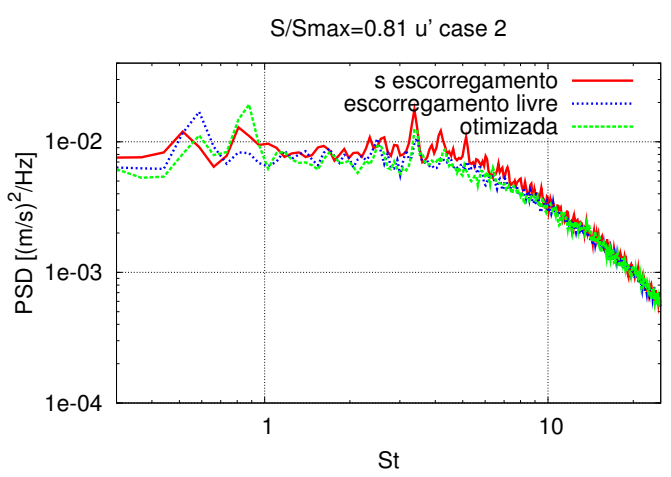

(b) $S / S_{\max }=0,81$

Figura 85 - Espectros de flutuações de $u$. Comparação entre soluções do caso com enflechamento de $35^{\circ}$, empregando paredes com e sem escorregamento. 


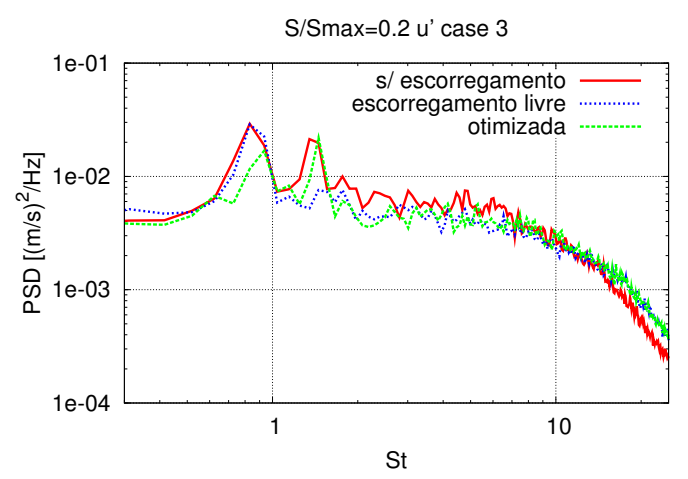

(a) $S / S_{\max }=0,20$

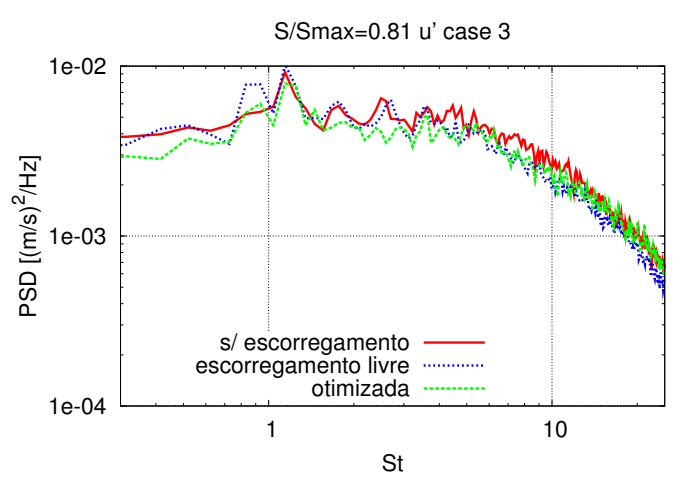

(b) $S / S_{\max }=0,81$

Figura 86-Espectros de flutuações de $u$. Comparação entre soluções do caso com enflechamento de $45^{\circ}$, empregando paredes com e sem escorregamento.

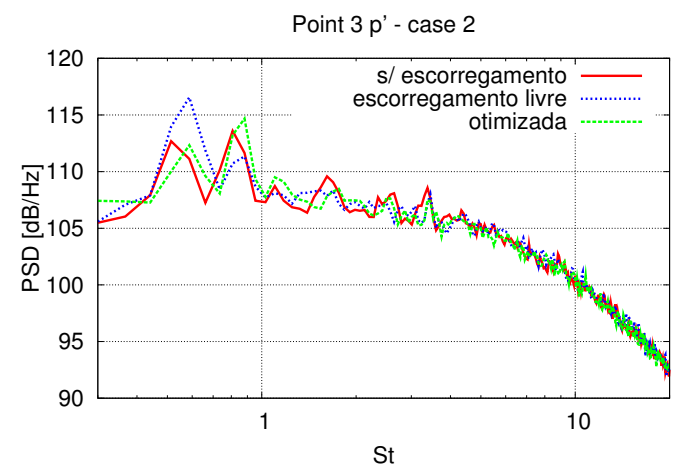

(a) Ponto 3

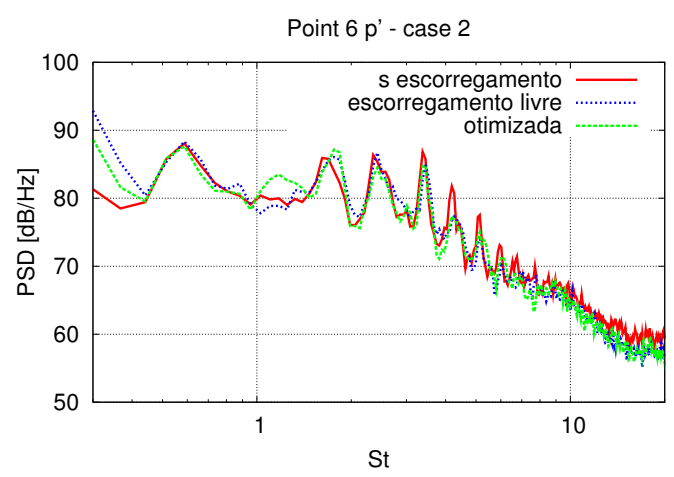

(b) Ponto 6

Figura 87 - Espectros de flutuações de pressão. Comparação entre soluções do caso com enflechamento de $35^{\circ}$, empregando paredes com e sem escorregamento.

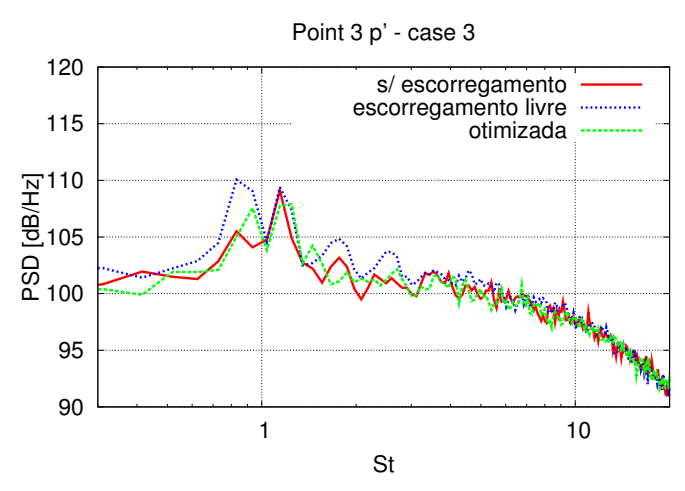

(a) Ponto 3

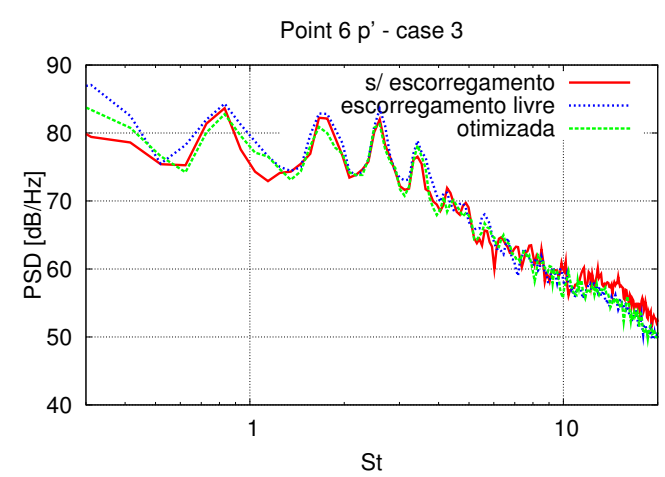

(b) Ponto 6

Figura 88 - Espectros de flutuações de pressão. Comparação entre soluções do caso com enflechamento de $45^{\circ}$, empregando paredes com e sem escorregamento. 


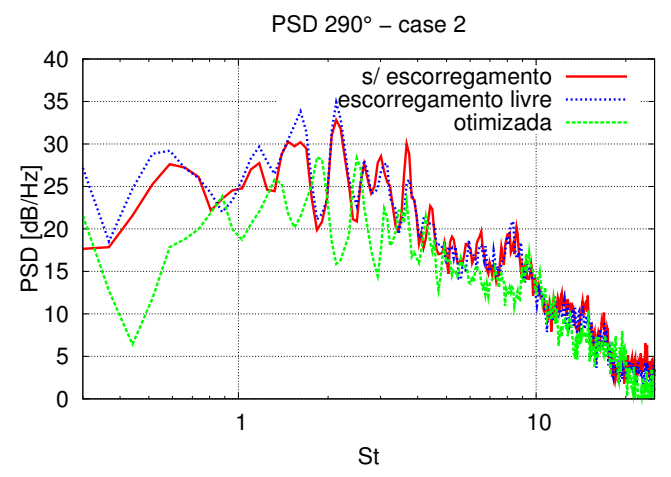

(a) Enflechamento: $35^{\circ}$

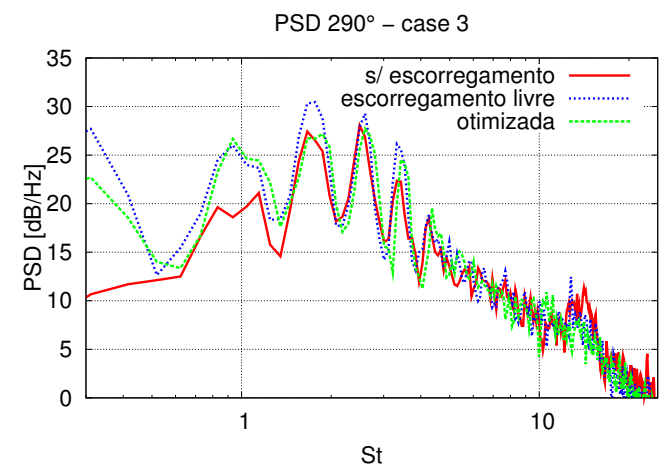

(b) Enflechamento: $45^{\circ}$

Figura 89 - Espectros de flutuações de pressão propagada a partir do eslate para uma distâcia de $10 c_{c r u z}$. Comparação entre soluções empregando paredes com e sem escorregamento. 


\subsection{Efeito do Tubo do Sistema Anti-gelo no Som Gerado pelo Eslate}

A metodologia testada na seção 5.3.3 para aerofólio com enflechamento foi empregada para simular o escoamento no aerofólio com o tubo do sistema anti-gelo na cova do eslate. Embora a configuração de malha otimizada no caso com enflechamento de $35^{\circ}$ tenha apresentado uma diferença significativa em relação à solução com paredes sem escorregamento no que diz respeito ao som propagado para o campo distante, decidiu-se empregar a configuração de malha otimizada tanto nos casos em com escoamento cruzado como no caso sem escoamento cruzado, para viabilizar as simulações com o tubo.

As figuras 90 e 91 mostram o efeito do tubo do sistema anti-gelo na distribuição do coeficiente de pressão $\left(C_{p}=\left(p-p_{0}\right) / 0,5 \rho U_{\infty}^{2}\right)$ na superfície do aerofólio. Duas posições ao longo da envergadura simulada foram levadas em consideração e os casos com o tubo são comparados com os casos da geometria limpa. Nos casos com o tubo, o eixo do mesmo está posicionado em $z=0$. Observa-se que, no caso sem escoamento cruzado (Fig. 90), o pico de sucção do elemento principal é reduzido na faixa $z=0$, enquanto no caso com escoamento cruzado a redução do pico ocorre em $z=18 \mathrm{~mm}$. Isso indica que tal redução é causada pela passagem da esteira do tubo. Entre os dois casos com enflechamento de $35^{\circ}$, nenhuma variação significativa na distribuição de pressão é observada.

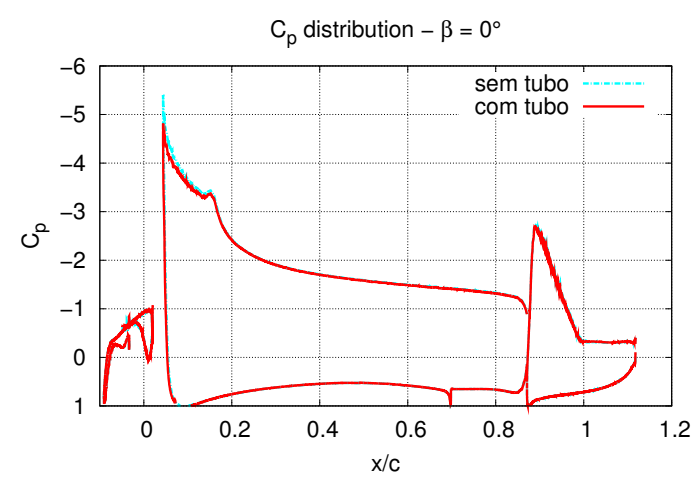

(a) $z=0$

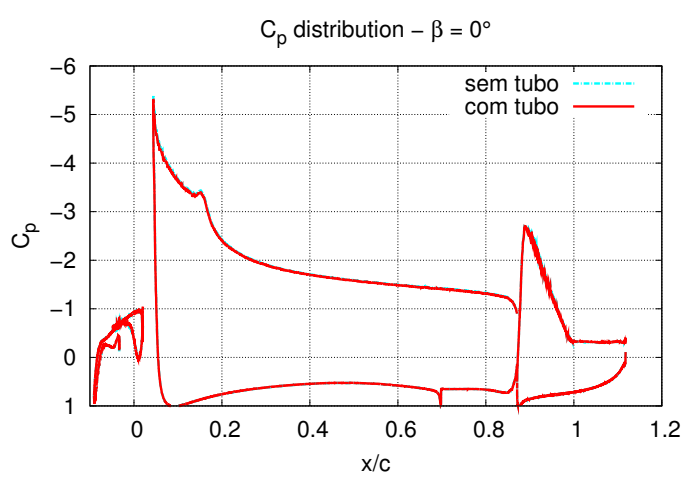

(b) $z=18 \mathrm{~mm}$

Figura 90 - Distribuição de pressão na superfície do aerofólio em duas posições da envergadura simulada. Desconsiderando-se efeito do enflechamento.

A variação causada pela presença do tubo na energia cinética turbulenta (a partir das flutuações resolvidas) é mostrada na figura 92 para o caso sem escoamento cruzado. Um aumento substancial na energia das flutuações é observado na região onde ocorre a interação entre a camada de mistura e a esteira do tubo. As iso-superfícies de $\lambda_{2}$ na figura 93 mostram que nessa 


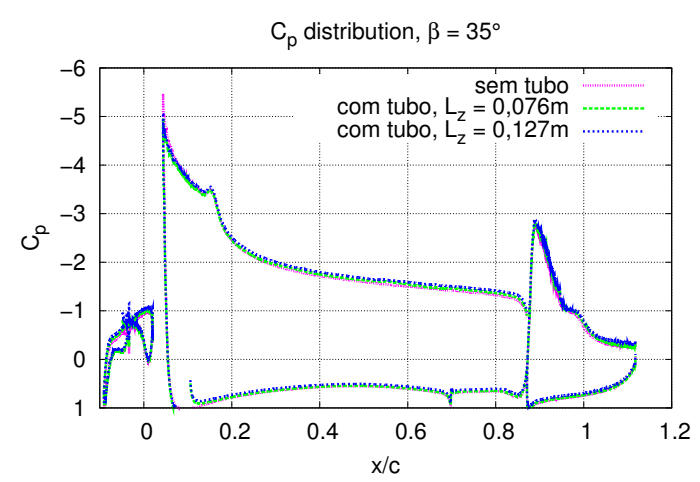

(a) $z=0$

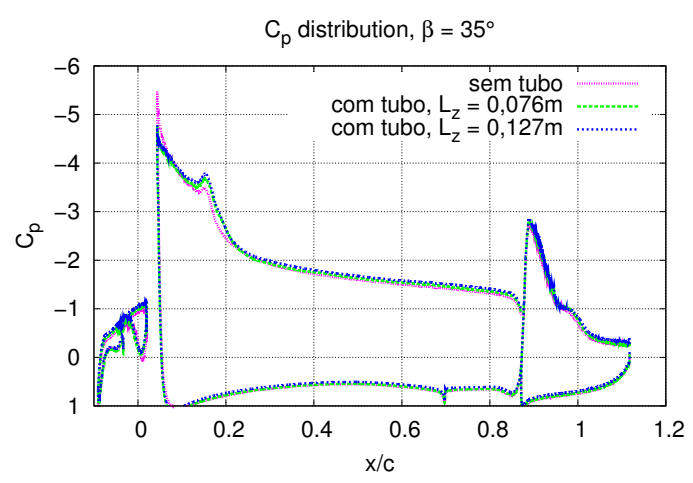

(b) $z=18 \mathrm{~mm}$

Figura 91 - Distribuição de pressão na superfície do aerofólio em duas posições da envergadura simulada. Enflechamento de $35^{\circ}$.

região os vórtices da camada de mistura interagem com vórtices que têm seu eixo na direção do escoamento, o que, provavelmente, causa o aumento da energia cinética turbulenta.

A origem dos vórtices com eixo na direção do escoamento pode estar ligada a um fenômeno descrito por Lamballais e Silvestrini (2002) que ocorre na interação entre uma camada de mistura e um esteira. Os resultados desse trabalho mostram que os vórtices de von Kármán formados na esteira do tubo são inclinados gradativamente devido ao gradiente de velocidade da camada de mistura. Embora a configuração estudada no presente trabalho seja muito mais complexa, na figura 93 é possivel ver, próximo ao cilindro, vórtices com eixo paralelo ao eixo do cilindro (Fig. 93(a)).

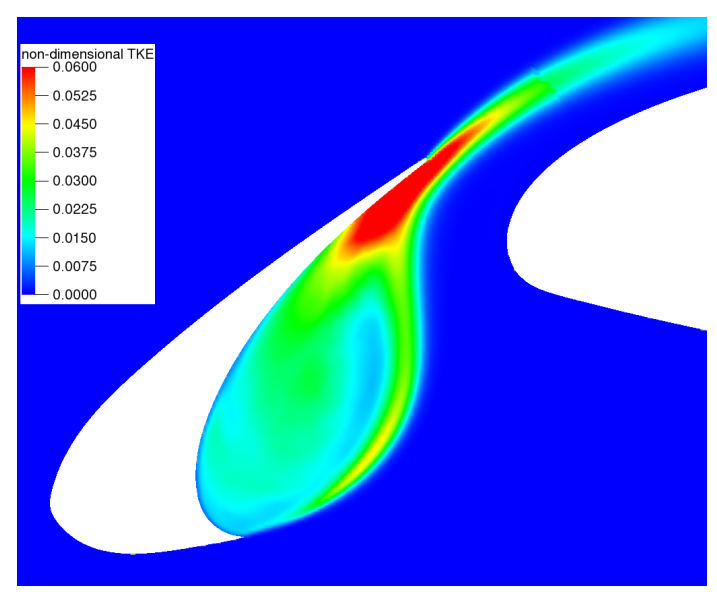

(a) Sem tubo

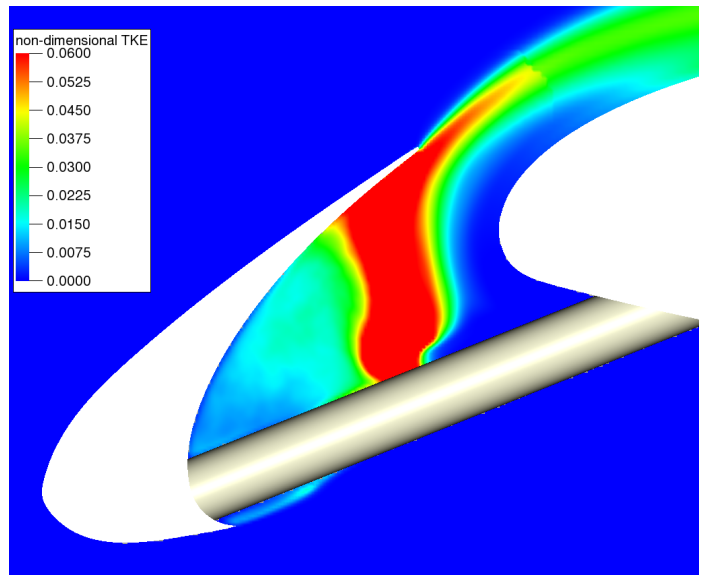

(b) Com tubo

Figura 92 - Campo de energia cinética turbulenta calculada a partir das perturbações. Desconsiderando efeito de enflechamento.

O densidade espectral de potência das flutuações de pressão foram calculados em pontos ao 


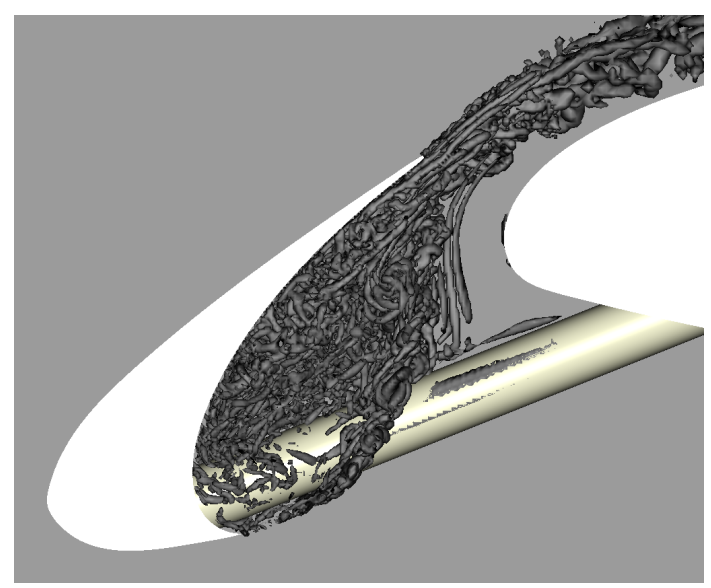

(a) $\beta=0^{\circ}$

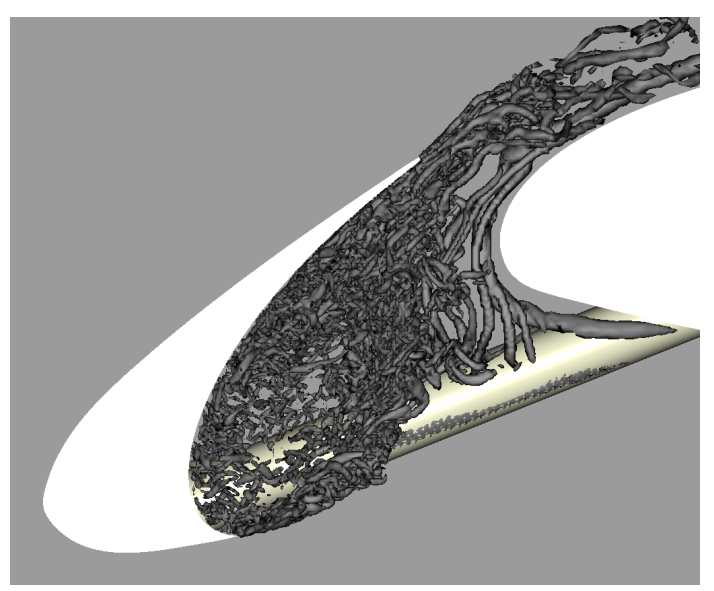

(b) $\beta=35^{\circ}$

Figura 93 - Iso-superfícies de $l a m b d a_{2}$ na cova do eslate.

longo da esteira do tubo. A figura 94 mostra as posições desses pontos no caso sem escoamento cruzado. Nos casos com escoamento cruzado, as posições foram modificadas para acompanhar a inclinação do escoamento livre. Os pontos 5 e 6 , se encontram na região de interação entre camada de mistura e esteira. Nessa região, pode-se ver que, nos três casos analisados, as flutuações são mais intensas do que nos outros pontos ao longo de todo o espectro mostrado, chegando até a $150 \mathrm{~dB} / \mathrm{Hz}$ no ponto 6 .

Nos gráficos referentes ao caso sem enflechamento, 95, chamam a atenção os intensos picos tonais entre $1000 \mathrm{~Hz}$ e $4000 \mathrm{~Hz}$. Esses picos poderiam estar relacionados à frequência de desprendimento de vórtices de von Karman na esteira do tubo. Entretanto, as frequências onde os picos ocorrem são as mesmas ao longo de toda a extensão do tubo, apesar de haver uma variação de velocidade significativa entre a cova e a região próxima do elemento principal. É interessante notar que as frequências em que esses picos aparecem no caso com o tubo do sistema anti-gelo sem enflechamento, são basicamente as mesmas dos picos que aparecem nos espectros de flutuação de velocidade da camada de mistura em alguns casos com o selo na cova do eslate, discutidos na seção 5.2. Nos dois casos em que o aerofólio está sujeito a escoamento cruzado, os picos tonais não estão presentes.

Comparando os dois casos que consideram enflechamento do aerofólio, com diferentes envergaduras simuladas, observa-se que não há uma diferença siginificativa entre os espectros em nenhum dos pontos. Nos espectros dos demais pontos que não estão apresentados, comportamento semelhante é observado. Esse resultado indica que, com uma envergadura simulada de $0,076 m$ a condição de contorno de periodicidade em z já apresenta pouca interferência na solução do campo próximo de escoamento, mesmo com a consideração de escoamento cruzado. 


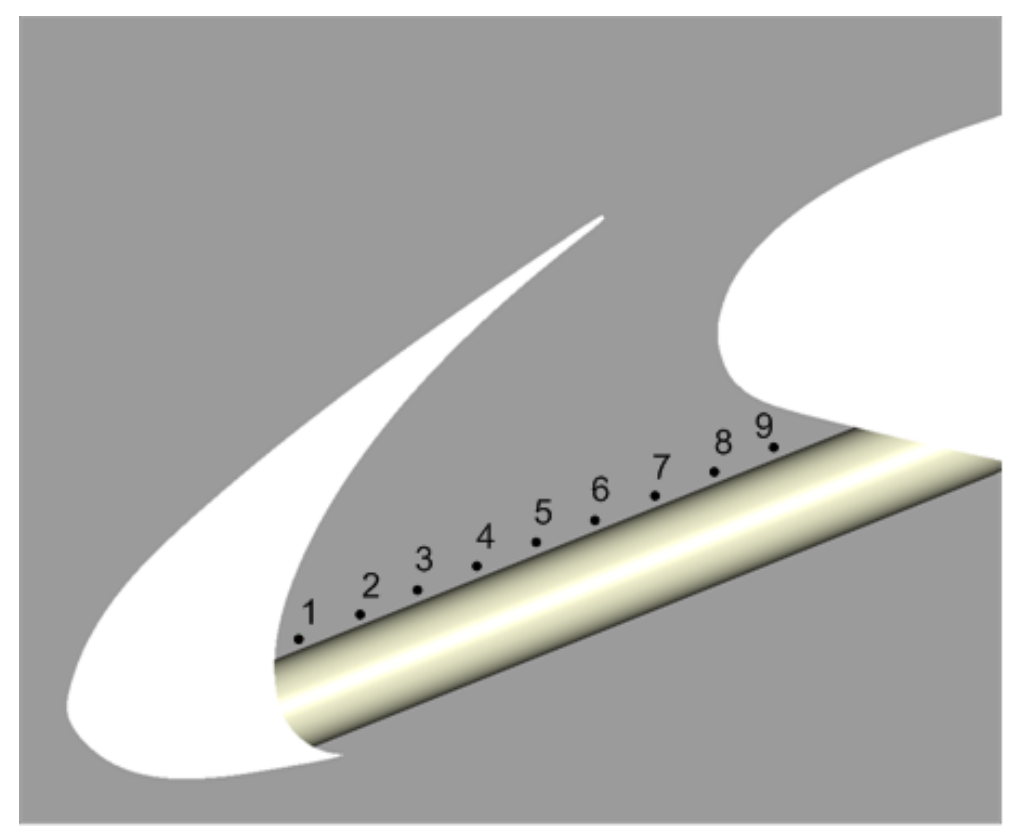

Figura 94 - Pontos onde da esteira do tubo onde foram medidas as flutuações de pressão.

Na simulação do aerofólio com o tubo do sistema anti-gelo e escoamento cruzado em que a envergadura simulada foi de apenas $L_{z}=0,076$, a parte do escoamento salva para os cálculos com a analogia de FW-H não teve tamanho suficiente para conter a região em que a esteira do tubo se choca com a parede da cova do eslate. Já na simulação com $L_{z}=0,127$, essa região pôde ser levada em consideração nos cálculos do som propagado. Utilizando-se a solução transiente com envergadura simulada de $0,127 \mathrm{~m}$, dois cálculos do som propagado pelo eslate com a analogia de FW-H foram feitos. Um com a região de integração com comprimento na direção z de $0,0635 m$ e outro com a mesma dimensão da região salva na simulação com $L_{z}=0,076 m$.

A figura 96 compara os espectros do campo distante calculados a partir da solução com $L_{z}=0,127$ com as duas região de integração de FW-H diferentes. O espectro calculado a partir da solução com $L_{z}=0,076$ também é mostrado na figura. $L_{z, F W H}$ significa a dimensão na direção z da região de integração de FW-H. É importante notar que nenhuma correção é feita nos gráficos para compensar a diferença no tamanho da região de integração. Observa-se que, em frequências abaixo de $4 \mathrm{kHz}$, a energia das flutuações é entre $4 d \mathrm{~B} / \mathrm{Hz}$ e $7 \mathrm{dbB} / \mathrm{Hz}$ mais intensa no cálculo que leva em consideração o choque da esteira do tubo na parede do eslate. Acima de $4 \mathrm{kHz}$ as diferenças na PSD são menores que $3 \mathrm{~dB} / \mathrm{Hz}$. Comparando-se os espectros baseados em simulações com diferentes $L_{z}$, mas usando regiões de integração semelhantes para os cálculos da analogia de FW-H, vê-se que não há praticamente nenhuma diferença, o que indica a convergência da solução com o tubo e escoamento cruzado em relação à envergadura 


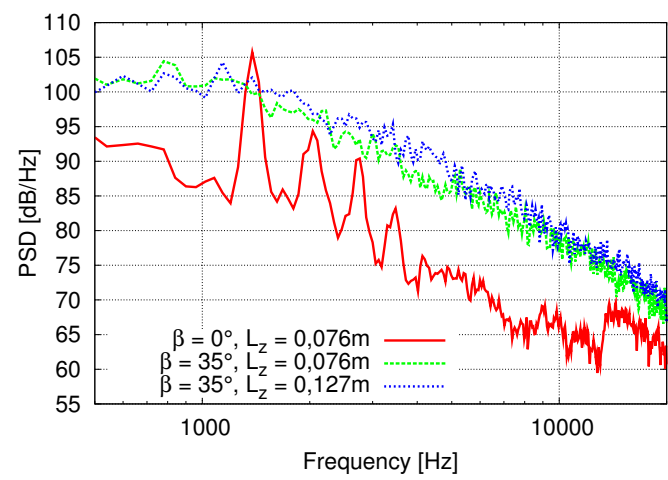

(a) Ponto 1

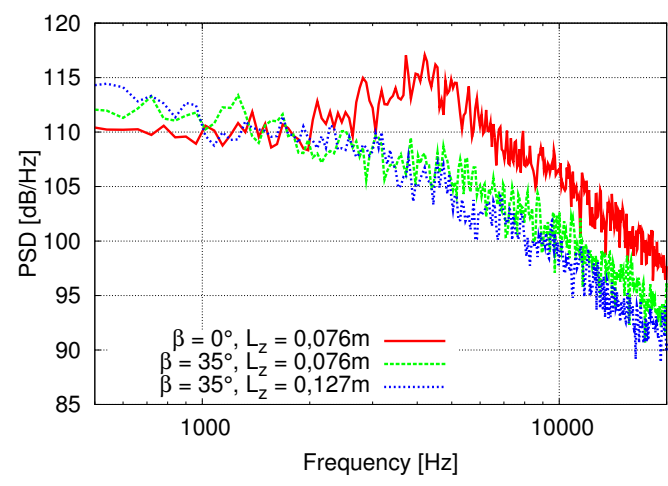

(c) Ponto 6

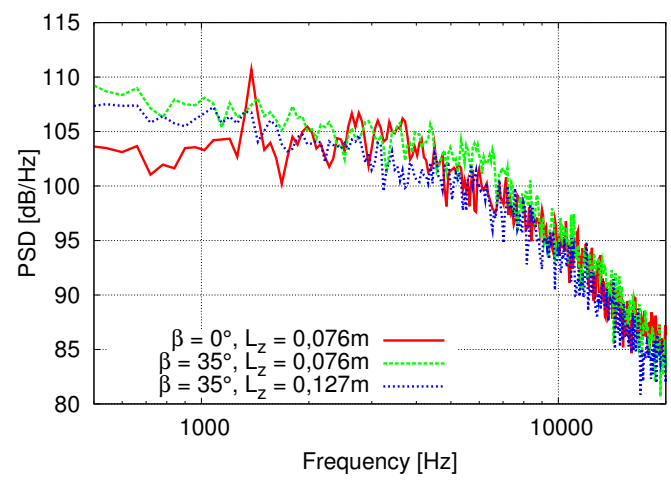

(b) Ponto 5

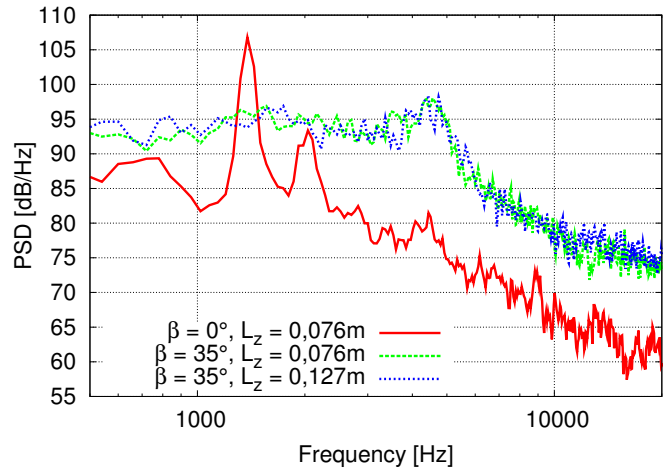

(d) Ponto 8

Figura 95 - Espectros de flutuação de pressão em pontos na esteira do cilindro.

simulada.

A figura 97 compara os espectros de som propagado entre a geometria com e sem o tubo do sistema anti-gelo. Tanto os casos sem enflechamento (Fig. 97(a)) como os casos com enflechamento de $35^{\circ}$ (Fig. 97(b)) são mostrados. Devido ao erro relacionado ao emprego da configuração de malha otimizada na simulação com escoamento cruzado, que foi discutido na seção 5.3.3, a figura referente aos casos com enflechamento, inclui o espectro calculado a partir da simulação com a malha de referência. As curvas nos dois gráficos são corrigidas em função da dimensão em z da região de integração. No gráfico da figura $97\left(\right.$ a), $L_{z, \text { ref }}$ é igual a $0,038 m$,

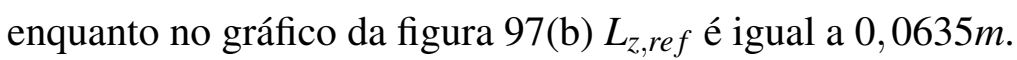

$\mathrm{Na}$ ausência de escoamento cruzado, fica claro um aumento do ruído em praticamente todo o espectro, devido à presenção do tubo. Além disso, chama a atenção o aumento substancial nos picos tonais. As frequências onde esses picos ocorrem são as mesmas dos picos na esteira do cilindro. É possível observar que esses picos também estão presentes no ruido do aerofólio sem o tubo, porém em menor intensidade. No escoamento sobre o aerofólio com enflechamento, observa-se também um aumento significativo no nível de ruído devido à presença do tubo. En- 


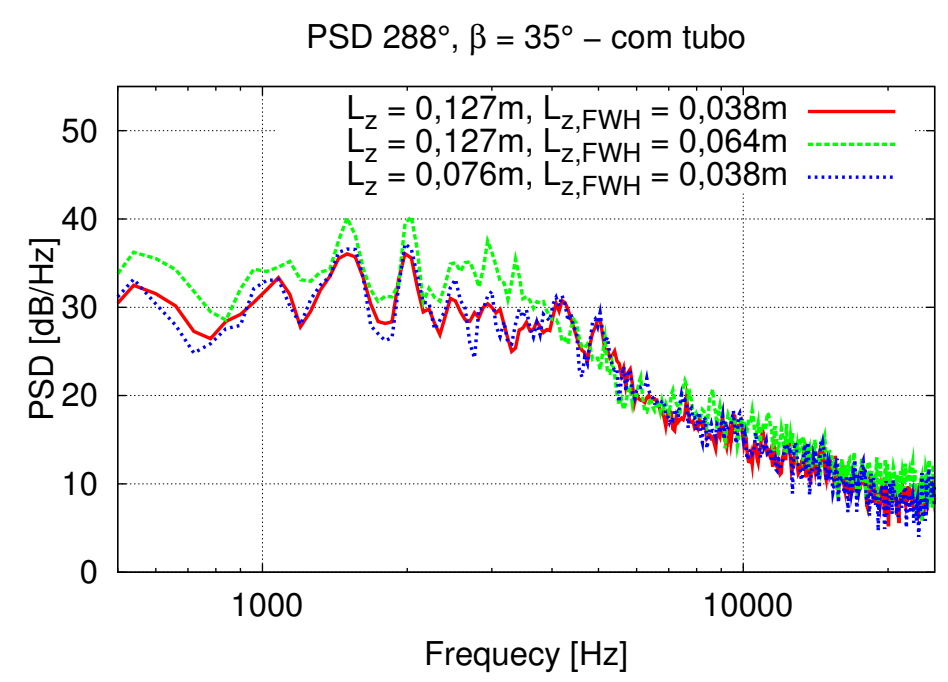

Figura 96 - Comparação da PSD de pressão entre casos com e sem escoamento cruzado, ambos com o tubo na cova do eslate.

tretanto, não é possível afirmar a intensidade desse aumento, devido ao erro associado ao cálculo do som propagado a partir da solução com a malha otimizada. Porém, mesmo comparando com a solução dada pela malha de referência, o ruído gerado pela geometria com o tubo ainda é mais intenso. No caso com escoamento cruzado, não se observa o aumento dos picos tonais que ocorre quando não há enflechamento. Embora o nível dos picos esteja maior, esse aumento segue o aumento do restante do espectro nessa faixa do espectro. 
$\operatorname{PSD} 290^{\circ}, \beta=0^{\circ}$

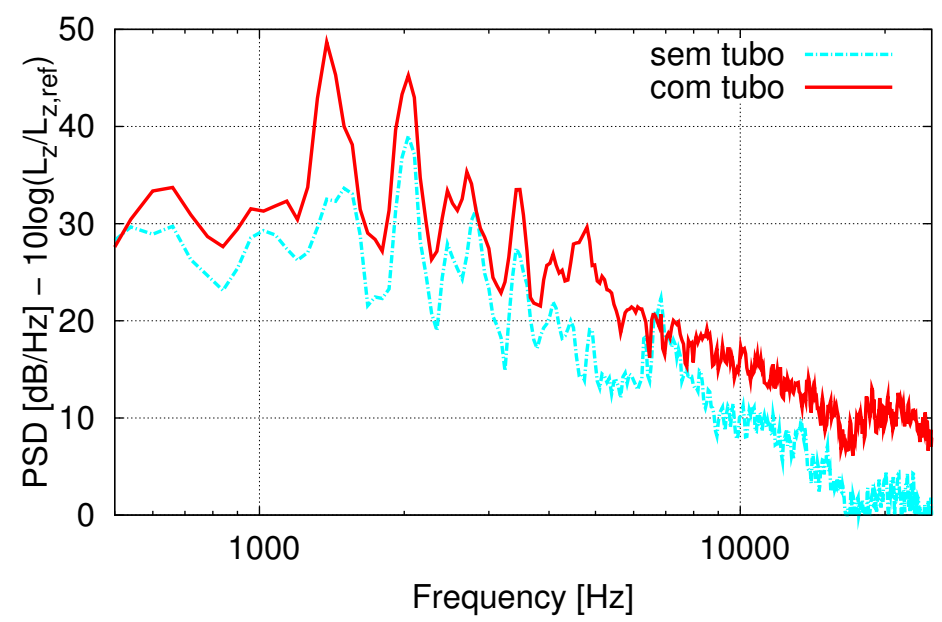

(a) $\beta=0^{\circ}$

PSD $290^{\circ}, \beta=35^{\circ}$

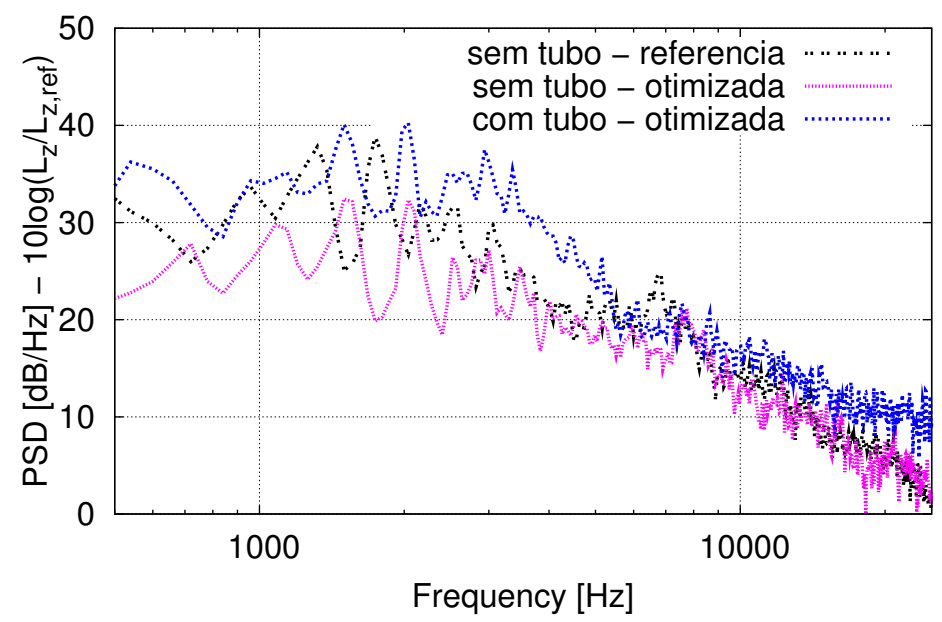

(b) $\beta=35^{\circ}$

Figura 97 - Comparação da PSD de pressão no campo distante entre casos com e sem o tubo do sistema anti-gelo. 


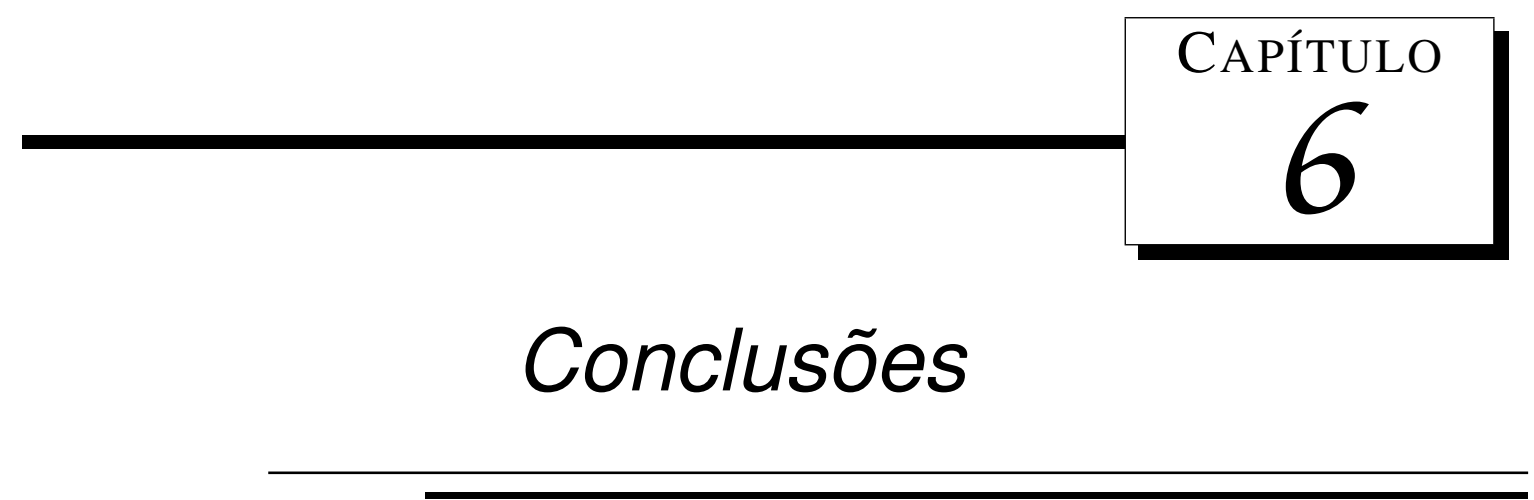

Este trabalho é dedicado à previsão, através de ferramentas computacionais, do ruído aeroacústico gerado pelo eslate. O principal programa utilizado foi o código comercial PowerFLOW, baseado no Método Lattice-Boltzmann, que permite uma paralelização massiva da solução. A questão da paralelização é importante, uma vez que o trabalho é destinado a aplicação de metodologias numéricas no âmbito industrial.

O foco do trabalho foi estender para condições mais complexas a metodologia de simulação numérica desenvolvida pelo grupo que permite o cálculo do ruído aeroacústico do eslate considerando parede com escorregamento livre. O enflechamento do aerofólio, bem como a presença de um selo no intradorso do eslate e um tubo do sistema anti-gelo passando pela cova foram levados em consideração separadamente. Uma proposta para aprimoramento da metodologia também foi feita no intuito de usá-la na simulação do aerofólio em altos ângulos de ataque.

A metodologia para o cálculo do ruído do eslate usando condição de parede com escorregamento livre no eslate e no elemento principal tem algumas limitações. Em condições em que a espessura das camadas limite tem efeito significativo na circulação do aerofólio, como em altos ângulos de ataque, elas não podem ser desprezadas. Uma proposta de modificação para que a metodologia pudesse ser usada no cálculo do ruído do eslate em altos ângulos de ataque foi testada. A proposta consiste em modificar a geometria desses dois elementos do aerofólio de acordo com a espessura de deslocamento. No trabalho, esta espessura foi obtida por um código que usa um método integral de camada limite. Três simulações com o aerofólio em um ângulo de ataque de $4^{\circ}$ foram comparadas para avaliar se a consideração da espessura de deslocamento da camada limite é capaz de melhorar a solução aeroacústica de simulações usando condição de parede com escorregamento livre.

Tomando como referência a simulação com paredes sem escorregamento, a modificação da 
geometria por $\delta^{*}$ na simulação considerando escorregamento livre no eslate e elemento principal apresentou uma pequena melhora na solução do ruído propagado. Essa melhoria na solução do espectro do ruído ratifica a idéia de que as características do som gerado pelo eslate depedem, principalmente, da geometria e da circulação dos elementos. Entretanto, apesar dos resultados favoráveis dados pela simulação com $\delta^{*}$, mais testes são necessários para comprovar a eficácia da metodologia. Embora houvesse uma pequena discrepância entre os espectros calculados com condição de parede sem escorregamento e os resultados da simulação com condição de escorregamento livre, discrepância essa que foi reduzida pela modificação da geometria, essa diferença se encontra dentro da faixa de incerteza estimada para a metodologia. Portanto, a modificação da metodologia deve ser testada em um ângulo de ataque em que as soluções com escorregamento livre e sem escorregamento apresentem resultados significativamente diferentes.

Em aeronaves comerciais, a região da cova do eslate pode possuir diversas excrescências. Uma delas é um selo posicionado na parede da cova do eslate. Simulações transientes foram feitas para estudar o efeito desse selo no ruído aeroacústico produzido pelo eslate. Os efeitos do tamanho e da posição do selo foram analisados. Três tamanhos de selo foram testados na mesma posição e um selo de tamanho fixo foi posicionado em três locais diferentes na cova.

Posicionado entre o recolamento e a cúspide, o selo tem a propriedade de bloquear a passagem dos vórtice para a região de recirculação. Dessa forma, a energia cinética turbulenta é reduzida na cova, o que diminui as perturbações sofridas pela camada de mistura nas proximidades da cúspide. Com isso, as estruturas vorticais ao longo da camada de mistura se mantêm mais coerentes. Comparando o ruído propagado para o campo distante a partir do eslate com o selo dentro da cova com o ruído gerado pela geometria limpa, um aumento na densidade de potência espectral do ruído de banda larga entre $4 d B / H z$ e $7 d B / H z$ em frequências abaixo de $S t=5$ foi observado. Considerando os picos tonais de baixa frequência nessa comparação, esse aumento pode chegar a até $13 \mathrm{~dB} / \mathrm{Hz}$. Portanto, mesmo reduzindo as flutuações dentro da região de recirculação, o selo pode provocar um aumento do ruído gerado pelo eslate, dependendo da posição e tamanho.

Um estudo de convergência de malha foi feito para os dois casos que consideraram escoamento cruzado. $\mathrm{O}$ caso com enflechamento de $35^{\circ}$ teve uma razão de refinamento entre as malhas comparadas de $25 \%$. Já o refinamento do caso com enflechamento de $45^{\circ}$ foi de $10 \%$. No espectro de som propagado, a comparação entre as malhas usadas no caso com enflechamento de $45^{\circ}$ não apresenta diferenças significativas. Porém, devido à baixa razão de refinamento, não é possível afirmar que a solução é independente da malha. No caso com enflechamento menor 
$\left(35^{\circ}\right)$, o refinamento da malha provoca um deslocamento do espectro de aproximadamente $8 \%$ em direção às frequências mais altas, porém, sem modificação significativa do formato. Como esse deslocamento não foi observado em um ponto do campo próximo onde as flutuações são dominadas pela passagem de ondas acústicas provenientes do eslate, a sua causa não é bem compreendida.

Os resultados das simulações com escoamento cruzado usando o PowerFLOW foram comparadas com resultados de simulações de um código Navier-Stokes disponíveis na literatura. Em geral uma boa concordância entre as duas metodologias é observada nas propriedades médias do escoamento. Comparando os espectros de flutuação de velocidade na camada de mistura com a literatura, uma diferença entre $5 \mathrm{~dB} / \mathrm{Hz}$ e $7 \mathrm{~dB} / \mathrm{Hz}$ é observada na densidade de potência espectral. Porém, a comparação do nível dos espectros de $u^{\prime}$ é inconclusiva, uma vez que outras publicações com resultados de simulações com a mesma condição de escoamento e usando o mesmo código Navier-Stokes do trabalho de referência apresentaram níveis de PSD com difereça de até $10 \mathrm{~dB} / \mathrm{Hz}$. Apesar da diferença no nível dos espectros, o formato das curvas e a evolução ao longo da camada de mistura são semelhantes nas simulações com os dois códigos. Há, entretanto, uma diferença na taxa de decaimento das flutuações, sendo que o resultado do PowerFLOW se aproxima mais da teoria de Kolmogorov que estabelece uma energia de flutuações turbulentas proporcinal a $f^{-5 / 3}$, o que corrobora com observações de que o MLB é menos dissipativo (MARIÉ; RICOT; SAGAUT, 2009).

Assim como ocorre com os espectros de $u^{\prime}$, as flutuações do campo distante apresentam níveis distintos entre resultados publicados em artigos diferentes a partir de simulações com o mesmo código Navier-Stokes. Dessa forma, os resultados do PowerFLOW são aproximadamente $15 \mathrm{~dB} / \mathrm{HZ}$ abaixo dos resultados do CFL3D para aerofólio com escoamento cruzado. Entretanto o formato dos espectros calculados a partir de simulações com o PowerFLOW são semelhantes aos das simulações Navier-Stokes.

Uma vez que foi mostrado por Simões, Souza e Medeiros (2011) que, em certas circunstâncias, as camadas limite do elemento principal e da superfície do eslate fora da cova não têm influência no ruído gerado pelo eslate em um aerofólio sem escoamento cruzado, simulações foram feitas no presente trabalho para testar tal hipótese em um aerofólio com enflechamento. Simulações com condição de parede com escorregamento livre no eslate (exceto na parede da cova, onde se considerou parede sem escorregamento) e no elemento principal foram comparadas com simulações onde todas as superfícies do aerofólio foram consideradas com parede sem escorregamento. Enflechamento de $35^{\circ}$ e $45^{\circ}$ foram analisados.

Nos espectros de flutuações da camada de mistura, pequenas diferenças são observadas nas 
proximidades da cúspide (aproximadamente $4 d B / H z$ ), porém, estas diminuem à medida que se aproxima do recolamento, chegando a valores insignificantes no ponto $S / S_{\max }=0,81$. As flutuações de pressão na superfície do aerofólio, por sua vez, não apresentam alterações significativas em função da existência ou não das camadas limite do eslate e do elemento principal. Da mesma forma, o espectro de ruído no campo distante não apresenta alteração maior do que $3 \mathrm{~dB} / \mathrm{Hz}$ no caso com enflechamento de $35^{\circ}$, mesmo se forem levados em conta os picos de baixa frequência do espectro. Já o ruído gerado pelo aerofófio com $45^{\circ}$ de enflechamento teve um aumento de até $5 \mathrm{db} / \mathrm{Hz}$ em frequências abaixo $S t=2$ com a eliminação das camadas limite do eslate e elemento principal. Essa variação provavelmente se deve à mudança na circulação do aerofólio causada pelo aumento da região de escoamento separado no flap.

Portanto, assim como observado em simulações sem escoamento cruzado, o ruído do eslate de um aerofólio enflechado se mostrou mais sensível à variação na circulação do aerofólio do que à camada limite na cúspide. Os resultados indicam que, mesmo com um erro pequeno no cálculo da circulação do elemento principal e do flap, a precisão no cálculo do ruído do eslate se mantém, contanto que a distribuição de pressão no eslate seja bem calculada (caso $\beta=35^{\circ}$ ).

O efeito do tubo do sistema anti-gelo, que atravessa a cavidade entre o eslate e o elemento principal, também foi estudado, empregando condição de parede com escorregamento livre nestes dois elementos. Aerofólio sem enflechamento e com escoamento cruzado correspondente a um enflechamento de $35^{\circ}$ foram simulados. No aerofólio sem enflechamento o tubo causa um aumento no ruído de banda larga de $5 \mathrm{~dB} / \mathrm{Hz}$ a $10 \mathrm{~dB} / \mathrm{Hz}$ ao longo de todo o espectro e intensifica significativamente os picos tonais de baixa frequência. No caso com enflechamento, o aumento do ruído de banda larga foi mais modesto e se concentra nas frequências abaixo de $6000 \mathrm{~Hz}$ e não se observa aumento dos picos tonais. Entretanto os resultados das simulações com o tubo e escoamento cruzado são inconclusivos, uma vez que a configuração de malha otimizada não foi capaz de resolver com a precisão desejada o espectro de ruído do campo distante no caso do aerofólio enflechado.

Duas simulações com enflechamento foram feitas com a mesma condição de escoamento mas com envergaduras simuladas diferentes para avaliar o efeito da condição de periodicidade na solução. Um domínio com extensão de $0,076 m$ na direção z e outro com extensão de $0,127 m$ foram comparados. Os espectros do campo próximo e do campo distante dos dois casos apresentam diferenças inferiores a $3 \mathrm{~dB} / \mathrm{Hz}$. Isso indica que uma envergadura simulada de $0,076 \mathrm{~m}$ é suficiente para representar os fenômenos relativos ao ruído do eslate com o tubo do sistema anti-gelo. Entretanto, com uma envergadura simulada $\Delta z=0,076 m$, uma região de integração para métodos integrais de propagação acústica com comprimento na direção da envergadura 
igual à metade de $L_{z}$ (prática comum para reduzir a influência da condição de periodicidade nos cálculos do campo distante) não inclui completamente a região de interação da esteira do tubo com o intradorso do eslate.

Baseado nas discussões apresentadas neste trabalho, pode-se propor estudos subsequentes voltados para a compreensão das fontes de ruído aeroacústico de eslate em configurações realistas, bem como para o desenvolvimento de metodologias para previsão deste ruído com precisão adequada ao ambiente industrial. Nesse sentido, as seguintes atividades são sugeridas:

- Comparar resultados de simulações com o aerofólio modificado por $\delta^{*}$ com simulações do aerofólio original com paredes com e sem escorregamento em ângulos de ataque mais altos;

- Testar a eficiência da metologia com $\delta^{*}$ em aerofólios com enflechamento;

- Estudar o efeito do selo em aerofólio com enflechamento;

- Estudar o efeito do selo em escoamento com alto número de Reynolds;

- Estudar a possibilidade de se usar o selo como dispositivo de controle de escoamento para reduzir o ruído de eslate;

- Propor e testar malha que reduza o custo computacional das simulações com escoamento cruzado empregando paredes com escorregamento livre. 


\section{Referências}

ARGÜELLES, P. et al. European aeronautics:A vision for 2020. [S.1.], January 2001.

BERKMAN, M. et al. Investigation of high-lift flowfield of an energy efficient transport wing. Journal of Aircraft, v. 37, n. 1, p. 45-52, 2000.

BHATNAGAR, P. L.; GROSS, E. P.; KROOK, M. A model for colision processes in gases. I. Small amplitude processes in charged and neutral one-component systems. Physical Review, v. 94, n. 3, p. 511-525, 1954.

BRÈS, G. A.; PÉROT, F.; FREED, D. Properties of lattice-Boltzmann method for acoustics. In: Proceedings of the 15th AIAA/CEAS Aeroacoustics Conference. Miami, Florida: [s.n.], 2009.

BRÈS, G. A.; PÉROT, F.; FREED, D. A Ffowcs Williams-Hawkings solver for latticeBoltzmann based computational aeroacoustics. In: Proceedings of the 16th AIAA/CEAS Aeroacoustics Conference. Stokholm, Sweden: [s.n.], 2010.

BRÈS, G. A.; WESSELS, M.; NOELTING, S. Tandem cylinder noise prediction using lattice Boltzmann and Ffowcs Williams-Hawkings method. In: Proceedings of the 16th AIAA/CEAS Aeroacoustics Conference. Stokholm, Sweden: [s.n.], 2010.

CHEN, H. Volumetric formulation of the lattice Boltzmann method for fluid dynamics:basic concept. Physical Review E, v. 58, n. 3, p. 329-364, 1998.

CHEN, H. et al. Extended Boltzmann kinetic equation for turbulent flows. Science, v. 301, p. 633-636, 2003.

CHEN, H.; TEIXEIRA, C.; MOLVIG, K. Realization of fluid boundary conditions via discrete Boltzmann dynamics. International Journal of Modern Physics C, v. 10, p. 1-11, 1999.

CHEN, S.; DOOLEN, G. D. Lattice Boltzmann method for fluid flow. Annual Review of Fluid Mechanics, v. 30, p. 329-364, 1998.

CHOUDHARI, M. et al. Aeroacoustic experiments in the Langley Low-Turbulence Pressure Tunnel. H, EUA, January 2002.

CHOUDHARI, M. M.; KHORRAMI, M. R. Effect of three-dimensional shear-layer structures on slat cove unsteadyness. AIAA Journal, v. 45, n. 9, p. 2174-2186, 2007.

CRIGHTON, D. G. Airframe noise. In: HUBBARD, H. H. (Ed.). Aeroacoustics of flight vehicles:theory and practice. [S.1.]: Nasa Publication, 1991. v. 1, p. 391-447.

DAM, C. P. v. The aerodynamic design of multi-element high-lift systems for transport airplanes. Progress in Aerospace Sciences, v. 38, p. 101-104, 2002. 
DECK, S. Zonal-detached-eddy simulation of the flow around a high-lift configuration. AIAA Journal, v. 43, n. 11, p. 2372-2384, 2005.

DIERKE, J. et al. 3D computation of broadband slat noise from swept and unswept high-lift wing sections. In: Proceedings of the 17th AIAA/CEAS Aeroacoustics Conference. Portland, EUA: [s.n.], 2011.

DOBRZYNSKI, W. Almost 40 years of airframe noise research:what did we achieve? Journal of Aircraft, v. 47, n. 2, p. 353-367, 2010.

DOBRZYNSKI, W.; POTT-POLENSKE, M. Slat noise source studies for farfield noise prediction. In: Proceedings of the 7th AIAA/CEAS Aeroacoustics Conference. Maastricht, Holanda: [s.n.], 2001.

DOWLING, A. P.; WILLIAMS, J. E. F. Sound and sources of sound. Chichester: Ellis Horwood Limited, 1983. 321 p.

FARASSAT, F. Derivation of formulations 1 and 1 A of Farassat. Hampton, Virginia, March 2007.

FARES, E. Unsteady flow simulation of the ahmed reference body using a lattice Boltzmann approach. Computers and Fluid, v. 35, p. 940-950, 2006.

FINK, M. R. Noise component method for airframe noise. Journal of Aircraft, v. 16, n. 10, p. 659-665, 1979.

HE, X.; LUO, L. Theory of lattice Boltzmann method:from the Boltzmann equation to the lattice Boltzmann equation. Physical Review E, v. 56, n. 6, p. 6811-6817, 1997.

IMAMURA, T. et al. Three-dimensional unsteady flow computations around a conventional slat of high-lift devices. AIAA Journal, v. 46, n. 5, p. 1045-1053, 2008.

JENKINS, L. N.; KHORRAMI, M. R.; CHOUDHARI, M. M. Characterization of unsteady flow structures near leading-edge slat: part I. PIV measurements. In: Proceedings of the 10th AIAA/CEAS Aeroacoustics Conference. Manchester, UK: [s.n.], 2004.

KAEPERNICK, K.; KOOP, L.; EHRENFRIED, K. Investigation of the unsteady flow field inside a leading edge slat cove. In: Proceedings of the 11th AIAA/CEAS Aeroacoustics Conference. Monterey, USA: [s.n.], 2005.

KALTENBACH, H.; JANKE, G. Directi numerical simulation of flow separation behind a swept, rearward-facing step at $R e_{H}=3000$. Physics of Fluids, v. 12, n. 9, p. 2320-2337, 2000.

KHORRAMI, M.; BERKMAN, M.; CHOUDHARI, M. Unsteady flow computation of a slat with a blunt trailing edge. AIAA Journal, v. 38, n. 11, p. 2050-2058, 2000.

KHORRAMI, M. M. et al. In search of the physics:the interplay of experiment and computationin slat aeroacoustics. In: Proceedings of the 41 st Aerospace sciences meeting and exhibit. Reno, EUA: [s.n.], 2002.

KHORRAMI, M. R.; CHOUDHARI, M. M.; JENKINS, L. N. Characterization of unsteady flow structures near leading-edge slat: part II. 2D computations. In: Proceedings of the 10th AIAA/CEAS Aeroacoustics Conference. Manchester, Reino Unido: [s.n.], 2004. 
KHORRAMI, M. R.; LOCKARD, D. P. Effects of geometric details on slat noise generation and propagation. In: Proceedings of the 12th AIAA/CEAS Aeroacoustics Conference. Cambridge, EUA: [s.n.], 2006.

KHORRAMI, M. R.; SINGER, B.; BERKMAN, M. Time-accurate simulations and acoustic analysis of slat free-shear-layer. In: Proceedings of the 7th AIAA/CEAS Aeroacoustics Conference. Maastricht, Holanda: [s.n.], 2001.

KHORRAMI, M. R.; SINGER, B.; LOCKARD, D. Time-accurate simulations and acoustic analysis of slat free-shear-layer: PART II. In: Proceedings of the 8th AIAA/CEAS Aeroacoustics Conference. Breckenridge, EUA: [s.n.], 2002.

KOLB, A. et al. Aeroacoustic wind tunnel measurements on a 2D high-lift configuration. In: Proceedings of the 13th AIAA/CEAS Aeroacoustics Conference. Rome, Itália: [s.n.], 2007.

LAFITTE, A.; PÉROT, F. Investigation of the noise generated by cylinder flows using a direct lattice-Boltzmann approach. In: Proceedings of the 15th AIAA/CEAS Aeroacoustics Conference. Miami, EUA: [s.n.], 2009.

LAMBALLAIS, E.; SILVESTRINI, H. Direct numerical simulation of interaction between a mixing layer and a wake around a cylinder. Journal of Turbulence, v. 3, 2002.

LASAGNA, P. L. et al. Landing approach airframe noise measurements and analysis. Hampton, EUA, February 1980.

LI, Y. et al. Numerical study of flow past an impulsively started cylinder by the latticeBoltzmann method. Journal of Fluid Mechanics, v. 519, p. 273-300, 2004.

LIGHTHILL, M. J. On the sound generated aerodynamically. I. basic theory. Proceedings of the Royal Society of London. Series A. Mathematical and Physical Sciences, v. 211, n. 1107, p. 564-587, 1952.

LIGHTHILL, M. J. On displacement thickness. Journal of Fluid Mechanics, v. 4, p. 383-392, 1958.

LOCKARD, D. P. A comparison of Ffowcs Williams-Hawkings solvers for airframe noise applications. In: Proceedings of the 8th AIAA/CEAS Aeroacoustics Conference. Breckenridge, Colorado: [s.n.], 2002.

LOCKARD, D. P.; CHOUDHARI, M. M. Noise radiation from leading-edge slat. In: Proceedings of the 15th AIAA/CEAS Aeroacoustics Conference. Miami, EUA: [s.n.], 2009.

LOCKARD, D. P.; CHOUDHARI, M. M. The effect of cross flow on slat noise. In: Proceedings of the 16th AIAA/CEAS Aeroacoustics Conference. Stokholm, Sweden: [s.n.], 2010.

LOCKARD, D. P.; CHOUDHARI, M. M. The variation of slat noise with Mach and Reynolds numbers. In: Proceedings of the 17th AIAA/CEAS Aeroacoustics Conference. Portland, EUA: [s.n.], 2011.

MARIÉ, S.; RICOT, D.; SAGAUT, P. Comparison between lattice Boltzmann method and navier-stokes high order schemes for computational aeroacoustics. Journal of Computational Physics, v. 228, p. 1056-1070, 2009. 
MOHAMAD, A. A. Lattice Boltzmann method. Londres: Springer Verlag, 2011. 178 p.

MORGAN, G. G.; HARDIN, J. C. Airframe noise - the next aircraft noise barrier. Journal of Aircraft, v. 12, n. 7, p. 622-624, 1975.

PASCHAL, K.; JENKINS, L.; YAO, C. Unsteady slat-wake characteristics of a high-lift configuration. In: Proceedings of the 38th Aerospace sciences meeting and exhibit. Reno, EUA: [s.n.], 2000.

RUMSEY, C. et al. Prediction of high-lift flows using turbulent clousure models. AIAA Journal, v. 36, n. 5, p. 765-774, 1998.

RUMSEY, C.; YING, S. Prediction of high lift:review of present CFD capability. Progress in Aerospace Sciences, v. 38, p. 145-180, 2002.

SHOCK, R. A. et al. Recent results on two-dimensional airfoils using a lattice Boltzmann-based algorithm. Journal of Aircraft, v. 39, n. 3, p. 434-439, 2002.

SIMõES, L. G. C. Estudo da geração de som em um eslate utilizando código comercial. Dissertação (Mestrado) - Escola de Engenharia de São Carlos, Universidade de São Paulo, 2011.

SIMõES, L. G. C.; SOUZA, D. S.; MEDEIROS, M. A. F. On the small effect of boundary layer thicknesses on slat noise. In: Proceedings of the 17th AIAA/CEAS Aeroacoustics Conference. Portland, EUA: [s.n.], 2011.

SMITH, A. M. O. High-lift aerodynamics. Journal of Aircraft, v. 12, n. 6, p. 501-530, 1975.

TAKEDA, K.; ASHCROFT, G.; ZHANG, X. Unsteady aerodynamics of slat cove flow in high-lift device configuration. In: Proceedings of the 39th Aerospace sciences meeting and exhibit. Reno, EUA: [s.n.], 2001.

TAKEDA, K.; ZHANG, X.; NELSON, P. Unsteady aerodynamics and aeroacoustics of a high-lift device configuration. In: Proceedings of the 40th Aerospace sciences meeting and exhibit. Reno, EUA: [s.n.], 2002.

TAKEDA, K.; ZHANG, X.; NELSON, P. Computational aeroacoustic simulations of leading-edge slat flow. Journal of Sound and Vibration, v. 270, p. 559-572, 2004.

WILLIAMS, J. E. F; HAWKINGS, D. L. Sound generation by turbulence and surfaces in arbitrary motion. Philosofical Transactions of the Royal Society of London. Series A. Mathematical and Physical Sciences, v. 264, n. 1151, p. 321-342, 1969.

YAKHOT, V.; ORSZAG, S. A. Renormalization group analysis of turbulence. I. Basic theory. Journal of Scientific Computing, v. 1, n. 1, p. 3-51, 1986.

ZIEGLER, D. P. Boundary conditions for lattice Boltzmann simulations. Journal of Statistical Physics, v. 71, n. 5/6, p. 1171-1177, 1993. 